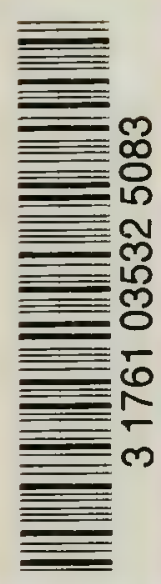


t.

is.

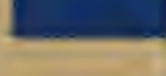

$\cdots$

. 


\section{La Tunisie}

AGRICULTURE - INDUSTRIE - COMMERCE

TOME II

DEUXIEME ÉDITION

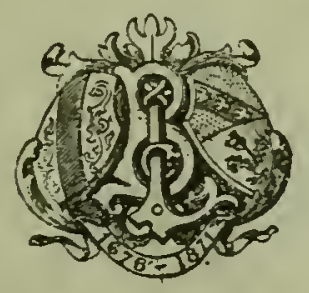

BERGER-LEVRAULT \& C ${ }^{\text {IR }}$, ÉDITEURS

\begin{tabular}{l|c} 
PARIS & NANCY \\
I RES BEAUX-IRTS & 900
\end{tabular}







\section{La Tunisie}


- 


\section{La Tunisie}

AGRICULTURE - INDUSTRIE - COMMERCE

TOME II

DEUXIËME ÉDITION

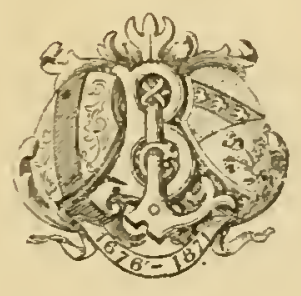

BERGER-LEVRAULT \& C ${ }^{\prime E}$, ÉDITEURS

\section{PARIS}

5, RUE DES BEAUX-ARTS

$$
\text { NANCY }
$$

$$
\text { I } 8 \text {, RUE DES GLACIS }
$$

1900 
HD

2425

T85T?

1900

t.2 


\title{
La Tunisie
}

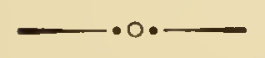

TROISIEME PARTIE

\section{Commerce}

\author{
CHAPITRE XVII \\ L'OUTILLAGE ÉCONOMIQUE \\ VOIES DE COMMUNICATION ET PORTS
}

SITUATION AVANT L'ÉTABLISSEMENT DU PROTECTORAT

Avant l'établissement du protectorat, l'outillage économique de la Régence était des plus rudimentaires. Deux lignes de chemin de fer, celle de Tunis à la Djendouba (Souk-el-Arba) et la ligne Tunis-Goulette-Bardo-Marsa, étaient exploitées, la première par une compagnie française et la seconde par une société italienne. En dehors de ces lignes, rien. Les routes, à l'exception de la route de Tunis au Bardo, étaient à l'état de pistes, suffisantes pour assurer, dans les temps secs, la circulation des légers véhicules à deux roues (arabıs) en usage dans la Régence, mais le plus souvent impraticables en hiver. Les ports étaient laissés II. TUXISIE. 
dans l'abandon le plus complet et n'étaient, en réalité, que des rades plus ou moins ouvertes, selon li disposition naturelle des lieux.

L.administration du protectorat ne pouvait admettre le maintien d'un pareil état de choses, et, depuis son établisscment, elle a attaché la plus grande importance à doter la Régence d'un outillage économique répondant aux besoins du pays. Aujourd'hui, cette ouvre est réalisée en partic, et son achèrement complet se poursuit arec méthode et activité.

Nous allons essayer de faire connaitre le programme général des travaux projetés et leur état d'avancement en examinant sucessivement les routes et pistes, les chemins de fer et les ports.

\section{I. - ROUTES ET PISTES}

TRAI'AUY EXECUTESS PAR L'ARMEE D'OCCUPATION

En l'absence de tout moyen de communication, l'armée d'occupition dut, dès son entrée dans le pays, prendre les mesures indispensables pour assurer le ravitaillement des troupes et la marche des colonnes, et, pendant deux ans, jusqu'à l'organisation de la Direction des travaux publics, elle exécuta d'importants travaux. C'est ainsi que fut affirmée, dès la première heure de l'occupation française, la volonté de doter la Tunisie de l'outillage économique qui lui faisait défaut.

L'armée n'a pas cessé de prêter son concours actif à cette cuvre de rénovation, et maintenant encore, sur de nombreux points, des chantiers militaires sont installés apportant une aide précieuse à l'administration civile. 
Les travaux exécutés par l'armée portèrent surtout sur les routes rayonnant autour d'Aïn-Draham, au centre de la Khroumirie. C'est ainsi que furent construites les routes d'Ain-Draham à la Calle, Tabarka, Souk-el-Arba et de Tabarka à la Calle.

Les autres routes construites par l'armée furent celles du Kef à Souk-el-Arba, de Béja-gare à Teboursouk et les I premiers kilomètres, à partir de Tunis, de la route de 'Tunis à Zaghouan.

Une partie de ces travaux n'eut d'autre objet que l'ouverture et l'amélioration des pistes, de façon à permettre simplement la circulation des animaux de bât; tels furent ceux exécutés sur la route d'Aïn-Draham à Béja.

Toutes ces voies ont été remises à la Direction des travaux publics qui se charge de leur entretien.

En dehors des routes, l'armée exécuta un travail important : le chemin de fer de Sousse a Kairouan dont il sera question plus loin.

\section{PROGRAMME ADOPTÉ PAR L'ADMINISTRATION}

On s'est contenté, à l'origine, de suivre un programme restreint qui peut se résumer en deux mots : " améliorer les pistes », et qui consistait à rectifier et à empierrer les passages les plus difficiles, à établir les ouvrages d'art destinés à assurer la permanence des communications entre les principaux centres de population ou de colonisation de la Régence, et à ne construire de routes empierrées, dans toute leur longueur, que sur des points particuliers ou cet empierrement est nécessité par la nature du terrain, l'exiguïté du parcours, le voisinage de Tunis ou quelque autre circonstance spéciale. 
On ne tarda pas à reconnaitre que les travaux dits d'amélioration de pistes, par leur dissémination, les déplacements qu'ils exigeaient, la minutie de leurs détails, demandaient autant de temps et de personnel que des projets de routes complets. Pour les mêmes raisons, il était difficile, ou même impossible, d'en assurcr l'entretien: ils étaient sans cesse à recommencer et n'offraient même plus l'avantage de l'économie. D'autre part, on avait pu organiser le service des prestations, desquelles on pourrait espérer l'exécution, à titre gratuit pour le budget, d'un million de travaux neufs en cinq ans, et ensuite une ressource assurée applicable à l'entretien du réseau.

C'est dans cet ordre d'idées qu'il faut aujourd'hui envisager le réseau des routes tunisiennes et que la Direction générale des travaux publics a procédé à un premier classement des voies terrestres de communication.

Le classement que nous allons indiquer n'implique en rien une priorité d'ordre quelconque d'une voie sur une autre; il a surtout pour but de fixer les désignations ct d'établir de l'ordre et de la clarté dans une matière qui a été assez longtemps et forcément confuse.

Le nom de "routes» est réservé aux voies qui ont fait ou paraissent devoir faire, à assez bref délai, l'objet d'un empierrement continu sur toute leur longueur.

Toutes les autres voies de terre sont des "pistes 》.

Il faut signaler que le lilométrage rigourcux du réseau n'étant pas encore terminé, la plupart des longueurs indiquées ne sont connues qu'approximativement. 
On remarquera spécialement dans la nomenclature:

Les routes nos 1 , 5, 6, qui relient Tunis à Gabès, au Kef et à Bizerte et présentent une importance que le chemin de fer ne saurait faire disparaître;

Les routes $n^{\text {os }} 7$ ì I 3 qui constituent le réseau suburbain de Tunis et assurent de ce chef une importante circulation ;

Les routes nos 3 I à 37 qui constituent le réseau du Sahel et desservent la région la plus peuplée et la plus productive de la Régence;

La route $n^{\circ} 27$, de Béja à Tabarka, qui desserrira les mines du Khanguet-et-Tout et celles de la Société royale Asturienne.

Actuellement, une grande activité est donnée à la construction des routes, grâce à d'importantes allocations budgétaires prélevées sur les ressources extraordinaires de la Régence.

Ces crédits supplémentaires ont permis d'entreprendre la construction des routes $n^{\text {os }} 3$ et 27 qui assurent les relations des régions minières et agricoles de Zaghouan-Fahs et de Béja au Nefzas avec les chemins de. fer et les ports d'embarquement.

Les routes 29 et 30 sont également très avancées et desservent deux régions agricoles, la plaine du Sers et la plaine de Béja ì Mateur, les plus fertiles de la Tunisie pour la culture des céréales.

Le profil type le plus employé comporte une plate-forme de 8 mètres de largeur entre fossés, avec 3 mètres ou $3^{\mathrm{m}}, 50$ de chaussée empierrée. Quelquefois la plate-forme est ré- 
duite it 7 mitres; aux abords des villes, elle est portée à IO, I 2 et I 5 mètres et la chaussée it t, j et 6 métres.

Les accotements sont plantés au moyen de sujets provenant des pépinières établies par l'administration à Tunis, à Souk-el-Arba et ì Kairouan.

Des bornes kilométriques et des poteaux indicateurs avec inscriptions en langue française ont été disposés suivant les règles adoptées en France.

\section{PISTES}

Les améliorations de pistes ont, comme nous l'arons indiqué, perdu limportance qu'elles avaient eue un moment. Elles se réduisent, en principe, à assurer, non pas la commodité et la pérennité de la circulation, mais seulement sa possibilité, dans certaines conditions déterminées. On borne les travaux aux suppressions des mauvais passages, sur demandes spéciales motivées.

Cependant, dans le sud de la Régence, où il ne saurait, à aucun degré, être question, pour le moment, de la construction de routes véritables, les pistes constituent une sorte de réseau qui a son importance propre.

Citons notamment les pistes :

de Gafsa à Sfax,

- à Gabès

- i Tozeur,

- à Tébessa,

de Gabès à Médenine et Tatahouine, de Médenine à Zarzis.

Grice à la nature du terrain et aux améliorations locales: 
empierrements, ourrages d'art, fascinages dans le sable, la circulation y est possible et même relativement facile pour les véhicules légers.

Les soins du service d'entretien se portent, en outre, sur lis création et le maintien des ouvrages d'alimentation d'eau: citernes, puits ou sources, qui sont, dans cette région, de première nécessité pour la circulation. Ce service assure de même l'établissement et la conservation des abris destinés aux voyageurs et connus sous le nom de cararansérails ou de bordjs. Ces édifices consistent généralement en une cour fermée de murs établis défensivement, sur un ou plusieurs côtés de laquelle sont disposées des chambres pour les hôtes et des écuries pour les inimaux; un puits et un abreuvoir sont installés toutes les fois que cela est possible. Un gardien èst généralement préposé à la garde du caravansérail. Parfois, des hangars extérieurs sont adossés au mur d'enceinte et laissés à lia disposition des passagers qui ne pourraient, pour un motif quelconque, être admis à l'intérieur. On a construit dans le sud neuf établissements de ce genre, savoir :

Le caravansérail d'Achichina (I892) sur la piste de Sfax à Gabès, au point de bifurcation de la piste de Gafsa;

Le caravansérail de Bir-Saad (1894) sur la piste de Gafsa à Gabès;

Le caravansérail d'Oued-Cherchera (I892) sur la piste de Gafsa à Sfax ;

Le caravansérail d'Oued-Jaâcha (I892) sur la piste de Gafsa à Tozeur ;

Le caravansérail de Bou-Chebka (I 884 ) sur li piste de Gafsa ì Tébessa. Ce dernier établissement peut recevoir, au besoin, quelques hôtes à demeure et fonctionner comme sanatorium; 
Le Bordj de Magen-bel-Abbès (IS96) sur la piste de Gafsa à Feriana;

Le Bordj d'El-Guettar (I \$94) sur la piste de Gafsa à Gabis ;

Le Bordj de Bir-el-Haffey (ISgS) sur la piste de Gafsa à Kairouan ;

Le Bordj de Majen-el-Feldj ( 1998 ) sur la piste de Gafsa i Kairouan.

L'espacement de ces caravansérails a été réglé de façon à permettre de les utiliser comme gites d'étapes.

II. - CHEMINS DE FER

DESCRIPTION DU RESEAU PROJETÉ

Le réseau des chemins de fer tunisiens, tel qu'il est projeté, doit mettre l'intéricur de la Régence en relations avec les trois ports de Tunis, Sousse et Sfax. Il se compose essentiellement de trois réseaux partiels rayonnant de chacun de ces ports sur les centres les plus importants de production, en traversant les régions où la colonisation et l'industrie ont déjà pénétré ou pénétreront dans un avenir rapproché.

Comme ces réseaux ne sauraient rester sans communication entre eux, tant au point de vue des relations de l'intérieur avec la capitale de la Régence, qu'au point de vue des facilités d'exploitation, on a prévu des lignes destinćes à en réaliser lia jonction et qui seront exécutées, soit immédiatement, soit dans un temps plus ou moins éloigné. 


\section{$I^{\circ}$ Réseau aboutissant à Tunis.}

De Tunis partent trois lignes principales : celle de Tunis à la frontière algérienne, celle de Tunis au Kef, celle de Tunis à Kélibia, et la ligne de banlieue Tunis-La GouletteMarsa-Le Bardo.

La ligne de Tunis à la frontière algérienne est à voie normale : elle a I 96 kilomètres de longueur. De cette ligne se détachent deux embranchements : celui de Bizerte, qui part de Djédeïda et a 73 kilomètres de longueur; celui de Béja-ville, qui part de la station de Béja-gare et a 12 kil. 800 mètres.

Cette ligne et ses embranchements sont en exploitation; la ligne de Béja doit être plus tard prolongée sur Tabarka.

La ligne de Tunis au Kef par le Fahs s'arrête actuellement au pont du Fahs, elle se détache à Djebel-Djelloud de la ligne Tunis-Kélibia; elle est à voie d'un mètre et aura une longueur d'environ 200 kilomètres. Un embranchement de I 3 kilomètres de longueur dessert Zaghouan.

Elle est actuellement construite jusqu'au pont du Fahs sur une longueur de 64 kilomètres.

La ligne de Tunis à Kélibia passe par Hammam-Lif, Hammamet et Nabeul. Elle est à voie d'un mètre; un peu après la station de Bordj-Cédria, se détache un embranchement desservant Soliman et Menzel-bou-Zalta (I 4 kilomètres).

Cette ligne est aujourd'hui exploitée jusqu'à Nabeul sur 77 kilomètres; le prolongement sur Kélibia n'est encore qu'en projet.

Aux lignes aboutissant à Tunis il convient de joindre la ligne de Tunis-La Goulette-Marsa-Bardo. C'est une simple 
ligne de banlieue, établie it voie normale, d'une longueur de 33 kilomètres; enfin, la ligne de tramway du Mornag : cet embranchement se détache de la ligne de Zaghouan à Bir-Kassa; il a une longueur de I 3 kilomètres; il sera prochainement prolongé jusqu’à Aïn-Bjerra.

\section{$2^{\circ}$ Rísean aboutissant à Sousse.}

De Sousse partent deux lignes : celle de Sousse à Tébessa, et celle de Sousse à Mokenine.

La ligne de Sousse à Tébessa construite jusqu'à Kairouan sera prolongée par Sbeittla et Kasserine. Deux embranchements s'en détacheront: le premier actuellement construit va de Kalaa-Srira à l'Enfida (43 kilomètres); l'autre ira de Kasserine à Fériana (40 kilomètres).

La voie d'un mètre a été adoptée pour ces lignes.

La section Sousse-Kairouan remplace la voie Decauville installée en 1892 par l'autorité militaire.

La ligne de Sousse ì Mokenine, également à voie d'un mètre, passe par Menzel et Djemal (47 kilomètres).

Elle est actuellement en exploitation.

$3^{\circ}$ Réseaul aboutissant à Sfax.

De Sfax part une seule ligne allant à Tozeur par Gafsa. De cette ligne se détachera, à Graïba, un embranchement allant ì Gabès.

Cette ligne est ì voie d'un mètre. Elle s'arrête actuellement à Metlaoui d'où se détache un embranchement industriel de 5 kilomètres qui dessert les gisements de phosphates en exploitation. 
$4^{\circ}$ Liaisons des trois réseaux.

Ces trois réseaux partiels seront reliés entre eux, les deux premiers le sont déjì par la ligne d'Hammamet à Enfidaville, le deuxième et le troisième le seront par la ligne projetée de Menzel à Sfax par El-Djem.

Les lignes encore à l'état de projet ne pourront être exécutées que dans un avenir plus ou moins lointain, lorsque l'état des finances de la Régence le permettra. Il est à espérer toutefois que la ligne du pont du Fahs à Thala sera prochainement construite.

En résumé, il y a actuellement en exploitation 726 kilomètres de voies ferrées, dont 339 kilomètres à voie normale et 387 kilomètres à voie d'un mètre, non compris le réseau du chemin de fer de Gafsa, de 244 kilomètres.

\section{EXPLOITATION}

$I^{\circ}$ Ligne de Tunis à la frontière algérienne et embranchements.

Conditions générales. - Les déclivités du profil en long seraient favoribles à l'adoption d'une vitesse de marche assez accélérée; il n'en est pas de même des conditions d'établissement de la voie et du matériel de traction.

La voie est bien constituée avec des rails Vignole en acier de 25 kilogr., mais le trop grand espacement des traverses est un obstable sérieux à l'augmentation de la vitesse.

Le matériel de traction en service sur le réseau n'est pas 
approprié au service des trains rapides. Les machines locomotives, d'un type simple, pratique et relativement puissant, bien conçu pour le passage dans les courbes raides, présentent, au point de vue de la marche aux grandes allures, tous les inconvénients inhérents d'ordinaire aux types similaires.

Le matériel-voyageurs comporte des roitures à quatre compartiments et il deux essieux et un petit nombre de voitures longues ì deux bogies, arec couloir latéral en $Z$.

On a mis en service, à l'occasion de l'ouverture de la ligne de Bizerte il l'exploitation, une grande voiture mixte de ce dernier type, contenant les trois classes, et qui parait réaliser tout le confort que l'on peut désirer sur les lignes tunisiennes.

Le matériel-marchandises est conforme aux types employés sur la plupart des lignes secondaires françaises qui n'ont point ì faire face à des transports spéciaux industriels ou agricoles.

Sur ce réseau, les vitesses de marche ne peuvent actuellement dépasser 45 kilomètres à l'heure, et les nécessités commerciales d'une exploitation par trains mixtes, à l'exclusion des trains pour voyageurs seuls, viennent encore aggraver la situation et réduisent à 27 kilomètres la vitesse commerciale des trains les plus accélérés sur les lignes de la Medjerda.

Les vitesses commerciales descendent actuellement jusqu'à 20 kilomètres pour les trains facultatifs les plus lents.

Cependant, la Compagnie B. G. vient de commander six machines d'un type plus puissant et on espère pouvoiravec elles augmenter sensiblement la vitesse.

Tarifs. - Les tarifs généraux pour voyageurs appliqués 
par la compagnie exploitante sont inférieurs aux maxima prévus au cahier des charges, soit:

$$
\begin{aligned}
& \text { Ire classe : of I } 2 \text { au lieu de of } 16 \text { par kilométre. }
\end{aligned}
$$

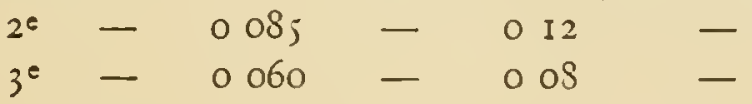

En outre, des billets d'aller et retour, comportant une réduction de $30 \mathrm{p}$. 100 et des conditions de délai avantageuses, facilitent notablement les relations commerciales entre les centres importants.

Enfin, des tarifs spéciaux, à prix plus réduits, sont appliqués dans certains cas : voyages en groupe de sociétés légalement reconnues, d'ouvriers agricoles, d'institutions diverses, voyages circulaires, réunions hippiques, etc.

Les tarifs généraux pour marchandises sont fixés ainsi qu'il suit par le cahier des charges de la Compagnie :

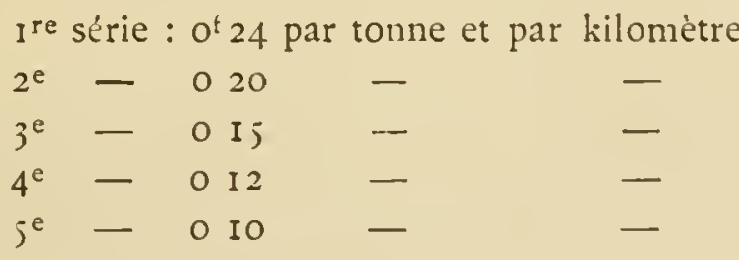

La Compagnie, reconnaissint l'exilgération de ces tarifs, n'a pas tardé à proposer et à faire homologuer des tarifs spéciaux, très réduits, généralement plus bas que ceux de toutes les autres compagnies algériennes, à appliquer aux produits, denrées et matières qui donnent lieu à un trafic important.

La tarification s'améliore d'ailleurs de jour en jour, au fur et à mesure des nouveaux besoins. 


\section{$2^{\circ}$ Ligne Tunis-Bardo-La Goulette-Marsa}

C'est une simple ligne de banlieue dont l'exploitation se fait dans les meilleures conditions en vue du trafic spécial à ces sortes de lignes. Exploitée autrefois par une compagnie italienne, elle fait aujourd'hui partie du réseau de la Compagnie Bone-Guelma.

EXPLOITATION DU RÉSEAU A VOIE D'UN METRE

Conditions générales. - Les conditions générales d'établissement des lignes de ce réseau sont très favorables à une exploitation économique.

La voie est constituée par des rails d'acier de 20 kilogr.; l'espacement des traverses est plus faible que sur les lignes de la Medjerda; la longueur des rails est de $9^{\mathrm{m}}, 60$.

La roie ainsi constituée se prêtera ì l'emploi de vitesses supérieures à celles obtenues sur les lignes de la Medjerda.

Matéricl-traction. - Un certain nombre de machines, présentant les mêmes arantages et inconvénients que ceux énumérés ì propos des lignes à voie normale déjà exploitées, seront utilisées aux ritesses modérées pour la traction des trains mixtes. Elles donneront, dans ces conditions, toute satisfaction.

Mais, comme il y a lieu de prévoir, dès aujourd'hui, la circulation sur certaines lignes à long parcours, de trains de voyageurs à grande vitesse, il sera fait usage d'un autre type de machines permettant d'assurer ce nouveau service.

Materiel-zoyagenrs. - Le matériel-voyageurs est ana- 
L'outillage Économique.

logue à celui de la ligne Souk-Ahras à Tébessa, composé de voitures-bogies, à couloir central.

Matériel-marchandises. - Le matériel de transport pour marchandises est construit suivant les types courants de la mêne ligne.

Vitesse. - La vitesse commerciale des trains mixtes, les seuls affectés actuellement au service des voyageurs, est, depuis l'ouverture de l'exploitation, d'environ 25 kilomètres à l'heure.

Tarifs. - Les tarifs à appliquer sur le nouveau réseau sont les mêmes que ceux en vigueur sur les lignes de la Medjerda.

\section{III. - PORTS}

Le réseau des voies de communication tel qu'il a été arrêté assure le trafic commercial de la Régence aux trois ports de Tunis, Sousse et Sfax. Il a donc fallu se préoccuper d'aménager et d'outiller complètement ces ports en se contentant d'apporter des améliorations sommaires et indispensables à tous les autres.

On a fait cependant une exception pour le port de Bizerte, encore qu'il ne commande pas, commercialement parlant, un grand rayon d'attraction. Mais, par sa position sur une des grandes routes maritimes de la Méditerranée, il offre, au point de vue du transit, un intérêt considérable qui justifie les travaux qu'on y a entrepris.

Nous allons indiquer rapidement quel est l'outillage actuel 
de ces ports, ainsi que l'outillage dont ils seront prochainement munis.

Port de Bizerte. - Ce port se compose essentiellement d'un canal mettant en communication la mer et le lac de Bizerte. Ce canal creusé à 9 mètres au-dessous des basses mers a une largeur de $6+$ mètres au plafond.

Il débouche en mer dans un avant-port d'environ 75 hectares formés par deux jetées; l'une, la jetée nord, en enrochements, d'environ I, ooo mètres de longueur, atteignant les fonds de I 3 mètres; l'autre, la jetée est, de 950 mètres environ, atteignant les mêmes fonds.

La passe d'entrée entre les musoirs des jetées a 400 mètres d'ourerture.

Deux cavaliers protègent l'entrée du canal dans l'avantport.

L'éclairage est assuré par deux feux placés sur chacune des jetées, deux feux placés sur chacun des cavaliers, enfin par un feu d'alignement placé sur la pointe de Sebra, dans l'axe du canal.

Sur la rive nord du canal, du côté de la ville, est un quai en maçonnerie de 200 mètres de longueur. Sur ce quai se trouve la gare terminus du chemin de fer de Tunis à Bizerte dont les voies ont été prolongées par la compannie du port, parallèlement au quai, de façon à permettre le débarquement ou l'embarquement direct des marchandises des navires sur les wagons ou inversement.

L'amarrage est facilité par 6 bolards en fonte, des canons d'amarrage et I $S$ organeaux; 3 escaliers descendent du quai jusqu'au nircau de l'eau.

L'ouillage du quai comporte une bascule pour wagons, une grue de 12 tonnes et une grue roulante de I, 500 kilogr. 
En arrière du quai est un hangar pour marchandises, de 660 mètres carrés de superficie, contenant un magasin pour les marchandises dédouanées ou d'exportation, une s.lle de visite et un magasin pour les marchandises d'importation non dédouanées. Un auvent régnant tout le long de ce magasin permet de faire à couvert les opérations de chargement ou de déchargement des wagons.

En dehors de ce quai, les opérations peuvent se faire à deux appontements: l'un, situé sur la rive nord du c.mal, a 25 mètres de long sur 6 mètres de large, il est muni d'une grue de 500 kilogr.; l'autre, plus petit, est situé sur la rive sud.

L'approvisionnement en eau des navires peut se faire directement la nuit à une prise d'eau installée sur le quai; dans le jour, cet approvisionnement est assuré par des bateaux-citernes remplis pendant la nuit.

La baie de Sebra, qui s'ouvre peu après le quai, sert aux évolutions des navires; elle est balisée, et un corps mort y a été installé.

Un service de remorqueurs pour les bateaux à voiles est organisé.

Une cale sèche, située dans l'ancien canal, peut servir pour les bateaux calant moins de trois mètres.

Enfin, les bateaux trouvent toutes facilités pour renouveler leur provision de charbon.

Le tableau A (annexes) indique les droits perçus sur les bateaux fréquentant le port de Bizerte.

Port de Tunis. -- Le port de Tunis comprend actuellement :

Un chenal orienté sud $60^{\circ}$-est, qui relie la mer au canal creusé dans les vases du lac de Tunis; 
Une jetée nord de ji j mitres de longueur couvrant les fonds de 6 mictres;

Une jetíe sud de 596 mètres de longueur;

Un canal de raccordement de 2,000 mètres de rayon;

Un bassin de six hectares de superficie creusé à $2^{\mathrm{m}}, 50 \mathrm{de}$ profondeur à La Goulette;

Un canal maritime de 8 kilomètres creusé à $6^{\mathrm{m}}, 50$ de profondcur, avec 30 mètres de largeur au plafond; les berges en sont munies de perrés; au milieu de la longueur sc troure un garage de 500 mètres de long;

Un bassin à Tunis de 300 mètres de large sur 400 mètres de long.

L'éclairage du port est assuré par dix-sept feux, dont sept rouges, et deux feux blancs de direction donnant l'axe du canal.

Le balisige consiste en deux bouées métalliques, ì l'entréc du bassin de Tunis, et une série de groupes de deux bouées, en bois, placées le long du canal, à 400 mètres d'espacement cn moyenne.

L'outillage comprend:

Une darse de carénage et une forme de radoub à Lal Goulette, des poteaux d'amarrage le long du canal et autour du bassin de Tunis, six coffres d'amarrage dans ce bassin, trois appontements en bois avec hangars et prise d'eau, et 600 mètres de quai; 2,500 mètres de chaussées pavées, 7,j00 mètres de chaussées empierrées, 4 terre-pleins couverts d'une superficie totale de 7,000 mètres carrés, une digue flottante de 20 tomnes, 4 grues de I, 500 à 3, 000 kilogr., complètent cet outillage.

Les bitiments d'exploitation comprennent, à Lal Goulette, un bureau de port avec poste de pilote; au garage, un poste-rigie; à Tunis, un bureau de port arec annexes; 
ces trois bâtiments sont pourvus de mâts de signaux et reliés par une ligne téléphonique spéciale.

Les bateaux entrant dans ce port sont assujettis au paiement de certains droits dont le tableau B (annexes) donne le détail.

Port de Sousse. - Le port de Sousse est le dernier des grands ports qui étaient à construire en Tunisie.

Il se compose essentiellement d'un bassin d'opérations de I 3 hectares, creusé à $60^{\mathrm{m}}, 50$ sous basse mer, bordé au nord par un quai de 560 mètres de longueur. Sur ce quai sont deux terre-pleins couverts, des voies ferrées et des grues.

Le bassin est protégé par une grande jetée de 670 mètres de longueur, atteignant les fonds de 9 mètres.

De cette jetée part un épi, dit épi nord, de I 84 mètres de longueur, qui s'avance à la rencontre d'un autre épi, dit épi sud, de 370 mètres de longueur, qui est lui-même relié à la terre par une digue en sable de 288 mètres. La passe d'entrée se trouve entre les musoirs des deux épis; elle a 7o mètres de longueur et est draguée à $7^{\mathrm{m}}, 50$ sous basse mer.

Les produits du dragage du bassin, déposés en avant des remparts du front de mer de Sousse ont constitué de vastes terre-pleins sur lesquels commence à s'élever un nouveau quartier de la ville européenne.

Le tableau $C$ (annexes) indique les droits perçus depuis la mise en service des ouvrages.

Port de Sfax. - Le port de Sfax comprend un chenal d'accès et un bassin d'opérations de ro hectares de superficie et de $6^{\mathrm{m}}, 50$ de profondeur, avec un canal pour les 
barques; 45 mètres de murs de quai ; r, ooo mètres carrés de chaussíes parées et 4,000 mètres carrés de chaussées cmpierrées: 2,000 mètres carrés de hangars couverts; 2 kilomètres de voies ferrées le reliant au chemin de fer de Sfax-Gafsa.

L'outillage se compose d'une bigne de 20 tonnes et de 3 grues mobiles de 1, 500 kilogr. La Compagnie des phosphates et du chemin de fer de Gafsa a fait des installations considérables pour l'emmagasinement sur les quais et l'embarquement rapide des énormes quantités de phosphates qu'elle exploite.

Les droits perçus dans ee port sont indiqués dans le tableau D (annexes).

L'aménagement rapide des quatre grands ports Bizerte, Tunis, Sousse et Sfax présentait pour la Tunisic une importance si grande que le Gouvernement, n'ayant pas les ressources nécessaires pour l'assurer directement, s'est adressé à des compagnies concessionnaires. Mais, en dehors de ces points principaux, il existe sur la côte tunisienne un certain nombre de ports secondaires à qui il convient de donner un aménagement réduit, auquel l'État pourvoit directement par des crédits en rapport avec le trafic qu'ils sont appelés à desservir. Des améliorations intéressantes ont déjà été apportées à quelques-uns d'entre eux ou sont en ce moment en cours d'exécution, notanment à Tabarca, Mehdia et Gabès.

Nous donnons ci-après la description de l'état actuel des ports tunisiens.

Port de Tabarca. - Ce port est le seul mouillage. médiocre d'ailleurs, qui se trouve sur la côte abrupte allant de Bizerte à la frontière algérienne. Exutoire naturel des 
produits forestiers et miniers de la Kroumirie, centre de pêche important, il est très fréquenté par un grand nombre de barques de faible tonnage qui viennent chercher un abri entre la côte et l'ile.

L'aménagement, aujourd'hui presque entièrement réalisé, consiste en un bassin d'un peu plus de deux hectares creusé au sud-ouest de l'ile ì 4 mètres de profondeur sous basse mer. Ce bassin est protégé par une jetée de I 50 mètres de longueur, construite sur les débris d'une ancienne jetée étalée par la mer.

Port de Porto-Farina. - Ce port n'existe guere que de nom, car il n'est accessible qu'aux canots. En I886, un chenal de 2 mètres de tirant d'eau avait été dragué, à titre d'essai, sur la demande du service de santé ; il s'est comblé en quelques mois.

Un bîtiment de douane a été établi en i 89 I.

Port de Kélibia. - Ce port n'est qu'un mouillage médiocre, abrité des vents du nord-ouest au nord-est par le nord; on y a installé, en I $\$ 9 \mathrm{r}$, une douane avec bureau de port.

Il est signalé par un phare.

Port de Nabeul. - Le seul ouvrage du port de Nabeul est un débarcadère-appontement d'une quarantaine de mètres de longueur, accostable anx embarcations calant moins de $I^{\mathrm{m}}, 50$.

Il at été livré en r 894.

Port d'Hammamet. - - Aucun ouvrage n'a été exécuté dans ce port qui consiste en une rade ouverte au nord- 
ouest, an nord et mème au nord-est, mais dont la tenue est médiocre.

Un service de doune y a été établi en I $\$ 86$.

Un appontement y a été construit.

Port de Monastir. - La rade de Monastir, dans la partie dite "movillage de la douane ", donne un bon abri contre les vents de nord-onest, d'est et sud-est.

Sur la plage, ì 600 mères au sud du bordj El-Kelb, est établic lia douane, avec son terre-plein et un appontement de 70 mères de longueur atteignant les fonds de $\mathrm{I}^{\mathrm{m}}, 60$ sous basse mer.

Un feu fixe ronge sur le bordj El-Kelb et un feu vert sur le débareadère signalent le port qu'une route empierrée, d'environ un lillomètre et demi, relie à la ville de Monastir.

Port de Mebdia. - Lat rade de Mehdia n'est guère pratiquée que dans la partie au sud de la ville, où elle fournit un mouillage passable aux grands paquebots.

Le port proprement dit n'est accessible qu'aux embarcations calant moins de $2^{\mathrm{m}}, 5 \mathrm{o}$. Ces fonds ne rignent que sur plus d'un hectare; le brise-lames, qui a été établi en I $S 66$, abrite une superficie totale de trois hectares.

Un quai en maçonnerie, de 200 mètres de longueur, borde le terre-plein, de i 5 mètres de largeur, le long duquel est établic la douane.

Un plan incliné et une petite grue constituent l'outillage du port.

Un feu fixe rouge signale l'extrémité du brise-lames.

En outre, en I $\$ 92$, I 894 et I $\$ 99$, des dragages imporrants y ont été effectués.

Port de Kerkemnah. - Aucun ouvrage n'a été établi 
dans ce port qui n'a pas du reste de définition bien précise, les bancs des Kerkenn.lh offrant partout un bon abri aux navires, et l'accostage n'ayant lieu que par des embarcations du pays, généralement affectées à la pêche.

Port de la Skira. - Aucun ouvrage maritime n'a été établi pour ce port, qui offre naturellement un excellent mouillage, grâce à l'abri des bancs des Sur-Kenis.

Une douane y a été construite en I 887 .

Un bureau de port, avec un feu rouge, y a été établi en I 894 .

Porl de Gabès. - Le port de Gabès n'est guère qu'une rade, d'assez bonne tenue, mais dont les communications avec la terre sont parfois difficiles.

Un appontement en bois y a été construit en I 882 par l'autorité militaire. Remis au gouvernement tunisien à la date du $\mathrm{I}^{\mathrm{er}}$ janvier $\mathrm{I} 894$, il rentre maintenant dans le régime ordinaire des ouvrages maritimes. Sa longueur est d'environ 200 mètres; il n'a guère à son extrémité que I mètre de tirant d'eau à basse mer, soit $3^{\mathrm{m}}, 50$ à marée haute. Cet appontement a été l'objet, en 1894 , d'une grosse réparation.

A 300 mètres au nord de l'appontement, débouche l'Oued-Gabès, sur la rive droite duquel on a établi un terre-plein où se trouvent situés la douane et un feu de port allumé en 1893 .

Un vannage en charpente sert de quai d'accostage. Malheureusement, l'entrée de l'Oued est obstruée par une barre de sable qui atteint près d'un nètre au-dessus du zéro des cartes maritimes. En I 889 et I 890 , le service des travaux publics, sur les instances du commerce local, fit 
draguer un chenal descendant ì la profondeur de $\mathrm{I}^{\mathrm{m}}$, jo sous basse mer, $m$ is ce travail ne se maintient pas, et la drague fut perdue dans un aceident.

Pour remédier à cette situation ficheuse, des travaux importants viennent d'être exécutés à Gabès. Ils consistent essentiellement en :

$I^{\circ}$ La construction de deux jetées parallèles aux rives de l'Oued s'arançant d'environ I 30 mètres en mer et se prolongeant à terre jusqu'en face du batiment de la dounane. La distance entre les musoirs est d'environ 60 métres;

$2^{\circ}$ Le creusement d'un chenal de 30 mètres de largeur au plafond, à $2^{\mathrm{m}}$, jo au-dessous du zéro. Ce chenal s'élargir. devant la douane de manière it former un bassin d'éritage de $\mathrm{I}^{\mathrm{m}}$, jo de tirant d'eau;

$3^{\circ} \mathrm{La}$ confection de terre-pleins sur la rive droite de l'Oued-Gabès ;

$4^{\circ}$ La construction d'un mur de quai de go mètres.

Ports de Djerba. - Le port principal de cette ile est celui d'Houmt-Souk; il existe à Adjun, à El-Kantara et à Aghir des ports secondaires où il n'a été établi aucun ouvrage, si ce n'est, pour les deux premiers, des feux de port.

Le port d'Houmt-Souk est muni d'un appontement métallique d'une trentaine de mètres de longueur, accostable avec 2 mètres de tirant d'eau ì haute mer.

En outre, un feu de port et un bureau de port y ont été établis en ISST-ISSS, en même temps que le bâtiment de la douane.

Port de Zarzis. - Ce port n'est qu'un mouillage ouvert aux vents du nord et du nord-est, mais où la tenue est 
L'outillage ÉCONOMIQUe.

bonne. Une petite jetée, un bureau et un feu de port constituent tous les ouvrages.

Éclairage des côtes. - En mème temps qu'on améliorait les ports, on s'occupait de rendre la navigation facile en tout temps sur les côtes par la construction de phares de grand et petit atterrissage. Aujourd'hui, l'éclairage des côtes est un fait accompli, et la Régence n'a, à ce point de vue spécial, rien à envier aux pays d'Europe les plus avancés. 
ANNEXE A

PORT DE BI7.ERTE

-TARIFS DES TAIES LOCALES ET SPICCIALES AU PORT DE BIZERTE

CHAPITRE jer

DROITS LOCAUX DE PORTS

Tarif $n^{0} 1$. - Droits d'abri et de canal.

Il sera perçu un droit de trente centimes . . . . . of $30^{c}$ par tonneau de jauge brute sur tout navire, venant du large, qui aura franchi la ligne des musoirs des jetées.

Le paiement donne aux navires le droit de stationner dans le port pendant cinq jours. Tout navire qui séjournerait dans les eaux du port au delì de cinq jours sans faire aucune opération commerciale, paierait par tonneau de jauge brute et par jour, trois centimies . . 003

Chaque jour commencé sera compté.

\section{Tarif $n^{0} 2 .-$ Droit d'accostage.}

Art. $I^{\text {er }}$ - - Taxe à perceroir sur la jauge des navires.

11 seril perçu un droit de deux francs quarante centimes par tonneau de jauge nette de tout navire entrant chargé ou venant prendre charge et accostant aux quais et appontements de Bizerte, soit directement, soit par l'intermédiaire de chalands. 
Toutefois, pour tout navire faisant simplement escale à Bizerte, sans y laisser ou prendre la totalité de son chargement, ce droit sera remplacé par un droit de deux francs quarante centimes . . . . . . . . . par tonneau d'affrétement applicable tant aux marchandises débarquées à Bizerte qu'à celles qui y seront embarquées.

Dans aucun cas, le montant des droits ainsi perçus sur un navire faisant escale ne devra ètre supérieugr à la somme qu'aurait produite la taxe appliquée au tonnage de jauge nette dudit navire.

l.a taxe perçue en vertu du présent article comporte le droit, pour l'expéditeur ou pour le réceplionnaire, de laisser stationner la marchandise à découvert sur les quais pendant I 2 heures. Ce droit remplace pour le port de Bizerte le droit d'accostage prévu par l'article 2 du décret du 25 août I 888 .

Art. 2. - Taxes a percevoir sur les voyageurs et leurs bagages.

Il sera perçu tant à l'embarquement qu'au débarquement, sur les voyageurs et leurs bagages, la taxe ciaprés :

Pour un passager (grande personne et enfant aul-dessus de 3 ans), deux francs quarante centimes . . . .

Pour chaque malle ou colis de bagages, un franc vingt centimes . . . . . . . . . . . I 20

Chaque chien, soixante centimes . . . . . 060

Art. 3. - Il est accordé à chaque navire accosté aux quais ou appontements de Bizerte, pour lui permettre d'effectuer ses opérations, les délais suivants :

Pour les voiliers, I 2 heures par Ioo tonneaux d'affrètement au chargement ou au déchargement.

Pour les navires à vapeur, I 2 heures pour 300 tonneaux d'affrètement au chargement ou au déchargement.

Passé les délais, chaque navire paiera quinze centimes. par tonneau de jauge nette et par jour. 
CHAPITRE II PILOTAGE, REMORQUAGE, ETC.

$$
\text { Tarif no } 3 .- \text { Pilotage. }
$$

Le pilotage, pour l'entrie des nuvires dans l'avantport ou a leur sortie, est facultatif; il ne sera payé qu'autint qu'il aura été demandé.

Le pilotage est obligatoire dans le port et le canal, il ne sera pas perçu de taxe pour ce service. Cependant, il sera payć pour chaque chuloupe porte-amarres du pilotige :

Pour un navire à voiles, vingt francs quarante centimes.

Pour un navire à rapeur, quinze francs.

$$
\text { Tarif no 4. - Remorquage. }
$$

Pour la perception du remorquage, il est établi deux zones : la premicire s'étend jusqu'à un demi-mille marin, la seconde, jusqu'à deux milles de la tète des jetées.

Entrée oul sortie.

a) Navires remorqués avec leurs cibles-remorques, de Ioo tonneaux de jauge brute et au-dessous :

Par navire ( ${ }^{\text {re }}$ zone), vingt francs quarante centimes. 2040

Par navire ( $2^{e}$ zonc), trente francs. . . . . . 30 »

b) Navires de plus de ioo tonneaux de jauge brute comme ci-dessus, suivant la zone, pour les 100 premiers tonncaux, plus pour chaque tonneau en sus de Ioo tonneaux :

$\mathrm{I}^{\text {re }}$ zone, neuf centimes . . . . . . . . . . 00 ?

$2^{\mathrm{c}}$ zone, quinze centimes . . . . . . . . . 0 is

c) Remorquage dans le canal ou changement de place des navires dans le port, non compris la fourni- 
ture des remorques, par chaque remorquage ou changement de place, vapeurs ou voiliers :

Par navire, jusqu'à 200 tonneaux, vingt et un francs. $21^{\mathrm{f}}$ " $^{\mathrm{c}}$ de 201 à 500 tonneaux, trente francs. . 30 » francs de 501 à I, ooo tonneaux, quarante-cinq

Par navire, au-dessus de I, ooo tonneaux, jauge brute, soixante francs.

d) En cas de fournitures de remorques pour les changements de place, il sera prélevé, en plus du changement de place :

Par navire, jusqu'à joo tonneaux, treize francs vingt centimes

Par navire, au delà de 500 tonneaux (jauge brute), dix francs vingt centimes

e) Location de remorqueurs faite à l'heure, non compris les remorques, ringt francs quarante centimes.

f) Fournitures de remorques pour remorqueurs loués à l'heure, quatre frincs quatre-vingt centimes . . .

Dans le canal, le remorquage des voiliers sera obligatoire.

La taxe $c$ sera diminuée de moitié quand le navire prendra le remorquage dans la première zone.

CHAPITRE III

SERVICES ACCESSOIRES

Tarif $n^{0}$ 5. - Taxes de stationnement.

Art. ${ }^{\text {er. }}$ - Pour marchandises à découvert : par tonne conventionnelle de la Société, après le délai de I 2 heures de stationnement accordé par le tarif $n^{\circ} 2$, et jusqu'à cinq jours, douze centimes . . . . . . . 
Au delil de cinq jours, par jour supplémentaire, six centimes

$0^{\mathrm{f}} 06^{\mathrm{c}}$

Passé le délai de dix jours, la Société, après avis donné à l'intéressé, aura le droit de faire procéder, aux frais dudit, il l'enlévement et à la mise en magasin des marchandises restées à découvert.

Art. 2. - Pour les marchandises à couvert sous les hangars; par tonne conventionnelle de la Société, de un ì cinq jours, cinquante et un centimes. . . . . .

Au delà de cinq jours, par jour supplémentaire, ringtsept centimes

Au delà de cinq jours les marchandises pourront être emmagasinées d'office d'après les tarifs.

Tarif n० 6. - Taxes de magasinage.

A.) Magasinage à couvert.

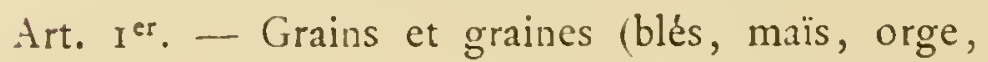
riz, etc.), en caisses ou sacs d'un arrimage facile :

Par tonne conventionnelle de la Société pour une durée quelconque, jusqu'à un mois de séjour, cinquante et un centimes.

0 SI

Chaque mois en plus ou fraction de mois, trente centimes.

Art. 2. - Pour toutes marchandises en caisses, ballots, barriques ou füts, excepté celles désignées aux articles 3 à 9 ci-après :

Par tonne conventionnelle de la Société, pour une durée quelconque jusqu'à un mois, un franc cinquante centimes.

Chaque mois en plus ou fraction de mois, trente centimes

Pour toutes marchandises en caisses, ballots, barriques ou fìts, excepté celles désign '́es aux articles 3 ì 9 ci-apris :

Par tonne conventionnelle de la Socićté, pour une durée quelconque jusqu'ì un mois, un franc cinquante centimes . . . . . . . . . . . 
Chaque mois en plus ou fraction de mo:s, soixante centimes

Art. 3. - Pour toutes marchandises dangereuses (autres que celles spécifiées aux articles suivants) et acceptées par la Société, telles que : Phosphores, allumettes, sulfure de carbone, éther, collodion liquide, huile de tous genres, benzine, acide nitrique, cotons et textiles, végétaux de toute nature en matière première, chiffons de tout genre, poix, goudron, brai, térébenthine, soufre, salpêtre, nitrate de soude, noir de fumée, suif, vernis, caoutchouc, gutta-percha, spiritueux non logés en bouteilles ou en caisses:

Par tonne conventionnelle de la Société et par mois, trois francs quarante-cinq centimes

Art. 4. - Pour marchandises précieuses (bijoux, or, argent, etc...) [ad valorem] sans responsabilité de conservation, pour $600 \mathrm{fr}$. et par mois : pour le I ${ }^{\mathrm{er}}$ mois, soixante centimes.

mois suivants, chaque mois, trente centimes

o 60

o 30

Art. 5. - Huile de pétrole en fùts, en caisses ou en vrac.

En magasin spécial :

Par tonne conventionnelle de la Société pour une durée quelconque jusqu'i un mois, un franc quaireringts centimes

Chaque mois en plus ou fraction de mois, un franc vingt centimes .

Art. 6. - Engrais chimiques, guanos, etc.

En magasin spécial :

Par tonne conventionnelle de la Société, pour une durée quelconque jusqu'à un mois, un franc cinq centimes.

Chaque mois en plus ou fraction de mois, soixantequinze centimes

Art. 7. - Poisson salé.

En magasin spécial :

Par tonne conventionnelle de la Société pour une 
durke quelconque jusqu'à un mois, deux francs cinquante-cinq centimes

Chaque mois en plus ou fraction de mois, un frane cinq centimes

Art. S. - Bois en grume, en plateaux, etc. :

Par tonne conventionnelle de la Société et pour une durée quelconque jusqu'à un mois, deux francs dix cen. times.

Bois débité en planches, douelles, etc., jusqu'à un mois, deux francs cinquante-cinq centimes.

Chaque mois en plus ou fraction de mois, un franc cinq centimes

Art. 9. - Marchandises de valeur (tissus, objets d'art mobilier, etc.), en ballots ou en caisses, sans responsabilité :

Tarif (ad valorem) joo fr. minimum jusqu'à un mois, un pour cent . . . . . . . . . . . . . I p. 100

Chaque mois en plus ou fraction de mois, trente centimes

B) Magasinage à découvert.

Art. Io. - Charbon en roche ou briquettes, minerais, métaux, matériaux de construction, bois, etc.

Par tomne conventionnelle de la Société et pour une durée quelconque, jusqu'à un mois, soixante centimes.

Chaque mois en plus ou fraction de mois, trente centimes

Art. 11. - Dípôts permanents, stocks donnant lieu à un mouvement d'entrées et de sorties :

Tarif à établir de gré à gré avec le commerce.

\section{Annexe au tarif $n^{0} 6$. - Conditions relatives au service des hangars.}

Les hangars sont exclusivement affectés à abriter la marchandise immédiatement avant son embarquement ou aprís son débarquement. 
La Société entretient, à ses frais, un nombre de gardiens suffisant pour la surveillance génćrale, mais la garde et la conservation des marchandises placées sur les quais ou dans les hangars ne sont point à sa charge.

Les risques de pertes, d'incendies, d'avaries ou de vols, lorsque ces accidents ne sont pas causés par les agents de la Société, ou par le défaut de solidité des constructions, restent à la charge des intéressés.

\section{Conditions relatives an magasinage.}

Indépendamment des taxes ci-dessus, il sera perçu par tonne conventionnelle de la Société une taxe de un franc cinquante centimes . . . . . . . . . . . pour l'entrée dans le magasin depuis la porte ou l'appontement de ce magasin, l'arrimage, le désarrimage et la sortie du magasin jusquà la porte ou l'appontement de ce magasin.

Nota. - Il est entendu que la surveillance de la douane s'exercera librement dans les magasins et hangars sur toutes les marchandises, quelle que soit leur nature, qui n'auront pas été dédouanées, et que les concessionnaires se conformeront au réglement qui sera établi à cet égard.

Les dispositions de l'article 3 du décret du ${ }^{\text {er }}$ Djoumadi-el-Aoual I299, relatives aux objets et marchandises non réclamées dans le délai de six mois, à compter du jour de leur dépôt continueront d'être appliquées à la diligence de l'administration des douanes et sur la demande des concessionnaires.

\section{Tarif $n^{0}$ 7. - Taxes de manutentions obligatoires pour la Société. \\ Pesage ell magasin.}

Art. I $^{\text {er }}$ - Pesage d'objets quelconques chargés sur un véhicule taré, soit charrette, soit wagon, en bloc ou par opération, un franc cinq centimes. . . 
Art. 2. - Pesage de toutes marchandises fractionnées par caisses, ballots, sacs, paniers, etc. :

La tonne conventionnelle de la Société, cinquante et un centimes

(Pour les poids supérieurs à I, ooo kilogr., chaque fraction de tonne sera comptée pour une tonne.)

Art. 3. - Pesage de toutes marchandises comme à l'article 2, pour un poids inférieur à 1,000 kilogr. par fraction de roo kilogr. et comptée comme roo kilogr., quinze centimes

(Le pesage ne comprend pas la manutention.)

Observations pour le travail de nuit.

Chaque manutention opérée de nuit, à la demande de l'intéressé, donnera lieu à une application du tarif qui précède augmenté de so p. Ioo.

\section{Tarif n० 8. - Taxes des manutentions facultatives pour la Société.}

Art. I ${ }^{\text {er }}$ - Désarrimer pour lerage dans la cale par les moyens du bord :

La tonne conventionnelle de la Société, cinquante et un centimes.

Art. 2. - Désarrimer, lever avec les mojens du bord et mettre sous palan le long du navire:

La tonne conventionnelle de la Société, un franc cinq centimes . . . . . . . . . . . . . I 05

Art. 3. - Recevoir sous palan, rouler sur quai et sous liangar, sans classement :

La tonne conventionnelle de la Société, un franc

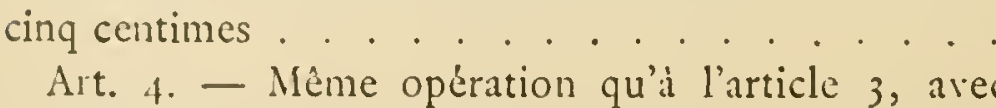
classement :

La tonne conventionnelle de la Société, un franc quatre-vingts centimes. 


\section{l'outillage Économique.}

Art. 5. - Même opération qu'à l'article 3, avec classement par la douane :

La tonne conventionnelle de la Société, deux francs dis centimes. . . . . . . . . . . . . .

Art. 6. - Transport du magasin à l'appontement en face pour mettre sous palan :

La tonne conventionnelle de la Société, soixantequinze centimes . . . . . . . . . . .

Art. 7. - Même transport jusqu'à un autre appontement :

La tonne conventionnelle de la Société, un franc ringt-six centimes . . . . . . . . . . . .

Art. 8. - Transport du quai à un local spécial ou inversement :

La tonne conventionnelle de la Société, deux francs dix centimes. . . . . . . . . . . . . .

Art. 9. - Recevoir sous panneaux et arrimer dans la cale :

La tonne conventionnelle de la Société, un franc vingt-six centimes . . . . . . . . . . . .

Art. Io. - Prendre sous palan et arrimer dans la cale :

La tonne conventionnelle de la Société, un franc cinquante centimes.

Art. 11. - Transborder d'une cale dans une autre avec les treuils du bord:

La tonne conventionnelle de la Société, deux francs

dix centimes.
Art. 12. - Transborder du pont d'un chaland sur le pont du navire avec les moyens du bord:

La tonne conventionnelle de la Société, un franc cinquante centimes.

Observations pour le travail de nuit.

Chaque manutention opérée de nuit, à la demande de l'intéressé, donnera lieu à une application du tarif qui précéde augmenté de 50 p. Ioo. 


\section{Tarif n० 9. - Divers.}

A) Eau.

Art. I ${ }^{\text {er }}$ - Eau prise aux robinets de la Société soit à l'aide de tuyaux, par mille litres:

Deux francs dix centimes

Art. 2. - Eau livrée à bord sur un navire accosté à quai par 1,000 litres jusqu'à ı, 000 litres :

Cinq francs dix centimes. . . . . . . . . S Io

Pour toute quantité au-dessus de io, 000 litres:

Trois francs par mille litres. . . . . . . . . . . . cumulées avec la taxe prévue par l'âticle 2 du décret du 2 I Moharem I $28 S$.

\section{B) Appareils de levage. - Grues.}

Art. 3.- Grue à vapeur pouvant lever I, ooo kilogr., par heure :

Quinze francs . . . . . . . . . I I; "

Par demi-journće:

Cinquante francs dix centimes . . . . . . 50 ro

Art. 4. - Grue fixe ou mâture à bras, par tonnes conrentionnelles de la Société.

Par colis indivisible de I a 3 tonnes:

Cinq francs dix centimes.

Par colis indivisible de 3 a 5 tonnes:

Six francs trente centimes

Par colis indivisible de 5 à 10 tonnes:

Sept francs cinquante centimes..... . 750

Par colis indivisible au delà de ro tonnes:

Dix francs cinq centimes. . . . . . . I 0 of

Art. 5. - Grue roulante à bras pouvant décharger des colis d'un poids inférieur à I, ooo kilogr. :

Location par demi-journée. 
'Conditions applicables aux diverses taxes de ce tarif.

Les taxes ci-dessus comprennent la location de l'engin et de ses accessoires, la fourniture de la force motrice nécessaire pour l'actionner, le graissage, les frais de conduite de l'engin ; tous les autres frilis de manœuvre, l'accrochage, le décrochage, l'approche et la manutention des colis, ainsi que la fourniture des chaines et cordages pour sai.ir les colis, seront à la charge du locataire.

Dans le cas spécial du déchargement de la houille ou du coke, les taxes comprennent la fourniture, par la Société, des bennes, crochets ou chaines destinés au chargement, au hissage et au déchargement des marchandises.

Les taxes sont dues par celui qui aura fait la demande.

Cette demande devra être faite par écrit.

Lorsque les appareils sont donnés en location à l'heure ou à la demi-journée, toute heure ou toute demi-journée commencée est due. Néanmoins, l'engin est' retiré par les agents de la Société dés que le travail est terminé.

Le prix de la première heure ou de la première demi-journée est payé d'avance à titre d'arrhes, lors de la demande de l'engin.

Ceux qui font usage des engins de la Société doivent employer pour le déchargement et l'embarquement des marchan. dises ainsi que pour leur arrimage à fond de cale (ou sur les wagons) et en général pour la manutention des marchandises, un nombre d'hommes suffisants pour accélérer le travail et ne pas laisser chômer l'engin, faute de quoi il peut leur être retiré.

Les grues ne peuvent être employées à soulever un poids supérieur à leur force. Toute avarie occasionnée par l'emploi de poids supérieur reste à la charge des personnes qui ont fait usage des grues.

Les personnes qui veulent travailler en dehors des jours et heures réglementaires du travail de la douane doivent en faire la déclaration écrite au moins six heures avant le commencement du travail supplémentaire en produisant une autorisation de la douane.

Pour ces travaux les taxes ci-dessus seront majorées de 50 p. Ioo. 


\section{CHAPITRE IV}

FVALUATIONS DES UNITES DE MESURE POUR L'APPLICATION DES TA.SES

\section{I. - Tonne conventionnelle de la Sociéti.}

Io L.es m.rrchandises ou matiéres d'une densité supérieure à I, ooo kilogr par métre cube et d'un arrimage facile comme les mitaux bruts, les minerais, la houille, les briquettes, les matériaux de construction, ctc., seront comptés pour leur poids réel.

En conséquence, on comptera une tonne conventio:melle de la Société pour i, ooo kilogr. du poids réel.

$2^{\circ}$ Les marchandises d'une densité égale ou supérieure à 1,000 kilogr. le mètre cube, dans des caisses, paquets ou paniers pesant moins de une tonne par colis seront comptées pour leur poids augmenté de $50 \mathrm{p}$. Ioo. La tonne conventionnelle de la Société correspondra en conséquence ì $2 / 3 \mathrm{de} \mathrm{la} \mathrm{tonne} \mathrm{métrique}$ ou $666^{\mathrm{k}}, 666$ de poids réel.

$3^{\circ}$ Les liquides en fùts seront comptés pour leur poids brut augmenté de 25 p. I00. La tonne conventionnelle de la Société correspondra en conséquence à $4 / 5$ de tonne métrique ou à 800 kilogr. de poids réel.

$4^{\circ}$ Les marchandises emball'es, en caisses, cages, paniers ou sacs d'une densité inférieure à I, ooo kilogr. par métre cube, mais supérieure à 500 kilogr., seront comptées pour leur poids réel augmenté de I00 p. I00. La tonne conventionnelle de la Société correspondra en conséquence à 500 kilogr. de poids réel.

Les marchandises légères, d'une densité inférieure à 500 kilogr. par mitre cube, en caisscs, cages, paniers ou sacs, les colis encombrants, les bois bruts ou débités, seront comptés à raison de 1,000 kilogr. par métre cube calculé en prenant le parallélipipède circonscrit. La tonne conventionnelle de la Société correspondra en conséquence à un métre cube de volume du parallélipipède circonscrit.

La Sociétés se réserve le droit de cuber tous les colis d'une 
densité au-dessons de I, 00o kilogr. le mètre cube et d'appliquer les droits au volume ou au poids selon sa convenance.

Pour les droits au volume, la tonne conventionnelle vaudra un mètre cube

$$
\text { I1. - Evaluation du tonnage de jange des navires. }
$$

Le tonnage de jauge brute des navires à voiles ou à vapeur dont il est question aux t.ırifs nos I et 4 est celui qui résulte de la méthode Moorsom appliquée conformément au règlement français.

Le tonnage de jauge $n$ atte dont il est question au tarif $n^{\circ} 2$ est égal :

Pour les voiliers, au tonnage de jaugre brute déterminé comme il est dit ci-dessus;

Pour les vapeurs, au to.nnage de jauge brute déduction faite des espaces occupés p.rr les machines et leurs accessoires conformément au règlement français eı vigueur.

\section{III. - Evaluation des tonneaux d'affrètement.}

Le tonneau d'affrètement aura la composition déterminée par les décrets français du 25 août I 66 I et du 24 septembre I864, insérés au Bulletin des lois.

Le tonneau d'affrètement qui n'est pas défini dans ces textes pour ce qui concerne les ani naux vivants ou morts et les primeurs le sera ainsi :

Nombre d'animaux ou poids correspondant à I tonneau d'affrètement.

a) Bœuf . I tête.

Cheval

Chameau ........... . . -

b) Anes, veaux, porcs, etc. . . . . . . 2 têtes.

c) Moutons, chèvres, chiens . . . . . . 6 -

d) Gibier, poissons frais, volailles . . . . . 40 kilogr.

e) Légumes frais, fruits, primeurs et autres produits aliment..ires frais analogues, en caisse, panier ou sac. . . . . . 6 60 kilogr.

Toute friction de tonneau d'affrètement sera comptée pour un ton:eau entier. 
ANNEXE B

TAXES MAXIMA DU PORT DE TUNIS

\section{I. - TAXES OBLIGATOIRES}

Taxe no 1. - Droit de pilotage, d'abri et de stationnement.

Pour tout narire, venant du large, qui a franchi la ligne des musoirs, par jour et par tonneau de jauge nette. . of $03^{c}$ (avec un minimum de perception de ro jours).

Ce droit est réduit de moitié pour tous les navires en provenance de la côte tunisienne qui paieront par suite, par jour et par tonneau de jauge nette. . . . (avec un minimum de perception de dix jours).

Les droits ci-dessus seront réduits d'un tiers pour les navires affectés à un service hebdomadaire régulier, ou à un service régulier mensuel avec un port de l'Océan.

Pour bénéficier de cette réduction, les intéressés devront déposer préalablement, au bureau du port, une déclaration indiquant la n.ture et la durée du service régulier qu’ils entendent faire.

Sont exemptés de la taxe $12^{\circ} I$ :

Les bateaux naviguant exclusivement entre Tunis et les points de la còte situés entre le cap Gammart et le Ras-Farthas.

Taxe $n^{\circ}$ 2. - Droits d'accostage au delà des délais réglementaires.

Il est accordé à tout navire accosté aux quais ou aux appontements un délai d'embarquement ou de débarquement calculé à raison de :

Un jour franc par 200 tonines de marchindises pour les vapeurs; 
Un jour franc par 40 tonnes de marchandises pour les voiliers.

Passé ce délai, le navire sera frappé, par tonneau de jauge nette et par jour, d'une taxe de ..... . $\mathrm{o}^{\mathrm{f}} 10^{\mathrm{c}}$

Taxe $n^{\circ}$ 3. - Droits de séjour dans les eaux du port.

Pour tout navire qui séjourne habituellement dans les eaux du port, par année.

Par tonneau de jauge brute, pour les vapeurs et re-

morqueurs. $\quad$ Par tonneau de jauge nette, pour les autres embarcations .. . . . . . . . . . . 250

Taxe no 4. - Droits d'embarquement et de débarquement des marchandises.

Pour tout navire opérant dans le port après accostage direct.

Par tonne de marchandise embarquée ou débarquée. $\quad 0^{f} 75^{\circ}$

Pour tout navire opérant sans accostage direct, par l'intermédiaire de chalands, mahonnes, etc.

Par tonne de marchandise embarquée ou délarquée. o so

Pour tout navire venant d'un point de la côte tunisienne et débarquant des narchandises destinées à la réexportation.

Pour tout navire à pleine charge, venant de la côte tunisienne ou s'y rendant.

Par tonne de marchandise embarquée ou débarquée.

Sont exemptés de la taxe $n^{\circ} 4$ :

L'eau, le charbon et les vivres destinés à la consommation du navire; les matériaux de construction provenant de la côte tunisienne, les çaisses, fùts et emballages vides.

Le poids des animaux vivants sera évalué en comptant pour une tonne :

Une tête de bœuf, une tête de cheval, une tête de mulet, une tête de chameau. 
Deux têtes de veaux, deux têtes d'ines, deux tétes de porcs.

Six têtes de moutons, six tittes de chèvres, six têtes de chevreaus.

Toute fraction de tonne sera comptée pour une tonne.

Taxe no 5. - Drjits d'embarquemənt et de débarquement sur les passagers.

Par passager civil em'sarqu'ó o’ébarqué directement ou par transbordement.

En première classe . . . . . . . . . . $4^{\mathrm{t}}{ }^{\mathrm{c}}$

En deuxieme classe. . . . . . . . . . . ; "

En troisicme et quatrième classe. . . . . . . I 50

Sont exemptes de la taxe $n^{\circ} 5$ :

Les militaires des armées française et tunisienne de toute provenance ei les pass.gers civils à destination ou en provenance des points de lia còte compris entre le cap Gammart et Ras-Farthas .

Taxe n० 6. - Droits de séjour des marchandises sur les terre-pleins au delà des délais réglementaires.

Pour les marchandis as qui séjournent d.uns la partie des terre-pleins désignée à cet effet, plus de troisjours francs, non compris les jours fériés,

Par tonne et par jour dans le cas de hangars couverts :

Pour chacun des six jours au delà des trois premiers. $\mathrm{O}^{\mathrm{t}} 15^{\mathrm{C}}$

Pour chacun des trois suivants . . . . . . o 30

Au delà, pour chaque jour . . . . . . . . 060

Dans le cas des terre-pleins no: couverts, les taxes précédentes scront réduites des deux tiers et ramenćes respectivement à . . . . o 0;, o Io,

Passé le délai total de 5 jours frazes, les marchandises pourront être enlevées d'ofice, aux frais des destinataires, dans les conditions fixées p.r les riglements.

Dans aucun cas, les dépôts ne seront admis sur les p.rties des terre-pleins non désignées à cet effet. 


\section{II. - TAXES FACULTATIVES}

Taxe $n^{0}$ 7. - Tarif du pilotage.

Pour pilotage d'un navire en dehors des e.ux du port, quel que soit le tonisage :

Le jour. . . . . . . . . . . $10^{\mathrm{f}}$ $^{\mathrm{c}}$

La nuit . . . . . . . . . . . . . . . Is

Pour pilotage de nuit dans les eaux du port (en sus de la taxe obligatoire no 1 ).

Pour tous navires :

Jusqu'à 300 tonneaux dz jau ge nette. . . . . . Iо »

De 301 à 800 ton:reaux de jauge nette . . . . Is"

De 8or tonneaux et au-dessus . . . . . . 20 ”

Pour tout navire qui sera mis en quarantaine, ayant pris le pilote à bord :

Par journée . . . . . . . . . Io »

\section{Taxe no 8 . - Tarif du remorquage.}

Pour tout navire, à l'entrée ou à la sortie.

Par tonneau de jauge nette :

Entre le bassin d'opérations et le mouillage en rade ou un point situé à $1 / 2$ mille au large des derniers ouvrages . . . . . . . . . . . . . O IS

Entre le bassin de Tunis et celui de la Goulette . . 》 》

En dehors des limites ci-dessus indiquées, de gré à gré.

Taxe n० 9. - Tarif damarraga ou de démarrage.

Pour tout navire à amarrer ou à démarrer, les amarres fournies par le bord :

Par tonneau de jauge nette. . . . . . . 002

Tarif $n^{\circ} 10 .-$ Tarif de prise d'eau.

Pour usage des prises d'eau du port et des manches à eau :

Par tonne d'eau embarquée. . . . . . . . I » 
Taxe $n^{\circ} 11$. - Tarif des opérations de chargement et da déchargement.

Pour prise en cale et mise sur terre-pleins courerts ou décourerts, ou vice virsa.

Par tonne de I, ooo kilogr. :

Le navire accosté à quai. ${ }^{\mathrm{f}} \mathrm{IO}^{\mathrm{c}}$

Le navire non accosté (la prise sous palan et mise en cale ou vice versa incombant aux mojens du bord).

Pour prise sous palan et mise en cale ou vice versa, le navire accosté . . . . . . . . . . . . o jo

Pour prise sous palan et mise sur terre-pleins couverts ou découverts, ou rice versa, le navire non accosté .

060

\section{Taxe no 12. - Tarif du bàchage.}

Pour bàchage sur les terre-pleins, gardiennage compris :

Par tonne et par jour.

$0 \quad 10$

\section{Taxe no 13. - Tarif des engins de levage.}

Pour une grue de 2,500 kilogr. de puissance :

Par heure de travail effectif

Par heure de travail effectif en dehors des périodes réglementaires :

Le jour. . . . . . . . . . . . 450

La nuit . . . . . . . . . . . . 550

Pour une grue de 3,00o kilogr. de puissance:

Par heure de travail effectif. . . . . . . . 6 »

Par heure de travail effectif en dehors des périodes réglementaires :

Le jour. . . . . . . . . . . 650

La nuit... . . . . . . . 750

Pour un treuil mobile de une tome de puissance :

Par heure de travail effectif . . . . . . . 3 » 
Par heure de travail effectif en dehors des heures réglementaires :

Le jour. . . . . . . . . . $3^{\mathrm{f}} 50^{\mathrm{c}}$

La nuit . . . . . . . . . . . . . . 450

Pour une bigue de 20 tonnes de puissance :

Allumage . . . . . . . . . . . 20 »

Par heure de travail effectif:

Avec une puissance maxima de 5 tonnes . . . . Io "

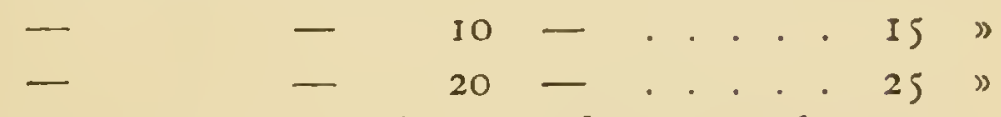

Pour une grue à main, les hommes fournis par le concessionnaire :

Par heure de travail effectif

Pour tous ces tarifs le mininum de perception est de 4 heures.

Toute heure commencée est due en entier.

Taxe $\mathrm{n}^{0}$ 14. - Tarif du magasinage.

Par 100 kilogr. et par semaine, pour magasinage aux conditions stipulées par les articles 24 et 2 ; du cahier des charges :

$\iota^{\mathrm{re}}$ catégorie comprenant:

Absinthe, cire en colis, alcool, amidon, chinvres non pressés, cotons en balles non pressées, cuirs tannés, eau-de-vie, garance en poudre, houblon en balles, papier pressé en balles, lièges en planches, mercerie, porcelaine en caisses, poterie fine en caisses, raisins secs en caisses, saindoux en caisses, tabacs en feuilles et en balles non pressées, tissus de laine en balles, verres et cristaux, vins en caisses et en petits fùts . .

$2^{\mathrm{e}}$ catégorie comprenant:

Amandes en barils ou en balles, bière en fûts ou en caisses, câbles de chanvre, chanvres pressés, colle forte en colis, conserves alimentaires en colis, cordages neufs ou vieux, cotons pressés en balles, fils de coton, de chanvre et de lin, garance en racine, graisse 
en caisses ou en füts, hule en füts, laine en suint ct larée, morue en balles, olives en barils, papiers pressés en balles, peaux de mouton en ballcs pressées, peaux de chère en balles pressées, poissons salés en barils, quincaillerie fine en colis, sacs vides, saindoux en füts, tissus de fils ou de coton en balles, toiles d'emballage, toiles à voiles, vermouth, verres à vitre en caisses, viande salée en barils, rins et liqueurs . . . . . . .

\section{$3^{\mathrm{e}}$ catégorie compronant.}

Arachides, biscuits de mer, chandelles en caisscs, cuirs pressés en balles, cuivre en planches, encre en fûts, fonte ouvrée, gomme laque, pierre à aiguiser, poivre en bal'.es, poterie commune cn caisses, salaisons non dénommées en colis, savon commun en caisses, sucre raffiné ou brut en fûts ou en couffes, tabacs en füts, tabacs en balles pressées, vinaigre ordinaire en fùts, bordelaises ou gros füts, vins ordinaires en fùts.

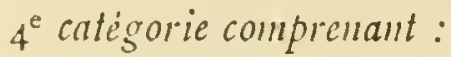

Aciers en füts, en barres et en vrac, asphaltes en bloc ou en fùts, blanc d'Espagne, bougies en caisses, chaines en fer, ciments en colis, chaux, couperose en fùts, cuivre en lingots, fer blanc en colis, figues sèches en colis, fonte en gueuses, noix, noisettes, pans carrés sans responsabilité de casce, quincaillcrie grosse en colis, tôles brutes, zinc en feuillcs, en plaques ou en lingots

se catégorie comprenant :

Blanc de zinc et de plomb, blé en sacs, farines en balles ou en barils, féves en sacs ou en grenier arec des sacs en quantité suffisante pour faire les séparations et les murs de souténement, grains ou graines de lin, colza, moutarde, sésame en sacs, haricors et légumes secs, mais en sacs, minerais de zinc ou de cuivre en füts ou en sacs, orge et aroine en grenier avec des sacs en quantití suffisante pour faire les murs de sou- 


\section{L'oUtillage ÉCONomique.}

tènement et les séparations, orges et avoines en sacs, plomb en saumons ou $\in \mathrm{n}$ feuilles, riz en sacs . . . $o^{\mathrm{f}} \mathrm{o} 7^{\mathrm{c}}$

Seront taxés à la valeur :

L'argenterie, bijouterie fausse ou fine, chapeaux de paille en caisses, cochenille en colis, fils de laine et de soie, corail brut ou ouvré, drap en balles ou en colis, horlogerie en colis, indigo, or et argent ourrés, soie écrue, grège et en balles, tissus de soie, à ra:son de, p. I00 . . . . . . . . . . . .

Les bouteilles vides en colis sans garantie de casse, à raison de, p. Ioo . . . . . . . . . . . 006

Les bourres de soie en balles, à raison de, p. I00 004 Les taxes ci-dessus se paient par semaine.

Toute semaine commencée est due en entier.

\section{Taxe $n^{0} 15 .-$ Tarif de pesage.}

Par tonne ou fraction de tonne ...... . . 005

Taxe n० 16. - Tarif de la forme de radoub de la Goulette. (Décret du 11 juillet 1892.)

Pour la première journée,

Compris manœuvre des portes et épuisement de la forme . . . . . . . . . . $50^{f} n^{c}$

Par chaque journée ou fraction de journée en sus,

$\mathrm{Y}$ compris (pour la dernière) le remplissage et la mancuvre de la porte. . . . . . . . Io » 


\section{ANNEXE C \\ TAXES MAXIMA DU PORT DE SOUSSE}

\section{I. - TAXES OBLIGATOIRES}

Taxe n० 1. - Droits de pilotåge, d'abri et de stationnement.

Pour tout navire venant du large qui a franchi la ligne des musoirs :

Par jour et par tonneau de jauge nette (arec un minimum de perception de dix jours)..... . of $03^{c}$

$\mathrm{Ce}$ droit est réduit de moitié pour tous les navires en provenance de la côte tunisienne, qui paieront par suite :

Par jour et par tonneau de jauge nette (arec un minimum de perception de dix jours). . . . . .

Les droits ci-dessus seront réduits d'un tiers pour les navires affectés à un service hebdomadaire régulier ou à un service régulier mensuel arec un port de l'Océan.

Pour bénéficier de cette réduction, les intéressés devront déposer préalablement au bureau du port une déclaration indiquant la nature et la durée du service régulier qu'ils entendent faire.

Sont cxemplés de la taxe $1^{\circ} \mathrm{I}$ :

Les bateaux naviguant exclusivement entre Sousse et les points de la còte situés entre Hergla et lil pointe de Monastir.

Taxe $n^{3} 2$. - Droits d'accostage au delà dəs délais réglementaires.

Il est accordé à tout navire accosté aux quais ou 
L'OUTILlage ÉCONOMIQUe.

aux appontements, un délai d'embarquement ou de débarquement calculé à raison de :

Un jour franc pour 200 tonnes de marchandises pour les vapeurs;

Un jour franc pour 40 tonnes de marchandises pour les voiliers.

Passé ce délai, le navire sera frappé par tonneau de jauge nette et par jour d'une taxe de. . . . . . o of $10^{c}$

Taxe n० 3. - Droit de séjour dans les eaux du port.

Pour tout navire qui séjourne habituellement dans les eaux du port, par année :

Par tonneau de jauge brute, pour les vapeurs et les remorqueurs. . . . . . . . . . . . I0 »

Par tonneau de jauge nette, pour toutes les autres embarcations .............. I 25

Taxe $\mathrm{n}^{\circ}$ 4. - Droit d'embarquement et de débarquement sur les marchandises.

Pour tout navire opérant dans le port, soit directement, soit par l'intermédiaire de chalands, mahonnes, etc. :

Par tonize de marchandise embarquée ou débarquée.

Cette taxe est réduite à .

$4^{\mathrm{f}}$ "c $^{\mathrm{c}}$

2 )

Pour les marchandises ci-aprés désionnées, dites de première catégorie :

Alfas bruts, chiffons, os, céréales et légumes secs, houille, bois à brûler, huiles de grignon, métaux bruts, matíriaux de construction de toutes sortes, paille et fourrages, vins.

Et à

Pour les marchandises ci-après désignées, dites de o 50 deuxiéme catégorie:

Grignons, phosphates, fumiers et engrais. 
Les taxes ci-dessus sont réduites de moitié,

Au débarquement :

$I^{\circ}$ Pour toute marchandise en provenance de la còte tunisienne;

$2^{\circ}$ Pour toute marchandise de provenance étrangère destinée à être réexpédice par mer sans avoir quitté les terre-plcins du port;

A l'embarquement :

Pour toute marchandise à destination de la cốte tunisienne.

Sont exemptés de la tave $n^{\circ}+$ :

L'eau, le charhon et les virres destinés à la consommation du navire; les matériaux de construction provenant de la côte tunisienne, les caisses, füts et emballages vides.

Le poids des animaux vivants sera évalué en comptant pour une tonne de la deuxiéme catégorie :

Une tête de bœuf, une tête de cheval, une tête de mulct, une tête de chameau.

Deux têtes de veaux, deux tètes d'ànes, deux têtes de porcs.

Six têtes de moutons, six tẻtes de chèvres, six tètes de chevreaux.

Toute fraction de tonne sera comptée pour une tonne.

Taxe no 5. - Droit d'embarquement et de débarquement sur les passagers.

Tout passager civil embarqué ou débarqué directement ou par transbordement :

En première classe . . . . . . . . . $3^{\text {f }}{ }^{\mathrm{c}}$

En deuxieme classe. . . . . . . . . . . 2 »

En troisieme et quatriéme clisse . . . . . . . I 》

Sont exemplis de la tave $n^{\circ} \mathrm{s}$ :

Les militaires des armées française et tunisienne de toute provenance et les passagers civils à destination 
ou en provenance des points de la còte compris entre Hergla et la pointe de Monastir.

Taxe n० 6. - Droit de séjour des marchandises sur les terre-pleins au delà des délais réglementaires.

Pour les marchan lises qui séjourneront dans la partie des terre-pleins désignée à cet effet, plus de trois jours francs, non compris les jours fériés.

Par tonne et par jour, dans le cas de hangars couverts :

Pour chacun des six jours au delà des trois premiers.

Pour chacun des trois suivants . . . . . . . .

$\mathrm{O}^{\mathrm{f}} \mathrm{I} 5^{\mathrm{c}}$

030

060

Au delà pour chaque jour.

Dans le cas de terre-pleins non couverts, les taxes précédentes seront réduites des deux tiers et ramenées respectivement $\dot{a}$. . . . . . . . 0050 o 10

Passé le délai total de 55 jours francs, les marchandises pourront être enlevées d'office, aux frais des destinataires, dans les conditions fixées par les réglements.

Dans aucun cas, les dépòts de marchan lises ne seront admis sur les parties des terre-pleins non désignées à cet effet.

\section{II. - TAAES FACULTATIVES}

Taxe no 7. - Tarif du pilotage.

Pour le pilotage d'un navire en dehors des eaux du port, quel que soit le tonnage :

Le jour.

La nuit.

Pour pilotage de nuit dans les eaux du port (en sus de la taxe obligatoire $n^{\circ}$ I):

Pour tous navires:

Jusqu’à 300 tonneaux de jauge nette. . . . . . Io »

De 30 I à Soo tonneaux . . . . . . . . I 5 》

De 80I tonneaux et au-dessus . . . . . . . 20 » 
Pour tout navire qui sera mis en quarantaine, ayant pris le pilote a bord.

Taxe no 8. - Tarif du remorquage.

Pour tout navire, à l'entríe ou à la sortie, par ton:zeau de jauge nette :

Entre le bassin d'op'rations et le mouillage en rade ou un pont situé à un demi-mille au large des derniers ouvrages .

En dehors des limites ci-dessus indiquées . . de gré à gré.

Taxe n० 9. - Tarif d'amarrage ou de démarrage.

Pour tout nuvire à amarrer ou à démarrer, les amarres fournies par le bord :

Par tonneau de jauge nette. . . . . . . 02

Taxe no 10. - Tarif de prise d'eau.

Pour usage des prises d'eau du port et des manches à eaux :

Par tonne d'eau embarquée.

Taxe n०11. - Tarif des opérations de chargement et de déchargement.

Pour prise en cale et mise sur terre-pleins couverts ou découverts, ou vice versa :

Par tonne de 1,000 kilogr. :

Le navire accosté à quai .

Le navire non accosté (lia prise sous palan et mise en cale et vice versa incombant aux moyens du bord).

Pour prise sous palan et mise en cale ou vice versa, le navire accosté

Pour prise sous palan et mise sur terre-pleins couverts ou découverts, ou vice versa, le navire non accosté.

Taxe n 12. - Tarif du bâchage.

Pour bâchage sur les terre-pleins, gardiennage compris :

Par tonne et par jour. . . . . . . . . o so 
Taxe n॰13. - Tarif des engins de levagə.

Pour une grue de I,500 kilogr. de puissance, par heure de travail effectif.

Par heure de travail effectif en dehors des périodes réglementaires :

Le jour.

La nuit.

Pour une grue de 3,000 kilogr. de puissance, par heure de travail effectif.

Par heure de travail effectif en dehors des périodes réglementaires :

Le jour.

La nuit.

Pour un treuil mobile de I tonne de puissance :

Par heure de travail effectif . . . . . . . . . .

Par heure de travail effectif en dehors des heures réglementaires :

Le jour.

La nuit.

Pour une bigue de 20 tonnes de puissance :

Allumage .

Par heure de travail effectif :

Avec une puissance maxima de 5 tonnes.

\begin{tabular}{llllllllll}
\hline & - & 10 & - & & &. &. & 15 & 1 \\
\hline & - & 20 & - &. &. &. &. & 25 &
\end{tabular}

Pour les grues a main, les hommes fournis par le concessionnaire :

Par heure de travail effectif.

Pour tous ces tarifs, le minimum de perception est de 4 heures.

Toute heure commencée est due en entier.

Taxe no 14. - Tarif dı magasinage.

Par too kilogr. et par semaine pour magasinage aux conditions stipulées par les articles 24 et 25 du cahier des charges. 
Ire catígurie comprenant:

Absinthe, cire en colis, alcool, amidon, chanvres non pressés, cotons en balles non pressées, cuirs tannés, cau-de-rie, garance en poudre, houblon en balles, lïges en planches, mercerie, papier pressé en balles, porcelaine en caisses, poterie fine en caisses, raisins secs en caisses, saindoux en caisses, tabacs en feuilles et en balles non pressées, tissus de laine en balles, verres et cristaux, vins en caisses et en petits fùts.

$2^{\mathrm{e}}$ catégorie comprenant:

Amandes en barils ou en balles, bière en fùts ou en caisses, câbles de chanvre, chanvres pressés, colle forte en colis, conserves alimentaires en colis, cordages neufs ou vieux, cotons pressés en balles, fils de coton, de chanvre et de lin, garance en racine, graisse en caisses ou en fùts, huile en fùts, laine en suint et larée, morue en balles, olives en barils, papiers pressés en balles, peaux de moutons en balles pressées, peaux de chérres en balles pressées, poissons salés en barils, quincaillerie fine en colis, sacs vides, saindoux en fùts, tissus de fils ou de cotons en balles, toiles d'emballage, toiles à voiles, rermouth, verres à vitre en caisses, viande salée en barils, vins et liqueurs . . . . . . . . .

$3^{\mathrm{e}}$ catégorie comprenant :

Arachides, biscuits de mer, chandelles en caisses, cuirs pressés en balles, cuivre en planches, encre en futs, fonte ouvrée, gomme laque, pierre à aiguiser, poivre en balles, poterie commune en caisses, salaisons non dénommées en colis, savon commun en caisses, sucre raffiné ou brut en fùts ou en couffes, tabacs en füts, tabacs en balles pressées, vinaigre ordinaire en futs, bordelaises ou gros futts, vins ordinaires en fúts .

$4^{e}$ catégorie comprentant :

Aciers en fùts, en barres et en vrac, asphaltes en bloc ou en fúts, blanc d'Espagne, bougies en caisses, chaines 
en fer, ciments en colis, chaux, couperose en fuits, cuivre en lingots, fer-blunc en colis, figues sèches en colis, fonte en gueuses, noix, noisettes, pans carrés sans responsabilité de casse, quincaillerie grosse en colis, tôles brutes, zinc en feuilles, en plaques ou en lingots

$S^{e}$ catégorie comprenant :

Blanc de zinc et de plomb, blé en sacs, farines en balles ou en barils, féves en sacs ou en grenier avec des sacs en quantité suffisante pour faire les séparations et les murs de soutenement, grains ou graines de lin, colza, moutarde, sésame en sacs, haricots et légumes secs, maïs en sacs, minerais de zinc et de cuivre en fûts ou en sacs, orge et avoine en grenier avec des sacs en quantité suffisante pour faire les murs de soutènement et les séparations, orges et avoines en sacs, p'omb en saumons ou en feuillcs, riz en sacs

Seront taxés it la valeur:

L'argenterie, bijouterie fausse ou fine, chapeaux de paille en caisses, cochenille en colis, fils de laine et de soie, corail brut ou ouvré, drap en balles ou en colis, horlogerie en colis, indigo, or et argent ouvrés, soie écrue, grège et en balles, tissus de soie à raison de, p. Ioo.

Les bouteilles vides en colis sans garantie de casse, à raison de, p. roo . . . . . . . . . . . 006

Les bourres de soie en balles, à raison de, p. Iоo. . 004

Les taxes ci-dessus se paient par semaine.

Toute semaine commencée est due en entier.

Taxe $\mathrm{n}^{0}$ 15. - Tarif du pesage.

Par tonne ou par fraction de tonne . . . . . 005 


\section{ANNEXE D}

TAXES MAXIMA DU PORT DE SFAX

\section{I. - TAXES OBLIG.HTOIRES}

Taxe no 1. - Droit de pilotagə, d'abri et de stationnement.

Pour tout navire renant du large qui a franchi la ligne des musoirs:

Par jour et par tomneau de jauge nette . . . . $0^{f} 03^{\circ}$ (arec un minimum de perception de dix jours).

Ce droit est réduit de moitié pour tous les navires en prorenance de la côte tunisienne qui paieront par suite :

Par jour et par tonneau de jauge nette. . . . . o o is (avec un minimum de perception de dix jours).

Les droits ci-dessus seront réduits d'un tiers pour les narires affectés à un service régulier mensuel arec un port de l'Océan.

Pour bénéficier de cette réduction, les intéressés devront déposer préalablement au bureau du port une déclaration indiquant la nature et la durée du service régulicr qu'ils entendent faire.

Sont exemptes de la tave $n^{\circ} \mathrm{I}$ :

Les bateaux naviguant exclusivement entre Sfax et les points de la côte situés entre le Bordj-Khadidja et Ras-'Tina, y compris les iles Kerkennah.

Taxe n०2. - Droits d'accostage au delà des délais réglementaires.

1] est accorde it tout navire accoste aux quais ou 
L'outillage ÉCONomique.

aux appontements un délai d'embarquement ou de débarquement calculé à raison de :

Un jour franc pour 200 tomnes de marchandises pour les vapeurs;

Un jour franc pour 40 tonnes de marchandises pour les voiliers;

Passé ce délai, le navire sera frappé, par tonneau de jauge nette et par jour, d'une taxe de ..... o of $10^{c}$

Taxe no 3. - Droits de séjour dans les eaux du port.

Pour tout navire qui séjourne habituellement dans les eaux du port, par année :

Par tonneau de jauge brute, pour les vapeurs et remorqueurs. . . . . . . . . . . . . . .

Par tonneau de jauge nette pour toutes les autres embarcations. . . . . . . . . . I 25

Taxe to 4. - Droits d'embarquement et de débarquement sur les marchandises.

Pour tout navire opérant dans le port, soit directement, soit par l'intermédiaire de chalands, mahonnes, etc. :

Partonne de marchandises embarquée ou débarquée. $\quad 4^{\mathrm{f}}$ " $^{\mathrm{f}}$

Cette taxe est réduite à . . . . . . . . . 2 » pour les marchandises ci-aprés désignées dites de première catégorie :

Alfas bruts, chiffons, os, céréales et légumes secs, houilles, bois à brûler, huile de grignon, métaux bruts, matériaux de construction de toute sorte, pailles et fourrages, vins.

Et à pour les marchandises ci-après désignées, dites de 050 deuxième catégorie :

Grignons, phosphates, fumiers et engrais. 
Les taxes ci-dessus seront réduites de moitié :

Au débarquement :

I Pour loute marchandise en prorenance de la còte tunisienne;

$2^{\circ}$ Pour toute marchandise de provenance étrangère destinée à être récxpédićc par mer sans avoir quitté les terre-pleins du port;

A l'embarquement :

Pour toute marchandise à destination de la côte tunisienne.

Sont exemptés de la taxe $n^{\circ}+$ :

L'eau, le charbon et les vivres destinés i la consommation du navire; les mitériaux de construction provenant de la còte tunisienne, les caisses, fùts et emballages vides.

Le poids des animaux virants sera évalu' en comptant pour une tonne de la deuxiéme catégorie :

Une titte de bœuf, une tête de cheval, une tête de mulet, une tite de chameau.

Deux têtes de veaux, deux têtes d'ines, deux têtes de porcs.

Six têtes de moutons, six têtes de chèrres, six têtes de chevraux.

Toute fraction de tonne sera comptée pour une tonne.

Taxe n०5. - Droit d'embarquement et de débarquement sur les passagers.

Parpassager civil embarqué ou débarqué directement ou par transbordement :

En $\mathrm{I}^{\mathrm{re}}$ classe. . . . . . . . . . $3^{\mathrm{t}}{ }^{\mathrm{c}}$

En $2^{\mathrm{e}}$ classe. . . . . . . . . . . . . . . 2 »

En $3^{\mathrm{e}}$ et $4^{\mathrm{e}}$ classe. . . . . . . . . . . . I

Sont exemptés de la taxe $11^{\circ} 5$ :

Les militaires des armécs française et tunisienne de toute provenance et tous les passagers civils à destination ou en provenunce des points de la còte compris entre Bordj-Khlhadidja et Ras-Tina, y compris les îles kirkennah. 
Taxe no 6. - Droit de séjour des marchandises sur les terre-pleins au delà des délais réglementaires.

Pour les marchandises qui séjourneront dans la partie des terre-pleins désignée à cet effet, plus de trois jours francs, non compris les jours féries, par tonne et par jour, dans le cas de hangars couverts :

Pour chacun des six jours au de'à des trois premiers. $\mathrm{O}^{\mathrm{f}}$ I $5^{\mathrm{c}}$

Pour chacun des trois suivants . . . . . . . 030

Au delà, pour chaque jour. . . . . . . . 060

Dans le cas de terre-pleins non couverts, les taxes précédentes seront réduites des deux tiers et ramenées respectivement à. . . . . . . o 05 o 10

Passé le délai total de is jours francs, les marchandises pourront être enlevées d'office, aux frais des destinataires, dans les conditions fixées par les règlements.

Dans aucun cas les dépôts de marchandises ne seront admis sur les parties des terre-pleins non désignées à cet effet.

\section{TAXES FACULTATIVES}

\section{Taxe n० 7. - Tarif du pilotage.}

Pour pilotage d'un navire en dehors des eaux du port, quel que soit le tonnage :

Le jour . . . . . . . . . . . Io »

La nuit . . . . . . . . . . . . I5

Pour pilotage de nuit dans les eaux du port (en sus de la taxe obligatoire $n^{\circ} 1$ ):

Pour tous navires:

Jusqu'à 300 tonneaux de jauge nette. . . . . IO "

De 30 à Soo tonneaux ........ Is "

De Sor tonneaux et au-dessus. . . . . . . . 20 »

Pour tout navire qui sera mis en quarantaine, ayant pris le pilote à bord :

Par journée. 


\section{Taxe n० 8. - Tarif du remorquage.}

Pour tout navire, à l'entrée ou à la sortie,

Par tonnenu de jauge nette :

Entre le bassin d'opérations et le mouillage en rade ou un point situé à un $\mathrm{I} / 2$ mille au large des derniers ouvrages

En dehors des limites ci-dessus indiquées, de gré d gré.

Taxe no 9. - Tarif d'amarrage ou de demarrage.

Pour tout navire à amarrer ou à démarrer, les amarres fournies par le bord:

Par tonneau de jauge nette. . . . . . . . 002

$$
\text { Taxe no 10. - Tarif de prise d'eau. }
$$

Pour usage des prises d'eau du port et des manches à eaux :

Par tonne d'eau embarquée.

$$
\begin{gathered}
\text { Taxe } \mathrm{n}^{0} 11 .- \text { Tarif des opérations de chargement } \\
\text { et de déchargement. }
\end{gathered}
$$

Pour prise en cale et mise sur terre-pleins couverts ou decourerts et vice versa, par tonne de I, ooo kilogr.

Le navire accosté à quai. . . . . . . . . I Io

Lc navire non accosté (la prise sous palan et mise en cille ou vice versa incombant aux moyens du bord).

Pour prise sous palan et mise en calc ou vice versa, le navire accosté . . . . . . . . . . . . o go

Pour prise sous palan et mise sur terre-pleins courerts ou découverts, ou vice vcrsa, le navire non accosté .

Taxe no 12. - Tarif du bâchage.

Pour bichage sur les terre-pleins, gardiennage compris :

Par tonne ct par jour. . . . . . . . . o 10 
Taxe $n^{\circ}$ 13. - Tarif des engins de levage.

Pour une grue de I, 500 kilogr. de puissance :

Par heure de travail effectif. . . . . . . . . $4^{\mathrm{f}}{ }^{\mathrm{c}}$

Par heure de travail effectif en dehors des périodes réglementaires :

Le jour. . . . . . . . . . . . . 450

La nuit . . . . . . . . . . . . . 5 50

Pour une grue de 3,000 kilogr. de puissance :

Par heure de travail effectif.

Par heure de travail effectif en dehors des périodes réglementaires :

Le jour. . . . . . . . . . . . 650

La nuit. . . . . . . . . . . . . . . . . . 750

Pour un treuil mobile de une tonne de puissance :

Par heure de travail effectif.

Par heure de travail effectif en dehors des heures réglementaires :

Le jour . . . . . . . . . . . . . 350

La nuit . . . . . . . . . . . . . 450

Pour une bigue de 20 tonnes de puissance:

Allumage . . . . . . . . . . . 20 »

Par heure de travail effectif :

Avec une puissance maxima de 5 tonnes ... . . Io

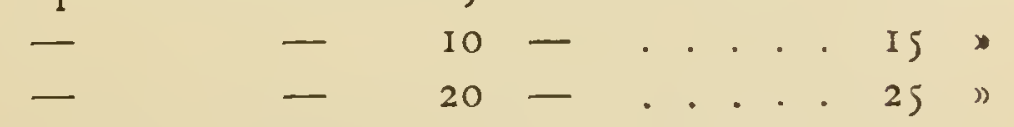

Pour une grue à main, les hommes fournis par le concessionnaire :

Par heure de travail effectif.

Pour tous ces tarifs, le minimum de perception est de 4 heures.

Toute heure commencée est due en entier.

$$
\text { Taxe } n^{\circ} 14 . \text { - Tarif du magasinage. }
$$

Par Ioo kilogr. et pa: semaine, pour magasinage aux conditions stipulées par les articles 24 et 25 du cahier des charges : 
Ire catigorie comprenant :

Absinthe, cire en colis, alcool, amidon, chanve non pressé, cotons en balles non pressées, cuirs tannés, eau-de-vie, garance en poudre, houblon en balles, lièges en planches, mercerie, papier pressé en balles, porcelaine en caisses, poterie fine en caisses, raisins secs en calisses, saindoux en caisses, tabacs en feuilles et en balles non pressées, tissus de laine en balles, verres et cristaux, vins en caisses ou en petits füts . . . . .

$2^{\mathrm{e}}$ catigorie comprenant :

Amandes en barils ou en balles, bière en fùts ou en caisses, cibles de chanvre, chanvres pressés, colle forte en colis, conserves alimentaires en colis, cordages neufs ou vieux, cotons pressés en balles, fils de coton, de chanvre et de lin, garance en racines, graisse en caisses ou cn füts, huile en fùts, laine en suint lavée, morue en balles, olives en b.rils, papiers pressés en balles, peaux de mouton en balles pressées, peaux de chèvre en balles pressées, poissons salís en barils, quincaillerie fine en colis, sacs vides, saindoux en fùts, tissus de fil ou de coton en balles, toiles d'emballage, toiles à voiles, vermouth, verres $\dot{a}$ vitres en caisses, riande salée en b.rrils, vins et liqueurs . . . . . .

$3^{\mathrm{e}}$ catégorie comprenant :

Arachides, biscuits de mer, chandelles en caisses, cuirs pressés en balles, cuivre en planches, encre en füts, fonte ourrée, gomme lique, pierre à aiguiser, poivre en balles, poterie commune en caisses, salaisons non dénommées en colis, savon commun en caisses, sucre raffiné ou brut en füts ou en couffins, tabacs en fùts, tabac en balles pressées, vinaigre ordinaire en füts, bordelaises ou gros füts, vins ordinaires en fùts

$f^{e}$ catégorie comprenant :

Aciers en füts, en barres et en rrac, asphaltes en blocs ou en fùts, blane d'Espıgne, bougies en caisses, 
chaines en fer, ciments en colis, chaux, couperose en fùts, cuivre en lingots, fer-blanc en colis, figues sèches en colis, fonte en gueuses, noix, noisettes, pans carrés sans responsabilité de casse, quincaillerie grosse en colis, tôles brutes, zinc en feuilles, en plaques ou en lingots.............. $\mathrm{O}^{\mathrm{f}} \mathrm{O} 3^{\circ}$

\section{$S^{\text {e }}$ catégorie comprenant:}

Blanc de zinc et de plomb, blé en sacs, farines en balles ou en barils, fèves en sacs ou en grenier avec des sacs en quantité suffisante pour faire les séparations et les murs de soutènement, grains ou graines de lin, colza, moutarde, sésame en sacs, haricots et légumes secs, mais en sacs, minerais de zinc et de cuivre en fùts ou en sacs, orge et aroine en grenier avec des sacs en quantité suffisante pour faire les murs de sontènement et les séparations, orges et avoines en sacs, plomb en saumon ou en feuilles, riz en sacs. . . .

\section{Scrout taxés à leur valeur :}

L'argenterie, bijouterie fausse ou fine, chapeaux de paille en caisses, cochenille en colis, corail brut ou ouvré, drap en balles ou en co'is, fils de laine ou de soie, horlogerie en colis, indigo, or et argent ouvrés, soie écrue, grège et en balles, tissus de soie, à raison de, p. 100

Les bouteilles vides en colis sans garantic de casse, à raison de, p. Ioo

Les bourres de soie en balles, à raison de, p. Ioo .

Les taxes ci-dessus se paient par semaine.

Toute semaine commencée est due en entier.

$$
\text { Taxe n०15. - Tarif du pesage. }
$$

Par tonne ou fraction de tonne . . . . . . o 05 



\section{CHAPITRE XVIII}

SITUATION ÉCONOMIQUE DE LA TUNISIE

AVANT ET APRÉS LE PROTECTORAT'

AVANT LE PROTECTORAT

Coup d'œil rétrospectif. - Dès le règne d'Hussein-Bey ( $1824-1835$ ), l'avidité des familiers, les dépenses exagérées de la cour, les concussions auxquelles se livraient les fonctionnaires de tous ordres, les emprunts usuraires, l'escompte même des récoltes futures étaient les signes précurseurs d'une banqueroute prochaine.

La gravité de la situation amena Hussein-Bey à recourir aux services de Salah-Et-Taba-Chakir, qu'il nomma premier ministre, en remplacement du Bachi-Mamelouk-Mustapha. Aussi résolu qu'habile, Chakir exécuta plusieurs réformes importantes qui ramenèrent l'ordre dans les finances. Sous sa sage administration, le commerce et l'industrie, négligés et sacrifiés pendant la période critique que le pays venait de traverser, reprenaient confiance lorsque, peu après l'avènement de Si-Ahmed-Bey, Chakir périt victime d'une intrigue de palais ourdie par Mustapha-Khasnadar, son successeur ( ${ }_{3} 8$ ). 
En s $S_{37}$, le mourement de la navigation ćtait représenté :

A l'entrée, par 26 ; navires, juugeant ensemble 27,270 tonnes (sur ce nombre, la navigation de caravane avec l'Albanie, les Etats barbaresques, Constantinople, Smyrne et l'Égypte occupait 64 navires, jaugeant 6,949 tonnes);

A la sortie, par 298 navires, juugeant ensemble 30,689 tomnes (dont 6+ navires, avec 6,363 tonnes, à destination des États barbaresques et du Levant).

Lia part du pavillon français ét.uit :

A l'entrée, de 62 navires, jaugeant 6,843 tonnes (dont 55 navires et 5,543 tonnes en provenance directe des ports français);

A la sortie, de 67 navires, jaugeant 6,494 tomnes (dont $6+$ navires et 6,185 tonnes à destination des ports français). Un paquebot, chaque quinzaine depuis I $\delta_{47}$, chaque seminine depuis I \$54, mettait seul la Tunisie en relations avec le monde extérieur par l'intermédiaire de l'Algérie. Pas un seul port ne permettait aux navires d'effectuer leurs opérations de chargement et de déchargement il l'abri du mauvais temps.

Aucune route empierrée n'existait dans l'ćtendue du pays.

Pendant cette même année 1837 , le mouvement du commerce cxtérieur s'élevait ì 17,635,900 piastres ${ }^{1}$ dont, il l'importation, Io,592,400 piasties et, ì l'exportation, $7,043,500$ piastres ${ }^{2}$.

Les échanges extéricurs portaient principalement sur lcs articles suivants :

I A cetse époque, la valeur de la piastrc osc llait entre o fr. $85 \mathrm{c}$. et o fr. $90 \mathrm{c}$.

: A l'importation, la France occupait le deuxième rang, avec 1,929,100 fixstres; à l'exportation, la Franic venait all premier rang, avec 2,575,900 piastres.

C'itdit de France et d'Italie que venaient en grande partie les furines; les denrées colonales, !es vins, les cotonnades venaient d'Angleterre. 
Importation.

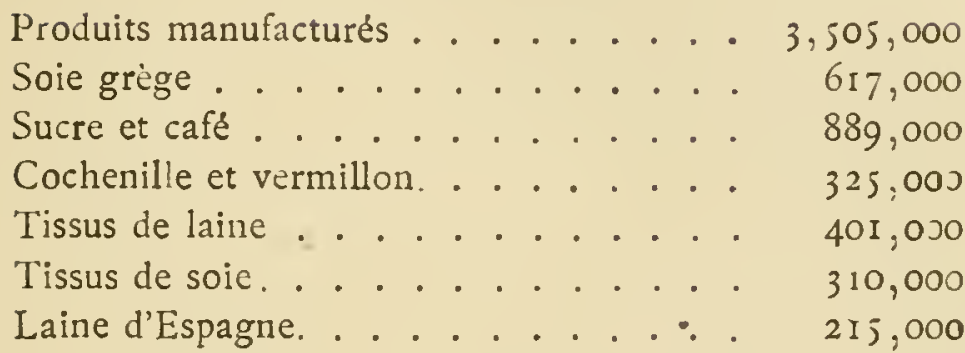

Exporlation ${ }^{\text {. }}$

Huile d'olive . . . . . . 2, 2, 260,000

Bonnets de laine (chéchias) . . . . I.742,000

Laine en suint. . . . . . . 88, 800

Blé .......... 622,500

Peaux et cuirs, secs ou salés. . . . . 280,300

Tissus de laine . . . . . . . 238,400

Thon mariné . . . . . . . . 224,800

Chevaux . . . . . . . . 93,030

Savons. . . . . . . . . 86,200

Bœufs ........... . . 72,300

Le règne de Si-Ahmed-Bey amena de nouveaux embarras financiers.

Les goûts fastueux du souverain le poussèrent à ordonner la construction de l'immense et éphémère palais de la Mohammedia ainsi que d'un grand nombre de casernes pour une armée permanente de 40,000 hommes. Il faisait, en même temps, creuser un port militaire à Porto-Farina, établir un arsenal à La Goulette, installer une manufacture de draps à Tebourba et une école polytechnique à 'Tunis.

Pour faire face a tous ces travaux, aussi dispendieux qu'inutiles, Ahmed-Bey augmenta les principaux impôts existants et en créa de nouveaux.

1. On exportait les blés en France et en Italie; les orges allaient en Angleterre, dans le Nord de la France et en Belgique; les huiles, les peaux et les laines en Italie et en France, les èponges et les légumes secs allaient surtout en France et l'alfa en Angleterre. 
Les droits de mahsoulat se perceraient alors en nature. Les céréales étaient taxées à une demi-ouiba par caffis, la laine il deux toisons par cent, les fruits et les légumes d’après leur espece et d'après l'importance du lor. L'huile était frappée, par charge de chameau, d'un droit en nature de neuf sais et d'une redevance, en espèces, de deux piastres ct quart.

Mais, dans la pratique, les droits acquirtés étaient toujours de beaucoup supérieurs ì ceux qui auraient dû être perçus; les abus sans nombre auxquels se livraient les fermiers concessionnaires aggravaient, dans une proportion inouie, les charges légales imposées aux contribuables.

Ahmed-Bey saisit l'occasion du mécontentement manifesté par les producteurs et par l'ensemble de la population, pour ordonner que les mahsoulats se percevraient désormais en argent, par les soins des agents du gouvernement. Toutefois, il décida que la taxe ainsi perçue s'élèverait it 25 p. 100 de la valeur des objets.

Les exactions des fermiers et des intermédiaires étaient telles que cet accroissement considérable de l'impôt fut accueilli avec joie. Mais les agents du gouvernement ne tardèrent pas ì pressurer le producteur tout autant que l'avaient fait les fermiers. Ceux-ci revinrent, du reste, bientót en faveur et purent continuer leurs manouves frauduleuses sans ètre aucunement inquiétés.

L'achour sur les céréales fut détourné de son affectation première et on convertit en impôt achour le kianoun alors de $o^{r}, 08$ par pied d'arbre - frappant les oliviers des régions de Tunis, Bizerte, Tebourba, Ouaten-el-Kabli et Zighouan. D'autre part, le gouvernement beylicil s'appropriait toutes les peaux de bœufs que produisait le pays.

C'est dans ces conditions que furent créés le Dar-el- 
Geld et divers établissements réservés à la fabrication des chaussures, du drap, du pain, de la galette et du bourghoul (blé concalssé mélangé avec de l'huile) à l'usage des troupes.

A cette époque, les produits exportés acquittaient les droits suivants :

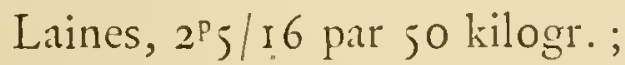

Cuirs en poils (avant leur accapurement par le gouvernement beylical), 2P5/I 6 les jo kilogr.

Pcaux de moutons, I/ 16 de piastre par unité ;

Tissus et bonnets tunisiens (autrefois exempts), 5 p. 100 de la valeur.

Le droit de sortie sur l'huile fut élevé à $7^{\mathrm{P}}$,jo par métal; le blé exporté fut taxé à 20P,75 par caffis (environ 500 kilogr.) ; les dattes furent imposées à 25 piastres par quintal tunisien ( $50 \mathrm{kilog} r$.).

La culture des céréales d'exportation se limitait au blé; la production en orge, fèves, pois chiches et milis ne dépassait pas les besoins de la consommation locale.

On en vint même ì subordonner l'exportation de l'huile et du blé à l'obtention d'un permis revêtu du sceau beylical. Sans avoir égard à la quantité mentionnée, la délivrance de ce permis donnait lieu à lia perception d'une redevance uniforme de 250 piastres, sur laquelle le recereur général prélevait jo piastres, à titre d'honoraires.

Fonctionnaires et nombre de commerçants trafiquèrent bientôt de l'Amra-Bey. De leur côté, les agents du gouvernement, tout aussi peu scrupuleux sur le choix des moyens, abusaient fréquemment de l'obligation imposée aux exportateurs de se munir du permis d'exporter, pour écouler, à de hauts prix, les blés et les huiles provenant de la perception des impôts et qui, par faveur spécille, étaient exempts de tous droits de sortie. L'application d'un pareil 
système ruinat le producteur et aussi le commerçant qui s'était approvisionné ailleurs que dans les silos beylicaux.

Devint lia misère qui s'étalait sous ses yeux, Ahmed-Bey réduisit les droits de malssoulat à 6 I/4 p. IOO (I 853 ). Toutefois, la taxe de $25 \mathrm{p}$. Ioo continula ì être perçue sur quelques articles et notamment sur les légumes frais. Le dégrèvement de ces derniers produits n'ayant été effectué que tout recemment, cette taxe excessive, de 25 p. Ioo, est done restée en vigueur pendant plus de quarante années.

Mohammed-Bey (i 855-I 859), fils d'Hussein-Bey et successeur d'Ahmed-Bey, eut pour premier soin de venir en aide aux agriculteurs et aux commerçants, en prescrivant direrses réformes dont le but était de les soustraire aux rexittions dont ils étaient l'objet, aussi bien de la part des fermiers que des agents beylicaux.

Les besoins sins cesse croissants du Trésor public joints il l'avidité des fermiers avaient laissé s'établir un certain nombre de taxes illégales, qui se superposaient à l'impôt principal. Mohammed-Bey n'hésita pas à supprimer ces abus, mais, contraint de se procurer de nouvelles ressources, il eut recours à la taxe de capitation (medjbia). Ce prince eut également le mérite de rétablir le kanoun dans les régions que son prédécesseur avait soumises au régime de la dime ${ }^{\text {. }}$

On doit it son successeur, Mohammed-Es-Sadok-Bey, un certain nombre de mesures utiles - telles que l'abolition de l'Amra-Bey, pour les exportations de l'huile et du blé, la suppression des droits de douane intérieurs, l'abaissement a $5^{p}$ I/S du droit de sortic sur les huiles, l'alimentation de Tunis en eau potable.

\footnotetext{
8. Devant l'attitude des contribuables, qui préféraient laisser vendre leurs oliviers plutót que d'acquifter le kanoun, Mohammed-Es-Sadok dut revenir au régime de l'acho. r.
} 
Malheureusement, Sadok maintint dans les fonctions de premier ministre le trop fameux Mustapha-Khasnadar.

Monté au pouvoir en 1838 , Mustapha-Khasnadar s'y maintint jusqu'en I 872 et, trompant la confiance de ses souverains, conduisit par ses agissements néfastes le pays à la ruine.

En i86I, la dette du gouvernement s'élevait d̀ i 2 ou I 5 millions de francs. Pour faire face ì ses engagements, l'État contracta un emprunt de pareille somme arec le caïd Nessim-Samana, receveur général du gouvernement. Cette première operation fut bientôt suivie de plusieurs autres, négociées sur place. Renouvelés à leurs échéances, ces emprunts répétés furent effectués de telle manière que, dès la fin de I 862 , le chiffre initial de la dette avait plus que doublé.

En 1863 fut traité un emprunt de 35 millions de franes, garanti par la medjba. On sait que, sur la somme emprun. tée, 6 millions de numéraire seulement arıivèrent jusqu'aux caisses publiques. Une fois sur la voie des expédients, le gouvernement beylical ne devait plus s'arrêter et, par la force même des choses, il dut recourir à des mesures plus désastreuses encore. C'est ainsi que, à diverses reprises, il fit procéder, à partir de I $\$ 64$, à la vente des récoltes futures, dont le prix lui était payé par anticipation.

L'établissement de la constitution libérale, les déprédations des caïds et surtout le doublement de la medjba provoquèrent une violente insurrection des tribus. Mis dans l'obligation de se procurer les ressources nécessaires à la solde des troupes chargées de combattre les rebelles, le Gouvermement contracta un emprunt de 5 millions, et, peu après, un autre emprunt de 25 millions, négocié à $\mathrm{Pa}$ ris dans les premiers mois de $\mathrm{I} 865$. A ce dernier emprunt 
araient été atfectés, ì titre de garantie, les revenus des dounes et du kinoun sur les oliviers.

Pour comble de malheur, la récoltc ayant complètement manqué pendant les années I 864 et 1865 , une famine terrible se déclara l'année suivante, trainant à sa suite le choléril et le typhus, qui réduisirent d'un tiers le chiffre de la population.

Sous l'influcnze de la sécheresse et de la disette de fourrage, une mortalité intense sévit sur les bestiaux. Bœufs, chevaux et chameaux disparurent presque totalement; plus résistants, les animaux des races ovine et caprine ne diminuèrent guère que de moitié.

Pendant cis trois années désastreuses, les impôts ne rentraient que peu ou point; les perceptions de l'achour et de la medjbar, notamment, durent être suspendues.

Le mouvement du commerce extérieur, à cette époque, reflete la triste situation économique du pays. Les échanges se limitaient, en effet, à des exportations considérables de peiux d'animaux et à des importations non moins importantes de grains, principalement fournis par la Russic et la Syrie. L'Algérie nous expédiait ses farines ordinaires.

Comme il est facile de l'imaginer, les denrées alimentaires subissaient un renchérissement progressif qui les rendait inabordables à la masse de la population. C'est ainsi que la ouiba de blé, de 32 kilogr., valait 60 piastres cuivre, équivalant ì 24 piastres argent. La ouiba d'orge de $24 \mathrm{ki}-$ logr. se payait 30 piastres cuivre, soit 12 piastres argent. Le métal d'huile, de $\mathrm{I}{ }^{\mathrm{kg}}, \mathrm{S}$, se payait la somme énorme de I 30 piastres cuivre, ou 52 piastres argent. La balle de filrine se payait, suivant qualité, de 22 à $29 \mathrm{fr}$.

Il est nécessaire d'expliquer l'apparition de la monnaic de cuivre dans les mercuriales de cette époque. Toujours 
aux abois, le Gouvernement avait lancé dans la circulation une quantité considérable de monnaie de billon. Émise au pair, cette monnaie, dans le cours d'une seule année, perdit jusqu'à près des deux tiers de savaleur, aux changes de 275 et de 300 p. IOO.

Déjà, sous les anciens beys, la piastre or, qui avait valu jusqu'ì $2 \mathrm{fr}$. - valeur intrinsèque - était tombée, à la suite d'aff.riblissements graduels de son poids, à I fr. (IS;O), à o fr. $90 \mathrm{c}$. ( I $\left.\$_{37}\right)$, à o fr. So $\left(\mathrm{I} \$_{45}\right)$, enfin à o fr. $60 \mathrm{c}$., lors des dernières émissions. Ces altérations des monnaies - et particulièrement des monnaies de cuivre et d'argent, dont l'émission coïncidait fatalèment avec le retrait d'une partie de l'or en circulation - entravaient nécessairement le commerce qui, toujours sur le qui-vive, se gardait des engagements à terme; ces altérations étaient encore plus préjudiciables au commerce de détail et à la petite production, en ce qu'elles modifiaient presque journellement le prix des denrées de première nécessité.

En outre, la fraude vint compliquer la situation en introduisant dans la circulation métallique - et principalement dans celle de la menue monnaie - une quantité considérable de pièces frappées au dehors et importées à son insu. La crise monétaire - conséquence forcée de la déplorable situation économique et financière de la Régence - s'aggrava encore du fait de la baisse fatale du change sur la France, qui, en se maintenant longtemps au-dessous du pair (entre o fr. $60 \mathrm{c}$. et o fr. 57. c.), favorisa la sortie de l'or tunisien.

Indépendamment des causes d'appauvrissement que nous venons d'énumérer, le Trésor public était battu en brèche par une contrebande effrénée. Dans les régions d'accès facile, les marchandises atterrissitient ou gagnaient le large, 
en fraude des droits et en dépit de la prohibition, au plus grand profit de commerçants peu scrupuleux.

Dis le commencement de l'année i 867 , le Gouvernement se trouva dans l'impossibilité absolue de remplir ses engagements il l'égard des porteurs de titres. C'est alors qu'intervinrent, entre l'État et ses créanciers, les arrangements connus sous le nom de "Conversions de mars, août, septembre et décembre $\mathrm{I} 87 \mathrm{7}$ ).

Il fut converti pour près de 40 millions d'anciennes créances. Les obligations émises en échange des anciens titres stipulaient intérêt à i 2 p. Ioo l'an. Elles étaient garanties par la cession des droits d'exportation sur l'huile, la laine, les dattes, le savon, etc., ainsi que par la cession du droit de timbre et par la remise des délégations sur lit régic des tabacs, sur les droits d'octroi et sur les caids. Après extinction, les garanties attribuées anx conversions de mars et d'août étaient reversibles sur les deux suivantes (septembre et décembre).

Comme si ces gagcs n'étaient pas suffisants, les bénéficiaires de ces conversions firent promulguer plusieurs décrets surélevant les droits de sortie qui grevaient un certain nombre d'articles et particulièrement les laines. C'est également à leur instigation que le droit de timbre fut, sinon créé, du moins singulièrement accru, et son application étendue à la plupart des actes.

La dette publique s'élevait alors à plus de 170 millions de francs. Elle fut ensuite réduite, par le rejet de diverses créances contestées, à la somme de 160 millions, non compris les intérêts impayés. 
Dans ce chiffre, les emprunts I863-I86; entraient pour .

66 millions

les 4 conversions pour.

la dette flottante pour.

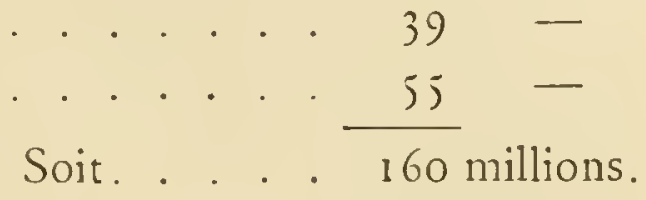

Telle était la situation vers la fin de l'année r 869.

C'est au début de l'année i 870 qu'apparait la commission financière, créée à la suite d'une convention entre le gouvernement tunisien, d'une part, et la France, l'Angleterre, l'Italie, d'autre part.

Pour faire face à sa dette de 160 millions, le gouvernement beylical ne disposait que de 13 millions de revenus annuels, en y comprenant ceux - les plus importants qu'il avait hypothéqués à ses créanciers. La moitié de ces I 3 millions était indispensable au fonctionnement des services publics, en admettant que les dépenses d'administration ou autres fussent ramenées au strict nécessaire. C'est done ce reliquat qui fut affecté au service de la dette, sur les bases arrêtées par M. Villet, vice-président de la commission financière.

Les titres de diverses natures furent échangés contre des obligations nouvelles, d'un type unique, émises au capital nominal de $500 \mathrm{fr}$. et portant intérêt à ; p. Ioo l'an. Il fut décidé que chaque obligation des emprunts contractés en IS63-I 865 donnerait droit à une obligation nouvelle; par contre, il était attribué six obligations nouvelles à tout porteur de cinq obligations ayant fait l'objet de la première conversion. Les porteurs des titres se rapportant aux conversions de 1867 et aux emprunts de I 863 et de I $86 ; \mathrm{fu}-$ rent seuls appelés au paiement des intérêts arriérés.

Il était difficile de ne pas accorder certaines faveurs aux 
bénéficiaires des quatre conversions, pour les amener à renoncer aux garanties particulières qui leur avaient été antérieurement concédées. Du fait de la fusion, en un type unique, de toutes les catégorics de créances, les revenus de l'État devenaient la propriété commune de ses créanciers, sans distinction.

La dette étant ainsi fixée et liquidée, les revenus suivants furent spécialement affectés au service des intérêts:
Mabsoulat.
$782.000 \mathrm{fr}$.
Rahbas de Tunis
97,000
Douane (Importation)
578,000
Douane (Exportation)
$2,640,030$
Droit de la caroube, à Tunis
100.000
Fermage des tabacs.
220,000
Droits sur les vins, à Tunis
55,000
Marché au bois et au charbon de Tunis. . 4 45.00J
Fermage du plàtre . . . . . . . 60,000
- des poulpes et des éponges. . . 55,000
- du sel ......... I . In,000
Kanoun du Sahel et de Sfax. 850,000f
des oliviers de Ouaten-el-Kabli. I50 00s
Droit sur la pê-he du Corail.
Octroi .
8,000
350,003
Droit du timbre. . . . . . . . . 300000
Fermage du poisson.. . . . . . . 100.000
Soit ... $\overline{6,500,000} \mathrm{fr}$.

Dans ce tableau, les droits de douane à l'entrée, éralués à 578,000 fr., représentent l'ancien droit de 3 p. roo. Ce n'est qu'en mai I $S_{72}$ que celui-ci fut élevé à $S$ p. roo, le supplément de 5 p. 100 ayant été spécialement affecté au remboursement, sans intérêt, des coupons demeurés impayés sur les titres de l'ancienne dette.

Ce réglement financier - que les souscripteurs des emprunts de IS63 et de IS65, les porteurs des titres de la dette flotante, la population tunisienne elle-mème récla- 
maient unanimement - demeurera l'œuvre d'un homme éminent, M. Yillet, inspecteur général des finances, dont l'intelligente initiative a su concilier les intérêts en présence et donner satisfaction équitable à toutes les parties en cause.

Il devenait désormais possible d'établir un budget reposant sur des bases fixées et comportant des charges modérées. Au lieu d'être grevé, pour le service de la dette publique, d'une dépense annuelle atteignant près de 20 millions de francs, le 'Trésor n'avait plus qu'à faire face au paiement de 6,250,000 fr. La dette elle-même, qui se trouvait excéder le chiffre de 560 millions, était réduite ì I 2 j millions.

Le point essentiel, capital, est que cette convention résolvait, une fois pour toutes, une question particulièrement grave, en suspens depuis nombre d'années et qui portait le plus grand préjudice aux intérêts généraux du pays. Le discrédit dans lequel la Régence était tenue, du fait des embarras financiers de son gouvernement, rejaillissait, en effet, sur la population tout entière qui se voyait en butte, dans ses entreprises commerciales ou autres, à une suspicion peu justifiée. D'un autre côté, producteurs et commerçants étaient livrés à des agioteurs qui se prévalaient des charges contractées par le gourernement beylical pour consommer la ruine de la Tunisie.

Lia commission financière, cependant, a peu contribué au développement écononique du pays, ainsi qu'à l'amélioration du régime des impôts. On ne peut, en effet, considérer comme des dégrèvements sérieux la réduction des droits de sortie opérée sur des articles de peu d'importance, tels que les bonnets rouges et les tissus de laine indigènes (taxés à ; p. 100 ad valorem au lieu de Io p. 100), tels que les dattes, dont l'exportation était des plus restreintes et qui 
furent imposées à 10 piastres (au lieu de 25 piastres) par quintal tunisien.

Il est vrai également que le droit de sortie sur les huiles fut, une première fois, ramené de $7^{\mathrm{p}} S / \mathrm{I} 6$ a $5^{\mathrm{p}}$ I/S et ensuite ่̀ 4 .

En regard de ces légères améliorations, qui n'en constituaient pas moins un progrès, la commission financière aggralva le régime des droits sur les céréales, en créant les droits de porte de $S$ piastres par caffis de blé ou de légumes secs, et de 3 piastres par caffis d'orge. Dès r 885 , le gouvernement du protectorat allégea l'exportation de ces taxes. Cette dernière disposition (dont le bénéfice fut étendu, sept années plus tard̀, à la consommation locale) avait été précédée d'une mesure excellente, qui eut immédiatement les plus heureuses conséquences pour le pays: la suppression des droits de sortie de $20^{P}$ I $2 /$ I 6 sur le blé et de I ${ }^{p} 5 / 16$ sur l'orge.

La commission financière sut mettre de l'ordre dans les finances publiques et sut faire produire à l'impôt tout ce qu'une gestion ì peu près régulière pouvait en tirer; mais elle pesa néanmoins lourdement sur le développement économique et fiscal de la Régence. Au gouvernement du protectorat était réservé d'établir un régime financier mieux approprié aux besoins du pays et de développer l'outillage économique de la Tunisie.

\section{APRÉS LE PROTECTORAT}

L'année ISS I marque, ì cet égard, le point de départ d'une nouvelle ère dans l'histoire de la Régence. 


\section{1. - DE I 88 I A I 890}

Une fois le pays pacifié, l'œuvre du protectorat commença par la réorganisation administrative et judiciaire du pays. Les nombreuses juridictions que désignait seule, au choix des plaideurs, la nationalité, parfois douteuse, du défendeur disparurent, ne laissant subsister que la justice indigène pour les sujets tunisiens et la justice française pour tous les autres habitants de la Régence. L'un des premiers soins des tribunaux français fut de mettre un terme aux pratiques commerciales répréhensibles que nous avons signalées. Après quelques années d'efforis, ils y sont parvenus, et ce n'est qu'à titre de souvenir historique d'une époque disparue que nous les avons mentionnées. La réorganisation financière, entreprise en même temps, fit disparaître successivement les fermiers d'impôts.

Un corps expéditionnaire nombreux stationné sur le sol tunisien avait donné une vigoureuse impulsion aux affaires; le commerce d'importation surtout, alimenté par les fournitures militaires, avait subi un accroissement notable. De nouveaux négociants, arrivés à la suite de l'armée française, avaient établi en Tunisie leur champ d'opérations. Mais on craignait que cette prospérité momentanée ne disparût avec les causes qui l'avaient fait naitre. Aussi, la situation économique du pays était-elle la préoccupation constante du monde commercial.

Il se trouvait précisément que le commerce tunisien était privé de toute représentation officielle. Jusqu'alors le "corps des notables de la colonie ", composé de négociants, chefs de maisons, et représenté par les deux «députés de la ma- 
tion ", éclairait de ses lumières le représentant de la France et fournissait les assesseurs au tribunal consulaire.

Depuis la création du tribunal français, la principale prérogative de ce corps ne pouvait plus subsister. Il se trourait, d'ailleurs, réduit à huit membres seulement. Cette antique institution, qui datait de plus de deux siecles, mais qui ne répondait plus aux exigences de la situation nouvelle créée par le protectorat, disparut en I $883^{2}$.

La préoccupation qui hantait les esprits de donner un corps aux aspirations commerciales du pays amena en I $S 84$ la création du «syndicat international des intérêts commerciaux, agricoles, industriels et financiers de lia Tunisie ${ }^{2} »$. Cette association se donnait pour mission de "s'occupar de tout ce qui peut être utile à la défense et au déreloppement du commerce et de l'industrie et d'étudier les moyens d'accroitre la prospérité du commerce, de l'industrie et de l'agriculture, ainsi que les améliorations à demander pour toutes les branches de l'organisation commerciale, y compris les droits de douane et de l'octroi ». A peine constituée, elle se mit ì l'œuvre et produisit plusicurs rapports sérieusement étudiés qui furent transmis, par la Résidence générale, au gouvernement français. Il ne sera pas sans intérêt de rappeler les principales questions sur lesquelles elle porta son attention: création d'un mont-de-piété, établissement du système métrique, union monétaire avec la France, création d'un laboratoire pour l'analyse des denrées

3. M. Alfred Chapelie fur le dernier des deputes de la nation.

2. Scs promoteurs étaient MM. Proust er Pisani. A lorigine, la sosiété fur constiruce

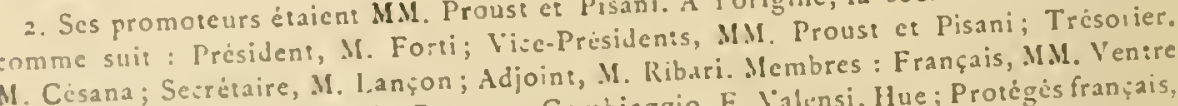
frères, Dumergue Padoa, Niille, Brou'set. Camªggio, E. Valensi, Hue; Protégés franł̧ais, M.M. Sidbon, lfai Constantini et Boulakia jeune; Italiens, MM. Moreno et Fedriall Aurelio; Kspagnol, M. Je drontes; Bclge, M. J'Aigremont, All Portugais, M. Silvera.

M. Blane; Grec, M. Siganaki; Autrichien, M. Achille Bogo; 
alimentaires, entrée en franchise des produits tunisiens en France, suppression des droits d'entrée en Tunisie pour les plants de vigne, d'arbres et d'arbustes et pour les semences, droits de sortie sur les builes, création d'un port à 'Tunis, régime fiscal des cuirs et des peaux. Presque tous les vœux émis par le syndicat sont aujourd'hui réalisés; leur énumération seule suffit à prouver qu'il y eut de la part des commerçants laissés à leur seule initiative un effort énergique et intelligent dont le souvenir méritait de n'être pas perdu. Ce concours de bonnes volontés échoua devant les compétitions créées par les diverses nationalités représentées dans le syndicalt. Aussi disparut-il après une courte carrière devant une institution officielle: la chambre de commerce française de Tunis.

En effet, par arrêté du 23 juin I 885 , le Ministre-Résident, "considérant qu'il importait de donner aux intérêts commerciaux, industriels et agricoles en Tunisie une représentation analogue à celle constituée en Francen, créait une chambre de commerce composée de douze membres et dont le siège était placé à Tunis ${ }^{\text {. }}$.

Le gouvernement du protectorat n'avait pas attendu l'organisation d'une représentation officielle du commerce pour se préoccuper de la situation et rechercher le moyen de le dégager de toutes les entraves qui gênaient son déreloppement; sa première pensée fut de supprimer les droits à l'exportation, qui n'existent dans aucun pays d'Europe et dont

1. La première chambre de commerce était a nsi composée : Président, M. Auguste Ventre; Vice-Président, M. Cèsaire Dumergue; Secrétaire, M. Ville; Trẻsorier, M. Albert Hue; Membres, MII. Cambiaggio, Chapelie, Chabert, Dubos, Padoa, Proust, Théphile Reynaud et Raymond Valensi. En $\mathbf{8 9 2}$, les intẻrêts agricoles du pays eurent une représentation distincte, la chambre d'agriculture, et une thambre de commerce du Sud fut criée à Sousse. Par suite de ces modifications, un arrêté résidentiel du 17 mars 1892 reconstituait lit cliambre de commerce de Tunis sous le nom de chambre de commerce du Nord. 
la situation obérée du Trésor beylical arait seule pu expliquer la création. Depuis que lis dette avait été convertie sous la garantie de la France, l'état des finances tunisiennes avait subi une amélioration sensible, mais la prudence commandant de ne pas se priver à la fois d'un trop grand nombre des sources de recettes qui alimentaient le budget, on fut obligé de ne procéder que progressivement à cette œuvre de dégrivement. Une série de décrets a supprimé ou réduit presque tous ces droits. Ils ne subsistent plus, à l'heure actuelle, considérablement atténués, que sur douze articles ${ }^{1}$.

La question des droits d'entrée exigés en France pour les produits tunisiens qui acquittaient les taxes du tarif général se posait aussi. Dès le $S$ décembre $S_{4}, M$. Cambon appelait sur ce grave sujet l'attention du gouvernement français.

Le droit de 5 fr. par quintal perçu sur les blés représentait environ le quart de la valeur du produit; il en était de même de celui de 4 fr. $50 \mathrm{c}$. par hectolitre de vin. On cillculait que les $3 S \mathrm{fr}$. payés par tête de bœuf enlevaient la valeur de 2 bêtes sur 5 dans un troupeau. A cette époque, les produits des puissances qui araient encore arec la France des traités de commerce étaient plus fivorisés par la dounane que les récoltes des colons français en Tunisie ${ }^{2}$.

A moins de se résigner à faire en pure perte les frais de l'occupation militaire de la Régence et de renoncer à tout espoir de coloniser le pays, la France devait trouver un moyen qui lui permit d'ouvrir ses ports alux produits de la colonie.

1. Chiffons, éponges, grignons, à l'execption de ceux qui sont traites par le sulfure de carbone, alfa es diss, lusiles d'olive et de grignon, laine en suint et dechets de laine, olives fraiches, peaux brutes, poissons frais autres que thon et boutargues, poulfes, tissus de laine.

2. La Tunisie devant les Chambres, Appel des colons français aux membres du Parlcment, Paris, 1890, p. 11. 
On ne reprendra pas ici l'exposé des phases diverses que subit la question et des différentes solutions qui furent successivement envisagées. Il suffira de rappeler que le 3 juillet 1890 , ce grand débat qui, depuis si longtemps, passionnait les esprits en Tunisie et en Algérie, s'ouvrit devant la Chambre des députés. Il débuta par une interpellation de M. Delafosse sur les affaires tunisiennes; M. Ribot, ministre des affaires étrangères, en expliquant et justifiant la politique de protectorat suivie en Tunisie, remporta un grand succès oratoire. Cette discussion, qui éclairait la Chambre sur l'état des choses en Tunisie, avait admirablement préparé le terrain pour la question douanière, qui fut traitée le lendemain. M. Thomson crut deroir répondre aux allégations qui présentaient l'Algérie comme une adversaire de la Tunisie, et il développa la théorie de la réciprocité. M.Jonnart, rapporteur de la commission, n’eut pas de peine à démontrer à la Chambre que le projet présenté par le Gouvernement était le seul réalisable dans la situation particulière de la Tunisie et que toutes les mesures possibles avaient été prises contre les tentatives de fraude. M. Des Rotours prit ensuite lia parole au nom des protectionnistes. M. Lockroy s'éleva contre la pensée de considérer la Tunisie comme une terre étrangère. Enfin, M. Camille Dreyfus ayant déclaré que le projet était en contradiction avec les engagements internationaux pris par M. Barthélemy Saint-Hilaire, le ministre des affaires étrangères monta à la tribune pour protester contre un semblable procédé de discussion. Il affirma le droit incontestable de la France de donner à un pays couvert de s.l protection le traitement douanier qui lui convenait, sans avoir à craindre en cette allaire aucune ingérence étrangère.

"Vous êtes la grande nation française, s'écria-t-il; vous 
pourez, sans préjudice appréciable pour nos intérêts, donner i la Tunisie un encouragement et une force. Qu'il lui soit permis d'attendre avec patience la solution des difficultés auxquelles je fais allusion. Vous lui donnez le temps, le temps traraille pour nous. Soyons unanimes pour accorder à la 'Tunisie ce qu'elle réclame... Votons le projet de loi; votons-le, et demain le retentissement sera grand daus toute notre colonie tunisienne. Et s'il y avait quelque part en Europe un pays intéressé à voir notre influence décliner en Tunisie, ce pays-lì considérera le vote de la loi actuelle comme un pas érident fait vers cet état définitif que vous souhaitez; tandis que l'ajournement, même motivé, croyezle bien, par toutes les théories, fussent-elles les plus éloquentes, fussent-elles les plus précises, fussent-elles les plus irréprochab!es, serait considéré et commenté comme une retraite et comme une défaillance de la France. ") Après cet éloquent discours, la cause de la Tunisie était gangnée. Le projet fut roté par 495 voix contre 23. Quelques jours après au Sénat, l'opposition fut réduite à une voix.

M. Ribot ne s'était pas trompé en amnonçant que le vote de la Chambre aurait en Tunisie un immense retentissement. Aussitôt que la nouvelle en parvint à 'Tunis, la ville fut spontanément pavoisée en signe de fête et le soir des illuminations s'improvisèrent partout. Quelques jours après, le is juillet, le jour même où le Journal officiel promulguait la loi tant désirée, Soo personnes se réunirent pour offrir au Résident général, M. Massicault, un punch de remerciements. Cet hommage unanime de la colonie était un juste tribut de reconnaissance payé à l'homme qui, dans cette victorieuse campagne, avait usé ses dernières forces au service d'un pays, où quelques mois plus tard il rendait le dernier soupir. 


\section{II. - LA loi du i 9 Juillet i 890}

Telle qu'elle est sortie des délibérations de la commission des dounanes et des deux Chambres, la loi du I 9 juillet I 890 accorde à la Tunisie le bénéfice de l'entrée en franchise pour les céréales en grains, les huiles d'olive et de grignon et les grignons d'olives, les animaux des espèces chevaline, asine, mulassière, bovine, ovine, caprine et porcine, les volailles mortes ou vivantes, et le gibier mort ou vivant. Les vins de raisins frais sont assujettis à un droit de o fr. $60 \mathrm{c}$. par hectolitre, tant que le titre ne dépasse pas $\mathrm{I}^{\circ}, 9$; au-dessus, ils paient une taxe supplémentaire de o fr. $70 \mathrm{c}$. par degré. Tous les autres objets sont soumis au tarif mininum. Ces dispositions ne s'appliquent pas aux produits dont l'entrée est frappée de prohibition, ni aux denrées coloniales telles que le sucre, le café, etc., que la Tunisie ne produit pas.

Ces " traitements de faveur », ainsi s'exprime la loi, sont subordonnés à un certain nombre de conditions destinées à empêcher la fraude :

$I^{\circ}$ Les expéditeurs doivent justifier de l'origine tunisienne des produits, au moyen d'un certificat de provenance délivré par un contrôleur civil et visé par un receveur des douanes de nationalité française. Avant d'accorder son visa, ce fonctionnaire doit procéder " à la reconnaissance effective de la nature et de l'origine tunisienne de la marchandise ${ }^{1} \gg$.

1. Instructions de la Direction des finances approuvées par la Résidence générale le 2 ; a oût 1890 . 
Pour faciliter l'exécution de cette mesure, dix ports seulement étaient ouverts ì l'exportation des marchandises bénéficiant de la loi: Tunis, La Goulette, Bizerte, Sousse, Souissa, Monastir, Mehdia, Sfax, Gabès et Djerba, cette liste pouvint être modifiée par décrets du Président de la République. Un décret du 2 I septembre 1 S92 y a ajouté le port de Tabarka.

$2^{\circ}$ Les marchandises ne peuvent être embarquées que sur des navires français et doivent se rendre directement en Fr.nnce, sans escale. Exception a cependant été faite à cette demière rìgle pour l'escale de Bône, en territoire algérien.

$3^{\circ}$ Le Président de la République fixe chaque année par un décret rendu sur la proposition des ministres des affaires étrangères, des finances, du commerce et de l'agriculture, et d'après les statistiques officielles fournies par le Résident général, les quantités de chacun des articles auxquels s'applique la loi. La Direction des dounes établit le compte des produits exportés et le rapproche des crédits ouverts; chaque quinzaine, une situation est publiée par le Journal officiel tunisien. Le jour où il apparait que le maximum fixé va être atteint, les contrôleurs civils avisés doirent refuser la délivrance de nouveaux certificats.

Dispositions spéciales pour les céréales. - Arant de délivrer les certificats d'origine pour les céréales, les contrôleurs doivent " se faire présenter par l'exportateur, soit une attestation du vendeur, si li vente a été faite au domicile de ce dernier, soit la quittance des droits de marché, si l'achat a été fait sur l'un des marchés de la Régence... En cas de doute, le contrôleur a la faculté de procíder à une enquête sur la valeur des déclarations qui 
accompagnent le produit, ou à une expertise sur le produit lui-même ${ }^{\mathrm{s}}$."

Dispositions spéciales pour les vins. - Les producteurs seuls, à l'exclusion des négociants, sont admis au bénéfice du tarif réduit établi par la loi. A cet effet, ceux qui désirent en bénéficier sont astreints par l'arrêté résidentiel du $I^{\text {er }}$ octobre I 890 à faire chaque année avant le zo septembre, au contrôleur civil de leur circonscription, la déclaration des quantités de vin qu'ils ont récoltées. L'exactitude de cette déclaration est vérifiée par une commission spéciale que préside un agent de l'administration désigné par le Résident général et qui comprend un délégué du syndicat des viticulteurs et un expert technique choisi par lui. Les quantités de vin dont l'existence est constatée par cette commission sont inscrites au bureau du contrôle sur un compte courant, ouvert à chaque viticulteur; au débit du compte sont portées les quantités déclarées pour l'exportation et qui ont fait l'objet de certificats d'origine.

Les vins vinés ne sont pas admis au bénéfice de la loi du I 9 juillet I $\$ 90$.

Cependant sont admis au régime de cette loi: $I^{\circ}$ les vins mutés à l'alcool d'origine tunisienne, sous la double condition que le mutage soit effectué au moyen d'alcool tunisien ou français et que la Régie les prenne en charge pour la fabrication des vermouts et vins de liqueur; $2^{\circ}$ les vins de liqueur tunisiens provenant de raisins frais.

Les viticulteurs tunisiens, en vertu d'une décision du Ministre des Finances datée du I4 août I 89 I, sont dis- 
pensés en France du paiement des droits de licence pour la rente en gros des vins de leur récolte. Cette exemption est subordonnée à la production d'un certificat nominatif délivré annuellement par les contrôleurs civils et indiquant l'étendue du vignoble et l'importance approximative des quantités récoltées.

Dispositions contre les fraudes. - Un décret beylical du 26 novembre 1894 punit les fabricants ou les falsificateurs de certificats d'origine, ou ceux qui auraient fait usage de certificats fabriqués ou falsifiés, d'un cmprisonnement de 6 mois à 3 ans; un emprisonnement de 3 mois à I an est prononcé contre ceux qui auraient fait une fausse déclaration ì l'autorité compétente, en vue d'obtenir un certificat d'origine, ou qui auraient fait usage, pour l'expédition en France des marchandises d'origine étrangère, d'un certificat délivré en vue de marchandises d'origine tunisienne.

CONSÉqueNCES DE L'OUVERTURE DES PORTS FRANÇAIS AU COMMERCE DE LA RÉGENCE

Une expérience de près de dix années permet aujourd'hui de formuler un jugement sur cette législation, qui porte dans l'histoire du commerce tunisien le nom de loi du I 3 juillet I 890 .

Le principe de l'admission en franchise de ses principaux produits étant posé, le commerce tunisien a accepté sans difficultés l'obligation des certificats d'origine. Les viticulteurs se sont soumis sans répugnance à la déclaration de leur récolte et méme à la surveillance administrative exercée 
sur leurs caves. Mais viticulteurs et négociants sont d'accord pour se plaindre des entraves que leur cause la linitation des quantités des produits admis à bénéficier de la loi. Ils sont unanimes à déclarer que leurs transactions sont gênées par le manque de certitude de pouvoir exporter la totalité de leurs récoltes ou de leurs produits en magasins. Il leur est impossible, par exemple, de passer des marchés à livrer, puisqu'ils ne sont jamais sùrs qu'à l'époque fixée pour la livraison de la marchandise le crédit ne se trouvera pas épuisé et l'exportation suspendue pour un temps plus ou moins long.

En outre, on s'est aperçu à la longue que n'accorder une modération de tarif qu'à un nombre restreint de produits tunisiens, c'était limiter à ces quelques produits l'horizon agricole des colons, et leur interdire toute tentative de cultures nouvelles.

Malgré ces défectuosités, personne ne peut nier que la loi du i 9 juillet I 890 n'ait constitué un progrès énorme sur la situation antérieure. Ses résultats commerciaux et politiques ont été immenses. Ainsi qu'on le verra au chapitre suivant, l'importance totale des transactions s'est trouvée accrue dans une proportion notable et la France a conquis une première place sur le marché tunisien; l'Italie, qui la lui disputait pendant les premières années postérieures à l'établissement du protectorat, est tombée à un rang tout à fait infime. C'est surtout pour les produits pour lesquels la France s'est montrée libérale, en supprimant toutes les barrières douanières, que le résultat obtenu a été frappant. Pour les céréales, les huiles et le vin, elle s'est assuré le monopole presque complet des exportations tunisiennes. Par ce moyen, notre pays a obtenu ce grand résultat politique, de lier à elle sa nouvelle colonie par la 
puissance de liens économiques extrêmement solides, puisqu'ils reposent sur le fondement difficilement ébranlable des intérits matériels. Par contre, la situation ne s'est guère modifiée en ce qui concerne les produits pour lesquels la France s'est bornée à accorder à la Tunisie le bénéfice de son tarif minimum, ce qui démontre que le sacrifice consenti par le Parlement n'a pas été suffisant pour produire les résultats attendus. Les faits se sont donc chargés d'établir que le principe de l'admission en franchise des produits tunisiens, qui a ćté posé par la loi du Ig juillet i 890 , doit devenir la règle de toutes les relations commerciales entre la France et la Tunisie.

Quelques personnes s'efforceront peut-être d'affaiblir la portée du triomphe de notre politique économique en Tunisie, en faisant remarquer que la situation nouvelle a surtout augmenté le chiffre des achats faits par la France dans la Régence, ce qui a procuré un bénéfice immédiat à la colonie beaucoup. plus qu'à la métropole. Rien ne serait aussi inexact que ce raisonnement. Dans une opération commerciale, ce n'est pas toujours le vendeur qui réalise le bénéfice le plus élevé. D’ailleurs, les produits que la France demande à la Tunisie, les céréales, l'huile, le vin, le bétail, etc., sont de ceux que son sol ne produit pas en quantité suffisante pour ses besoins, et que, malgré l'élévation de ses tarifs dounniers, elle est obligée d'importer chaque année par millions de francs de l'étranger. Il n'est donc pas juste de dire, ainsi que certains adversaires de la Tunisie ont essayé de le faire, que les produits de la Régence font concurrence en France a la production nationalc. La vérité est que c'est uniquement aux importations étrangères que nos produits agricoles font concurrence sur le marché français. 
Une dernière constatation achèvera de démontrer victorieusement les bienfaits de la loi du I 9 juillet I 890 . Ce ne sont pas seulement les importations de Tunisic en France que cette loi a eu pour résultat d'accroître, ce sont aussi les exportations de France en Tunisie. Pendant les années qui ont suivi l'occupation et précédé la promulgation de la loi, la valeur des marchandises expédiées de France en Tunisie n'a jamais dépassé 17 millions de francs; depuis lors, elle a atteint près de 28 millions. La part totale de la France dans le commerce de la Régence (importations et exportations réunies), qui ne dépassait pas 22 millions avant la loi de I 890 , a atteint près de 55 millions en 1898 .

Ainsi se vérifie ce phénomène bien connu que, lorsque deux nations ont entre elles des rapports commerciaux, il leur est plus avantageux de payer leurs achats par des commandes que de les solder en argent. La Tunisie vendant ses produits agricoles à la France a plus d'avantage à lui acheter les produits manufacturés dont elle a besoin qu'i s'adresser à l'étranger pour les avoir.

\section{LA RÉFORME DE I 898}

Le gouvernement français pour obtenir du Parlement le vote de la loi de 1890 avait dû. déclarer formellement que le nouveau régime douanier franco-tunisien n'était qu'un expédient temporaire imposé par les circonstances. En effet, les adversaires du projet, oubliant que la Tunisie est une dépendance politique de la France et ne peut pas traiter avec elle d'égale à égale, lui opposaient la théorie de la réciprocité en matière de traités de commerce; ils se déclaraient disposés à accorder aux produits tunisiens des condi- 
tions spéciales, mits seulement à la condition que la Régence accorderait des concessions équivalentes aux produits français.

Ils perdaient de vue que cette prétention n'était pas acceptable dans la situation spéciale de la Tunisie, liée arec les principaux États européens par des traités contemant la clause de la nation la plus favorisée, traités que la France arait solennellement déclaré maintenir et confirmer en établissant son Protectorat sur le pays. Il fallait donc, si l'on voulait favoriser le développement des relations commerciales entre la Régence et la France, accorder des faveurs donanières sans obtenir en apparence aucune compensation. C'est ce que fit la loi du is juillet i $\$ 90$, qui fut un acte de souveraineté et de générosité de la France envers la Tunisie. Mais le ministre des affaires étrangères prit l'engagement de mettre fin dès qu'il serait possible à un état de choses qui semblait anormal. L'expiration en I 896 du traité de commerce avec l'Italie permit de négocier une nouvelle convention qui assurait à la France en Tunisic une situation privilégiée au point de vue douanier, et le même avantage fut obtenu successivement de l'Angleterre et des autres États intéressés.

Cette victoire diplomatique qui achevait de consacrer l'autorité complète de la France dans la Régence allait permettre de tenir l'engagement pris en I 890 envers le Parlement. C'est ce qui a été fait par les décrets tunisiens du 2 mai 1898 qui ont promulgué un tarif des douanes de la Régence.

Jusqu'alors presque tous les produits importés étaient frappés d'un droit uniforme de 8 p. ioo ad valorem. I. e nouveau tarif, tout en conservant pour un petit nombre d'articles ce droit de $\delta$ p. Ioo, reproduit la plupart des 
taxes du tarif minimum français et il admet en franchise, lorsqu'ils sont d'origine française, les articles suivants: animaux vivants, laines, soies, huiles, vins (pour lesquels il ne subsiste qu'un droit intérieur de io p. Ioo de la valeur), eaux-de-vie, alcool et liqueurs, fer, cuivre, plomb, étain, zinc, fils, tissus, broderies et vêtements, machines et mécaniques, et ouvrages divers en métaux, c'est-ì-dire les principaux produits que la Tunisie reçoit de France. Certains auraient désiré qu'on fit davantage, que toutes les marchandises françaises sans exception fussent admises en franchise et que tous les droits, souvent prohibitifs, du tarif minimum de la métropole fussent appliqués aux marchandises étrangères. Agir ainsi eût été créer dans le budget tunisien un déficit considérable, il eût fallu le combler par la création d'un grand nombre de taxes intérieures, qui eussent arrêté brusquenıent le mouvement de colonisation si précieux à entretenir. C'eût été aussi mettre fin brutilement et sans aucun profit pour la France au courant des transactions établi depuis des siècles entre la Régence et certains marchés étrangers, et précipiter le pays sans utilité dans une crise où il aurait pu sombrer. La prudence la plus élémentaire commandait d'éviter ces dangers. C'est ce que les décrets du 2 mai 1898 ont réussi à faire; ils ont su "ménager autant qu'il se pouvait les intérêts locaux, dit l'exposé des motifs, et ouvrir enfin plus largenent au pays protecteur un marché dont le développement lui importe au premier chef $)$.

Mais de l'engagement pris en I $\$ 90$ par le gouvernement français de considérer le régime institué alors comme un état de choses temporaire et lié à l'existence des traités en vigueur à cette époque, il résulte une autre conséquence que les colons tunisiens considèrent comme natu. 
relle et inévitable, c'est la suppression des entraves au libre commerce entre la métropole et la Régence qu'on a dû établir en I $\$ 90$ par suite de la situation particulière dans laquelle se trouvait la Tunisie. Ces entraves doivent disparaitre avec la situation qui les avait rendues nécessaires. C'est au Parlement français qu'il appartient de compléter la réforme commencée en I $\$ 90$ et continuée en i $\$ 9 S$. Il comprendra la nécessité d'accorder les plus grandes facilités pour l'écoulement en France des produits tunisiens. C'est à cette condition seule que la colonisation agricole et industrielle, enfermée par le tarif de douane dans l'exploitation de trois ou quatre produits pourra prendre un nouvel essor en étendant le champ de ses opérations.

La métropole de son côté trouvera un avantage direct à l'accroissement de la prospérité de sa colonie. Ainsi qu'il a été constaté plus haut, les produits devant s'échanger contre des produits, plus la France ouvrira largement ses portes aux marchandises tunisiennes, plus elle aura chance d'écouler en Tunisie ses propres marchandises. C'est lì la véritable réciprocité, celle qui n’est pas basée sur des dröits théoriques et discutables, mais qui résulte de l'intérêt même des deux pays. 


\title{
CHAPITRE XIX
}

\author{
MOUVEMENT DU COMMERCE DE LA TUNISIE \\ DEPUIS L'OCCUPATION
}

PART DES DIVERSES NATIONS

Lorsqu'on désire étudier les fluctuations subies par le commerce d'un pays, le seul moyen employé consiste à se reporter aux documents officiels publiés par le service des douanes. En Tunisie, cette source de renseignements n'existe que depuis une date assez récente. Jusǫu'en I 87I, les revenus des diverses tixes douanières, comme les autres impôts, étaient affermés par le gouvernement beylical; il traitait à forfait avec un certain nombre de fermiers, abandonnant à chacun d'eux les taxes frappant une catégorie spéciale de produits. C'est ainsi que la ferme de la douane des vins, qui a été abolie la dernière, a duré jusqu'en I 885 . L'administration, à qui n'incombait que le soin de percevoir le -montant du fermage, ne se préoccupait pas des sommes encaissées par les fermiers; ceux-ci, de leur côté, étaient libres de tenir leurs écritures à leur guise. Aussi n'existet-il pour cette période aucune statistique du commerce tunisien.

En I87r, la situation changea. L'administration des revenus concédés, chargée, par suite des arrangements inter- 
mationaux, de percevoir les revenus des dounes pour le compte des créanciers de la Régence, renonçal pour cette catégorie de taxes au systéme de la ferme, et organisa, quoique d'une façon encore rudimentaire, un service de douanes. A partir du I er juillet I $S_{7} \mathrm{I}$, des statistiques furent dressées. Malheureusement, les quatre premières années de ces précieux documents ont été entièrement perdues; on n'en possède les résumés succincts que depuis le $1^{\text {er }}$ juillet $1 S_{75}$. Ces statistiques, établies dans un intérêt purement fiscal, négligeaient de tenir compte de la destination ou de la provenance des produits; elles permettent seulement de connaitre le chiffre total des importations et des exportations tunisiennes depuis l'année IS75. En IS $S_{4}$, par suite de l'établissement du protectorat et de la garantie accordée par la France ì la dette tunisienne, l'administration des revenus concédés céda la place à la Direction des finances, et le service des dounnes tunisiennes fut réorganisé par un personnel français et sur le modele de l'administration des douanes françaises. De ce moment date la publication régulière de documents statistiques complets.

Il faut donc renoncer à se faire une idée parfaitement exacte basée sur des chiffres de ce qu'était le mourement commercial de la Régence antérieurement à $1 S_{75}$.

\section{I}

Le tablenu suivant indique, année par annee, le chiffre total du commerce de la Régence, importitions et exportations réunics. 
Statistique du commerce de la Tunisie.

Importations el exportalions réunies.

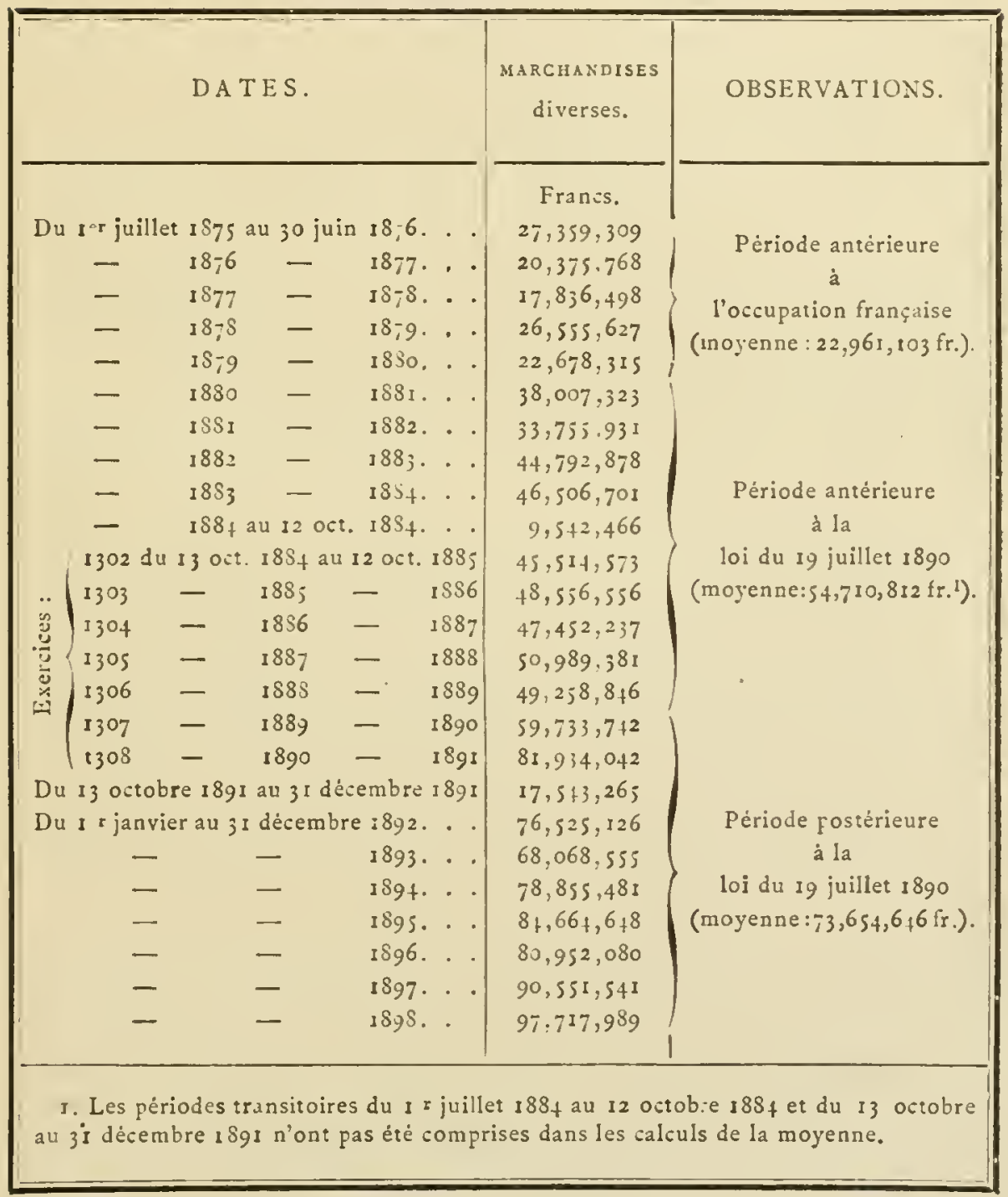

Le graphique ci-après rendra sensible à l'œil l'essor rapide pris par le commerce de la Tunisie depuis l'établissement du protectorat français.

II. TUNISIE. 
GRAPHIQUE $\mathfrak{N}^{\circ} 1$

\section{COMMERCE TOTAL DE LA TUNISIE}

(Importations et exportalions réunies.)

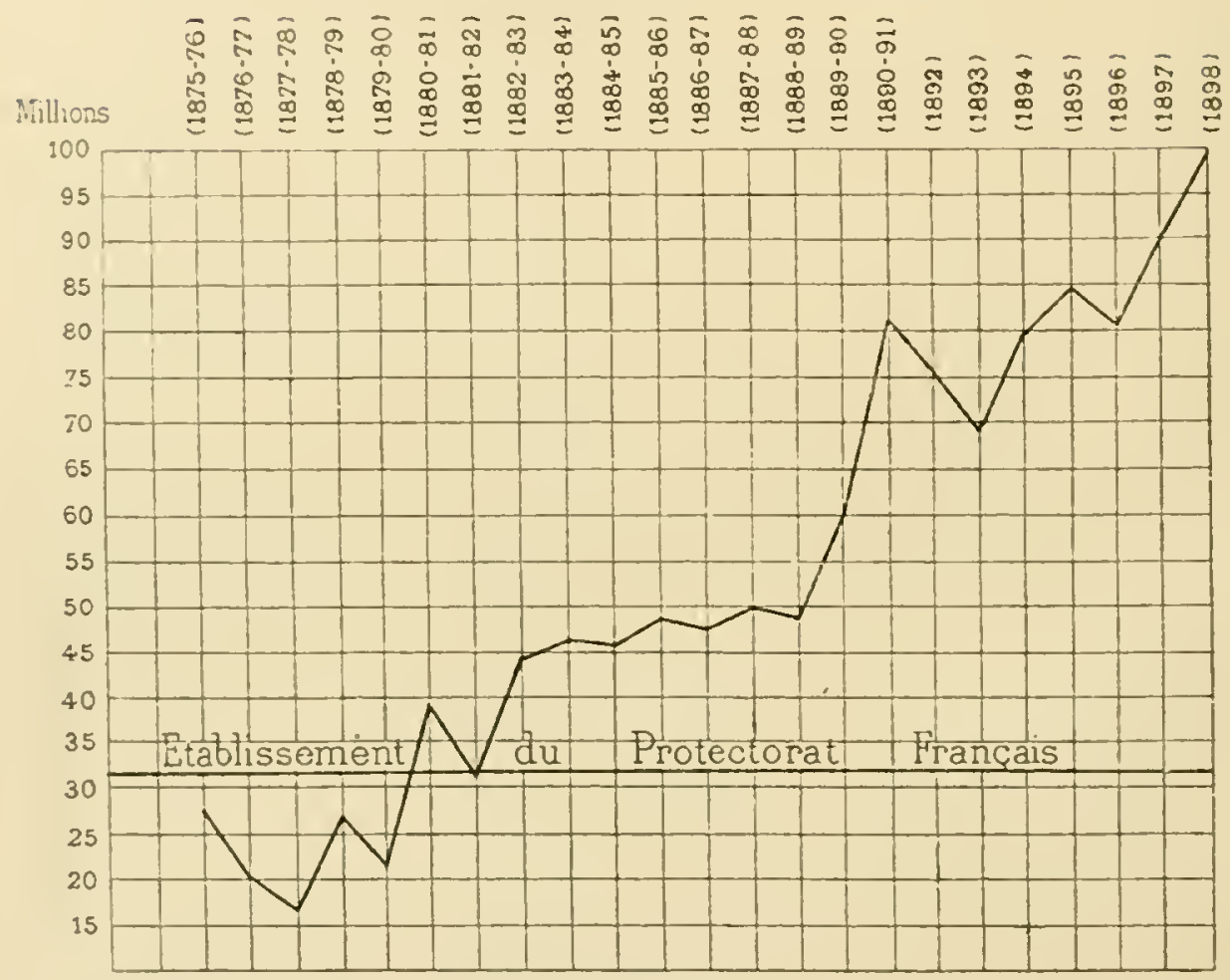

Pendant les cinq années qui ont précédé le traité du Bardo, les seules pour lesquelles on possède des chiffres, de I $S_{7 j}$ ì ISSo, la moyenne du commerce de la Régence a été de 22,96I,103 fr.; le total le plus élevé a été de $27,359,309 \mathrm{fr}$. et le pius faible de $17,836,498 \mathrm{fr}$. Pendant les dix-huit années qui ont suivi ce même traité, de I $S S_{I}$ ¿̀ I $\$ 9 S$, la moyenne a été de 60,88 I, $462 \mathrm{fr}$.; le total le plus élevé a été de 97,7 1 7,989 fr. et le plus faible de 33,75j,93 I fr. Ces quelques chiffres suffise.zt pour niontrer le développe- 
ment subit qu'à pris la Tunisie considérée au seul point de vue commercial depuis l'année ISS I : le chiffre moyen de ses transactions a plus que doublé.

Il ne sera pas sans intérêt de rechercher quelles ont été les causes intimes du phénomène économique que nous venons de constater. On peut les ramener à trois grands faits qui découlent du nouveau régime apporté par la France au pays qu'elle a couvert de sa protection : le rétablissement de l'ordre matériel et de l'ordre administratif, l'augmentation de la population européenne et l'importation des capitaux étrangers.

L'occupation du territoire tunisien par les troupes françaises a eu pour premier résultat, après une courte période de troubles, de faire régner, du nord au sud de la Régence, l'ordre le plus parfait, la sécurité la plus complète. Autrefois, même en temps normal, en dehors des villes et des environs immédiats de la capitale, l'action du pouvoir central se faisait difficilement sentir; chaque année, le bey du camp devait parcourir le pays à la tête d'une armée pour faire rentrer les impôts; l'ordre public était souvent compromis par les rivalités et les querelles des tribus, et la sécurité des voyageurs n'était pas toujours assurée.

Aujourd'hui, la situation s'est complètement modifiée. Même en Khroumirie et dans les territoires voisins de la frontière tripolitaine, qui étaient en état de rébellion ouverte et constante contre l'autorité des beys, la tranquillité est aussi complète que dans n'importe quel État civilisé. Il était impossible que ce nouvel état de choses ne réagit pas favorablement sur l'importance des transactions commerciales; désorm.is, le cultivateur et l'éleveur indigènes, certains de n'être pas dépouillés en route, apportent plus volontiers leurs produits sur les marchés. 
La réforme administrative accomplie par le gouvernement du protectorat n'a pas eu une action moins eflicace sur le développement des transiactions. Sous l'ancien régime tunisien, les cultivateurs, abandonnés sans défense à l'arbitraire et i la rapacité des caïds, n'ensemençaient que les espaces strictement nécessaires à leurs besoins. Depuis qu'ils sont assurés de ne payer que l'impôt légal, ils ont étendu leurs cultures dans une notable proportion. Les statistiques officielles qui existent depuis l’année I 869 constatent que le chiffre le plus éleré des surfaces ensemencées en céréales pendant la période antérieure au protectorat al été de 55,998 méchias; en I \$92, cette superficie a atteint $\$ 6,695$ méchias. Il est done naturel que la quantité des produits exportables ait augmenté dans la ınême proportion. Sous l'ancien régime, le produit des impôts était affecté presque en totalité à un double usage : entretenir le luxe de la cour et payer à l'étranger les intéréts de lis dette; le p.yss n'en profitait done que fort peu. De $188_{4}$ ì 1896 , au contraire, il a été dépensé, en travaux publics de diverses natures (routes et ponts, ports maritimes, phares et fanaux, aménagements d'eaux, construction et entretien des bâtiments civils, forages artésiens, fixation de dunes), une somme de 70,000,000 fr., soit une moyenne de 6,000, 000 fr. environ par an. L'outillage économique qui a été constitué à l'aide de cette dépense a certainement contribué dans une large mesure au développement des transactions commerciales. D'autre part, cet argent, répandu en grande partie dans le pays sous forme de min-d'œuvre, a servi à augmenter le bien-être des habitants et ì accroitre la consommation locale, obligée de demander il l'extérieur une partie des objets qui lui sont nécessaires. La même remarque s'applique aux sommes qui ont servi à payer le personnnel administra- 
MOUVEMENT DU COMMERCE DE LA TUNISIE. IOI

tif. Tandis qu'autrefois les fonctionnaires beylicaux, mal et irrégulièrement appointés, se voyaient trop souvent dans l'obligation de recourir, pour vivre, à des procélés condamnables, le nouveau régime, dont le premier souci a été d'instituer la régularité des paiements, a répandu dans le p.ys, de ${\mathrm{I} S S_{4}}_{4}$ ì $\mathrm{I} \mathrm{S}_{93}$, sous forme de salaire des fonctionnaires réguliers, une somme qui n'est pas inférieure à $36,354,104$ fr. ou a 4,039,347 fr. par an en moyenne.

L'effort de l'administration dans le but de favoriser le commerce s'est encore manifesté par des mesures de trois ordres principaux : $I^{\circ}$ la création de nouveaux marchés; il en a été ouvert une trentaine sur le territoire tunisien; $2^{\circ}$ les dégrèvements d'impôts; ils ont surtout porté sur les droits d'exportation qui entouraient les transactions de mille entraves gênantes; le sacrifice consenti de ce chef par le Trésor est évalué à 5,927,945 fr. au 3 I décembre I 897 ; $3^{\circ}$ l'obtention des conditions de faveur accordées par la France aux produits tunisiens importés sur son territoire. Cette mesure bienfaisante, en ouvrant au pays protégé le marché de la nation protectrice, a donné aux transactions une énorme impulsion. Pendant la première période du protectorat, de I 88 I à I 890 , la moyenne annuelle du commerce tunisien s'était élevée de 22,96I, I03 fr., chiffre antérieur au protectorat, à 54,7 I0, 8 I 2 fr.; après l'adoption de la loi du I 9 juillet $I 890$, qui fixe les relations douanières de la France et de la Tunisie, cette moyenne a passé à 60,86 I, I 57 fr. pour les années I 890 à I 894 , et à 88 millions 563,610 fr. pour les années I 895 à I 898 .

L'immigration des hommes et des capitaux n'a pas eu une influence moindre sur le développement du commerce extérieur de la Tunisie. Avant l'occupation française, la population européenne fixée dans la Régence n'était pas 
considérable. On ne commit malheureusement, d'une façon certaine, que le chiffire des Français; mais on peut affirmer que toutes les nationalités réunies ne dépassaient pas 20,000 imes, soit I 0, coo Italiens, 9,000 Maltais, 700 Français et 300 autres Européens. Actuellement, on est mieux fixé à cet égard; on peut supposer que la population civile européenne approche de 100,000 ames (dont 20,000 Français non compris l'armée, i 2,000 Maltais et 60,000 Italiens). Ces So,ooo immigrants ont apporté avec eux leurs gouts et leurs habitudes d'Europe, que l'industrie locale est le plus souvent impuissante à satisfaire, d'où est résultée une augmentation dans les importations. Ils ont en outre fondé des exploitations agricoles (il existe actuellement en Tunisic enriron I, 000 propriétés rurales européennes); ils ont créé des industries nouvelles ou perfectionné des industries existantes, ce qui a amené un accroissement de la production et une tendance à une plus forte exportation.

Enfin, ces immigrants ont apporté avec eux des capitaux qui faisaient surtout défaut dans la Régence avant leur arrirée. Il s'est produit là un phénomène dont l'importance n'a pas été assez remarquée et qui mérite de retenir un instant l'attention. Le rôle des capitaux étant prépondérant dans la transformation économique d'un pays, il serait intéressant de savoir exactement quel a été l'apport des capitaux du dehors qui a suivi l'établisscment du protectorat français sur la Tunisie.

A défaut d'informations précises sur ce sujet, qu'il n'a pas ćté possible de recueillir, nous avons rassemblé quelques données approximatives qui permettront de se faire une idée de l'importance qu'a prise depuis quinze ans l'immigration des capitaux en Tunisie. Le premier apport considérable a eu lieu au moment même de l'occupation; une forte 
MOUVEMENT DU COMMERCE DE LA TUNISLE. IO3 part des sommes affectées à l'expédition de I8S r (I 4 I millions 995,53 I fr. d'après M. Louis Vignon ${ }^{5}$ ) a été dépensée sur le théâtre des opérations militaires sous forme de solje des troupes et de prix d'approvisionnements ou de transports. De plus, il y a lieu de tenir compte des sommes dépensées annuellement en Tunisie par les divers services de l'armée (elles sont évaluées à I 2 ou 13 millions par an, non compris les constructions édifiées par le génie et l'artillerie), et de celles apportées ou reçues de France par les homnies qui forment le contingent annuel de la division d'occupation; avant l'augmentation récente des garnisons de la Régence, les hommes recevaient de France par l'intermédiairc des vaguemestres des corps une moyenne annuelle de 60,000 fr. par mois ou de 720,000 fr. par an.

Il est plus difficile d'évaluer les sommes apportées dans la Régence par les immigrants civils. Beaucoup, surtout parmi les ouvriers italiens et maltais, n'apportent presque rien avec eux; par contre, les colons, ce sont pour la plupart des Français, qui viennent créer des exploitations agricoles, y immobilisent des capitaux d'importance variable, mais qui dans quelques cas particuliers ont dépassé, à ce qu'on assure, deux millions pour une seule exploitation. Pour les seuls domaines immatriculés ou en instance d'immatriculation au 3 I décembre 1898 , la valeur vénale déclarée par les propriétaires atteint $82,896,970$ fr. pour 722,3 r 4 hectares ${ }^{2}$. Ce chiffre ne représente que la valeur de la terre plutôt diminuée qu'exagérée. Il faudrait y ajouter les sommes dépensées en constructions de bâtiments agricoles, en achat de matériel ou de cheptel et en améliorations culturales;

I. En France, dans l'Afrique du Nord : Algérie et Tunisie. Paris, I887.

2. Dans ces chiffres sont confondues les propriètés rurales et les propriétés urbaines. 
mais les éléments font défaut pour présenter, ì ce sujet, même une approximation lointaine. Tout ce qu'on peut dire, c'est que le rignoble européen de 6,000 hectures peut représenter une dépense de 4,00o à 5,00o fr. par hectare, soit approximativement 25 millions de franes ${ }^{1}$. A còté de la colonisation agricole, l'industrie européenne, qui n'existait pas davantage dans la Régence avant ISS I, y a pris pied et s'y développe tous les jours davintage. Une statistique établic en 1893 par la direction des renseignements avec le concours des contrôleurs civils, évalue à plus de neut millions de franes le capital employé en immeubles et matériel industriel par des Européens en Tunisie. Depuis que cette statistique a ćté faite, douze nouvelles huileries européennes ont été ouvertes dans le seul contrôle de Sousse et plusieurs dans celui de Sfix. Il faut enfin men-

COMMERCE DE LA TUNISIE. - EXPOR

Part revenant à lu France et l'. Algérie, à l'Italie,

\begin{tabular}{|c|c|c|c|c|c|c|c|c|}
\hline \multirow[b]{2}{*}{ PAYS. } & \multirow{2}{*}{\multicolumn{2}{|c|}{ 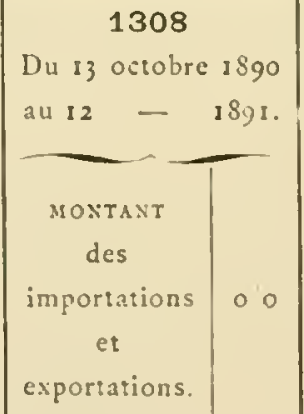 }} & \multicolumn{2}{|c|}{$\begin{array}{c}1308 \text { PROLONGE } \\
\text { Du I } 3 \text { octobre } 89 \text { I } \\
\text { au } 3 \text { I décembre is9:. }\end{array}$} & \multicolumn{2}{|c|}{$\begin{array}{c}189: 2 \\
\text { Du I r janver } \\
\text { au j d decembre. }\end{array}$} & \multicolumn{2}{|l|}{1893.} \\
\hline & & & $\begin{array}{c}\text { MoNtant } \\
\text { des } \\
\text { importations } \\
\text { et } \\
\text { exportations. }\end{array}$ & 0,0 & $\begin{array}{l}\text { MoNtaxt } \\
\text { des } \\
\text { importations } \\
\text { et } \\
\text { exportations. }\end{array}$ & 00 & $\begin{array}{l}\text { Montant } \\
\text { des } \\
\text { importations } \\
\text { et } \\
\text { exportations. }\end{array}$ & $0 / 0$ \\
\hline $\begin{array}{l}\text { France et Algérie. } \\
\text { ltalie. . . . } \\
\text { Angleterre et Malte. } \\
\text { Autres pays. . } \\
\text { Tot^ux. . }\end{array}$ & $\mid \begin{array}{r}52,174,076940 \\
7.025,27160 \\
14,770,62960 \\
7.954 .06460 \\
81,954,042520\end{array}$ & $\mid \begin{array}{rr}63 & 70 \\
8 & 50 \\
18 & 00 \\
9 & 80\end{array}$ & $\begin{array}{r}11,-81,69600 \\
1,757,53 ; 00 \\
2,260,72200 \\
1,723.31260 \\
17,523,205160\end{array}$ & $\left|\begin{array}{r}6750 \\
10.09 \\
13.00 \\
9.41\end{array}\right|$ & $\mid \begin{array}{l}50,508,6,2500 \\
7,770,71700 \\
9,335,12900 \\
8,910,60600 \\
76,525.124^{8} 00\end{array}$ & $\left\{\begin{array}{l}66.00 \\
10.05 \\
12.31 \\
11.64\end{array}\right.$ & $\mid \begin{array}{l}12,752,467900 \\
3,6,2,13200 \\
3,293,52800 \\
\frac{3 ; 6 ;, 42800}{68 \text { oc } 8,555100}\end{array}$ & $\begin{array}{l}62.50 \\
13.40 \\
12.17 \\
11.92\end{array}$ \\
\hline
\end{tabular}

1. Dans ce chiffre on a fait cntrer en ligne de compte l'achat de la terre, la flan:ation, les constructions de 
MOUVEMENT DU COMMERCE DE LA TUNISIE. IOS tionner les capitaux employés en constructions d'immeubles urbains qui pour la seule ville de. Tunis sont éralués à une vingtaine de millions de francs. Ces quelques chiffres, tout incomplets qu'ils sunt, suffiront pour donner une idée approximative de l'importunce des capitaux que le protectorat de la France a attirés en Tunisie.

Nous avons constaté quelles ont été au point de vue commercial les conséquences générales de l'établissement sur la Tunisie du protectorat français. Nous allons étudier maintenant quelle a été l'influence de cette révolution éco-

CATIONS ET IMPORTATIONS REUNIES

l'Angleterre et Malte, et anx autres pays.

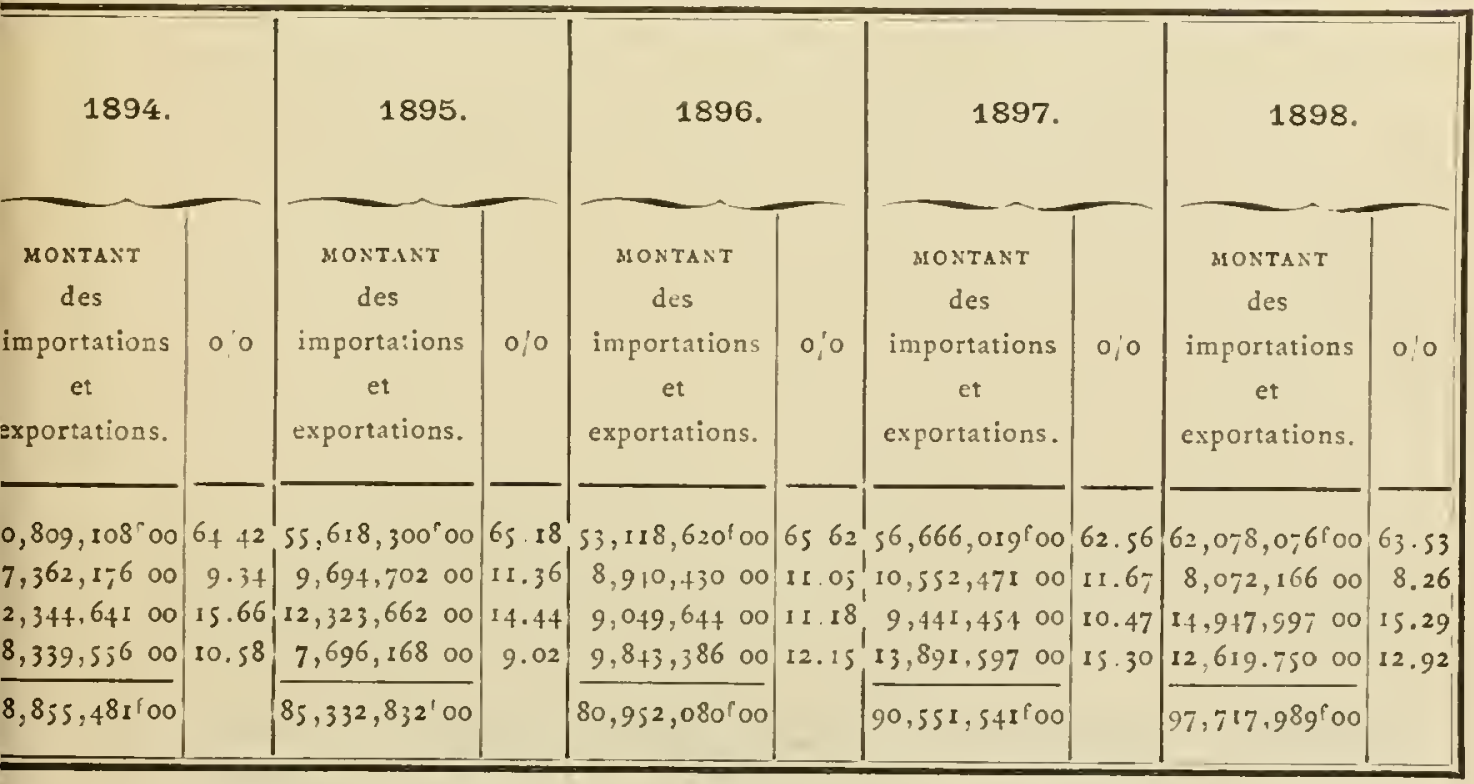

eaves et l'achat du matér'el vinaire. 
nomique sur les transactions respectives des diverses puissances avec la Régence.

Ainsi qu'il a été expliqué plus haut, il n'est pas possible defaire remonter les recherches plus loin que le i 3 octobre I $S S$; , les statistiques tunisiennes étant muettes jusqu'i cette dilte sur la provenance et la destination des marchandises. Cette omission est d'autant plus regrettable que les statistiques françaises de cette époque ne fournissent, jusqu'en ISS 4 , aucun renseignement précis en ce qui concerne la Tunisic.

Le tableau précédent montre la part de la France et de l'Algérie, de l'Italie, de l'Angleterre et de Malte et des autres pays dans les importations et les exportations réunies de la Tunisie de I 885 ì i $89 S$.

La part proportionnelle de la France et de l'Algérie dans le mouvement commercial de la Tunisie n'a pas cessé de croitre. De 3\$.So p. I oo en i $\$ 8$ - I $\$ 86$ elle s'élève ì 56.2 I p. I oo en ISSS-ISS9, a 60.35 p. Ioo en I $8 S 9$ - I $\$ 90$ et à 66 p. Ioo en I892. Par contre, la part de l'Italie et celle de Malte et de l'Angleterre ont subi une diminution notable. L'Italie entrait en I\$S;-ISS6 pour 29.40 p. Ioo dans le commerce total de la Régence; sa part est tombée à I 4.50 P. Ioo en ISSS-ISS9, puis ì 8.50 p. Ioo en I $\$ 90-$ IS9I; elle s'est un peu relevée ensuite, mais sans dépasser I 3.40 p. Ioo en I \$93. Elle a été de I I.04 p. I 00 en i S96. Malte et l'Angleterre, qui occupaient le $3^{\mathrm{e}} \mathrm{rang}$, comptaient pour 21.54 p. Ioo en I 885 -ISS6; elles ne comptent plus que pour i 2 p. Ioo en i $S_{92}$ - I $S_{93}$ et en r $\$ 96$ pour i I I 8 p. I oo. Le courant commercial de la 'Tunisie s'est donc déplacé au profit de la France sous l'infuence du protectorat et de la loi douanière du i 9 juillet I 890 . C'est là une vérité que l'on ne saurait proclamer trop haut, car elle est la preuve que les 
MOUVEMENT DU COMMERCE DE LA TUNISIE. IOT sacrifices accomplis en Tunisie par notre pays ne sont pas restés infructueux. Le diagramme ci-après permet d'embrasser d'un coup d'œil les fluctuations qu'a subies de I $S S$; à 898 le commerce en Tunisie des trois pays qui y ont pris la plus large part.

GRAPHIQLE \० 2

PART RESPECTIVE DES PRINCIPAUX PAYS

DANS LE COMMERCE TOTAL DE LA TUNISIE

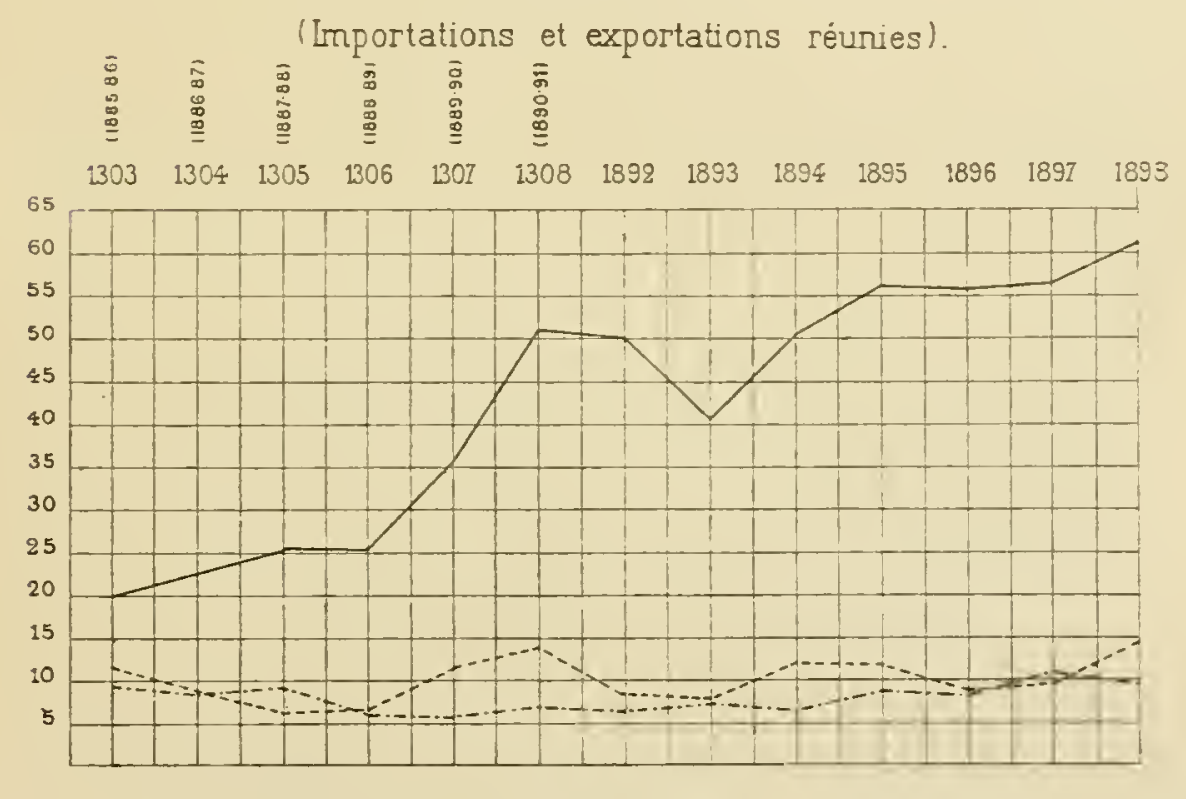

France et Algerie

Angleterre et Malte

Italie

III

On a considéré jusqu'à présent le mouvement commercial tunisien dans son ensemble, en réunissant en un seul bloc les importations et les exportations. Il est temps de passer à l'étude de chacune de ces deux branches du commerce en elles-mêmes qui feront l'objet des deux chapitres 
suivants; mais il ne sera pas sans intérêt de les examiner d'abord dans leur importance respective. Le graphique ci après facilitera notre tâche.

GRAPHIQLE N० 3

\section{MOUVEMENT COMMPARATIF DES IMPORTA'TIONS}

ET DES EXPORTATIONS
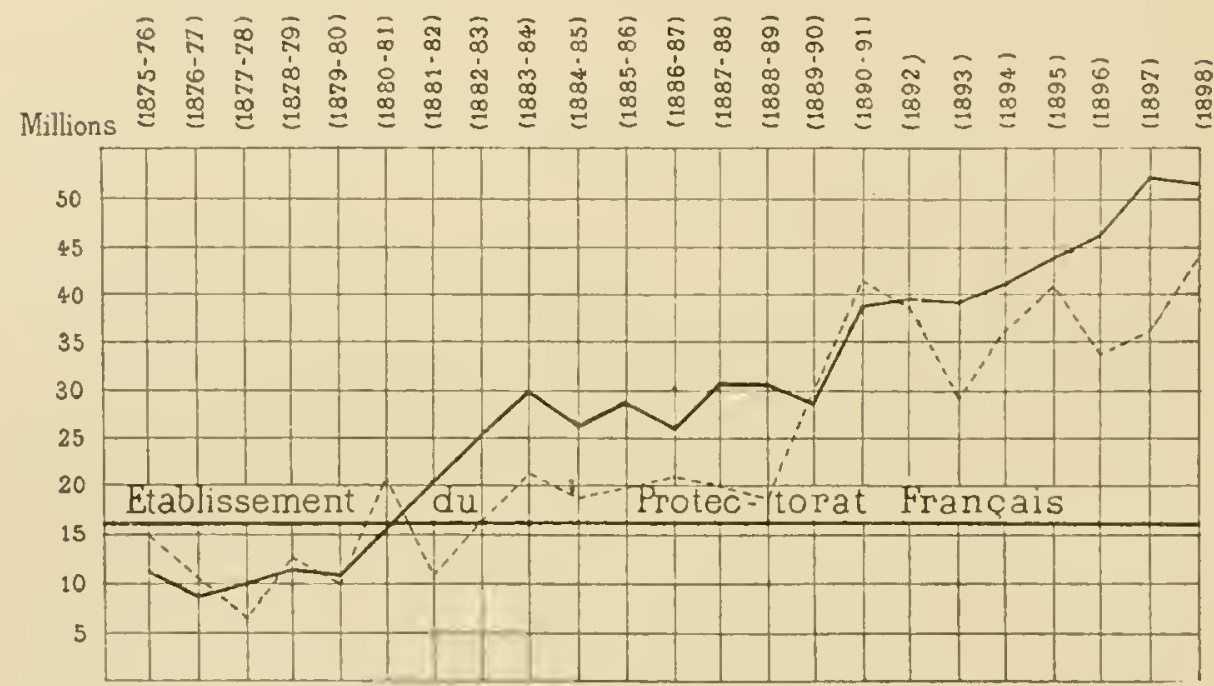

Importations

Exportations

Si l'on compare le mouvement des importations à celui des exportations, on constate tout d'abord que le chiffre des importations est presque toujours supérieur à celui des exportations. Pendant les premières années, celles qui ont précédé l'établissement du protectorat, cette supériorité est peu accentuée et assez intermittente, mais depuis l'année I $\$ 81$ - I $\$ 82$ jusqu'à l'année I $\$ 89$-I $\$ 90$, le diigramme des importations se tient constamment à une grande hauteur au-dessus de celui des exportations. Cette constatation a inquiété certains esprits, il y a quelques années; on s'est demandé si elle n'était pas un indice d'appauvrissement pour 
le pays, et on a cherché à en tirer un argument défavorable au nouveau régime politique de la Régence.

De semblables appréhensions dérivaient de la fausse théorie de la balance du commerce, dont les économistes les plus éminents, depuis J.-B. Say et Bastiat, ont fait justice.

L'explication que, pendant un moment, on a cru avoir trouvée de l'accroissement subit des importations en Tunisie, en l'attribuant à láprésence du corps d'occupation, n'était pas exacte, puisque la réduction de l'effectif des troupes, bien loin d'amener une réduction dans les importations, n'a pas ralenti leur accroissement. C'est à l'établissement du protectorat et à ses heureuses conséquences: augmentation de la population européenne, immigration des capitaux et création de nouvelles entreprises agricoles ou industrielles, qu'il faut demander le secret de ce phénomène économique. On aurait dû s'en réjouir, tout en constatant que la situation du commerce d'exportation était moins favorable que celle du commerce d'importation.

En effet, jusqu'à l'année i 888 -i 889 le diagramme des exportations se maintient à un niveau qui n'est pas de beaucoup supérieur à celui qu'il occupait avant le protectorat. Cet état de stagnation s'expliquait par ce fait que le nouveau régime, qui avait en s'établissant déclaré respecter les traités signés par le gouvernement tunisien avec les puissances étrangères, n’avait pas encore modifié les conditions du marché d'exportation; la suppression de quelques droits de sortie n'était pas suffisante pour donner une impulsion sérieuse à cette branche du commerce. Il a fallu pour cela que la France, abattant des barrières dounières qui n'avaient plus de raison d'être depuis le jour oú elle avait planté son drapeau sur la Régence, se décidât enfin à ouvrir largement ses portes aux produits tunisiens par la loi du ig juillet

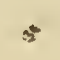


I 900 . Bieln que les faveurs accordées par cette loi ne s'appliquent qu’à un petit nombre de produits, les résultats de cette bienfaisante mesure n'ont pas tardé à se faire sentir. En deux ans le diagramme des exportations monte d'un bond de IS millions à près de 44; et, ce qui montre que, contrairement à l'opinion des partisans attardés de la théorie de la balance commerciale, les produits, d'une nation à l'autre, ne s'échangent pas contre de l'argent, mais bien contre d'autres produits, l'accroissement des exportations a amené un accroissement noureau des importations. 


\section{CHAPITRE XX}

- EXPORTATION

MOUVEMENT GÉNÉRAL ET PART DES DIFFÉRENTS PAYS

Dans un chapitre précédent, on a fait ressortir les conséquences générales des abus de toute nature qui régnaient à tous les degrés de l'ancienne administration de la Régence. Dans un pareil état de choses, les transactions commerciales ne peuvent que péricliter; en fait, pendant la période la plus critique, celle de I $86_{4}$ à i $\delta_{72}$, la moyenne annuelle des exportations fut à peine de six millions de francs, moyenne qui avait été atteinte et même dépassée plus de trente ans auparavant, sous la sage administration de Chakir.

A partir de $\delta_{72}$, les échanges extérieurs se relèvent peu à peu, sous l'influence des réformes apportées dans l'ancienne organisation financière, de la régularisation des rôles de perception et de l'usage obligatoire des quittances à souche. Il convient d'ajouter que la facilité avec laquelle le général Khérédine accueillait les indigènes qui avaient à réclamer contre les exactions des caïds contribua à ramener une confiance et une prospérité dont le pays était depuis longtemps déshabitué.

Dès les années s'étendant de IS74 à IS79 - période 
qui va nous servir de point de départ dans cette étude la commission financière constate une reprise sérieuse des affaires. A l'cffet de montrer le mouvement ascensionnel de nos exportations, nous allons considérer successivement les résultats obtenus pendant chacune des cinq périodes quinquenriles : I 874 à I 879 - I 880 à I $884-I 88$ j ì I 889 - I 890 à I 894 - I 895 à I $899:$

Première période quinquennale (allant de la $j^{\mathrm{e}}$ à la $9^{\mathrm{e}}$ année d'exercice de la commission financière):

$$
\begin{aligned}
& \text { I } 874 \text {-1875 . . . . . . II,900,000 fr. } \\
& 1875-1876 \ldots \ldots \text {. . . . . . . 15,036,493 } \\
& \text { I } 876-1877 \ldots \ldots \text {. . . . . II }, 784,622 \\
& \text { I } 877-1878 \ldots \ldots . \ldots 7,8 \ldots 24,250 \\
& 1878-1879 \ldots \ldots \ldots \ldots . \ldots 13,615,548 \\
& 60,160,913 \mathrm{fr} \text {. }
\end{aligned}
$$

Moyenne annuelle : I $2,032, \mathrm{I} \delta_{3} \mathrm{fr}$.

Denxième période (avant la suppression de la commission financière) :

$$
\begin{aligned}
& \text { I879 I8S० . . . . . . . 10,918,997 fr. } \\
& \text { IS83-ISSI . . . . . . . . . . 2I, . 232,788 } \\
& \text { I881-1882 . . . . . . . . II, 237,670 } \\
& \text { I } 882-1883 \ldots \ldots \ldots \ldots \\
& 1883-1884 \ldots \ldots \ldots \ldots \text {. . . . . . } 18,542,053 \\
& \overline{80,458,8 ; 4} \text { fr. }
\end{aligned}
$$

Moyenne annuelle : 16,09 I,77 I fr.

Troisième période (après la suppression de la commission financière et avant le vote de la loi douninierc) :

$$
\begin{aligned}
& 188 \text {;......... . . 20,570,34; fr. } \\
& \text { I885 . . . . . . . . . . . I9,2II,387 } \\
& 1887 \ldots \ldots \ldots 20,351,736 \\
& 1888 \ldots \ldots \ldots \ldots \ldots \\
& 1889 \ldots \ldots . \ldots 20, \ldots \ldots 18,785 \\
& 97,664,649 . \mathrm{fr} \text {. }
\end{aligned}
$$


Moyenne annuelle : 19,532,930 fr.

Quatrième période (après le vote de la loi douanière) :

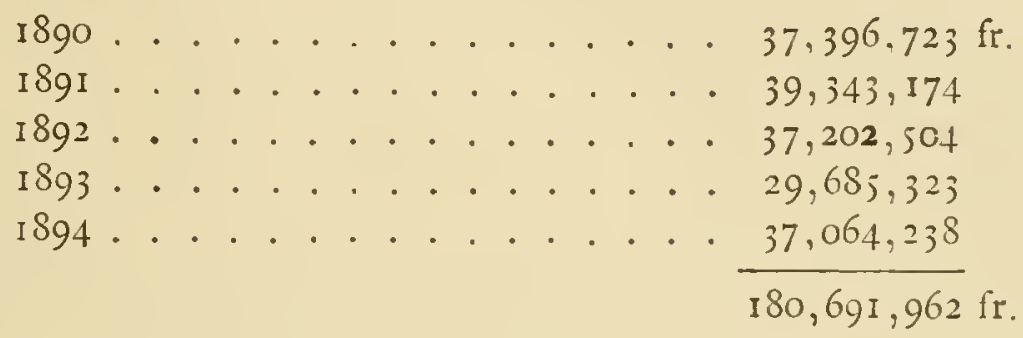

Moyenne annuelle: $36,138,392 \mathrm{fr}$.

Cinquième période (période actuelle de IS95 à I 899):

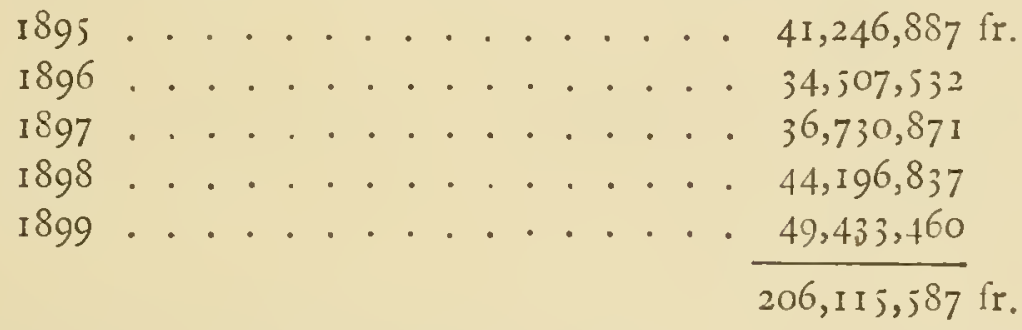

Moyenne annuelle : 4I,223, I I 7 fr.

Chacune de ces progressions correspond à l'une des étapes qui ont marqué l'érolution historique de la Régence en ces derniers temps.

C'est ainsi que, dès les premières années qui suivirent l'établissement du protectorat, le mouvement des exportations s'élève immédiatement et dans une proportion qui, comparée avec la période précédente, représente une augmentation de $33 \mathrm{p}$. Ioo.

Le gouvernement de la République rachète la dette tuinisienne, slipprime la commission financière et, brusquement, la moyenne annuelle présente, sur la seconde période, une plus-value de près de 22 p. Ioo, sur la première période, une plus-value de $62 \mathrm{p}$. IoO.

Le Parlement français vote la loi douanière (I 9 juillet 
I 90 ) et nous constatons aussitôt : sur la troisième période considérée, une augmentation de $S_{5}$ p. Ioo; sur la deuxième période, une hausse de I 54.5 p. Ioo; sur la première période, une plus-value de 300 p. Ioo.

Enfin, la dernière période marque une plus-value considérable du chiffre des exportations puisque de 36 millions, moyenne annuelle de la périołe précédente, nous passons à la moyenne de plus de $f$ i millions pour la période actuelle.

Les caluses d'une aussi rapide progression sont connues de tous; nous nous contenterons de les résumer.

Indépendamment de la confiance justifiée qu'inspire le gouvernement du protectorat et du contrôle plus sévère auquel est soumise l'administration des finances, la création de routes et de chemins de fer reliant les centres de production aux ports d'embarquement, l.ı fréquence èt la rapidité de nos communications avec la métropole, l'abaissement progressif du prix du fret ont, dans une large mesure, contribué à l'extension de notre commerce extérieur. Toutefois, il importe d'insister sur ce que la meilleure part dans le développement de la richesse publique revient à la loi douniniere.

Il s'ensuit que, jusqu'à ce jour, les plus-values portent principalement sur les articles ci-iprès : céréales, animaux vivants, huiles, vins, produits de pêche, minerais, bois et liciges.

Les progrès déjà réalisés laissent entrevoir que l'accroissement de la production des grains de toutes especes, l'extension de la culture de l'olivier et de la vigne, l'élevage du bétail et l'exploitation de nos forêts sont de nature à enrichir le pilys. Ce résultat serait sûrement atteint, dans un avenir prochain, par les modifications à la loi du is juillet i $\$ 90$ que lopinion publique de la colonie appelle de tous ses voux. 
Examinons maintenant quelle est la situation respective des pays qui ont pris part aux exportations de la Régence.

Nos exportations pendant la période de r 885 à r 889 se sont élevées à . . 97,664,649fr.

Défalquant le produit de l'année i 885 , en raison de l'impossibilité de déterminer, pour cet exercice, la part de chaque nation, soit. . . . . . . .

le résultat des quatre années I 886-I 889 $20,570,345$ se trouve ainsi représenté par la différence de

L'ensemble des exportations, pour la période de 1890-r 894 , est de . . . .

Et pour la période I 895 à I 899 les exportations se sont élevées à. . . 206, I I 5,287 fr.

Jetons un coup d'œil d'ensemble sur les fluctuations annuelles de notre commerce d'exportation avec les différentes nations.

France. - Un coup d'œil jeté sur ces chiffres montre que, dès I 886, c'est-à-dire bien avant le vote de la loi douanière, le courant de nos expéditions sur la France commençait sa marche ascensionnelle, sauf pendant l'année I889, où l'Algérie bénéficiait seule de l'incertitude que provoquaient, dans le pays, les retards apportés au vote de la loi douanière.

La Tunisie se trouvait, sur le marché français, dans un état d'infériorité absolue, non seulement vis-à-vis de l'Al- 
gérie - dont les produits étaient admis en franchise mais encore vis-i-vis des puissances étrangères qui, pourant se prévaloir des traités de commerce — du moins pour des articles autres que le bétail et les céréales - n'avaient à supporter que les droits du tarif conventionnel de $3 \mathrm{fr}$. par r oo kilogr. sur l'huile, et de $2 \mathrm{fr}$. par hectolitre sur les vins, tandis que les produits similaires d'origine tunisienne étaient assujettis au tarif général de l'époque, c'est-i-dire à un droit de 4 fr. 50 c. pour chacune de ces unités.

En I890, grâce à la loi douanière, la part proportionnelle de la France, qui n'était; pour la moyenne des quatre années précédentes, que de 20.92 p. 100 , s'élève brusquement à 46.09, soit à plus du double; elle triple en I 89 I, atteignant son maximum de $62.50 \mathrm{p}$. roo; de $\mathrm{I} S 92$ it I $\$ 94$. nous la voyons tomber successivement à j6.35, 49.89 et 53.80 p. I0o. Sa part proportionnelle était en I $\$ 96$ de 65.75 p. Ioo dans le commerce de la Régence.

Quoi qu'il en soit, la France, qui occupait le deuxième rang avant les remaniements de son tarif général, et qui était descendue au troisième après le vote des surtaxes sur les céréales et le bétail, est, depuis I89o, maitresse incontestée du marché tunisien. Depuis cette époque, ce mourement ascensionnel s'est accru puisque les exportations de Tunisie en France, qui étaient en I $\$ 90$ de 5 millions de francs seulement, ont passé à près de 30 millions certaines années.

Italie. - L'Italie qui, pendant un certain nombre d'années, avait tenu le premier rang, est ajourd'hui descendue au quatrième. Après être restéc notre plus gros acheteur de céréales - principalement de blés - jusqu’ì la promulgation de la loi douanière, elle n'arive plus aujourd'hui qu'après la France, l’Algérie, l’Ang'eterre et Malte. 
Les surtaxes que l'Italie a établies sur les céréales exotiques ont égallement contribué à ce résultat.

La part du commerce italien dans le mouvement de nos exportations, après être tombée de 43.97 à 7.52 p. 100, s'est légèrement relevée à 8.50 dans les dernières années, avec une hausse brusque en I 893 (I 5.30 p. roo), principalement provoquée par ses achats considérables d'écorces à tan. En i $\$ 96$, la part proportionnelle de l'Italie dans le commerce de la Régence a été de Ir.04 p. roo et en I 898 de 8.96 p. 100.

Angleterre. - L'Angleterre, qui a longtemps disputé le deuxième rang à la France, a vu son chiffre d'affaires décroître sensiblement à partir de $\mathrm{I} 89 \mathrm{I}$; elle est entrée en I $\$ 96$ pour une part de Ir.I 8 p. Ioo dans le commerce de la Régence, et en I 898 de I3.99 p. 100. 



\title{
CHAPITRE XXI
}

\author{
IMPORTATION
}

MOUVEMENT GENERRAL ET PART DES DIFFÉRENTS PAYS

Il est impossible de trouver des données officielles de l'importation étrangère en Tunisie avant I875. Aucune statistique n’était tenue à cette époque. La sịtuation politique du pays qui amena l'intervention de la France, de l'Angleterre et de l'Italie indique suffisamment l'état précaire dans lequel était tombée la Tunisie.

En I 875 , la commission financière installée par les puissances précitées, sous la présidence d'un inspecteur des finances français, apporta un peu d'ordre dans l'administration. Cette commission n'eut qu'à se préoccuper de l'encaissement des revenus qui lui étaient concédés. L'accomplissement de cette tâche permit, dès lors, sinon d'établir des statistiques régulières, du moins de recueillir des indications d'après lesquelles il est possible d'évaluer annuellement à I 2 millions de francs la moyenne des importations pendant les cing années précédant le protectorat.

Ces chiffres sont basés sur l'année musulmane d'après laquelle étaient fixés les règles administratives et les budgets.

En I880-I 88 I, la situation change, la présence du corps 
d'occupation, entretenu jusqu'à fin $I 8 S_{2}$, donna une plusvalue importante aux importations, qui atteignirent subitement 16 millions de franes en ISSO-ISS I, I 2 millions en I $S S_{2-I} S S_{3}$ et 26 millions en I $8 S_{3}-$ I $\$ S_{4}$.

A partir de $1 \$ S 3$, le corps d'occupation fut notablement réduit et continua à l'être régulièrement pour arriver à l'effectif actuel. Cependant, les importations, loin de fléchir, continuèrent ì progresser, atteignant en chiffres ronds successivement 29 millions en 1886,32 millions en 1888 , 38 millions en I $\$ 93,42,635, \mathrm{I} 66 \mathrm{fr}$. en I 894 , et enfin, en I $898,53,52$ I, I 52 fr. (numéraire non compris).

L'établissement du protectorat, la réorganisation du pays, la création des administrations nécessitaient la venue d'un certain nombre de fonctionnaires qui, eux et leurs familles, remplacèrent en premier lieu, dans la consommation, l'élément militaire. Un mouvement colonisateur très prononcé se fit sentir également vers I $\$ S_{j}$-I $\$ S_{4}$. C'est de cette époque que date la création, en Tunisie, des grands domaines, des grandes exploitations agricoles que l'on admire aujourd'hui.

Quoi qu'il en soit, l'élément français, fonctionnaire ou colon, continua l'élan progressif des importations et lui donna une orientation différente de celle due à l'occupation purement militaire du début. Celle-ci avait attiré à sa suite l'escorte habituelle des expéditions: fournisseurs de toutes sortes qui pullulaient partout où un camp se formait, où un poste s'établissait. Aussi le mouvement de progression des importations de cette première époque porte-t-il de préfèrence sur les articles de consommation, sur les liquides, les vins et spiritueux.

Le retrait des troupes fut un cataclysme pour ces négociants improvisés sortis de toutes les classes, venus de 
tous les pays, population spéciale, hétérogène, qui se retrouve où est la tourmente.

A nos colons, à nos fonctionnaires, classe aisée, habituée sinon au luxe, du moins au confort de France, il fallut procurer ce qui manquait en Tunisie : la marchandise élégante, soignée et de bon goût.

Les campements, les bazars primitifs disparurent; bientôt des magasins à larges étalages se créèrent dans les quartiers neufs de Tunis; les vieilles boutiques sombres des rues étroites et sans soleil, autrefois si mouvementées, furent délaissées avec leur amas de marchandises enfonies pèle-mêle.

Le commerce français, important des marchandises bien supérieures tant par leur fabrication que par leur qualité, ne tarda pas à voir ses produits facilement acceptés.

La France fut ainsi appelée à bénéficier dans une très large mesure du mouvement d'augmentation qui se m.nnifesta dans les importations. Les importations françaises, qui déjà s'élevaient à $16,305,792 \mathrm{fr}$. en I 890 , ont atteint en I 894 le chiffre de $25,642,47 \mathrm{I} \mathrm{fr}$, et en I 898 le chiffie de $29,875,73 \mathrm{I}$ fr., c'est-ä-dire presque le montant total des importations en Tunisie pendant l'année r $882-1883$.

Les droits de douane acquittés à l'entrée étaient, au mo. ment de l'établissement du protectorat, de 8 p. Ioo ad valorem sur tous les articles, sauf les vins, liqueurs et spiritueux qui payaient ro p. roo de leur valeur. La bijouterie or et argent, l'orfèvrerie et les matières précieuses subissaient un droit moindre.

Depuis le 2 mai I898, les droits de douane sont, pour un grand nombre d'articles ceux du tarif minimum français d'importation. L'ancien droit de 8 p. roo ad valorem a été conservé pour un certain nombre de produits : viandes 
et conserves de viundes, charcuterie, œufs, hait, fromage, miel, graisses, poissons, légumes secs, fruits, graines, essences, résines, goudrons, plantes médicinales, bois, bières, vinaigres, matériaux, pétrole, teintures et couleurs, savons, bougies, papier et papeterie, articles de cuir, un grand nombre d'ouvrages en bois et de vannerie, la bimbeloterie, etc., etc.

Comme dans l'ancien tarif, la bijouterie et les matières d'or et d'argent paient de $\mathrm{I} / 4$ à 3 P. Ioo.

En outre, les instruments et machines agricoles sont admis en franchise ainsi que le gibier mort, les volailles mortes; les céréales (blé, orge, maïs), les livres, brochures et journaux; les douilles et bourres; l'or et l'argent en lingots, les pierres meulières, les appareils de sondage et de forage des puits artésiens; les produits chimiques et organiques destinés ì l'amendement des terres et au traitement des maladies de la vigne et, en général, presque tous les produits admis en franchise dans le tarif minimum français.

Le tarif d'importation du 2 mai I $\$ 9 S$ est applicable ì toutes les provenances sans distinction. Cependant, un grand nombre d'articles français sont, par exception, admis en franchise: anim.tux vivants, laines, soies, sucres, huiles d'olives, vins, eiux-de-vie, alcools et liqueurs, fer, cuivre, plomb, étaine, zinc, les fils, les tissus, les vêtements, les machines et mécaniques, la carrosserie.

ARTICLES DONT L'INTRODUCTION EST PROHIBÉE

Armes et munitions de guerre, poudre à tirer.

Sel, tabac, kif, chira haschich, cartes à jouer, allumettes et monnaies de cuivre et de billon de fabrication étrangère. Dans le but de protéger le vignoble contre l'invasion du 
phylloxéra, la loi du 29 janvier I 892 prohibe l'importation de tous les objets pouvant servir de véhicule à l'insecte dévastateur et notamment des ceps, sarments, raisins et feuilles de vigne et des plants d'arbres, arbustes et végétaux de toute nature à l'état vivant. Exception est faite pour les fruits autres que ceux de la vigne, et pour les pommes de terre et les topinambours, qui sont admis sous certaines. conditions.

Les importations françaises en Tunisie atteignent aujourd'hui près de 60 p. Ioo du mouvement total; dins ce chiffre les importations d'Algérie sont comprises. Ces chiffres sont ceux qui ressortent de la statistique générale des douanes tunisiennes.

Voici du reste la quote-part revenant à chacun des principaux pays commerçant avec la Tunisie d'après la statistique des douanes de 1898 :

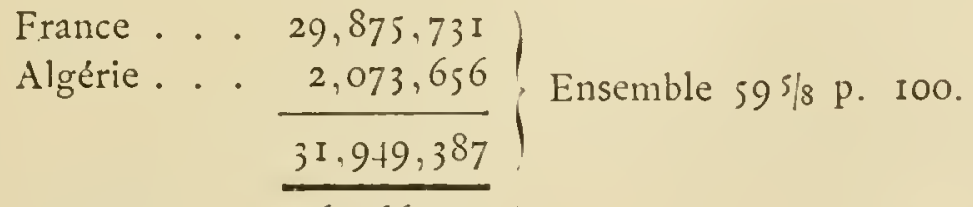

$$
\begin{aligned}
& \left.\begin{array}{l}
\text { Angleterre. } \\
\text { Malte... } \frac{3,566,797}{1,089 \text { I I6 }} \\
\hline 7,655913
\end{array}\right\} \text { Ensemble I4 I/3 p. Ioo. }
\end{aligned}
$$

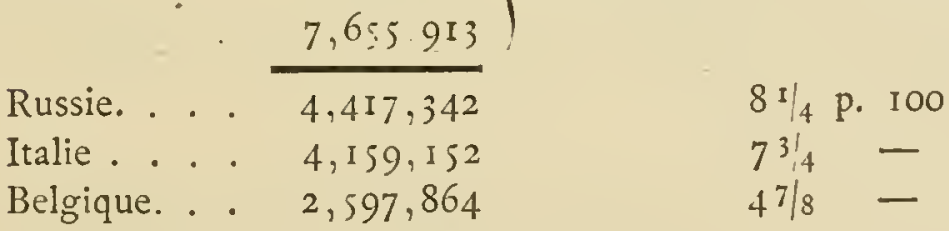

L'industrie française devrait fortement cultiver ce champ d'expériences, de renseignements qu'est la Tunisie, où elle peut par l'intermédiaire d'agents dévoués se mettre au courant des améliorations apportées par ses concurrents dans. leur fabrication.

Elle ferait son profit de ses études non seulement ici, mais. 
sur les zutres marchés d'Orient, où clle est en moins bonne situation. Les populations de ces pays-ci sont passives, attachées à leurs usages. Leur vie actuelle est sensiblement la même que celle de leurs pères, notre civilisation les entoure, mais ne les absorbe pas. Il ne suffit donc pas d'arriver avec des modèles ou des échantillons se vendant bien en France, mais avec des échantillons en rapport avec les besoins du pays.

Nous conseillons aux maisons françaises d'apporter tous leurs soins dans le choix de leurs représentants, et de ne pas accepter sans contrôle ceux qui peuvent à leur choix augmenter le renom de leurs maisons ou jeter sur elles le discrédit.

En résumé, les importations françaises sont satisfaisantes en Tunisie. Ce résultat est une des conséquences non seulement de l'excellence de la fabrication, mais de la situation privilégiée que lui crée le prestige du protectorat et de la valcur morale et pécuniaire de ses nationaux dans le pays.

Ces considérations exposées, il nous reste à examiner en détail le mouvement général des articles importés. C'est ce que nous allons nous efforcer de faire en prenant pour base la nomenclature des douanes tunisiennes et en donnant pour plus amples renseignements le mouvement des importations des années I 892, I 893, I 894, I 895, I 896, I $\$ 97$ et I 898 pour chaque article.

Mentionnons que l'année I $\$ 93$ a été une année de récolte médiocre. Les années I $\$ 92$ et I $\$ 94$ sont des années moyennes. I 94 a bénéficié dans une certaine mesure des privations que s'est imposées la population en I $\$ 93$. IS9j est une annéc de bonne récolte, I $\$ 96$ à I $\$ 97$ des années de récolte très médiocre, i $\$ 9 S$ une année moyenne.

Nous divisons ce travail en cinq paragraphes: 
$I^{\circ}$ Matieres animales.

Comprenant: Animaux vivants,

Produits et dépouilles d'animaux,

Pêche,

Substances animales brutes, propres à la médecine et à la parfumerie,

Matières diverses.

$2^{\circ}$ Matières végétales.

Comprenant: Farineux alimentaires,

Fruits et graines,

Denrées coloniales de consommation,

Huiles et sucs végétaux,

Espèces médicinales,

Bois,

Filaments, tiges et fruits à ouvrer,

Teintures et tanins,

Produits et déchets divers,

Boissons.

$3^{\circ}$ Matières minérales.

Comprenant: Marbres, pierres, terres, combustibles, minéraux, etc.

Métaux.

$4^{\circ}$ Fabrications.

Comprenant: Produits chimiques,

Teintures préparées,

Couleurs,

Compositions diverses,

Poteries, 
Verres et cristaux,

Fils,

Tissus,

Papier et ses applications,

Peaux et pelleteries ouvrées,

Ourrages en métaux,

Armes, poudres et munitions,

Meubles,

Ouvrages en bois,

Instruments de musique,

Ouvrages de sparterie et vannerie,

Ouvrages en matières diverses.

$5^{\circ}$ Autres ouvrages en matières diverses.

Comprenant: Objets et m.rrchandises expédiés en colis postaux.

Il y a lieu de tenir compte et nous tenons ì le répéter, que la valeur de certains articles tels que soieries, bijouterie, horlogerie, articles de mode et autres pouvant s'expédier en colis postaux, est bien supérieure à celle mentionnée au tableau des douanes pour chacun de ces articles. Les marchandises arrivant par colis postaux ou boites postales sont désignées sous un titre spécial qui forme le parigraphe $V$ de ce chapitre.

\section{I. - MATIERES ANIMALES}

ANIM.AUE HITATS

La Tunisie cherche ì déveiopper son troupeau, et surtout ì améliorer son espèce ovine. Des achats sont faits $\mathrm{cn}$ 
vue de substituer la race à queue fine, appréciée en France, à celle à grosse queue, propre à la Tunisie et qui jouit de moins de faveur sur le marché français; l'Algérie est notre pourvoyeur pour les races ovine et bovine.

Les chevaux et juments nous arrivent d'Algérie. Malte nous fournit des chèvres très estimées, résistantes et bonnes laitières.

Enfin, quelques échantillons de race porcine nous viennent d'Italie.

\section{PRODUITS ET DÉPOUILLES D'ANMMAUX}

Viandes fraîches. - Les viandes fraîches introduites en Tunisie sont des viandes de luxe vendues par quelques bouchers français. Elles consistent surtout en veaux dits veaux de Vichy et quartiers de bœufs gras. Ces articles disparaitront de l'importation d'ici peu, par suite des soins donnés actuellement aux bêtes à l'engrais.

Viandes salées. - Les lards et autres salaisons d'Amérique forment une bonne partie des articles portés au compte de la France et de l'Italie.

Lait concentré. - Le lait concentré est de fabrication suisse et française.

Fromages. - Nous trouvons en I 898 pour $499,653 \mathrm{fr}$. en chiffres ronds d'importations de fromages.

Les fromages de gruyère fournis par la Suisse entrent pour une bonne part dans cet article. Les formes de 60 à Ioo kilogr. sont très demandées. La France fournit les gruyères ordinaires, dits de Comté, les roqueforts et les fromages de fantaisie. 
L'Italie, dont le chiffre d'affaires doit être diminué de celui des gruyères suisses, nous importe le gorgonzola, le parmesan et surtout le fromage dit de Sardaigne, très apprécié par la population italienne ouvrière.

Beurres. - La France et l'Italie se partagent, à peu de chose près, cet article.

Graisses et saindoux. - Les graisses, livrées en majeure partie par Marseille, sont des graisses d'Amérique en tierçons ou baquets. Marseille livre aussi des graisses de sa fabrication, dites graisses alimentaires. Le peu de marchandises renant de Belgique est d'origine américaine.

Soies grèges et moulinées. - Les soies grèges et moulinées fines nous sont fournies par la France. Les soies plus grossières viennent d'Italie et sont d'origine essentiellement italienne; elles sont naturellement meilleur marché que les soies françaises et sont employées pour les garnitures des costumes indigènes et pour le tissage ordinaire.

Les soies teintes, nuance bleu marine en écheveaux, servant pour les glands des chéchias, viennent de Constantinople. Lyon et Zurich s'essaient dans cet article. La France importe principalement des soies sur bobines, teintes.

\section{PECHE}

Poissons frais, secs ou salés. - Il n'entre pas de poissons frais en Tunisie qui, au contraire, en exporte déjil et peut accroitre encore ce commerce.

Par poissons secs et fumés il fiut entendre la morue et les harengs salurs. La majeure partic nous vient de l'importation française et nous arrive par le port de Marscille. 
Poissons marinés à l'buile ou autrement préparés. - L'Italie nous importe notanment le thon et la sardine en grandes boites pour le détail. Il est à remarquer que la pêche de ces poissons se fait sur la côte tunisienne par les pêcheurs italiens, la préparation en est faite en Italie pour nous revenir ensuite. Il est permis d'espérer que cette anomalie cessera promptement et que cette industrie viendra a l'actif du pays.

\section{il. - matiéres végétales}

Froment. -- Depuis dix ans, les surfaces ensemencées ont considérablement augmenté en Tunisie. Une sélection est faite afin d'élever la qualité de nos céréales; la Tunisie demande donc ses semences à divers pays.

Maïs. - Quant au maïs, la culture est encore peu répandue. Le chiffre de nos importations de France, en cet article, est à peu près l'équivalent de celui que nous lui retournons.

Orges. - Les orges importées sont destinées au corps d'occupation.

Farines et semoules. - Les farines et semoules, par suite de la prime accordée à la minoterie par le gouvernement français, nous viennent à peu près toutes de Marseille et donnent lieu à un important mouvement dont bénéficient les compagnies de navigation françaises.

Par contre, les minoteries de Tunisie sont à peu près délaissées, ne pouvant lutter à armes égales contre l'importation. 
Pâtes dites d'Italie. - Les pâtes dites d'Italie sont d'une consommation très grande, mais la Tunisie produisant excellemment les semoules nécessaires à cette industrie, de nombreuses fabriques de pâtes existent à Tunis. La France, dont l'importation est la plus forte en cet article, ne nous adresse que des pâtes de luxe.

Rzz. - Les fabriques de riz d'Italie, bien que très nombreuses et réputées, arrivent en deuxième rang dans nos importations.

Légumes divers. - La situation des légumes secs est en général satisfaisante pour la France. Les arrivages et provenances peuvent varier suivant les récoltes des uns ou des autres pays.

\section{FRUITS ET GRAINES}

Fruits de table, secs et tapés. - La France et l'Italie se partagent à peu près le marché pour ces articles, par lesquels il faut entendre noix, noisettes, raisins secs pour distiller ou pour table.

Fruits à distiller, anis verts et autres. - Viennent du Levant.

\section{DENREES COLONIALES DE CONSOMMATION}

Sucres bruts et raffinés. - Les sucres bruts (cassonade) sont surtout employés par les indigènes. Cependant, leur chiffre diminue par suite du bas prix des sucres raffinés. Leur importation est d'cnviron un million de kilogrammes. Les importations annuelles de sucre raffiné peuvent s'éva- 
luer à 5 millions de kilogrammes en prenant pour base le prix moyen de $35 \mathrm{fr}$. les 100 kilogr., la valeur totale étant évaluée à r , 800,000fr.

Bonbons. - La France nous adresse les sortes fines. Constantinople nous enroie des confitures nommées "raoua", dont les indigènes font une très grande consommation, surtout au moment du Ramadan.

Cafés. - Le Havre et Marseille peuvent ei doivent s'assurer la presque totalité de cet important article.

Chocolat et cacao. - Les chocolats et cacaos n'offrent aucun intérêt statistique. La France fournit presque tout. Jusqu'ici la consommation indigène est restée en dehors de ces articles.

Poivre. - Le poivre se trouve dans les mêmes conditions que les cafés.

Piment. - Le piment est une denrée importante pour la consommation indigène. Le marché en est relativement très actif.

Thés. - Le thé est dans une situation satisfaisante. Les quatre cinquièmes viennent de France.

Tabac. - Le tabac, monopole de l'État, est acheté par le gouvernement pour l'approvisionnement de la manufacture. 
Il y a quelques années encore, les importations d'huiles d'olive avaient une raison d'être. Il n'existait pas alors les grandes usines si perfectionnées que l'on peut admirer aujourd'hui a Sousse, Monastir, Mahdia et Sfax, etc. Les huiles tunisiennes, plus ou moins mal traitées, avaient parfois un goût qui les faisait rejeter de la clientèle délicate; nos huiles s'exportaient donc pour nous revenir sous des marques quelconques. Actuellement, il n'en est plus ainsi. Même les grignons sont traités dans le pays. Bientôt donc, l'article huile d'olives, déjà tombé de roo,000 à jo,000 fr., disparaitra, nous l'espérons, de l'importation.

Autres builes fixes. - Par contre, les autres huiles fixes pour machines, conséquence des industries se créant dans le pays, sont en progression et la grosse part est pour la France.

Essences. - Les essences de roses et de géraniums proviennent plutôt de Constantine et sont achetées par les indigènes. La Tunisie est dans les meilleures conditions pour produire elle-même cet article.

Les gommes et résines, le benjoin, le baume et le camphre sont fournis en majeure partic par la France.

\section{BOIS}

La Tunisic est tributaire, pour les bois, des pays du centre de l'Europe, de l'Amérique et de Suède-Norvège. Chacun de ces pays lui adresse ses espèces particulieres. 
De Suède-Norvège elle reçoit les sapins; du Canada, les pichepins; Trieste nous envoie directement, ou par voie des grands spécialistes marseillais, ses merrains. Malte, où il n'existe pas un arbre, nous importe pour 65,000 fr., venant de Trieste ou de Russie, dont les sapins nous parviennent également.

En résumé, le commerce des bois est florissant en Tunisie et d'importantes maisons possèdent, non seulement ì Tunis mais dans diverses villes, de grands stocks. Les chemins de fer en construction prennent les traverses en Khroumirie, ce qui est une bonne fortune pour la Tunisie, sans quoi le chiffre des importations serait bien plus important.

TEINTURES ET TANINS

Teintures et tanins ont peu dimportance et nous arrivent en général de Marseille, quel que soit leur pays d'origine.

Foins et pailles ne sont demandés au dehors que dans les années de sécheresse.

\section{BOISSONS}

Vins ordinaires. - Sous la rubrique de vins ordinaires, il faut entendre les vins de toutes sortes en cercles ou en bouteilles, sauf les vins de liqueurs. La production de plus en plus grande du vignoble tunisien a fait baisser dans une notable proportion l'importation des qualités ordinaires. 
L'importation italienne, malgré ses bas prix, a perdu plus de 50 p. Ioo de son importance. La moyenne de ses importations de ISS5 à IS9I, de Soo, ooo fr. environ (exactement $\left.7 S_{3}, 264\right)$, n'est plus que de $429,502 \mathrm{fr}$. en I $S 94$, et I57,684 fr. en I 998 . Elle ne se maintient que par l'habitude de la colonie italienne de consommer ses vins à goût particulier. Bien des négociants les coupent déjà avec des vins du pays. Il est à présumer que les importations italiennes iront en diminuant de plus en plus.

Vins de liqueurs. - Pour les vins de liqueurs, la France tient de beaucoup la tête. I.'Italie est également en dimimution continuelle, les muscats de Tunisie remplaçant arantageusement les vins de liqueurs que nous pouvons importer.

Bières. - Les bières viennent de France et sont de bonnes marques. Les bières ordinaires sont produites dans le pays. Tunis possède deux brasseries bien outillées, fabriquant une bière légère, bonne pour la consommation de la place.

Eaur.-de-vie. - Les eaux-de-vie sont à peu près toutes de production française. Les marques supérieures dominent; vu le bas prix des alcools, les distillateurs trouvent plus avantageux de faire eux-mêmes leurs cognacs ordinaires. Les principales marques de rhum sont importées. Les tafias demandés sont presque tous à haut degré (de 78 is $S 0^{\circ}$ ).

En résumé, pour toutes les liqueurs, la France tient sans conteste le marché. Quelques marques étrangères seules trouvent preneurs en petite quantité. 


\section{II - MATIÉRES MINÉRALES}

MARBRES, PIERRES, COMBUSTIBLES, MINERAUX

Marbres. - De toute époque, le marbre a joui d'une grande vogue en Tunisie. Les admirables ruines de tous les âges, que l'on découvre sur tout le territoire de ce pays, en témoignent éloquemment. Ses carrières d'abord, sa proximité de l'Italie ensuite ont contribué à faire de cette matière, luxueuse pour d'autres pays, un article de consommation journalière et servant, vu le bas prix des sortes communes, à tous les usages.

Aujourd'hui, les palais sont peu nombreux, mais il n'est maison arabe un peu confortable dont l'intérieur ne soit revêtu de marbre blanc. Les maisons européennes ont en grande partie les escaliers en marbre et dans bien des cas le carrelage intérieur des appartements est fait de même. Les marbres de couleur sont destinés à des ouvrages plus artistiques.

L'Italie nous fournit les marbres. Constatons cependant que la Tunisie renferme de riches carrières de marbre, dont on a pu admirer les échantillons à l'exposition de Lyon; elles ne sont que peu ou pas exploitées en ce moment.

Ciments. - Les ciments nous viennent de France, particulièrement de Grenoble, de la Valentine et de l'Ardèche.

Chaux. - Les chaux, dont l'importation s'est élevée en I 898 à 250,23 I fr., sont des chaux hydrauliques. La Tunisie produit d'excellente chaux grasse, et des usines très 
importantes font de vigoureux efforts pour conquérir le marché intérieur.

Briques et tules. - Marseille est notre grand pourvoyeur pour les briques, il en est de même et d'une facon encore plus complète pour les tuiles. S'il n'y a pas augmentation pour ces deux articles (la moyenne de iSS; à I 944 est en chiffre rond $250,000 \mathrm{fr}$.; en $1898,252,142 \mathrm{fr}$.), c'est qu'ì Tunis, notamment, il s'est créé depuis quelques années plusieurs briqueteries importantes dont les produits, s'ils ne sont aussi irréprochables que ceux de Marseille, sont néanmoins appréciés.

Carreaux en terre et tn ciment comprimé. - Nous recerons de France les carreaux en ciment comprimé ou carreaux de terre émaillés en qualité supérieure, à dessins riches. Les modẻles courants sont fabriqués dans le pays.

La municipalité de Tunis a reçu pour la plus grande part, en I 893, les tuyaux en terre ou en ciment nécessaires pour la réfection de ses égouts; c'est pourquoi l'importation de cet article en I $_{93}$ est d'une importance particulière.

Honille. -- Les statistiques douanières nous indiquent 2, I09,S I 8 fr. comme total général des importations de charbon de terre de 188 ; it I 89 I, soit une moyenne annuelle de 300,000 fr.; la part de l'Angleterre était pour cette période de près des huit dixièmes, et des deux dixièmes pour la France. La moyenne des trois années $1 \$ 92,1893$ et I 994 accuse $560,000 \mathrm{fr}$. (importations totales, $1,682,652$ ).

L'Angleterre est comprise dans ce chiffre pour $922,+18$ francs, soit 44 p. I00. La France a livré, l'Algérie comprise, pour $590,580 \mathrm{fr}$, soit 35 p. I00. Il y a done pour 
cet article progression sérieuse de l'importation française. Les houilles passées par la voie algérienne sont pour le compte de la compagnie Bône-Guelma, en grande partie sinon en totalité.

METAUX

Or, argent, platine, tirés, laminés, filés. - La fabrique indigène de la bijouterie a été très florissante. La Tunisie fournissait non seulement sa nombreuse clientèle locale, mais exportait notamment en Algérie et dans l'intérieur de l'Afrique du Nord. A ce moment, les relations avec l'Europe étaient moins fréquentes; aujourd'hui, les produits européens font concurrence à l'industrie locale. Le montant des importations d'or et d'argent est d'un assez gros chiffre et presque tout à l'actif de la France, qui nous a adressé en I 898 pour $94,313 \mathrm{fr}$. d'or et 7, Soo fr. d'argent laminé, filé, en lingots ou en masse. Les filés servent à broder les costumes indigènes de toutes sortes.

Fontes de toutes sortes. - Par fontes de toutes sortes s'entendent les fontes brutes; nous trouverons les fontes ouvrées sous la rubrique "ouvrages en métaux». Il en est de même des autres métaux.

Rails. - Les rails de chemin de fer, dont le montant se chiffre par I 063,669 fr. pour I 893 -I $\$ 94$, et en I $\$ 98$ par I, 65 I, $835 \mathrm{fr}$., sont la conséquence des nouvelles voies ferrées en construction et ont été demandés ì la France.

Les autres métaux, fer-blanc, acier, cuivre, plomb, étain, nous viennent de la France. 
Les teintures diverses dont les indigènes font grand usage nous viennent presque toutes par la voie française, quelle que soit leur origine.

Il en est de même des ocres et vernis. Les indigos ont une séricuse plus-value en I 894 , en proportion, du reste, arec les importations des cotonnades qu'ils servent à teindre; leur chiffre d'importation s'élève en I $\$ 94$ a 23 I, 7 I 8 fr. contre $80,000 \mathrm{fr}$, en moyenne, pour les années $\mathrm{I} \$ 92$ et I $\$ 93$. En I $\$ 9 S$, il en a été exporté pour 229, I 42 fr.

\section{COMPOSITIONS DIVERSES}

Médicalinents composés. - La majeure partie des médecins exerçants étant Français, les produits pharmaceutiques viennent de la métropole.

Parfuntrie et savons. - La parfumerie, sauf les sortes absolument ordinaires, est livrée par les grandes fabriques parisiennes.

Les sarons, dits de Marseille, sont consommés exclusivement par la population européenne et plutôt française. Son chiffre peu important est la conséquence du bon renom du savon dit de Sousse, à base véritablement d'huile d'olive, très apprécié dans le pays et même en Algérie.

Bongies. - Marseille a presque le monopole de cet article 
en Tunisie. La Belgique a fait des efforts, mais ils n'ont pas abouti. Lyon et Montpellier ont quelques clients.

Glaces. - La France nous expédie les trois quarts des glaces entrant dans le pays et surtout les belles qualités. La Belgique a une tendance à augmenter ses importations, car de $6,403 \mathrm{fr}$. elle est montée à 10,802 fr. en I 898 , alors que les importations françaises restent dans la moyenne de $30,000 \mathrm{fr}$., exactement $27,919 \mathrm{fr}$. en 1898 .

Gobeleteric. - La gobeleterie de verre nous vient en partie de Bohême; services, vases, verres et carafes, verres de lampes surtout; mais de France nous viennent à peu près tous les autres articles. Le montant des importations reste à peu près stationnaire pendant ces trois dernières années.

Bouteilles. - L'importation des bouteilles s'est élevée de $5 \mathrm{I}, 36 \mathrm{I}$ fr. en I 892 à 68,592 fr. en I 894 , rien que pour la France. Les autres pays sont en baisse. De I3,502 fr. en I 892 , ils sont descendus à 6,784 fr. en 1894 . En I 898 , sur 53,985 fr. chiffre total, la France entre pour 39,3 I 7 fr.

Fils de laine. - Autrefois, l'Angleterre vendait en 'Tunisie la laine en masse, qui était filée dans le pays et servait à la fibrication des chéchias. Aujourd'hui, cette laine brute est remplacée par la laine mèche filée, que la France expédie et 
qui nous vient principalement de Tourcoing, ce qui simplifie la fabrication des chéchias, du reste en complète décroissance par suite des importations curopéennes en cet article.

\section{TISSUS}

Tissus de chanz're, de lin et de jutc. - La France prend le dessus pour les articles fabriqués, surtout dans la toilerie fine, la toile pour ameublement, etc.

Tissus de soie. - - La France, dont le chiffre est le plus éleré, nous adresse l'article soigné, quel qu'en soit le genre.

Tissus de laine. - Un des importants articles en tissus de laine consiste en draps molletons destinés aux costumes des Arabes et des israćlites indigènes.

L'importation de cet article est très considérable et scrait rémunératrice pour l'industrie française.

La part dela métropole reste satisfaisante, elle nous fournit en majeure partie les belles qualités des tissus en laine importés en Tunisie.

\section{PAPIER ET SES APPLICATIONS}

Cartons, papier, livres, gravures et cartes à jouer sont importés de France. L'Italie a contre-balancé un moment la France pour le papier paille et en cet article son importation est encore assez forte; mis actuellement les fabricants de l'Isère et de l'Ardeche ont repris le dessus.

Les papiers à écrire d'Italie sont de qualité inférieure et peu appréciés; il en est de même des registres. 
La France importe lis plus grande quantité de peaux et pelleteries ouvrées, ouvrages en peau et en cuir.

L'Algérie nous importe des cuirs de chèvres dénommés " filali » et venant du Maroc; l'Égypte et la Turquie, des "kaisserié ", cuirs teints venant de Syrie ainsi que de Tripoli. Les cuirs de ces pays sont destinés aux chaussures arabes.

\section{OUVRAGES EN MÉTAUX}

Orfivrerie d'or, a'argent, de vermeil et de platine. - Ces trois dernières années montreint une progression sensible dans les importations françaises.

Par colis postaux et par boites postales, il arrive des quantités de bijoux dont il est impossible de déterminer la part restant dans le pays. Ces envois constituent en général des envois conditionnels dont un partie fait retour à l'envoyeur après choix faits. Mentionnons que si la bijouterie ordinaire, apparente, trouve facilement preneur, quelques maisons à Tunis peuvent lutter pour la richesse de leurs collections avec les bonnes maisons de France.

Machines et mécaniques. - Machines et mécaniques de toutes sortes constituent un important article dont le chiffre vil toujours en augmentant, ce qui démontre les progrès de l'industrie et de l'agriculture en Tunisie.

C'est à la France que nous nous adressons pour la plus grande partie de cette fourniture.

Fonte et ferronneric. - Il en est de même four les ouvra- 


\section{42}

L. TƯNISIE.

ges de fonte et la ferronnerie dont les quantités fournies par les pays étrangers sont à peu près insignifiantes, soit d'un dixième environ. Les importantes canalisations des villes de Tunis, Sousse, Sfax, Gabès notamment, ont donné ì ces articles une importance réelle et tout au bénéfice de l'industrie française.

Contellerie. - La plus grande part vient de France.

Serrurcrie. - Les articles ouvrés en métaux, fer, acier, cuivre ou plomb, sont pour la plus grande partie de fabrication française.

\section{OUVRAGES EN BOIS}

Les futailles vides montées ou démontées comprennent foudres ou cuves, achetés aux grands chantiers de France par nos viticulteurs. Les autres ouvrages en bois comprennent la robinetterie, les tamis, toupies, etc., tous articles désignés généralement sous le nom d'articles de SaintClaude.

OUIRAGES DE SPARTERIE ET V.ANERIE

Tripoli nous importe des sparteries très appréciées des indigènes et dont les étrangers font volontiers collection dans les souks de Tunis.

Nous disons du chapeau de paille ce que nous dirons du chapeau de feutre : ce sont les fabriques françaises qui nous approvisionnent. En somme, la vannerie est presque tout entière à l'actif de la France. 
Carrosserie de toute sorte. - Tunis est une des villes où les voitures de place sont le plus luxueuses par suite de l'émulation qui règne entre les loueurs.

Il y a quelques années, la carrosserie était ici très florissante. Mais il y a lieu de croire, d'après le tableau des importations depuis I 892 , que les grandes fabriques spéciales (de Marseille notamment) augmenteront encore leurs relations avec 'Tunis.

Chapeaux de feutre. - La plupart des chapeliers de Tunis sont Italiens. Il a été constaté, factures en mains, que la fabrication française avait leur préférence.

Tabletterie. - La tabletterie nous vient pour moitié environ de France.

La brosserie vient du nord de la France.

Bimbeloterie. - La bimbeloterie et la tabletterie atteignent un chiffre d'une assez grande importance, $234,956 \mathrm{fr}$. en I 898, sur lequel chiffre la France est comprise pour I97, $883 \mathrm{fr}$.

Parasolerie. - La parasolerie fine ainsi que le parapluie nous viennent de France.

Lingerie. - La lingerie est un article essentiellement français; aussi tout article un peu soigné nous arrive-t-il de la métropole. En dehors du commerce de gros, de nombreux voyageurs de Grenoble, Lyon et Toulouse parcourent le pays en détail avec des collections d'échantillons. 
Vètements confectionnés. - L'importation totale, de $367,+36 \mathrm{fr}$. en 1892 , s'est élevée en i 898 à $526,739 \mathrm{fr}$.

La France figure dans ce chiffre pour 390,0 $2 \mathrm{fr}$.

$\therefore$ - autres ouvrages eN matiéres diverses

Il s'agit ici de la valeur totale des colis postaux dont le développement prend une grande extension au détriment, il faut bien l'avouer, du commerce local. C'est li une conséquence économique de la multiplicité des relations et des facilités de correspondance et d'envoi.

En I 898 , les importations par colis postaux accusent une valeur de 2,431,506 fr. dans laquelle la France entre pour $2, \mathrm{I} 94,3$ So fr. 


\section{- CHAPITRE XXII}

MOUVEMENT DU COMMERCE ET DE LA NAVIGATION

DANS LES PRINCIPAUX PORTS

Le mouvement du commerce maritime de la Tunisie a, depuis I 885 , subi d'assez nombreuses fluctuations qui marquent dans leur ensemble une progression constante.

Les 4 tableaux graphiques ci-après ${ }^{1}$ montrent très clairement ces fluctuations de I 885 à i 898 en faisant ressortir la part dans le mouvement commercial des principaux pavillons fréquentant les ports tunisiens.

Le second tableau montre que le mouvement général des importations a été constamment en s'augmentant au fur et à mesure que se développait le pays. De I25,000 tonneaux en I 885, il dépasse aujourd'hui les 300,000 tonneaux et le pavillon français a la plus forte part dans cet accroissement.

Mais si les courbes représentant l'importation présentent une grande irrégularité d'allure, il est loin d'en être de même des courbes du $3^{e}$ tableau (exportation des marchandises). Ces courbes présentent une série de pointes très marquées, mais leur ensemble fait également voir une tendance incontestable à l'accroissemene des exportations. Le pavillon français a d'ailleurs l'entier bénéfice de cette augmentation de trafic.

1. Ces tableaux sont les tableaux no I, II, III et IV. 
TONNAGE DE JAUGE PAR

DES NAVIRES EN PROVENANCE DIRECTE DE FRANCE

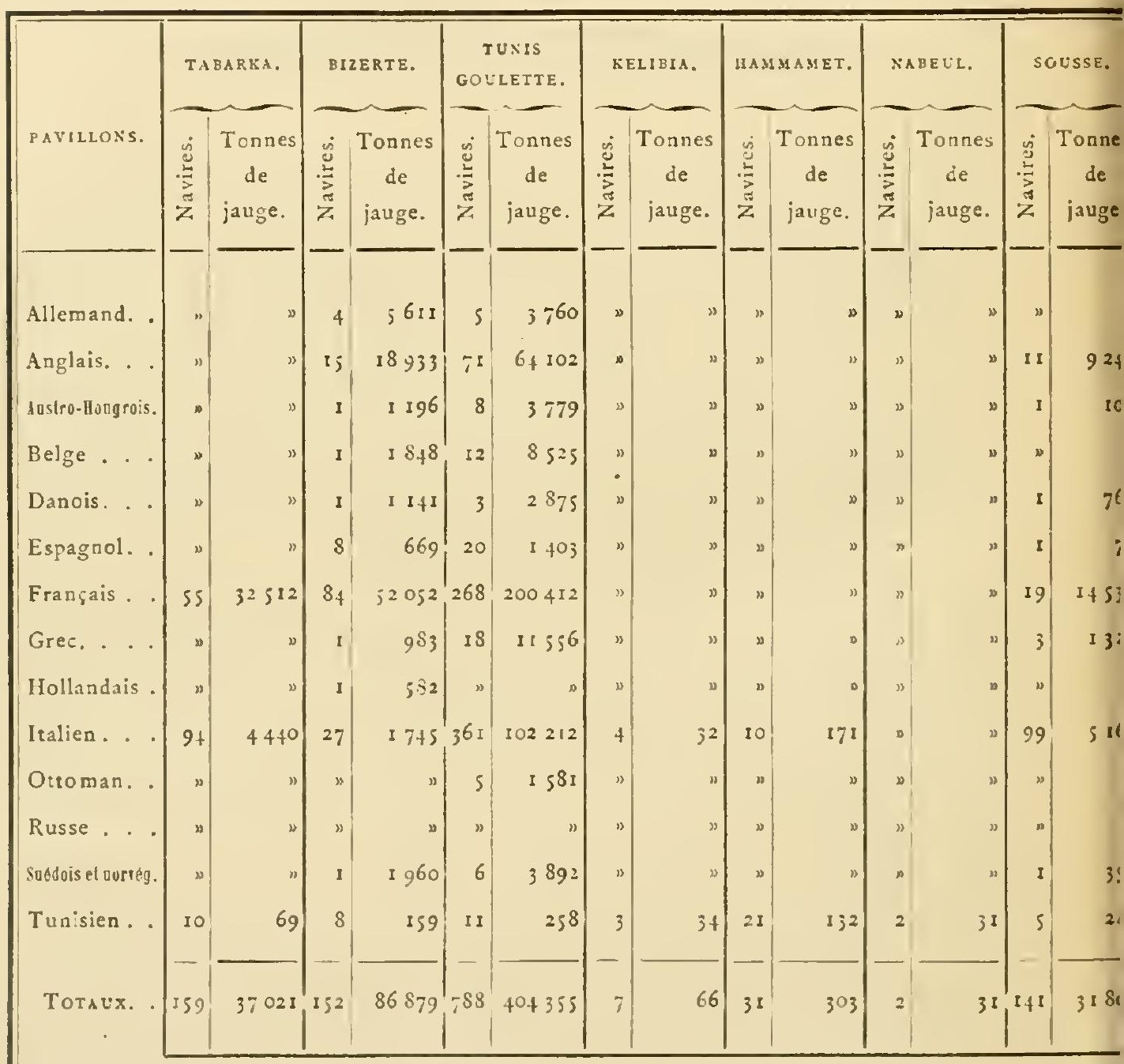




\section{ORT ET PAR PAVILLON}

DU DES PAYS ÉTRANGERS PENDANT L'ANNÉE I898

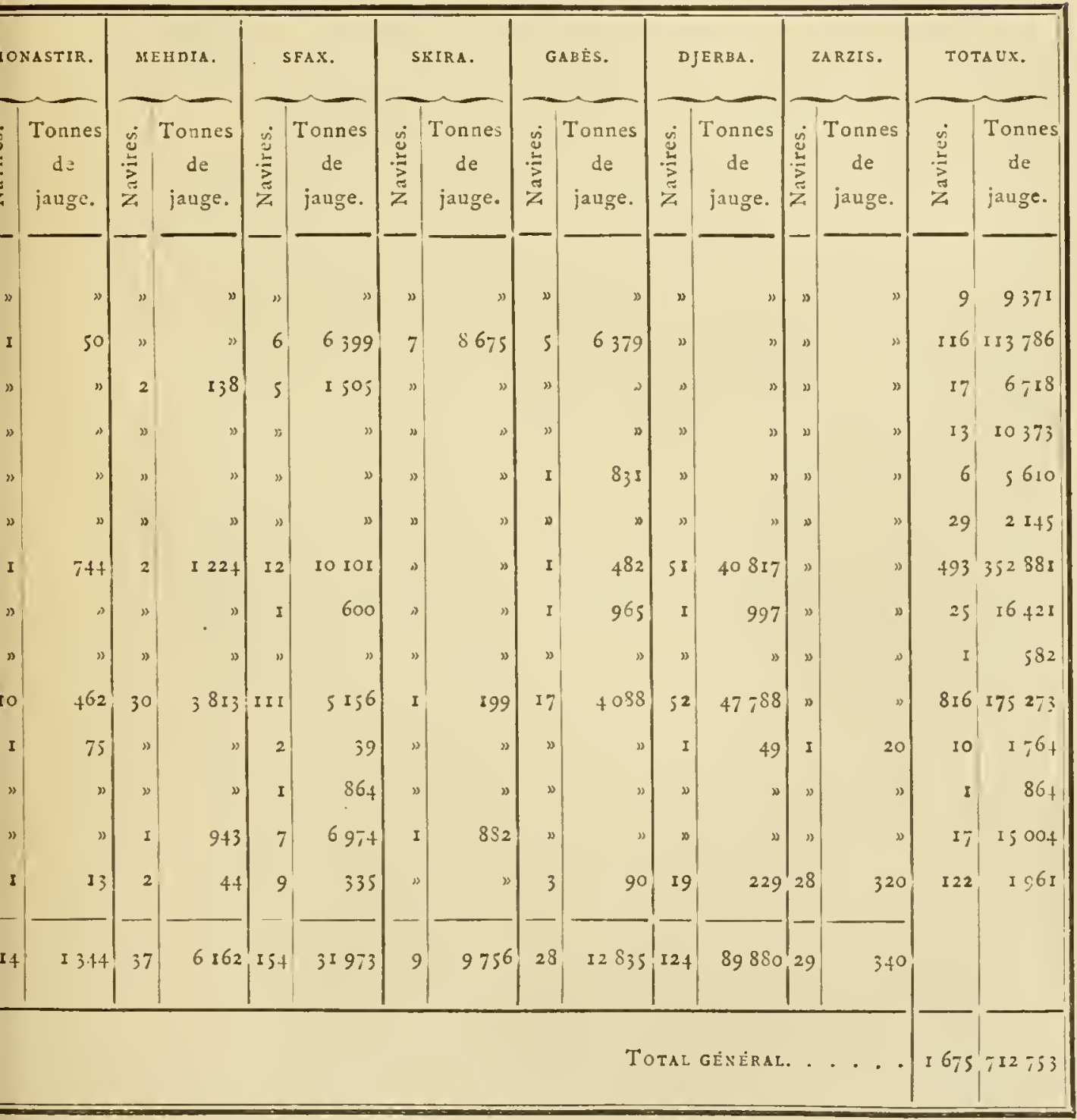


L'irrégularité des courbes du mouvement d'exportation s'explique aisément par la nature très spéciale de ces expor. tations. La Tunisie est à peu près exclusirement agricole et, suivant que la récolte est bonne ou non, les produits du sol s'exportent ou sont presque entièrement consommés sur place; de lia ces variations considérables dans les exportations. Le développement agricole de la Régence s'affirme trés nettement par l'allure ascendante de la courbe.

Le $4^{\text {e }}$ tableau, qui résume les précédents, montre le développement rapide du commerce général qui, de 200,000 tonnes en ISS 5 , atteint 562,000 tonnes en I 998 . Il a donc presque triplé en I 4 ans. La part du pavillon français devient de plus en plus prépondérante : de 60,000 tonnes en IS85, elle dépasse 264,000 tonnes en IS9S, ayant ainsi plus qua quadruplé.

Le tableau des pages 146 et I 47 donne le mourement par port et par pavillon du commerce général en $\mathrm{I} \delta 98$, ce qui permet de se rendre compte de l'importance actuelle de chaque port. 
MOUVEMENT DU COMMERCE ET DE LA NAVIGATION. I 49

COMPARAISON DU MOUVEMENT DES PASSAGERS ET DES MARCHANDISES POUR L'ENSEMBLE DES PORTS DE LA RÉGENCE pendant les quatorze dernières années

I

Entrées

PASSAGERS

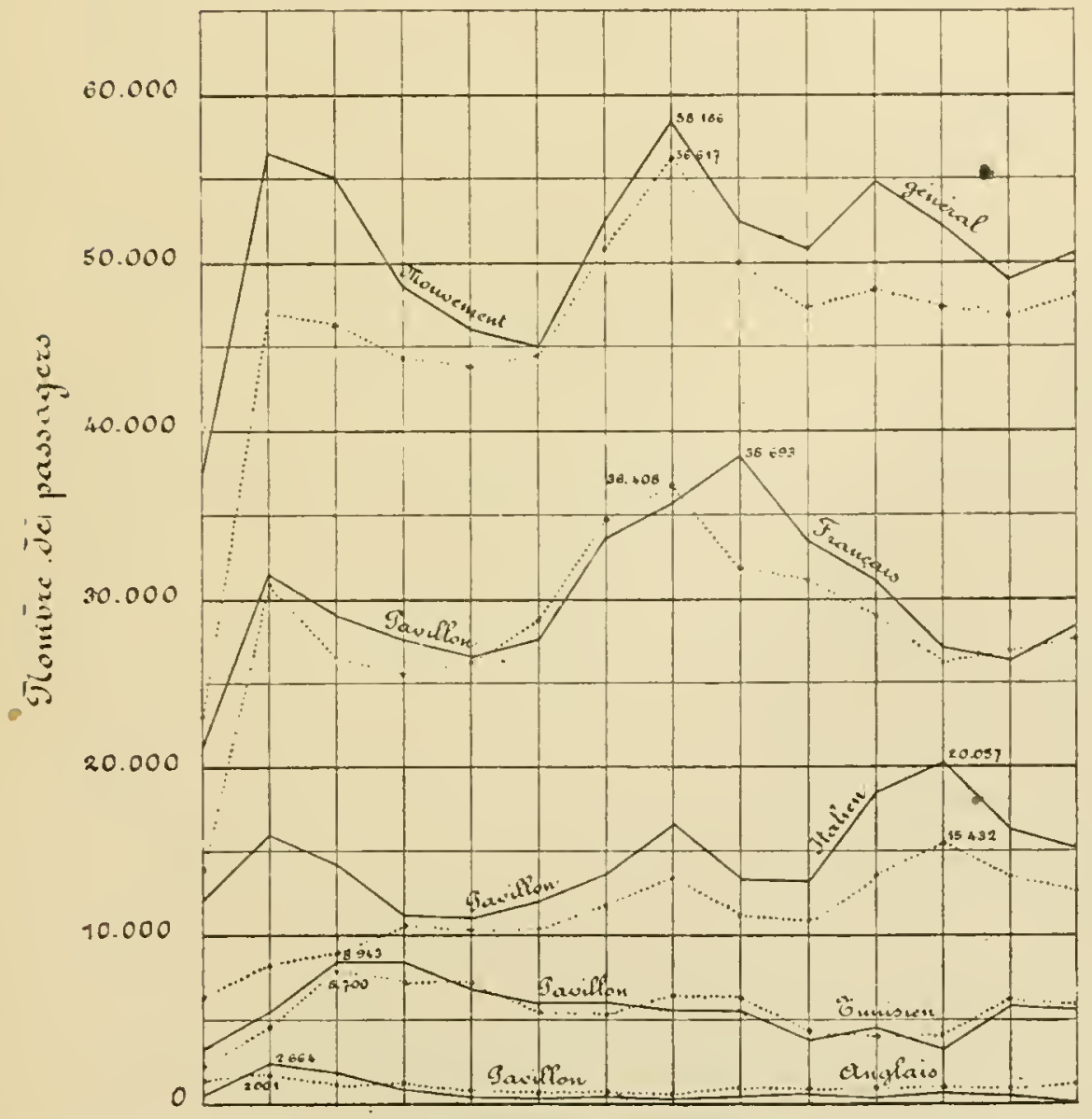

$\begin{array}{llllllllllllll}\text { Qunies } 1885 & 86 & 87 & 88 & 89 & 90 & 91 & 92 & 93 & 94 & 95 & 96 & 97 & 1898\end{array}$ 
COMPARAISON DU MOUVEMENT DES PASSAGERS ET DES

pendant les quatorze II

MARCHANDISES

Entrées

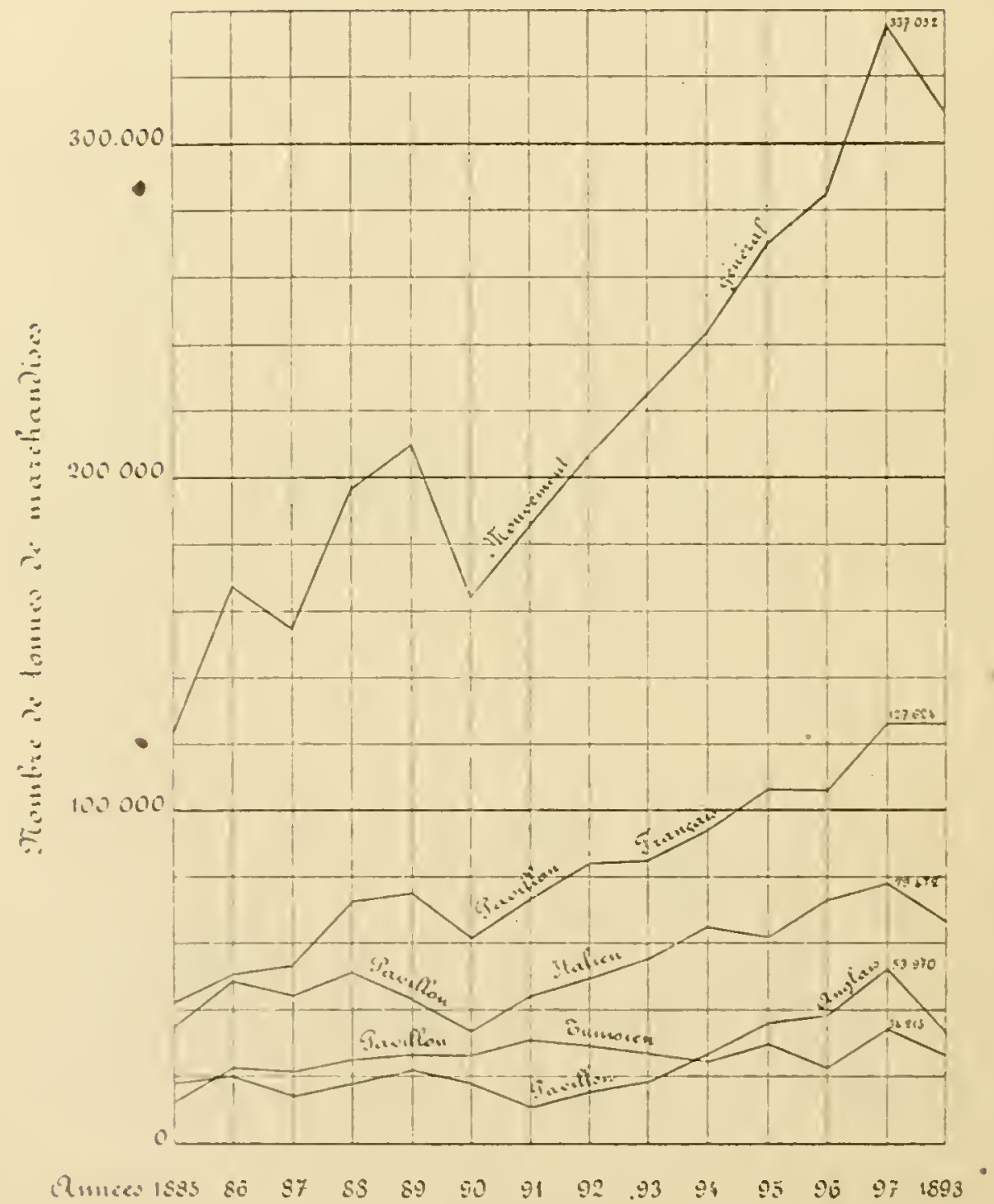


MOUVEMENT DU COMMERCE ET DE LA NAYIGATION. ISI

MARCHANDISES POUR L'ENSEMBLE DEŚ PORTS DE LA RÉGENCE dernières annẻes

III

\section{MARCHANDISES}

Sorties

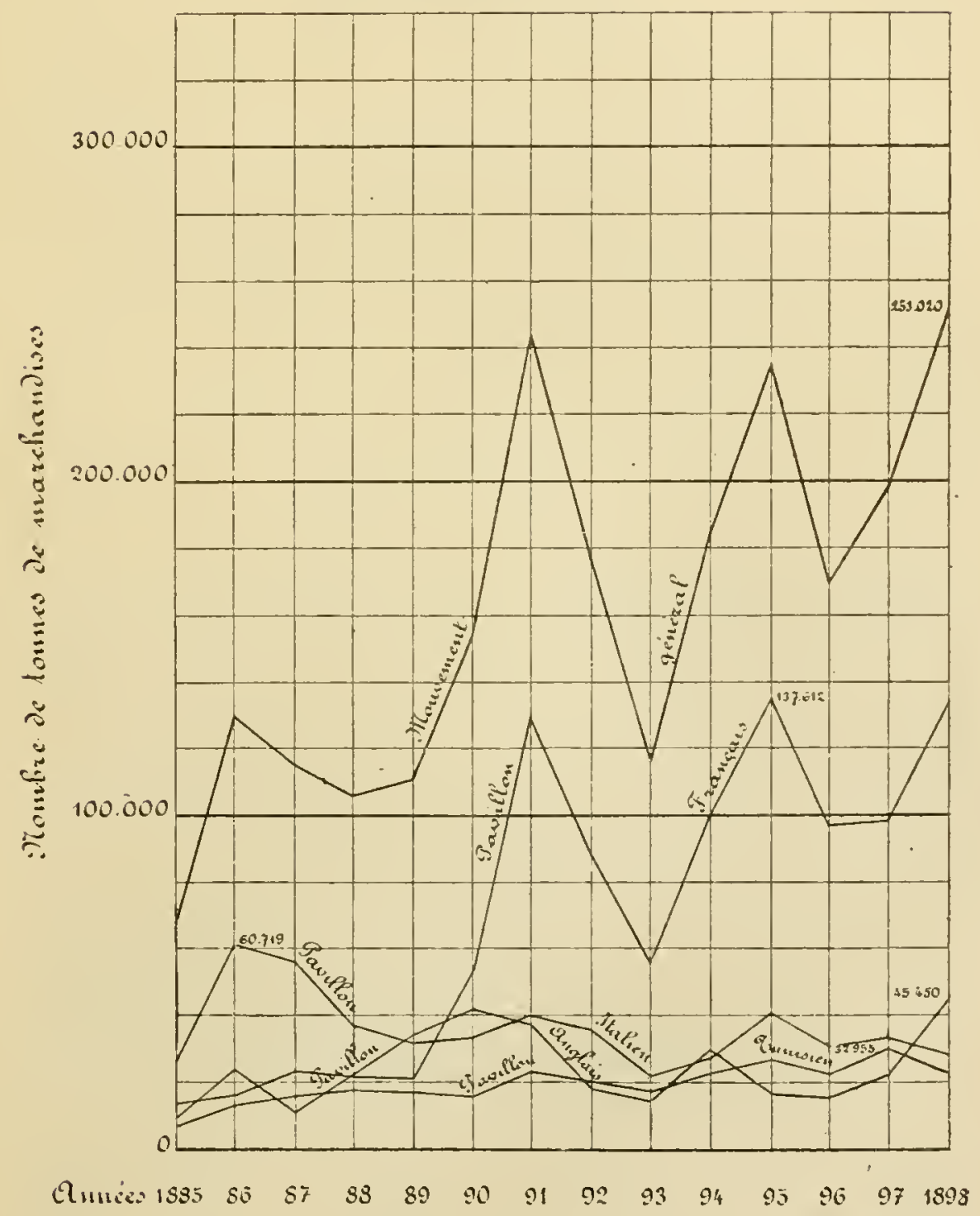


COMPARAISON DU MOUVEMENT DES PASSAGERS ET DES MARCHANDISES POUR L'ENSEMBLE DES PORTS DE LA RÉGENCE pendant les quatorze dernières années

IV

\section{MARCHANDISES}

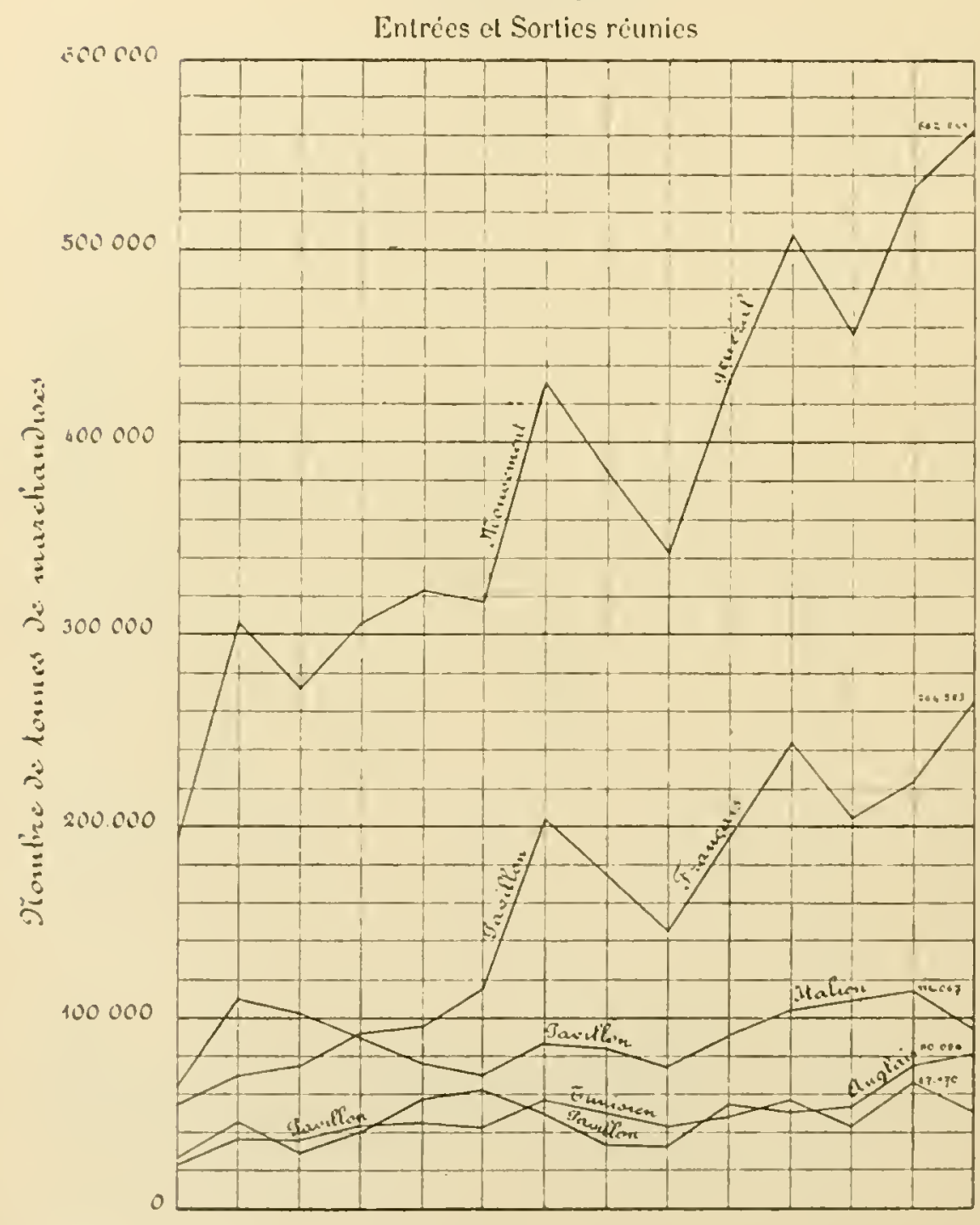

$\begin{array}{llllllllllllll}\text { Qunuew } 1885 & 86 & 87 & 58 & 58 & 90 & 91 & 92 & 93 & 94 & 95 & 96 & 97 & 1898\end{array}$ 


\title{
QUATRIEME PARTIE
}

\section{Finances}

\author{
CHAPITRE XXIII \\ LES FINANCES TUNISIENNES
}

HISTORIQUE

La suite de toutes les affaires concernant les finances de la Régence appartient à la direction générale des finances.

Cette direction générale, dont relèvent tous les agents des finances quel que soit leur grade et à quelque service çu'ils appartiennent, a été créée par un décret beylical du 4 novembre I 882 , mais elle n'a été complètement organisée qu'en I 884, comme conséquence de l'établissement du protectorat de la France en Tunisie, et dès la suppression de la commission financière qui fonctionnait depuis 1870 . Pour bien comprendre son organisation, il est nécessaire de connaitre le régime financier de la Tunisie antérieurement à I 884 .

A cet effet, deux périodes sont à considérer : la période antérieure à I 870 et la période de I870 à I 884 . 
Cette période a été marquée par la maissance de la dette tunisienne et le développement excessif qu'elle a pris en quelques années. En i 860 , elle n'était que de i i $, 875,000 \mathrm{fr}$. Dix ans après, elle était de $169,000,000$ de francs, et elle exigeait un service d'intérêts de 19,500,000 fr., supérieur de 6,000,000 de francs aux rerenus du Gouvernement. Il ne faut pas chercher les causes de cet accroissement rapide et extraordinaire de la dette ailleurs que dans l'exagération des dépenses publiques. Le pays avait, en effet, une organisation à peu près régulière, dont on aurait pu tirer de bons effets avec une stricte application des principes sur lesquels elle reposait. Mais le gouvernement ne sut pas toujours se renfermer dans les limites de ses revenus, $e_{i}$, en outre, la facilité avec laquelle il trouva à emprunter pour faire face ì ses premiers déficits l'incita encore aux prodigalités les plus excessives. Devant le fardeau croissant de la dette et les réclamations de ses créanciers, le gouvernement. beylical dut reconnaitre l'impossibilité de suffire ì ses charges avec ses ressources. Sur la recommandation de la France, de l'Angleterre et de l'Italie, il consentit, par un décret du 4 avril I 868 , à l'institution d'une commission financière internationale et lui confia la mission de reviser, de liquider et de réduire son passif.

\section{PÉRIODE DE $\quad$ IS $S_{7 O}$ A I I $S S_{+}$}

La commission financière fut défnitivement organisée par un décret du 5 juillet I 869 . Elle était présidée par le pr:mier ministre du Bey, assisté ou suppléé par un inspec- 
teur des finances françaises; elle se divisait en deux comités distincts : le comité exécutif et le comité de contrôle.

Le comité exécutif, compose de deux fonctionnaires tunisiens et de l'inspecteur des finances français, fut chargé de dresser l'état des dettes et celui des ressources de la Régence.

Le comité de contrôle, composé de deux membres français, de deux membres anglais et de deux membres italiens, reçut la mission de vérifier les opérations du comité exécutif et de leur conférer par son approbation la force exécutoire.

Le comiré exécutif se mit résolument à l'œurre; après avoir dressé le budget du gouvernement, il impartit un délai aux créanciers de la Régence pour produire leurs titres de créance et procéda à la vérification de ces titres. Tous les créanciers qui ne produisirent pas dans le délai fixé, ou dont les titres ne furent pas rcconnus valables, se trouvèrent frappés de déchéance. Quant aux créances reconnues, elles furent fusionnées et leurs porteurs admis, au prorata de leur montant, à la répartition des revenus que, d'accord avec les trois gouvernements de France, d'Angleterre et d'Italie, le Bey jugea possible d'abandonner ì ses créanciers, ne conservant pour lui-même que les ressources strictement nécessaires au fonctionnement des services publics les plus essentiels.

La portion des créances non admise à la répartition se trouva de la sorte éteinte.

Par l'effet de cette liquidation et de ce concordat, la dette, qui était auparavant de 169 millions, fut ramenée ì 143 millions, dont i 25 millions pour la nouvelle dette consolidée et I 8 millions de certificats de coupons arriérés.

Les revenus innuels affectés au service de la dette, et 
qui servirent de base à ce concordat, furent fixés à 6 millions et demi, soit à la moitié des revenus de la Régence. Ils furent concédés aux créanciers, qui reçurent en même temps le pouvoir de les percevoir et d'en employer directement le produit tant aux frais d'administration et de perception qu'au service des intérêts et éventuellement de l'amortissement de la dette. Cette gestion fut confiée, pour le compte des créanciers, à un conseil d'administration dit des revenus concédés, composé de cinq membres et placé sous le contrôle et la surveillance du comité exécutif.

Le comité exécutif conserva, d'autre part, la suite directe de la gestion des revenus réserrés au gouvermement.

Cette organisation fut soumise au Bey par la commission financière, avec l'adhésion des trois gouvernements de France, d'Angleterre et d'Italie. Elle fut définitivement sanctionnée le 23 mars is 70 . L'accord qui le constate a reçu le nom "d'arrangement du 23 mars i 870 ». Cet arrangement a constitué la charte financière de la Tunisie jusqu'en r 884.

La commission financière se trouva ainsi investie de la direction et du contrôle de toutes les finances tunisiennes, sans distinction entre celles déléguées aux créanciers et celles conservées par le gouvernement. Son œuvre a été considérable: pendant quatorze ans, elle obligea les administrations placées sous sil miln à renfermer leurs dépenses dans les limites de leurs revenus, et lorsque, le I 3 octobre 1884 , à sa suppression, elle remit son service à la direction des finances, la dette de la Régence n'était, comme en i 870 , que de 43 millions de francs environ.

Mais son mérite le plus grand fut d'aroir liquidé le passif antérieur à son institution, et opposé aux revendications 
des créanciers qui n'avaient pas produit en temps utile, ou dont les titres avaient été insuffisants, une barrière insurmontable dont la légalité a été reconnue par la jurisprudence constante des tribunaux français et tunisiens. Elle a permis ainsi à la nouvelle administration d'entreprendre, en $188_{4}$, sa tâche de réformes sans avoir à se préoccuper d'un passé définitivement réglé.

\section{ORGANISATION FINANCIERE.DE ISSA}

La commission fin.uncière, quelle que fût son utilité pour la Tunisie, était fatalement appelée à disparaitre le jour où, par suite d'un changement politique, le gouvernement du Bey ressaisirait sa liberté d'action. Cette éventualité s'est produite lorsqua, à la suite de l'établissement du protectorat de la France en Tunisie, le gouvernement françalis et le gouvernement tunisien eurent signé la convention du 8 juin I 883. Aux termes de cette convention, le gouvernement de la Régence prenait l'engagement de procéder aux réformes administratives, judiciaires et financières jugées utiles par le gouvernement français; la France s'engageait, de son côté, à garantir la dette tunisienne.

Par l'effet de cette garantie, les créanciers que représentait la commission financière se trouvèrent définitivement assurés du paiement de la dette. lls n'eurent plus, dès lors, de motifs pour maintenir les finances tunisiennes sous leur contrôle. Il ne leur resta plus, par suite, qu’à renoncer aux privilèges spéciaux que leur avaient conférés les arrangements du 25 mars I 870 .

Aussi, la commission financière n'hésita pas à se retirer d'elle-même, et, le 2 octobre I884, un décret du Bey, consacrint sa suppression, ordonna la remise de tous ses ser- 
rices à la direction généra'e des finances, déjà créée dès le 4 novembre $1 \$ S_{2}$, en prévision de cette éventualité. Cette remise a eu lieu à la date du I 2 octobre $188_{+}$au soir : c'est donc à partir du lendemain I; octobre I884 qu'a commencé à fonctionner la nouvelle organisation financière de la Tunisie.

Le directeur des finances était alors M. Depienne, inspecteur de l'administration française des finances, qui exerçait en 'Tunisie, depuis $1 \$_{77}$, les fonctions de vice-président de la commission financière. Son premier acte fut de fusionner les attributions de la commission financière et celles confiées en ISS2 à la direction des finances. Cette fusion donna naissance aux services suivants, placés sous l'autorité du directeur des finances :

I Le service central;

$2^{\circ}$ La recette générale des finances;

$3^{\circ}$ La direction des contributions direrses;

$4^{\circ}$ La direction des douanes;

$5^{\circ}$ Le service des recolivrements de l'impót direct confié aux caids et aux cheilihs;

$6^{\circ}$ Le service des recouvrements des produits domaniaux, confié à Tunis à un administrateur des domaines et, à l'ıntérieur de la Régence, aux cailds et aux cheilihs.

Plus tard, la direction générale des finances s'accrut :

$7^{\circ}$ Du service de la conservation de la propriété foncière, chargé de l'application de lat loi du rer juillet isS sur les immatriculations ;

go De la direction des monopoles, créée à partir du

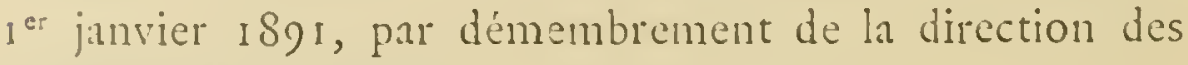
contributions diverses.

Chacune des régies relevant de lib direction générale a des attributions propres, mais dans la pratique elles se prê- 
tent les unes aux autres un concours incessant et illimité, et c'est un principe que les agents d'une quelconque de ces régies peuvent êtré, suivant les nécessités du service, chargés d'attributions incombant à d'autres régies. En un mot, l'ensemble des services de la direction générale des finances forme une seule administration dirigée, sous lia haute autorité du directeur des finances, par des directeurs techniques et dont les agents d'exécution relévent indistinctement de tous ces directeurs, suivant les attributions qui leur sont confiées.

ATTRIBUTIONS DE LA DIRECTION GÉNÉRALE DES FINANCES

RËGLE.MENT QUI RËGIT CES AITRIBUTIONS

La direction générale des finances est chargée:

$I^{\circ}$ De la perception de tous les revenus de l'État tunisien sauf les produits des postes et télégraphes, directement perçus par l'office;

$2^{\circ} \mathrm{Du}$ paiement de toutes les dépenses publiques tunisiennes;

$3^{\circ}$ De tous les services de trésorerie du Trésor tunisien;

$4^{\circ}$ De la vérification des caisses et écritures des receveurs municipaux et des receveurs des établissements publics;

$5^{\circ}$ Depuis le $1^{\text {er }}$ janvier i 898 , des recettes et des dépenses du Trésor français ailleurs qu'à Tunis.

La direction générale des finances assure les recouvrements et effectue les dépenses sous le contrôle du résident général à Tunis et du ministère des affaires étrangères. Son fonctionnement est d'ailleurs rég'é par les décreis bey'icaux des 12 mars et 19 décenbre $I S S_{j}, S$ novembre $I 8 S_{+}$et 
I6 décembre 1890 , qui subordonnent à la promulgation d'un budget annuel toutes les opérations de recettes et de dépenses du gourernement tunisien.

Le budget tunisien commence le I er janvier depuis I $\$ 92$; il est désigné par le millésime de l'année grégorienne avec laquelle il s'ouvre. Autrefois, il commençait le i 3 octobre et recevait son nom du millésime de l'année de l'hégire au cours de laquelle il prenait naissance. L'organisation financière actuelle, qui a commencé a fonctionner le i 3 octobre I $88_{4}$, s'est ouverte au cours de l'année musulmane I 301, puisque le I 3 octobre I $\$ 8+$ correspond au 23 hidjé I 30 I. Le budget commencé le I 3 octobre I $S S_{4}$ aurait dû régulièrement porter le nom de budget de I 30 I; mais il a paru préférable de lui donner le nillésime de l'année musulmane I 302, qui devait commencer sept jours après, et il n'y a pas ell, par suite, de budget de i jor.

Les budgets suivants ont continué à être désignés par le millésime de l'année musulmane ( 303 , I 304 , etc.) jusques et $\mathrm{y}$ compris le budget de $\mathrm{I}$ joS, dont la durée normale (I 3 octobre I $\$ 90-12$ octobre IS9I) a été prolongée à titre exceptionnel jusqu'au 3 I décembre i $\$ 9$. Le lendemain, $I^{\text {er }}$ janvier I $\$ 92$, a commencé le premier des budgets désignés par le millésime de l'année grégorienne.

La durée du budget (ou exercice) est, comme en France, de scize mois, tant pour les recettes que pour les dépenses; c'est-ì-dire que les opérations du budget se prolongent jusqu'au 30 avril de l'année suivante.

Le budget tunisien est préparé par le directeur des finances, qui, après avoir établi personnellement les évaluations de recettes, en rapproche les prévisions de dépenses établies pour chaque service public par le chef de ce service. Le budget est ensuite délibéré en Conscil des ministres, sous 
la présidence du résident général, soumin au gouvernement français, présenté ensuite à la sanction de S. A. le Bey, et finalement promulgué au Journal officiel. Il peut être rectifié, s'il y a lieu, dans le cours de l'exercice, d'après les formes suivies pour son établissement.

Le budget des recettes est établi en faisant état de tous les impôts existants ou décidés en principe. Leur produit probable pendant la durée du budget est évalué d'après les résultats moyens des icinq budgets antérieurs, augmentés ou diminués des sommes que les réformes ou les dégrèvements projetés peuvent rapporter ou faire perdre au Trésor. Aucun impôt ne peut être établi ni perçu s'il n'a été proposé par le Conseil des ministres et chefs de services, auto. risé par le gouvernement français et sanctionné par S. A. le Bey.

Les prévisions des dépenses sont établies d'après les besoins probables des services publics pendant l'année du bud. get. Aucune dépénse ne peut être faite, engagée ou payée si elle n'a été prévue au budget annuel.

Aưcun crédit ne peut être ouvert en cours d'exercice sur les ressources générales du buidget. Si des dépenses imprévues, mais d'un caractère ordinaire, se présentent, il y est fait face au moyen d'un prélévement sur les ressources d'un chapitre spécialement ouvert pour cet objet par les lois annuelles de finances et qui est doté, depuis I 887 , d'une somme de 360,000 fr. S’il échet de faire face à des dépenses exceptionnelles et extraordinaires, le décret d'ouverture de crédit doit être rendu dans la forme prévue pour le budget et faire mention des ressources extraordinaires existantes sur lesquelles il sera prélevé. C'est à l'observation rigoureuse de cette règle tutélaire, qui n'a jamais été enfreinte, qu'est due la bonne gestion financière de l'administration du protectorat. 
Dans les trois mois qui suivent la clôture de l'exercice, le directeur des finances dresse les tableaux des recettes et des dépenses dudit exercice, lesquels sont, après examen en conseil des ministres et chefs de services sous la présidence du résident général, présentés à la sanction de S. A. le Bey, qui les arrête par décret.

Les créances restant à recouvrerà la clôture de l'exercice, d'après le rìglement du budget, sont reportées à l'exercice courant et s'ajoutent à ses propres crémees en vue de leur recouvrement sur les débiteurs du Trésor.

Les sommes restant dues aux créanciers de l'État il la clôture de l'exercice et liquidées par le tableau de règlement des dépenses sont appelées dépenses d'exercice clos; elles sont payces sur l'exercice suivant, par imputation sur des crédits ouverts à cet effet dans chaque budget. Ces créances d'exercices clos peuvent être, à défaut de payement, reportées ainsi d'exercice en exercice jusqu'au moment où la loi les déclare prescrites et définitivement éteintes au profit de l'État.

Cette déchéance a pour objet de mettre l'État, qui n'a que des ressources annuelles limitées aussi strictement que possible à ses besoins, à l'abri de revendications anciennes accumulées qui auriant pour effet de faire supporter par la génération présente les charges du passé; clle a été édictée cn 'Tunisie par les articles 43 et suivants du décret beylical du 12 mars I 883 ; elle est d'ordre public, et les créanciers déchus ne peuvent en être relevés que s'ils fournissent la preuve que le défaut d'ordonnancement et de paiement de leurs crénnes ne leur est pas imputable et que, ou bien il provient du fait de l'administration, ou bien il a été empêché par des actions judiciares.

Le délai de déchéance court à partir du jour de l'ouver- 
ture de l'exercice auquel appartient la créance; il est de cinq ans ou de six ans, suivant que le créancier est domicilić en Tunisie ou hors du territoire tunisien.

DIVERSES SOURCES DE RECETTES DU TRÉSOR BEYLICAL

Les recettes du gouvernement tunisien se divisent en recettes ordinaires, recettes extraordinaires et recettes spéciales.

10 Ressources ordinaires.

Les recettes ordinaires sont de cinq sortes : les impòts directs, les impôts indirects, les produits des monopoles et exploitations industrielles de l'État, les produits et revenus du donaine public et du domaine de l'État, et les produits divers.

\section{IMPÓTS DIRECTS}

Les impôts directs se divisent en quatre catégories :

La première, composée de trois taxes qui frappent directement le contribuable dans sa personne: la medjba, la prestation et la tase de routes;

La seconde, comprenant les cinq taxes assises directement sur les biens fonciers : oliviers et dattiers (kanoun ou dime), terres ensemencées en céréales (itchour), terrains maraichers et vergers (mradjas et khodors), et les propriétés bâties (caroube sur les loyers ou la valeur locative des dites propriétés);

La trọisième comprenant l'impôt des patentes. 
Medjua: - A l'exception des autres impots, qui frappent tes Européens aussi bien que les indigènes, la medjba, impot personnel et de capitation, ne s'applique qu'à ces derniers. Elle est due par tous les sujets tunisiens mâles, sauf ceux nés et résidant à Tunis, Sousse, Kairouan, Monastir et Sfax, et par tous les musulmans établis dans la Régence. Les causes d'exemptions sont définies par le décret du 25 mili I 7 I et par diverses décisions subséquentes. L'administration du protectorat s'attache à ce qu'elles ne soient pas abusivement étendues. Ses efforts n'ont pas été sans succès, puisque le nombre des cotes, qui était de I90,000 il $\mathrm{y}$ a douze ans, est aujourd'hui de 277,500 .

Le taux de la medjba a été de 24 fr. jusqu'à la fin de I $\$ 92$. Il a été abaissé à $22 \mathrm{fr}$. en I $\$ 93$, et depuis le $\mathrm{I}^{\text {er }}$ janvier I 894 il n'est plus que de $20 \mathrm{fr}$. En sus de ce principal, l'impôt comprend des frais accessoires : la remise des collecteurs, qui est de $2 \mathrm{fr}$. $30 \mathrm{c}$., et le droit de timbre de o fr. $20 \mathrm{c}$.

La medjba est due en un seul terme dès le I I $^{\text {er }}$ janvier. Toutefois, dans la pratique, les collecteurs sont autorisés à accepter des acomptes.

Prestation et taxe spéciale de routes. - En vertu d'anciens usages rappelés: dans les considérants du décret beylical du I 2 avril I 897 , il a toujours été pourvu en Tunisie au développement et à l'entretien des chemins au moyen des prestations en nature.

L'organisation de ces prestations a été réglementée par un décret du Io août I $\$ 96$, depuis modifié et complété par un autre décret du I 2 avril 1897 qui est entré en vigueur le I $^{\text {cr }}$ janvier I 899 .

Ces décrets ne s'appliquent qu'aux indigènes, qui seuls 
doivent la prestation en nature, sauf le droit de se racheter dans la période du is décembre au is janvier.

Les Européens contribuent également à l'entretien des routes en vertu d'un décret du ro mars i 898 , pris en conformité d'une délibération de la Conférence consultative du Is novembre 1896 , mais au moyen d'une contribution en argent dite taxe de routes. Une différence essentielle sépare donc la prestation de la taxe de routes: tandis que la prestation est due en nature par les indigènes, qui ont seulement la faculté de s'en racheter en argent, la taxe de routes est due en argent tant que les contribuables n'ont pas manifesté, par une demande spéciale qui doit être adressée aux contrôleurs civils avant le ${ }_{5}$ décembre de chaque année ${ }^{1}$, leur intention de s'acquitter en journées ou en tâches.

La prestation est au maxinum, par an, de quatre journées d'homme, et de deux pour les voitures, charrettes et bêtes de somme, de trait ou de selle.

Le taux du rachat de la prestation est de:

I fr. 20 c. la journée de prestataire (travailleur, conducteur de charrettes, de bêtes de trạit ou de somme, etc.);

o fr. $90 \mathrm{c}$. la journée de cheval, mulet ou chameau, avec harnachement;

o fr. 30 c. la journée d'âne (avec harnachement);

3 fr. la journée de charrette attelée, conducteur non compris.

La taxe des routes est liquidée sur les mèmes bases.

Kanoun sur les oliviers et dattiers; dime des builes. Les palmiers-dattiers sont ass'jettis à un droit fixe par

I. Exceptionnellement, ce délai pour la taxe des routes de 1879 a été prorogé au I; avril 1899 par un décret spécial du it décembre 1898 (27 redjeb 1316). 
pied d'arbre; ce droit varie suivant la catégorie dans laquelle l'arbre est placé et suivant les régions; le tableau ci-dessous indique ses diverses quotités:

\begin{tabular}{|c|c|c|}
\hline & $\begin{array}{c}\text { Dattiers } \\
\text { degla }\end{array}$ & $\begin{array}{l}\text { Autres } \\
\text { dattiers }\end{array}$ \\
\hline Tozeur, Oudiane et Nafta & ${ }_{1} f^{5}+0$ & of 67 \\
\hline Gafsa . . . . . . . & I 40 & $" 67$ \\
\hline Chebika, Tamerza et Midas. & $» 90$ & 2045 \\
\hline Nefzaoua. . . . . . & $" 90$ & 1225 \\
\hline Gabès . . . & $» "$ & 1225 \\
\hline
\end{tabular}

Les oliviers sont assujettis, dans les régions de l'est, du sud et du centre, à une taxe fixe par pied d'arbre (kanoun) et dans certains autres territoires (région de Bizerte, de Tebourba, de Tunis, de Zaghouan et de Soliman, et dans l'ile de Djerba), dits pay's de dime, à un prélèvement sur l'huile tirée de sa récolte en olives.

Le kanoun des oliviers varie, suivant les régions, d'après le tableau ci-dessous:

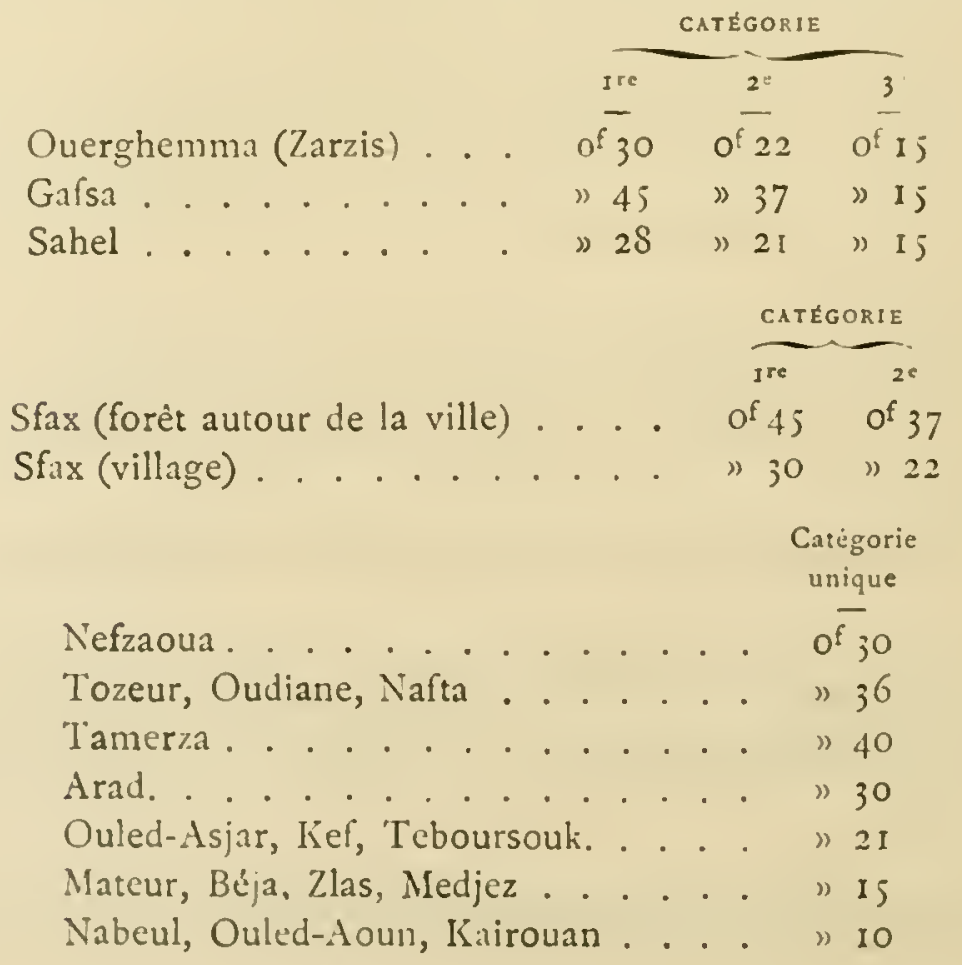


La dime des huiles est de $\mathrm{r} / \mathrm{I} / \mathrm{OO}^{\mathrm{e}}$ de l'huile produite, dont $\mathrm{ro} / \mathrm{I} O \mathrm{O}^{\mathrm{es}}$ représentent la dìme proprement dite et $\mathrm{I} / \mathrm{IOO}^{\mathrm{e}}$ le salaire ou remise du collecteur. Dans les circonscriptions de Tunis, de Tebourba et de Zaghouan, l'État a droit, en outre des I I/ 1 oos $^{\text {es }}$ de l'huile, a la totalité des grignons qui, dans les autres régions, restent aux propriétaires d'olives.

En sus des sommes revenant au Trésor, l'administration de la Ghaba, préposée à la surveillance et à la gestion des olivettes dans les pays de dime autres que Djerba, perçoit I $/ 8^{e}$ de dime pour rétribution de ses frais de garde et $2 \mathrm{p}$. I 00 du prix des récoltes lorsque les propriétaires ont besoin de son concours pour procéder à la vente des fruits.

En vertu d'un décret du 17 ncvembre 1897 , la dime des huiles, autrefois exigible en nature, est obligatoirement payable en argent. Elle est assise sur la valeur du rendement du quintal métrique d'olives en huile et en grignous fixée chaque année à forfait par décret pour toute la durée de la campagne. En 1897-1898 et pour la campagne i 898I 899 , le rendement en huile a été fixé à 20 p. Ioo et lé rendement en grignons à $32 \mathrm{p}$. 100 par quintal métrique d'olives. Sur ces bases, et eu égard au cours de l'huile, la dìme a été fixée par quintal d'olives:

\begin{tabular}{|c|c|c|c|c|}
\hline & Dime & Grignons & A la Ghaba & Total \\
\hline :n $1897-98$, à & If 76 & of $^{6} 64$ & of 22 & $2^{f} 62$ \\
\hline En $1898-99$, a & I 28 & $\Rightarrow$ so & $\Rightarrow 16$ & I 94 \\
\hline
\end{tabular}

Pour compléter ces indications relatives aux impôts qui frappent les dattiers et les oliviers, il faut noter que tout arbre nouvellement planté est exempté pendant vingt ans de kanoun (décret du 22 janvier I 894) et pendant quinze ans de la dime des huiles (décret du 6 novembre i 869 ). D'autre part, les oliviers sauvages nouvellement greffés 
sont cxemptés d'impóts pendant dix ans, en vertu d'un décret du 2 avril I $\$ 96$.

Le kimoun est actuellement perçu en vertu de rôles fort anciens qui ont cessé d'être en rapport avec la consistance exacte des arbres. Leur revision a été commencée en I $89 t$, et elle esi sur le point d'être terminée. Les nouveaux rôles seront sans doute publiés prochainement

Achour on dime sur les céréales. - Cet impòt, d'instituion coranique, frappe toutes les terres ensemencées en blé ou en orge ${ }^{\mathrm{r}}$, quelque en soit le propriétaire. Toutefois, il n'est pas assis, comme son nom semblerait l'indiquer, sur la récole effective en blé ou en orge, mais sur la quantité de céréales ensemencée par méchia et qui varie suivant les localités. La méchia (unité de la matière imposable) est l'étendue de terrain (le plus communément ro hectares) qui a reçu la quantité de céréales en us.ıge dans la région pour ensemencer la superficie qu'une charrue normalemenr attelée peut exploiter pendant une campagne agricole. Actuellement, la quantité de semences que comporte la méchia résulte des usages locaux.

La quotité de l'impôt est de quatre hectolitres par méchia complète de blé ou d'orge; l'impôt est dû en argent d'après un taux de conversion fixé chaque année par décret. Outre le principal de l'impôt, les redevables payent au Trésor la remise des collecteurs, qui est du dixième du principal, des frais fixes de I fr. So c. par méchia, et le timbre et la quittance qui était autrefois proportionnel à l'impôt et qui n'est plus aujourd'hui que de o fr. os c., ou

1. Aux iermes d'un decret don: le projet a été soumis à la Conférence consultative, les cultures d’avoine sont également imposables, mais l'impó ne sera exigible pour la fremicre fois que sur la récolte pendante de l'année $80 \mathrm{r}$ et, frovisoirement, au taux reduit de deux heciolitres par dix hectares. 
o fr. $20 \mathrm{c}$. suivant que la taxe est inférieure ou supérieure à ro fr. (Décret du 20 juillet I 896. )

Les rôles d'achour sont établis chaque année par des commissions de recensement où assiste obligatoirement un délégué du contrôle civil quand il s'agit de recenser des propriétés européennes. Les frais de recensement payables contre quittance à souche à la commission sont de I fr. $20 \mathrm{c}$. par méchia.

Bien que l'achour ne soit pas assis sur la récolte, en fait les agriculteurs peuvent être dégrevés de l'impôt si les semailles n'ont pas poussé ou si elles ont poussé sans produire d'épis et si les récoltes sont détruites par l'incendie, les pluies torrentielles, la grêle ou les sauterelles.

L'achour est dû par tous les agriculteurs quelle qu'en soit la nationalité. Toutefois, ceux d'entre eux qui labourent à la charrue française, sur des terrains entièrement débroussaillés, et c'est le cas de la presque généralité des colons européens, sont exonérés, par un décret récent du 3 I mai I 898 , des $9 / 10^{\text {es }}$ du principal de l'impôt, à la condition d'en faire la déclaration au plus tard le is janvier, au bureau de la perception de l'achour.

Mradja. - L'impôt mradja frappe les terrains maraîchers et les jardins fruitiers d:Ins les caïdats de Sfax, Nabeul et Soliman.

La quotité de l'impôt est fixée par merdja (ou parcelle d'environ 600 mètres carrés), ainsi qu'il est indiqué ciaprès:

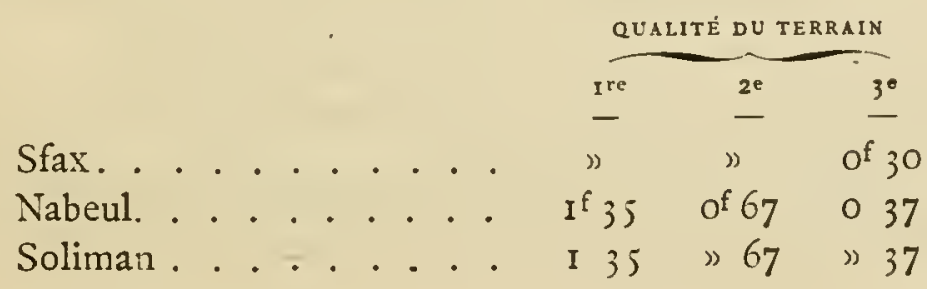


Khodor. - Les khodor constituent une taxe d'abonnement de 60,000 fr. par an, spéciale à l'ile de Djerba, et qui a été établie par un décret du 22 décembre $18_{45}$, en remplacement des droits de mahsoulats sur les dittes, millets, fruits et herbages. Cette taxe parait done à première vue une sorte d'impòt indirect. En fait, cependint, les usages et la répartition dont elle est l'objet entre les propriétaires fonciers de Djerba, qui fixent cux-mêmes leur quote-part respective d'après l'importance de leurs propriétés, l'ont transformée en un véritable impòt foncier qu'il est question depuis longtemps de régulariser au moyen d'une opération de cadastre.

Taxe (anciennement dénommíe curoube) sur les loyers et sur la valenr locative des immenbles. - Cette taxe, fixée, par le décret de i $\$ 40$ qui l'a instituée, à une caroube par piastre, c'est-à-dire à $6.25 \mathrm{p}$. I00, a été originairement établie sur le prix de location de tous les immeubles loués, autres que ceux des exploitations rurales (enchirs), dans toute l'étendue de la Régence. Plus tard, un décret du 27 mali 1873 , modifié et complété par un autre décret du 7 juin I $\$ S 2$, a étendu l'impôt dans les villes de Tunis, La Goulette, Sonsse, Monastir, Sfax et Kairouan et dans certaines localités de la banlieue de Tunis, à la valenr locative de toutes les propriétés bâties et des constructions de toute nature occupées soit par le propriétaire lui-même, soit par des tiers, à n’importe quel titre, même autrement qu’à bail. Sont également soumis à la taxe sur la valeur locative les terrains urbains aliénés à titre d'enzel.

La transformation de la caroube sur les loyers en caroube sur la valeur locative a été ultérieurement étendue aux villes de Bizerte, du Béja, du Kef et de Mehdia et le sera vrai- 
semblablement peu à peu à toutes les villes de la Tunisie érigées en communes.

La taxe en question, quelque forme qu'elle revête, est incontestablement un impôt d'État dont le Gouvernement serait fondé à se réserver le principal, sauf à concéder des centimes additionnels aux budgets municipaux. Cependant, par une mesure de bienveillance et en attendant qu'il soit possible de doter toutes les communes de leurs ressources naturelles, l'État a concédé ladite taxe aux villes de Tunis, La Goulette, Sfax, Monastir, Kairouan, Béja, Bizerte, Le Kef et Mehdia.

La taxe sur les loyers est assise, ainsi que l'indique son nom, sur les prix des locations portés aux actes de bail. Mais l'impôt sur la valeur locative a pour base la valeur locative des immeubles telle qu'elle résulte des recensements quinquennaux opérés par des commissions spéciales. Les commissions peuvent s'inspirer, dans leurs évaluations, des baux en cours, mais elles ont la faculté de substituer leur estimation aux indications de ces actes si elles les jugent insuffisantes ou inexactes.

Patentes. - L'impôt actuel des patentes consiste exclusivement en droits fixes qui ne frappent que le commerce de certains objets d'alimentation indigène, tels que les chemenka, tebikh, torchi, baloua, balaouyat, fōul, leben, etc.

Ce genre de commerce n'est généralement pratiqué que par des indigènes; mais si des Européens s'y adonnent, ils deviennent également passibles de la taxe.

Des droits de patentes sont, en outre, établis (voir plus loin: mahsoulats) sur la fabrication de la chaux, des briques et des produits similaires, et du plâtre. 
Les impots et revenus indirects se composent :

$I^{\circ}$ Du timbre et de l'enregistrement;

$2^{n}$ Des droits sur les mutations d'immeubles;

$3^{\circ}$ Des droits de douane;

$4^{\circ}$ Des droits maritimes;

$5^{\circ}$ Des droits de mahsoulat.

Timbre et cnregistrement. - L L'impòt du timbre a été établi en Tunisie en novembre I 8 j I, par conséquent peu de temps après l'institution de la Commission financière, sur l'initiative de linspecteur des finances françaises, viceprésident de cette commission, qui s'est proposé de faire de cet impôt en Tunisie l'équivalent des impôs du timbre et de l'enregistrement existant alors en Algérie. C'est ainsi que tous les actes, quels qu'ils fussent, portant mention de sommes d'argent, ont été invariablement assujettis à un droit de 1 p. Ioo qui eût été excessif comme simple droit de timbre, mais dont le taux s'explique si l'on considère qu'il représentait aussi à forfait l'équivalent des droits d'enregistrement.

Cet impôt a été exactement payé, même par les Européens, jusqu'à l'établissement des tribunaux français en Tunisie. Toutes les conventions usuelles se faisaient, en effet, avant cette époque, devant les notaires indigènes qui ne pouvaient instrumenter sans l'acquittement préalable du droit de timbre. Mais lorsque l'usage se fut introduit et rapidement généralisé de rédiger sous la forme de sousseings privés, avee l'assistance officieuse des officiers ministéricls français, et même de passer dans les chancelleries 
des consulats des actes qui, jusqu'alors, avaient paru nécessiter l'intervention des notaires arabes, l'emploi du timbre devint de moins en moins fréquent, et il arriva un moment où les conventions entre Européens ne furent plus établies que sur papier libre.

L'impôt du timbre n'était plus ainsi payé que par les indigènes, qui protestaient d'ailleurs contre les tarifs de I $87 \mathrm{I}$; auxquels ils reprochaient de frapper du même droit toutes les conventions. La réforme de la législation s'imposait. A la suite des travaux d'une commission spéciale composée de représentants de l'administration, de l'agriculture et du commerce, le Gouvernement promulga, le 20 juillet I $\$ 96$, les décrets actuellement en vigueur sur le timbre et l'enregistrement.

L'objet de ces décrets est, sous réserve des ménagements que comporte la situation économique de la Tunisie, de ramener l'assiette de l'impôt du timbre aux règles fondamentales de la législation française, avec réduction de moitié des tarifs.

Quant aux droits d'enregistrement, ils ont été calculés aux taux strictement nécessaires pour compenser la moinsvalue des droits de timbre nouveaux et, par suite, pour indemniser le Trésor de l'abandon des tarifs de I 87 I sur les actes des indigènes et de leur non-application aux actes entre Européens.

L'impôt du timbre est établi sur tous les papiers destinés aux actes civils, judiciaires ou extrajudiciaires, et aux écritures publiques ou privées qui peuvent être produites en justice et y faire foi. ( $\mathrm{V}$. décret du 20 juillet í 896.)

Il y a trois sortes de droits de timbre : le droit de timbre de dimension, le droit de timbre proportionnel et le droit de timbre spécial. 
Le droit de timbre de dimension comprend quatre quotités: o fr. $30 \mathrm{c}$, o fr. $60 \mathrm{c}$., o fr. $90 \mathrm{c}$. et I fr. $20 \mathrm{c}$, et s'applique à tous actes et écritures sujets au timbre et non expressément soumis au droit de timbre proportionnel ou au droit de timbre spécial;

Le droit de timbre proportionnel est établi sur les sommes et valcurs à raison de o fr. of c. pour cent francs ou fraction de cent francs et comprend dix-neuf quotités échelonnées de o fr. os c. à 5 fr. Y sont assujettis les billets simples et reconnaissances de dettes, tous autres effets non négociables, les actions et obligations des sociétés ayant leur siège en Tunisie;

Le droit de timbre spécial est particulier à certains actes, écrits ou formules déterminés par la loi. Il est de o fr. Io c. pour les lettres de voiture, récépissés de chemin de fer, connaissements et toutes autres pièces en tenant lieu, pour les bulletins d'expéditions de colis postaux; de o fr. of c., o fr. IO c. et o fr. $20 \mathrm{c}$. pour les quittances délivrées par les comptables de deniers publics; de o fr. of c., ofr. $10 \mathrm{c}$, o fr. I $\mathrm{c}$. et o fr. $20 \mathrm{c}$, pour les affiches illustrées, suivant leur dimension; de I fr. par mètre carré ei par année, s’il s'agit d'aftiches peintes; de o fr. $20 \mathrm{c}$. pour les autorisations d'achat de poudre; de o fr. os c. pour les titres de mouvement en matière de contributions diverses et de donane; de I fr. 20 c. pour les récépissés de déclarations et les permis de port d'armes.

Toute contravention au timbre de dimension et au timbre spécial est punie d'une amende de $20 \mathrm{fr}$. et, s'il s'agit d'une contrivention au timbre proportionnel, d'une amende égale au montant du droit de timbre, sans que cette amende puisse être inférieure à $20 \mathrm{fr}$.

Les droits de timbre peuvent être acquittés soit au moyen 
de l'achat du papier de la débite, soit par le timbrage à l'extraordinaire donné à l'atelier général à Tunis, soit au moyen de l'apposition de timbres mobiles dûment oblitérés, soit enfin par le visa des receveurs des contributions diverses ou agents en faisant fonctions.

L'article i 6 du décret précité du 20 juillet I $\$ 96$ contient l'énumération des actes exemptés du droit et de la formalité du timbre. On peut citer notamment: les quittances délivrées par des particuliers, les factures des commerçants non acceptées par les débiteurs, les actes venant de France et de l'étranger, les effets de commerce, warrants, chèques et autres obligations négociables, ainsi que les reconnaissances du mont-de-piété. Sont en outre exempts du droit, en vertu du décret du ${ }^{\text {er }}$ aouit I $\$ 98$, les factures ou mémoires produits à l'appui des ordonnances et mandats délivrés pour le paiement des dépenses du Trésor tunisien.

Les actes dressés sous l'empire de l'ancienne législation sur le timbre, et qui n'ont pas acquitté l'impôt, sont passibles des droits et amendes édictés.par le décret du 20 juillet I 896 (décret du I er aoht i 898 ).

L'enregistrement, tel qu'il a été institué par le décret précité du 20 juillet I $\$ 96$, répond, suivant le cas, à un double objet: tantôt il a pour but de fournir aux particuliers un moyen de donner date certaine à leurs actes, qu'ils peuvent à leur choix faire enregistrer par extrait ou transcrire intégralement; tantôt il constitue une formalité purement fiscale.

En principe, les actes ne sont obligatoirement assujettis à l'enregistrement que s'ils sont produits en justice. Toutefois, certains actes ou conventions sont, par leur nature même, astreints obligatoirement à la formalité de l'enregistrement. Ainsi, doivent être enregistrés (art. 5 du décret du 20 juillet 1896 ) les actes indiqués au tableau suivant. 


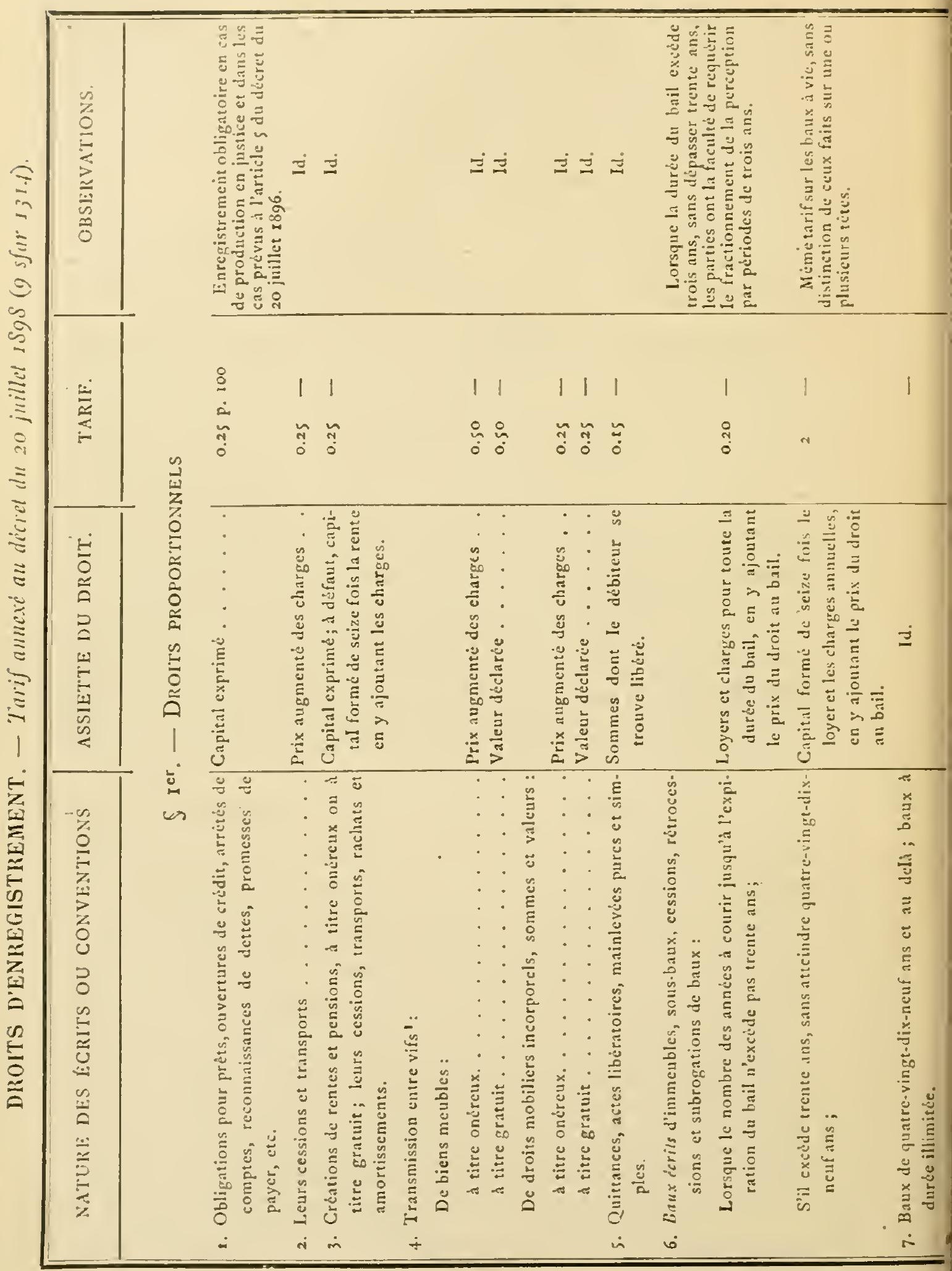


$1^{\circ}$ Dans les trente jours de leur date, s’ils sont passés en Tunisie, et dans les soixante jours s'ils sont passés hors du territoire de la Régence : les hypothèques volontaires, antichrèses, mantissements immobiliers, leurs constitutions, cessions, transports et mainlevées, lorsque l'immeuble grevé est situé en Tunisie; les cessions, transports, rachats et amortissements de rente d'enzel, ainsi que les constitutions, lorsque le constituant se réserve le domaine utile; les baux érits d'immeubles situés en Tunisic, à l'exclusion des conrentions rerbales; les actes des notaires musulmans et israélites;

$2^{\circ}$ Dans les vingt-cinq jours de leur date: les ordonnances de référé et les jugements rendus tant en premier qu'en dernier ressort ou sur appel, en matière civile, administritive ou commerciale, les jugements préparatoires et interlocutoires correctionnels et criminels exceptés;

$3^{\circ}$ Dans les dix jours de leur date: les procès-verbaux de ventes publiques de meubles auxquelles il est procédé par les officiers publics à ce compétents.

Sont exempts de l'enregistrement :

$I^{\circ}$ Les actes passés antérieurement au I ${ }^{\text {er }}$ août I $\$ 96$, date de la mise à exécution du décret du 20 juillet 1896 ;

$2{ }^{\circ}$ Ceux énumérés par l'article $S$ de ce décret, savoir : les procès-verbaux et exploits des huissiers et ayants qualité pour verbaliser, y compris les protîts; les actes d'avoué ì aroué; les actes de greffe; les contrats d'assurances; les effets publics, actions, part d'intérêts et obligations, l'émission et la circulation de ces titres; les lettres missives, à moins qu'elles n'aient le caractère d'un contralt; les jugements du tribunal mixte, les jugements et ordomnances tant en action qu'en défense ayant pour objet le recouvrement des taxes dues à l'Etat ou aux communes. 
Les droits d'enregistrement sont fixes, proportionnels ou gradués, suivant la nature des conventions, ainsi que l'indique le tableau ci-dessus. Les droits proportionnels suivent les sommes et valeurs de Ioo fr. en Ioo fr. inclusivement et sans fractions.

Droits de mutations d'immenbles. - De tout temps, les mutations d'immeubles ont été assujetties en Tunisie par les tarifs des Mahsoulats à une taxe fiscale. Les tarifs ne distinguaient pas d'ailleurs entre les mutations entre vifs et les mutations opérées par décès.

Le tarif a été, jusqu'en I893, d'une caroube par piastre (6.25 p. I00), d'où le nom de caroube donné encore aujourd'hui aux droits de mutation. A la caroube s'ajoutait un droit de timbre de I p. I00, ce qui portait a 7.25 P. I00 l'impôt qui frappait les mutations d'immeubles. Cette tarification était excessive, et l'un des premiers soins de la Direction générale des finances a été de la réduire dès que la situation budgétaire le lui a permis.

Actuellement, les actes de mutations immobilières ne paient plus qu'un droit de ofr. $30 \mathrm{c}$, o fr. $60 \mathrm{c}$. et o fr. $90 \mathrm{c}$, suivant la dimension du papier employé et abstraction faite de la valeur de l'immeuble transmis. Quant au droit même de mutation, il a été réduit (décrets du 2 novembre 1893 et du 8 février i 897 ) de $6.25 \mathrm{p}$. Ioo, à savoir :

0.20 p. Ioo pour les mutations qui s'opèrent en ligne directe ou entre époux, entre vifs à titre gratuit ou par décès;

$4 \mathrm{p}$. roo pour toutes les autres mutations quelles qu'elles soient.

Le droit est exigible: pour les mutations à titre onéreux, sur le prix exprimé; pour les mutations à titre gratuit entre 
vifs, sur l'évaluation de la valeur vénale (décret du 2 novembre 1 $\$ 93$, art. 3 ); pour les cessions et constitutions d'enzels, sur le prix stipulé en capital, augmenté de la somme fixée pour le rachat de la rente; à défaut de stipulation de rachat, le droit est liquidé tant sur le prix exprimé que sur le capital formé de seize fois la rente (décret du 5 mai r $\$ 9 S$, art. 2).

Les droits sont supportés par les nouveaux possesseurs, mais toutes les parties contractantes sont tenues solidairement à l'égard du Trésor. Les anciens possesseurs peurent toutefois s'affranchir du droit en sus, ainsi que du versement immédiat du droit simple, en déposant au bureau de l'enregistrement, dans les soixante jours de la mutation, un double de l'acte soumis aux droits ou en $\mathrm{y}$ faisant la décliration de la mutation.

Le paiement des droits doit aroir lieu dans les soixante jours de la mutation, sous peine pour l'ancien et le noureau possesseur d'un droit en sus au minimum de 50 fr.; en cas de dissimulation, l'amende est du quart de la somme dissimulée.

En ce qui concerne les mutations par décès, l'impôt est liquidé sur la valeur vénale des biens, évaluée par les parties, sans que ceite valeur puisse être inférieure à scize fois le revenu des biens sur les prix des baux courants. Cette valeur ainsi déterminée doit être, pour l'assiette du droit, diminuée du passif qui grère l'immeuble: dettes hypothécaires, reprises matrimoniales, capital des rentes d'enzel (décret du $S$ février I $S 9 S$, art. 2 ).

Les cohériticrs et les colégataires sont solidaires pour le paiement des droits.

Le délai pour passer la déclaration et acquitter l'impôt est de trois mois à compter du décés s'il a eu lieu en Tunisie, et de six mois s'il a eu lieu partout ailleurs. 
Les déclarations doivent être établies sur des formules spéciales dont sont approvisionnés les bureaux de l'enregistrement et des contributions diverses.

Le détaut de déclaration, les omissions, insulfisances d'évaluation, fausses indications d'hérédité, fausses déclarations du passif, donnent ouverture à un demi-droit en sus, suivant les distinctions établies par l'article 5 du décret précité du 8 février I 897.

Droits de douane. - Il existe en Tunisie des droits de douane à l'importation et à l'exportation; il n'en existe pas à l'intérieur.

Le cabotage, ou transport de marchandises d'un port tunisien à un autre port tunisien, ne donne pas lieu à l'impót; toutefois, les marchandises en cabotage ne peuvent sortir du port d'embarquement qu'après consignation des droits d'exportation auxquels elles donneraient ouverture si elles étaient expédiées à l'étranger; ces droits sont ultérieurement restitués sur la justification de l'arrivée de la marchandise au port tunisien de destination.

L'administration du Protectorat poursuit la suppression graduelle des droits à l'exportation. Les articles qui paient encore cet impôt ne sont plus qu'au nombre de douze, alors qu'ils étaient soixante-deux à la créntion de la direction générale des finances. Le rendement des droits à l'exportation, qui était de $2,400,000 \mathrm{fr}$. en I $\$ 84$, n'est plus prévu, par suite, dans le budget de i 899 , que pour $660,000 \mathrm{fr}$.; les dégrèrements ainsi opérés représentent done pour le Trésor une perte annuelle de I,700,000 fr.

Les marchandises qui sont encore frappées de droits d'exportation, et le tarif applicable à chacune d'elles, ont fait l’objet du tableau B annexé au décret du 2 mai I 898, qui a 
réformé la législation antérieure. Ce tableau est reproduit ci-après :

Tableau B. - Droits de sortie.

\begin{tabular}{|c|c|c|}
\hline DESIGNATION DES MARCHANDISES & UNITESS & DROITS \\
\hline 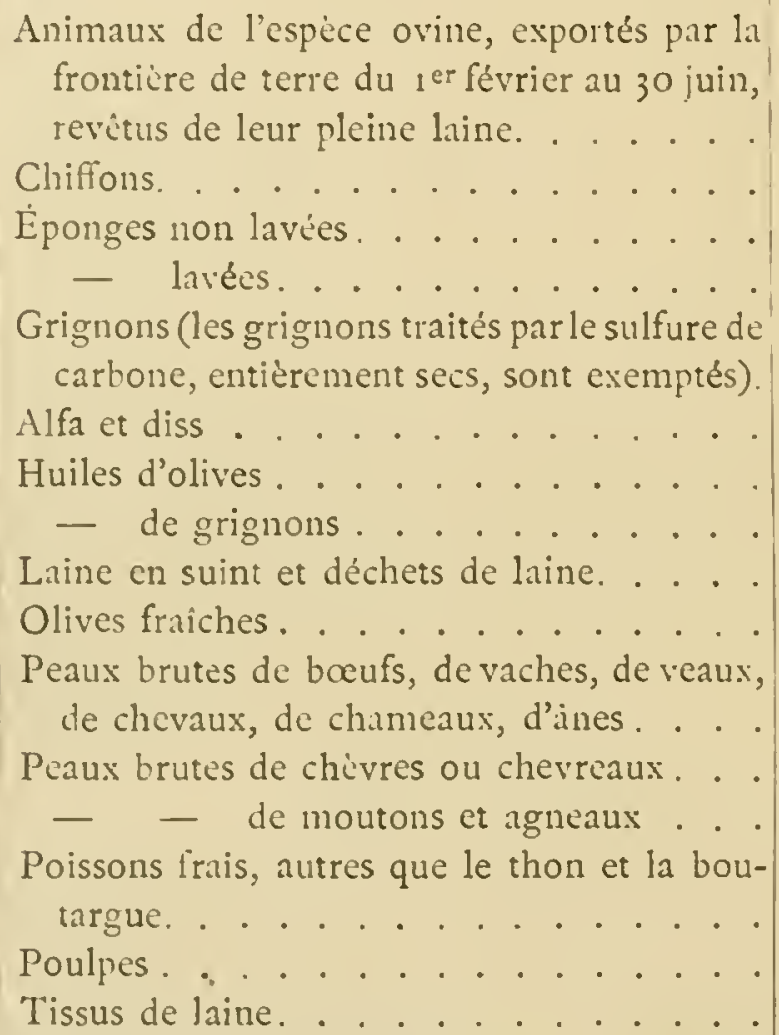 & $\begin{array}{c}\text { par tête } \\
\text { roo kilos } \\
- \\
- \\
- \\
- \\
- \\
- \\
- \\
- \\
- \\
- \\
- \\
- \\
- \\
\text { Valeur }\end{array}$ & 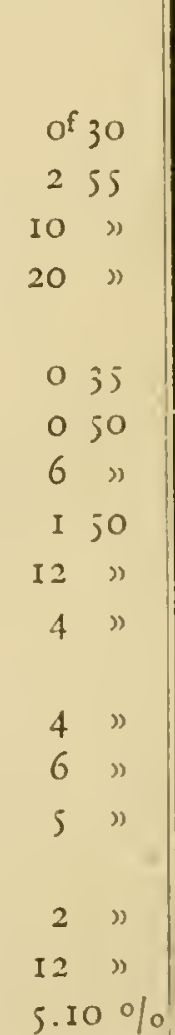 \\
\hline
\end{tabular}

Le régime de la douane à l'importation a été complètement réformé par un décret du 2 mai r 898. Antérieurement, les marchandises importées en Tunisie étaient, sauf certaines exemptions, assujetties au droit de $S$ p. I oo ad valorem, si elles provenaient d'un pays ayant un traité avec lit Tunisie; au cas contraire, aux droits d'un tarif général édicté le $2 S$ septembre I $\$ 96$. Aucune faveur n'était con- 
cédée aux produits français. Cette législation a fait place, le 2 mai 1898 , à un nouveau tarif qui est commun aux marchandises de toute origine, sous réserve d'immunités établies en faveur de certains produits de la France et de l'Algérie (à l'exclusion des produits des possessions françaises autres que l'Algérie). Ce sont: les animaux vivants, les laines, les soies, les sucres, les huiles d'olive, de lin et de ricin, les vins, eaux-de-vie, alcools et liqueurs, les métaux, les fils et tissus, les broderies et vêtements, les machines et mécaniques, les ouvrages en métaux, la carrosserie et les agrès et apparaux de navires ${ }^{I}$.

Comme la franchise ainsi accordée à ces produits français aurait pu ne pas constituer à elle seule une protection suffisante; on a frappé les marchandises similaires d'origine étrangère de droits calculés de manière à assurer la préférence à l'importation des produits franç.ıis.

Les immunités dont bénéficie la métropole ne peuvent être revendiquées par aucun autre pays, eût-il droit au traitement de la nation la plus favorisée. En effet, les conventions internationales ont admis que la France devait jouir en Tunisie d'une situation privilégiée.

Le nouveau tarif fait l'objet du tableau A imnexé au décret du 2 mai 1898 .

Les dispositions du tableau A maintiennent les prohibitions de l'ancien régime. Telles sont, notamment, les prohibitions sanitaires ou de police, celles concernant les armes et les munitions de guerre, celles nécessitées par la défense contre le phylloxéra, etc.

Sont également maintenues en vigueur les dispositions

1. Toutefois, les vins français ou algériens sont assujettis à une taxe fiscale de ro p. roo ad ulorem, et les sucres et alcools de même origine sont soumis à la taxe de consommation. (Voy. plus loin : Droits de mabsoulats, alcools et sutres.) 
d'un décret du 28 janvier I $\$ 9 S$ admettant en franchise les effets des voyageurs, le mobilier des personnes qui viennent se fixer en Tunisie, leurs outils, machines, instruments et matériel agricole, les objets destinés aux collections des musées et bibliothéques, les échantillons sans valeur mar. chande, etc.

Les marchandises sont imposées au nombre, à la mesure, au poids brut, au poids net ou à la valeur. La valeur imposable comprend, outre le prix d'achat à l'étranger, les frais postérieurs à l'achat, tels que droits de sortie acquittés aux doumes étrangères, transport ou fret, assurance, etc., en un mot tout ce qui contribue ì former, à l'arrivée cn Tunisie, le prix marchand de l'objet, droits d'entrée non compris. Lorsque la valeur attribuée aux ma:chandises parait insuffisante, la douane a la faculté de préempter ou de percevoir le droit en mature (décret du is janvier I $S 98)$.

Toute marchandise qui entre en Tunisie ou qui en sort doit être présentée et déclarée en détail au bureau des douanes, pour y être vérifiée, si les employés l'exigent, et soumise aux droits, s'il y a lieu. La forme de la déclaration en détail, dont l'objet est d'assigner une destination à la marchandise et qui doit contenir toutes les énonciations nécessaires pour l'application du tarif, est réglée par le décret organique sur les douanes du 3 octobre i $\$ S_{4}$.

Les marchandises qui entrent dans la Régence peuvent recevoir diverses destinitions : elles peurent être mises en consonmation, expédiées en transit par chemin de fer, réexportées ou transbordées. Certaines marchandises peurent aussi être entreposées ou déclarées pour l'admission temporaire en franchise.

Les marchandises qui sont déclarées pour la consomma- 
tion sont sujettes aux droits en vigueur au moment du dépôt de la déclaration en détail ; elles forment le gage des droits et ne peuvent être enlevées qu'après leur acquittement.

Les marchandises qui transitent et celles qui sont transbordées ou réexportées sont affranchies du droit d'entréc; les marchandises admises temporairement pour recevoir un complément de main-d'œuvre doivent être réexportées ou réintégrées en entrepôt dans les délais déterminés.

A ces indications, il y a lieu d'ajouter que, par décret du 22 avril I $\$ 95$, il a été créé un entrepôt réel de marchandises étrangères à Tunis et à Bizerte, et qu'aux termes d'un autre décret du 24 décembre I\$93, les houilles peuvent être, dans tous les ports ouverts aux opérations de commerce à l'importation, placées en entrepôt fictif pour la durée maxima d'une année, sous lil soumission cautionnée de les réexporter ou de payer les droits d'entrée au moment où elles sont livrées à la consommation.

Droits maritimes. - Les droits maritimes sont de deux sortes: droits sanitaires et de phares, droits de ports.

Les droits sanitaires de reconnaissance à l'arrivée et les droits de phares sont payés par tous les navires venant de l'étranger, dans les vingt jours de l'arrivée et en tout cas arant le départ du navire. Ils sont fixés ensemble à o fr. $18 \mathrm{c}$. par tonneau de jauge pour les navires de 500 tonneaux et au-dessous, et uniformément à $90 \mathrm{fr}$. pour ceux qui jaugent plus de 500 tonneaux.

Les navires sont tenus, en outre, dans lés temps d'épidémie et de quarantaine, à des droits journaliers de s:ation et de séjour au lazaret, ainsi qu’à des taxes pour la désinfection des marchandises. 
Les navires faisant le cabotage tunisien, les batiments de gruerre, les batiments en relìche forcée qui ne se livrent à aucune opération de commerce dans le port d'abri et n'y font pas d'eau ou de provisions, les bateaux de pêche, les yalits de plaisance, sont exempts des droits.

L.es droits de ports, concédés dans les cinq ports les plus importants de la Régenee (Tunis, Bizerte, La Goulette, Sousse et Sfax) à des compagnies concessionnaires, en compensation de leur engagement de construire ou d'acherer les ports et de les mettre à la hauteur des exigences modernes, n'ont été réservés à l'État que dans les autres villes maritimes de la Régence où leur rendement est peu élevé.

Droits de mabsoulats. - Ces droits, de nature essentiellement variable, frappaient tantôt la production ou la fabrication, tantôt la vente, tantôt l'apport sur les lieux de consommation ou de vente. Ils étaient liquidés, suivant les cas, sur la valeur, le poids, le nombre, etc. Ils frappaient lia plupart des produits du sol et de l'industrie. Ils étaient affermés annuellement ì de simples particuliers qui ne devaient compte au Trésor que du produit de leur fermage.

Dis I $\$ 87$, l'administration du protectorat a entrepris simultanément la réforme de l'assiette de la tarification et du mode de perception de ces divers droits. De nombreux décrets ont modifié complètement la législation qui les concerne et les ont transformés insensiblement en taxes indirectes de stationnement, d'entréc, de circulation, de fabrication et de consommation. Comme conséquence, l'expression "mahsoulats» est appelée d̀ disparaitre de la nomenclature budgétaire.

En même temps, la direction générale des finances substituait le système de lia régie et de la perception directes ì 
celui de l'affermage. Depuis le $\mathrm{I}^{\text {er }}$ janvier $\mathrm{I} 899$, il n'existe plus dans la Régence de droits de mahsoulats affermés.

Les principaux produits atteints par la nouvelle législation sont les suivants :

$I^{\circ}$ Céréales et lígumes secs. - Un dérret du 3 I mai i 898 a substitué aux droits de mahsoulats et autres tixes sur les céréales et les légumes secs une taxe unique dite de circulation, qui est perçue, savoir:

Sur les produits en provenance de l'extérieur, à leur entrée dains la Régence;

Sur les produits de provenance tunisienne, soit à leur sortie du territoire, soit à leur introduction dans le périmètre de perception de toute localité du littoral ou de la frontière de terre ayant une population agglomérée d'au moins 500 habitants.

Le droit de circulation est de o fr. $35 \mathrm{c}$. par quintal sur le blé, le sorgho, les fèves, les pois et la graine de lin; de o fr. 25 c. sur l'orge, le maïs, les millets autres que le sorgho, le seigle et les autres variétés de légumes secs autres que les pois et les fèves.

Une portion des droits de circulation est attribuée aux municipalités de Tunis, Bizerte, La Goulette, Sousse, Monastir, Mehdia et Sfax, auxquelles les droits d'entrée sur les céréales et les légumes secs avaient été antérieurement concédés.

Les céréales et légumes secs sont assujettis, en outre:

A un droit de stationnement de ofr. 05 c. par jour ou fraction de journée et par quintal ou fraction de quintal, à l'occasion de leur introduction et de leur séjour sur les marchés publics;

A un droit de pesage ou de mesurage de 0 fr. $0 ;$ C. par 
quintal ou fraction de quintal et de o fr. Io c. par hectolitre ou fraction d'hectolitre.

Le pesage et le mesurage sont facultatifs.

Les droits de stationmement, de pesage et de mesuragre appartiennent à l'État, sauf sur les marchés municipaux, où ils sont perçus pour le compte des municipalités.

$2^{\circ}$ Chanx, briques et produits similaires. - Le décret du 2 I juillet I $\$ 96$ a substitué au droit de fabrication de $S$ P. I 00 ad valorem, auquel étaient autrefois assujetris ces produits, une taxe perçue à l'entrée des localités d'une population ag glomérée d'all moins soo babitan!s. Ce tarif est fixé comme suit :

Io Chaux et ciments :

Chaux dite keddel, par tome . . . . . . . $3^{\text {f }}$ "

Ciments, pur tome .......... . . 250

Chuux hydraulique, par tonne. . . . . . . . I 30

Chaux grass en entieres, dites zaoual, par mitre cube. . o 90

Chaux grasses en poussière, dite zaouek, blutée ou non,

par métre cube . . . . . . . . . . o 25

$2^{\circ}$ Briques et produits similaires, par mille :

Briques à trois trous. . . . . . . . . ${ }_{1}^{\mathrm{f}} 60$

- à $\operatorname{six} \quad \ldots \ldots \ldots . \ldots 240$

- pleines, de $0^{m}, 0 ; \ldots \ldots . . .240$

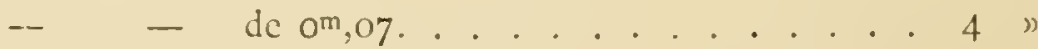

- indigènes de to stes sortes........ I 160

luiles plates . . . . . . . . . . . . . s"

Carreaux. . . . . . . . . . . . . 4 "

$3^{\circ}$ 'Tous autres produits de chlux et de ciment, de céramiques non dénommés au tarif ci-dessus, $8 \%$ de leur valeur.

Tout fabricant de chaux et de ciment ou de briques ou produits simil.ires doit faire, au bureau des contributions diverses de sil circonsiription, une fois pour toutes si sa fabrication doit être permanente, et avant toute reprise du travail si sa fabrication n'est pas continue, une déclaration 
indiquant la situation de l'usine ou des fours et la nature des produits qu'il se propose de fabriquer.

Il est assujetti à une patente fixe annuelle de $60 \mathrm{fr}$. s'il ne fabrique que l'une des deux variétés de produits; de I 20 fr. s'il fabrique les deux variétés. La patente est $i$-yable par semestre et d'avance.

Des licences temporaires de fabrication peuvent être accordées par la direction des contributions diverses, moyennant une redevance mensuelle de $5 \mathrm{fr}$.

Le régime des droits d'entrée n'est applicable qu'aux produits fabriqués en dehors du périmètre des agglomérations de 500 habitants et au-dessus; les produits obtenus dans l'intérieur de ces périmètres continuent à être assujettis à l'ancien droit de fabrication, sous le bénéfice toutefois de la détaxe pour ceux destinés à la consommation extra-urbaine. Il résulte de ce régime que les matériaux destinés à l'agriculture, et notamment les chaux destinées à l'amendement des terres, sont totalement affranchis de l'impôt.

Les ciments et produits en ciment ne doivent être imposés qu'à partir de IgOI.

$3^{\circ}$ Plâtre. - La fabrication et la vente de ce produit faisaient autrefois l'objet d'un monopole d'État à Tunis et. dans sa banlieue. Le décret du 2 mai I 895 a supprimé ce monopole et assujetti le plâtre, dont la fabrication et la vente sont par suite devenues libres, à un droit d'entrée de o fr. $20 \mathrm{c}$. par quintal à Tunis et à o fr. Io c. dans les autres localités de la Régence désignées par arrêté du directeur des finances. Les localités où ce droit est perçu sont actuellement : Tunis, La Goulette, Kairouan, Sousse, Sfax, Monastir, Mehdia, Bizerte, Le Kef et Béja (arrêté du I 2 dé- 
cembre 1S95). Dans toutes les autres localités, le droit est de 6.25 p. roo ad valorem.

A Tunis et dans sa banlicue, la fabrication du plittre est soumise à une patente annuclle de $60 \mathrm{fr}$. payable par trimestre et d'avance.

$t^{\circ}$ Poteries. - Le décret du 29 août I 89 I assujettit les poteries it un droit de vente fixé comme il suit :

Poteries vernies:

$$
\begin{aligned}
& \text { If } 20 \text { par charge de chameau. } \\
& 060-\text { de cheval. } \\
& 0 ; 0 \text { d'ane. }
\end{aligned}
$$

Poteries non vernies:

$$
\begin{aligned}
& \text { of } 60 \text { par charge de chameau. } \\
& \text { o } 30 \text { - de cheval. } \\
& \text { o is - d'ine. }
\end{aligned}
$$

Ces droits sont transformés en droits d'entrée dans les diverses localités soumises au régime des droits de porte, savoir: Tunis (décret du 29 janvier r S95), La Goulette, Kairouan, Sousse, Sfax, Monastir, Mehdia, Bizerte, Le Kef et Béja (décret du zo décembre i $S_{97}$ ).

- So Savon. - Le décret du $S$ juillet I $S_{9}$ I n’a laissé subsister des anciennes taxes auxquelles était assujetti le savon qu'un droit de fabrication de 4 fr. So c. par quintal. Le droit est perçu d'après la déclaration que doit faire le fabricant avant chaque cuite. Le décret du I 2 mai I $\$ 98$ a affranchi du droit de fabrication le saron exporté, sous retenue d'un droit de o fr. $40 \mathrm{c}$. par quintal pour frais de statistique et de ofr. ro c. par plomb apposé sur les colis. Le remboursement est effectué sur la représentation d'un acquit-i- 
caution délivré par le service et dûment déchargé par lui et d'un certificat de sortie délivré par la douane.

$5^{\circ}$ Peaux el laines. - Le décret du i 3 décembre I $\$ 94$ assujettit la vente de ces produits à une taxe de $6.25 \mathrm{p}$. Ioo ad valorem, et décide que la vente devra avoir lieu obligatoirement sur les marchés. A Tunis, La Goulette, Kairouan, Sousse, Sfax, Monastir, Mehdia, Bizerte, Le Kef et Béja, le droit de vente est remplacé par un droit perçu à l'entrée et qui est fixé comme il suit :

Peaux de bœufs ou de raches:

fraîches. . . . . . . $2^{\mathrm{f}}$ Io par quintal métrique.

sèches. . . . . . . 420

Peaux de veaux :

fraiches......... 250

sèches.

Peaux de chèves :

fraiches.

sèches.

Peaux de chevreaux :

fraiches........ . 6 »

sìches. . . . . . . . . I 2 »

Peaux de moutons ou d'agneaux :

lainés, fraiches...... . 210

- sèches. ....... 420

rason, sèzhes.

Les peaux non dénommées au tarif qui précède paient 6.25 p. Ioo ad valorem.

Ce droit est exigible, que les peaux soient brutes ou préparées, entières ou coupées, sans aucune exception.

Laines en suint ou en toison et déchets

(bonnetouf) . . . . . . $4^{\text {f } ~}$ par quintal métrique.

Laines lavées ou de mégisserie . . . 8 ”

Laines filées, chaine et tra ne . . . 2.) „ 
La perception à l'entrée peut être faite dans toutes les localités qui seraient désignées par arrêtés du directeur des funances.

$7^{\circ}$ Datles. - En rertu du décret du I 3 août I $S S_{7}$, les dattes sont assujetties à un droit de 6.25 p. Ioo de leur vialeur sur le prox de vente; à Tunis, le droit est perçu à l'entrée en vertu du décret du 13 janvier ISS5, qui a fixé ce tarif de la manière suivinte:

Lorsque l'introduction a lieu par la voie de terre (par charge de ch.meau):

$\left.9^{f}\right)$ sur les dattes degla;

4 so sur les dattes horral, ghars, alig, kenta, dattes de Gabès, de Hamma, de Djerba, ctc. ;

3 "sur les dattes bserr.

Lorsque l'introduction a lieu par voie de mer (par quintal):

Gf $״$ sur les dattes degla;

3 " sur les dattes d'autres qualités;

o go sur les dattes bserr.

So Bétail. - La vente des animaux est assujettie à un droit de 6.25 p. Ioo de la valeur en vertu du tarif général des mahsoulats. Le décret du 29 février ISSS a décidé que la rente des animaux ne pourrait avoir lieu que sur les marchés ou chez leurs propriétaires. Celles faites chez le proprićtaire et sans publicité sont affranchies de l'impôt. En cas de rente, le droit est dì solidairement par le vendeur et l'acquéreur.

$9^{\circ}$ Huiles. - Le régime fiscal de ce produit, qui autrefois variait de région à région, a été modifié par un décret 
du $1^{\text {er }}$ avril I 897 qui a soumis uniformément les huiles à un droit de 4 fr. par quintal à l'entrée des agglomérations d'au moins 500 hibitants. Le droit est perçu sur les olives d'après leur rendement présumé en huile, lorsque les producteurs font triturer ces produits dans les usines situées dans l'intérieur des périmètres de perception.

Le décret de i 897 a, en outre, institué pour les huiles et les olives le régime de l'entrepôt fictif. En accomplissant les formalités prévues par un arrêté du directeur des finances $\mathrm{du} \mathrm{I}^{\text {er }}$ avril $\mathrm{r} \$ 97$, les producteurs ou négociants d'huile peuvent obtenir le crédit de l'impòt sur des produits qui entreront ultérieurement dans la consommation locale, et la détaxe sur ceux qui seront exportés ou consommés en dehors des lieux sujets.

Indépendamment des droits d'entrée, le décret du I ${ }^{\text {er }}$ avril I 897 a imposé sur les huiles des droits de stationnement et de mesurage. Le droit de stationnement est fixé à o fr. $25 \mathrm{C}$. par quintal si le marché est situé à l'intérieur d'une localité sujette au droit d'entrée, et à I fr. si le marché est situé à l'extérieur. Le droit de mesurage est uniformément de o fr. 25 c. par hectolitre. Afin d'encourager le mode de transaction au poids, le décret décide que le pesage ser.ı gratuit.

D'après les dispositions de son article 7 , les municipalités peuvent, par décisions motivées, demander l'addition à leur profit, au principal du droit d'entrée, de centimes additionnels, jusqu'à concurrence de $2 \mathrm{fr}$. par quintal au maximum.

Afin de permettre aux populations des pays de production de s'affranchir des formalités inhérentes au régime de l'entrepôt, un décret du 28 décembre i 897 a permis lá conversion de la taxe sur les huiles en un droit d'abonnement mieux approprié aux besoins de chaque région. 
Les demandes d'option formulées par les représentants légaux des localités sont soumises à l'examen du directeur des finances, qui fixe par arrêté la taxe de substitution.

C'est en vertu de ces dispositions que sont intervenus les arrêtés des 26 septembre et 3 I octobre I 898 qui ont converti, dans les caïdats du Sahel, de Sfax, de La Skira, de l'Arad et des Ouerghamma, le droit d'entréc en un abonnement annuel de o fr. $50 \mathrm{c}$. par habitant, réparti sur les quantités d'huile d'olive exportées, à raison de I fr. par quintal métrique.

IO $0^{\circ}$ Bois a briler et charbon. - Ces produits sont assujettis à un droit de 6.25 p. 100 de leur valeur sur le montant des prix de vente, sauf à Tunis où ils acquittent les droits ci-après :

Charbon :

Charge d'ane .............. of 35

- de cheval ou de mulet. . . . . . . . o so

- de chameau ............ I "

Bois .

- de charrette........... 3 ".

Charge d'àne............. of is

- de cheval ou de mulet.......... . 020

- de chameau . . . . . . . . . o 40

- de charrette ............ I 20

Menus branchages et broussailles:

Charge d'âne. . . . . . . . . of Io

- de cheval ou de mulet. . . . . . . . o Ij

- de chameau . . . . . . . . . . . o 30

- de charrette ........... . . o 90

I $I^{\circ}$ Fruits el légumes. - Les droits sur les fruits et les légumes, qui étaient autrefois de 25 p. IOo ou I 2.50 p. Ioo de la valeur calculée d'après le prix de vente obligatoire sur. les marchés, ont été transformés en des droits spécifiques 
perçus à l'entrée. Le tarif de ces droits pour Tunis a été annexé aux décrets des 25 janvier el I m mars I 895 . Il est réduit du quart pour les villes de La Goulette, Kairouan, Sousse, Sfax, Monastir, Mehdia, Bizerte, Le Kef (décret du i2 décembre I895) et Béja (arrêté du directeur des finances du I 7 juillet I 897 ).

Dans toutes les autres localités, et en vertu du décret du I 2 décembre $1 \$ 95$, les anciennes taxes ont été remplacées par un droit de stationnement ì raison de o fr. $20 \mathrm{c}$. et de o fr. 40 c. par mètre superficiel occupé, suivant que les marchés sont à l'intérieur ou à l'extérieur des localités sujettes.

Aux droits d'entrée et de stationnement dont il est parlé ci-dessus peut s'ajouter, le cas échéant, un droit facultatif de criée fixé à I p. Ioo à Tunis et, dans les autres localités, à 2 p. roo du montant du prix de l'adjudication.

I $2^{\circ}$ Poisson. - Le poisson, qui était autrefois soumis au même régime que les fruits et les légumes, a été assujetti; par le décret du I 7 juillet I $S_{97}$, à une taxe perçue à l'entrée des agglomérations d'au moins 500 habitants. Le tarif annexé à ce décret détermine les catégories de poissons imposables et fixe pour chacune d'elles le taux de l'imposition. ..

Les poissons grossiers, tels que squales, gran łes raies, chiens de mer, sont affranchis du droit d'entrée.

Il est question de reviser ce tarif; en attendant, des instructions ont été données pour qu'en aucun cas le tarif ne dépasse le montant des anciens.

$I 3^{\circ}$ Paille ct fourrages. - - Les pailles et fourrages sont assujettis au droit d'entrée à Tunis, La Goulette, Kairouan, Sousse, Sfax, Monastir, Mehdia, Bizerte, Le Kef et Béja. 
Le tarif est de ofr. 25 c. par roo kilogr. de paille, o fr. 20 c. par 100 kilogr. d'autres fourrages secs et o fr. Io c. par Ioo kilogr. de fourrages verts. Partout ailleurs, le droit est fixé d̀ raison de 6.25 p. roo du prix de vente.

$14^{\circ}$ Alcools. - Le Trésor tunisien a subi en I 898 , du chef de la réforme du régime fiscal des céréales et légumes secs et de l'établissement du nouveau régime douanier, une perte considérable que l'administration du protectorat, d'accord avec la conférence consultative, a dû couvrir par l'établissement de droits de consommation sur l'alcool et les sucres et l'institution des monopoles des allumettes et des cartes à jouer.

Les droits de consommation sur l'alcool et les spiritueux ont été fixés, par un décret du 2 mai 1898 , à raison de 5o fr. par hectolitre d'alcool pur. Les vins naturels alcoolisés ou non alcoolisés ne supportent l'impôt que sur les quantités d'alcool excédant $15^{\circ} 9$. Les absinthes, eaux-devie et liqueurs en bouteilles sont considérées comme titrant $60^{\circ}$. Les bouteilles sont comptées pour un litre et les demibouteilles pour un demi-litre.

La réglementation des droits sur l'alcool a fait l'objet d'un arrêté du directeur des finances du 20 mai I 898 . Aux termes de cet arrêté, le droit est dù :

$I^{\circ}$ Au moment de l'importation dans la Régence;

$2^{\circ}$ A l'entrée dans les lieux sujets (agglomérations d'au moins joo habitants);

$3^{\circ}$ A la sortie des établissements producteurs, lorsque ceux-ci sont situés en dehors des lieux sujets.

La fabrication des eaux-de-vie, esprits et liqueurs de toute nature, ainsi que la fermentation des matieres sucrées ou de distillation, doit faire l'objet d'une déclaration préalable 
au bureau des contributions diverses de la circonscription du fabricant. Toutefois, les bouilleurs de cru distillant exclusivement les produits de la vigne sont affranchis de cette formalité. Les eaux-de-vie qu'ils produisent ne sont assujetties à l'impôt qu'à leur entrée dans les localités de 500 habitants et au-dessus, à moins qu'elles ne doivent simplement transiter par ces agglomérations, auquel cas elles sont admises au régime du passe-debout.

Les détenteurs d'une quantité minima de vingt hectolitres d'alcool pur peuvent demander pour leurs produits l'application du régime de l'entrepôt fictif, qui leur est accordé s'ils présentent une caution solvable s'engageant solidairement avec eux au paiement des droits afférents aux quantités de spiritueux dont la sortie de l'entrepôt ne serait pas régulièrement justifiée. Les fabricants d'alcools et de spiritueux composés sont, de droit, entrepositaires.

La circulation des produits à base d'alcool n'est permise à l'extérieur des lieux sujets que si le conducteur est muni d'un titre de mouvement qui, en principe, doit toujours être demandé au bureau des contributions diverses et qui, exceptionnellement, peut être établi par l'expéditeur luimême s'il est bouilleur de cru ou s'il y a été spécialement autorisé par l'administration. Le titre de mouvement n'est obligatoire dans le périmètre des localités sujettes que pour les spiritueux circulant en cercles ou en bonbonnes, si leur volume dépasse Io litres.

Les fabricants, marchands et détenteurs d'appareils distillatoires sont tenus d'en faire la déclaration au bureau des contributions diverses de leur circonscription. Aucun déplacement d'appareil ne peut être effectué sans une autorisation de l'administration.

Le vinage, interdit en Tunisie par un décret du 27 jan- 
vier 1898 ì l'égard des vins destinés à la consommation intérieure du pays ou à l'exportation en France, a été autorisé par un décret du 29 août I $\$ 9$ S, en franchise des droits sur l'a!cool emploreé à certe manipulation, à l'égard des vins destinés à l'exportation dans tous autres pays que la France et l'Algérie. Les exportateurs des vins doivent, pour bénéficier de l'exemption du droit, se soumettre aux formalités prescrites par ledit décret. Ces formalités, réduites au strict nécessaire, sont réglées sur celles en vigueur en Algérie. Les producteurs seuls ont la faculté du vinage, et seulement pour les vins provenant de leur récolte.

: Le mutage est autorisé en Tunisie, mais la franchise du droit n'est accordée qu'aux alcools employés au mutage des vins destinés à l'exportation, même en France et en Algérie. Les producteurs et les fabricants de vins mutés sont:de plein droit entrepositaires des quautités d'alcool nécessaires à leur fabrication.

- Le mouillage et le survinage sont prohibés, en Tunisie comme en France et en Algérie, par le décret du 27 janvier I $\$ 9 S$.

$15^{\circ}$ Sucres. - Ainsi qu'il a été dit au paragraphe relatif à l'alcool, les sucres ont été assujettis, le 2 mai $I S 9 S$, à des droits de consommation destinés à couvrir les dégrèvements opérés sur les céréales et là modification du régime douanier.

- Ces droits de consommation sont exigibles:-

$I^{\circ}$ Au moment de l'importation des produits en Tunisie;

$2^{\circ}$ Au moment de la fabrication en Tunisie; mais aucune fabrique n'existant actuellement en Tunisie, il n'a pas paru encore nécessaire de réglementer la perception des droits exigibles sur la fabrication. 
Les droits de consommation sont, par quintal métrique: de $6 \mathrm{fr}$. sur les sucres bruts, de Io fr. sur les sucres raffinés autres que candis, et de 25 fr. sur les candis.

I $6^{\circ}$ Autres produits. - Ils sont imposés d'après le tarif général des mahsoulats, reproduits à la page zor de i'ouvrage de M. Bompard: Législation de la Tunisie.

ObSERVATION GENERRALE. - Pour tous ceux des produits dont la désignation précède, qui sont soumis aux droits d'entrée, il est à noter que les introducteurs peuvent s'affranchir du paiement du droit lorsque les produits introduits rie sont pas destinés à la consommation locale et doivent simplement transiter à travers la localité sujette; il leur suffit d'en faire la déclaration et de déposer en consignation les droits d'entrée, ou de fournir caution. Moyennant cette formalité, il leur est délivré un passe-debout au vu duquel ils obtiennent, à la sortie des produits, le remboursement de leur consignation ou la décharge de la caution. Les introducteurs qui veulent s'affranchir de la consignation ou de la formalité du cautionnement peuvent demander l'escorte du produit, moyennant le versement d'une somme de un franc, qui reste en tout état de cause acquise au Trésor.

I $7^{\circ}$ Foulons de chéchias. - La fabrication des chéchins est une des plus importantes industries indigènes. Le foulage des chéchias s'opère à l'usine de Tebourba, qui appartient à l'État, et dont la direction technique appartient au service des monopoles.

Pour le foulage, les fabricants paient à l'État une redevance de o fr. $90 \mathrm{c}$. par kilogr. de chéchias. L'État fait face, 
au moyen de cette redevance, aux dépenses de l'usine à foulons et du personnel chargé de la réception des chéchias i fouler et de leur restitution aux fabricants. I.c produit net, s'il en existe, est encaissé par le Trésor, parmi les droits de mahsoulats.

PRODUITS DES MONOPOLES ET EXPLOIT.ATIONS MNDUSTRIELLES $D E$ L'ETAT

Monopoles. - Les produits monopolisés sont, depuis la suppression du monopole du platre indigène à $\mathrm{T}$ unis et dans sa binlieue, les tabacs, les poudres à feu, les sels et, en vertu des deux récents décrets du I 4 juillet I 898 , les allumettes et les cartes i jouer.

Le monopole des poudres a toujours été administré en régie par l'État.

Les monopoles des tabacs et des sels ont été affermés par la direction des contributions diverses jusqu'au 3 I décembre $1 \$ 90$. Depuis le I er janvier I 89 I, ils sont régis, avec celui des poudres, auquel se sont ajoutés, au cours de i $\$ 9 S$, les monopoles des allumettes et des cartes i jouer, par le service spécial dit "des monopoles " que dirigent des ingénieurs français, sous l'autorité du directeur général des finances.

Les tabacs livrés à la consommation proviennent soit de la culture tunisienne, soit de la régie française, soit d'achats faits directement dans les pays producteurs des diverses varićtés de tabacs.

La culture du tabalc en Tunisie est subordonnéc it l'autorisation préalable de l'administration; clle est limité aux territoires des caildats de Nibeul, Soliman, Mateur, Bizerte et Béja, et aux o.ısis de Tozeur, Nefta et Oudiane. Les 
planteurs doivent se soumettre à la surveillancé des agents des monopoles et à la réglementation spéciale du décret du 25 août i 898 et de l'arrêté réglementaire du directeur général des finances du 27 du même mois.

Les tabacs en feuilles provenant de la culture tunisienne ou des achats à l'étrànger sont manutentionnés et transformés en produits fabriqués à la manufacture des tabacs de Tunis.

Les poudres de chasse et de mine vendues par le service des monopoles proviennent toutes de l'administration fran- çaise.

Les sels proviennent en majeure partie de l'exploitation des salines indigènes. Seul, le sel pour la pêche provient d'achats faits il l'étranger.

Les allumettes et les cartes à jouer sont achetées par le service des monopoles aux maisons dont les produits sont recherchés par la consommation.

Les monopoles ont produit, en I897, un revenu brut total de 5,404, I 2 f fr. 95 c., ainsi décomposé :

Tabacs $4,569,020^{f} 06$

Poudres I 60,3 I 279

Sels . 674,789 10 $5,404,12 \mathrm{If}^{\mathrm{f}} 9 \mathrm{~s}$

Les frais de régie, y compris l'achat des matières premières, ayant été de. $1,501,76383$

Le produit net ou bènéfice de l'État a été de $3,902,358 \mathrm{f}+2$ En 1890 les fermages avaient rapporté net à l'État :

Tabacs.......... I, . 1,365,000 "

Sels

$$
\begin{array}{r}
405,600 \text { ") } \\
84,82048 \\
\hline 1,8 ; 5,420^{f} 48
\end{array}
$$

Poudres.

Le rendement net en 1897 a donc été supérieur de. . I, $855,420^{f} 48$ à celui de 1890 . 
Le produit des allumettes et des cartes à jouer est préru au budget de IS99 pour une somme brute de 400,000 fr.

Exploitations industrielles de l'État. - En dehors de celles des monopoles, les seules exploitations de l'État tunisien sont celles régies par l'office postal et télégraphique, à savoir : la poste, les télégraphes, les téléphones, les colis postaux et la caisse d'épargne postale.

\section{- PRODUITS DES DOMAINES}

Ces produits proviennent : $\mathrm{I}^{\circ} \mathrm{du}$ domaine public; $2^{\circ} \mathrm{du}$ domaine privé de l'État; $3^{\circ}$ du domaine forestier; $4^{\circ}$ des mines; $5^{\circ}$ des pêcheries.

Produits dn domaine public. - Le domaine public est géré par le directeur général des travaux publics (décret du 24 septembre 1885 ), mais les produits en sont encaissés par les comptables de la direction générale des finances.

Produits du domaine de l'Etat. - Le domaine immobilier de l'État est géré: le domaine affecté aux services publics, par la direction générale des finances; le domaine non affecté, par le directeur de l'agriculture et du commerce.

Les produits du domaine de l'État consistent en lojers et fermages, en prix de vente des récoltes des propriétés domaniales, en rentes domaniales et enzels et en prix de vente d'immeubles domaniaux.

Toutefois, les prix des ventes d'immeubles consenties ou a consentir depuis le $x^{e r}$ janvier I 898 sont, jusqu'à concurrence d'un million de francs, encaissés au compte du bud- 
get extriordinaire et affectés au développement de la colonisation en Tunisie.

L'ensemble des opérations que comporte l'exécution de ce programme doit être réparti sur une durée de six ans qui arrivera à expiration le 3 I décembre 1903.

Indépendamment du domaine immobilier, l'État possède un domaine nobilier garnissant les immeubles domaniaux affectés à des services publics. Ce mobilier ne peut être, en principe, aliéné qu'après que la réforme en a été prononcée par l'autorité compétente. La vente a lieu aux enchères, et le produit est enciissé au compte du budget ordinaire, avec les autres produits domaniaux.

Produits du domaine forestier. - Le domaine forestier est géré par un personnel détaché de l'administration française des forêts et placé actuellement sous l'autorité du . directeur de l'agriculture. Les produits du domaine forestier font l'objet d'un article spécial du budget des recettes; ils sont recouvrés par les agents des finances.

Produits des mines. - L'exploitation des mines donne lieu à la stipulation, au profit de l'État, de redevances qui sont encaissées au budget sous un article spécial, par les agents des finances.

Produits des pêcheries:- Les produits des pêcheries consistent en :

$\mathrm{I}^{\circ}$ Une, redevance de $8, \mathrm{I} 00$ fr. payée au gouvernement tunisien par les pêcheurs de corail;

$2^{\circ}$ Le produit de la pêche des poulpes et des éponges;

$3^{\circ}$ Les redevances des amodiataires des pêcheries dans les lacs de la Tunisie. 
Le produit des pêcheries fait l'objet d'un article spécial du budget.

Les produits divers ont, pendant longtemps, compris des ressources provenant de la liquidation de droits litigieux du Gouvernement dans les affaires antérieures à l'institution du protectorat français. Cette source de revenus est aujourd'hui à peu près épuisée et, sous le titre : "Droits et produits divers", le budget tunisien ne comprend plus que des sommes d'un caractère à peu près permanent. Tels sont les droits d'immatriculation de la propriété foncière, les droits de plombage et de magasinage en dotiane, les droits de chancellerie des tribunaux indigènes, les droits de chancellerie perçus aux vice-consulats de France, les amendes infligées par les tribunaux français et indigènes en Tunisie, les taxes de vérificition de poids et mesures, le produit du travail des détenus, etc.

\section{$2^{\circ}$ Ressources extraordinaires.}

Les diverses ressources extraordinaires du gouvernement tunisien ont consisté, jusqu'ici, dans les bénéfices des conversions de sa Dette et en fonds de concours.

La conversion en 1884 dé la Dette perpétuelle 5 p. Ioo en 4 p. 100 a rapporté . . . . . . . . . 4,472,796 19 I. a conversion en 1889 de la Dette perpétuelle 4 P. 100 en amorissable $31 / 2 \mathrm{p}$. Ioo a produit une soulte de $6,132,24772$ Celle de la Dette ; I/2 p. Ioo en amortissable 3 p. I00 9,805,766 25 Total ...... 20,410,81 of 16

Le bénéfice de l'emprunt ISS4 a été affecté à la dotation 
du fonds de réserve. Les bénéfices des conversions de I 889 et de 1892 ont été employés en grands travaux publics.

Les fonds de concours proviennent des contributions volontaires des compagnies et des particuliers aux dépenses de travaux auxquels ils sont directement intéressés. Le budget de la Régence présente tous les ans, sous un article spécial, le détail des encaissements au titre de fonds de concours et l'emploi qui leur est donné en dépense.

Parmi les ressources exceptionnelles, il faut citer encore:

Les prélèvements, qui ne sont opérés qu'avec l'autorisation du gouvernement français, sur les diverses réserves du Trésor tunisien;

Les prix des ventes de biens domaniaux aliénés ou à aliéner, jusqu'à concurrence d'un million de francs, pour faire face aux dépenses de colonisation;

Les sommes versées par les collectivités indigènes aux dépenses d'aménagement de points d'eau et d'alimentation en eau potable (décret organique du 25 janvier I897);

Les remboursements par les associations syndicales d'irrigation des avances qui peuvent leur être faites en matière d'hydraulique agricole (décret organique du is septembre I 897);

Ces diverses ressources extraordinaires ont contribué et contribueront de plus en plus à donner de l'essor au développement des grands travaux de premier établissement de la direction générale des travaux publics.

3o Ressources spéciales.

Les divers comptes de ressources spéciales, qui ont longtemps figuré au budget tunisien, sont aujourd'hui définiti- 
LA TUNISIE.

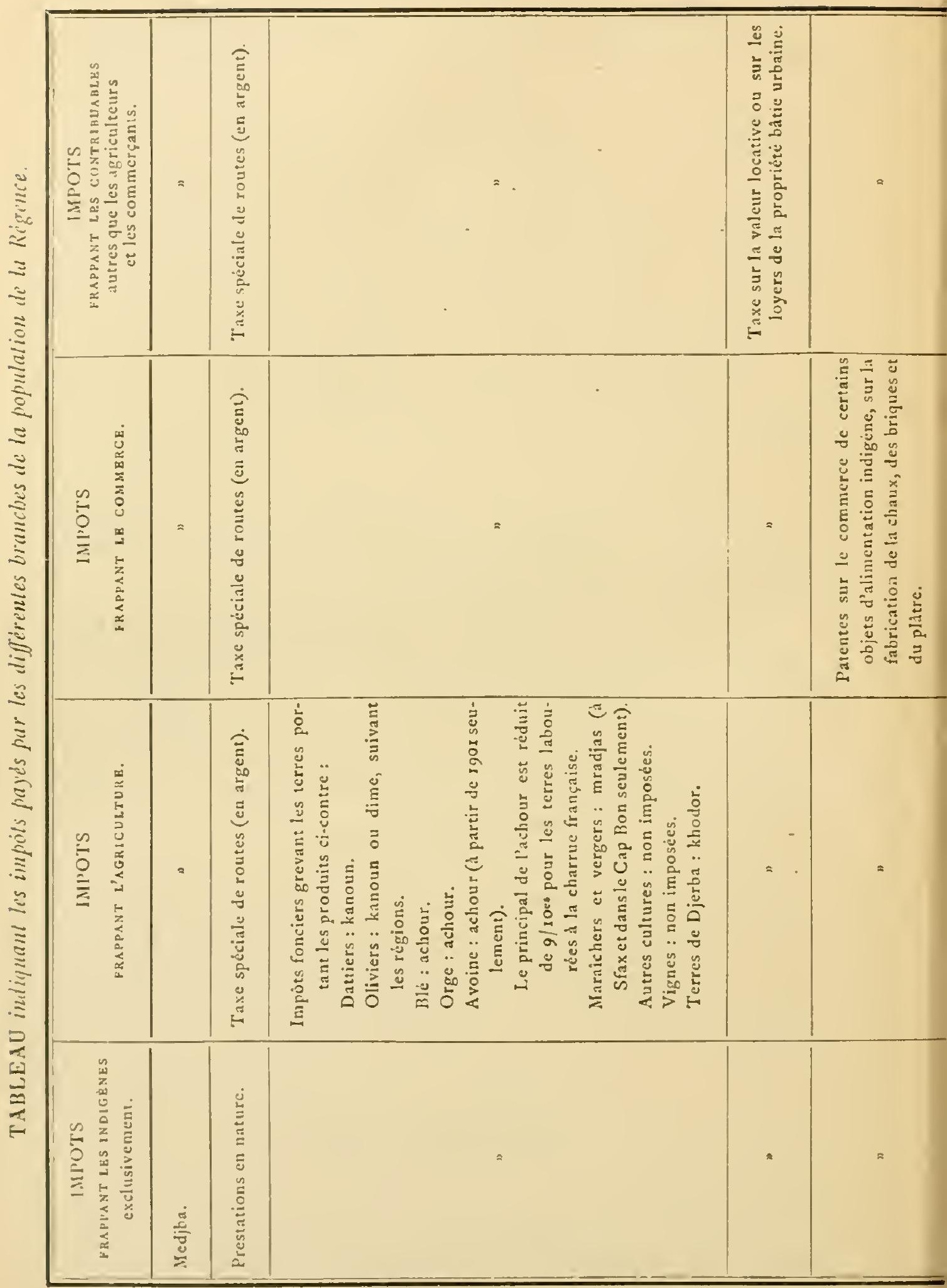




\begin{tabular}{|c|c|c|c|}
\hline 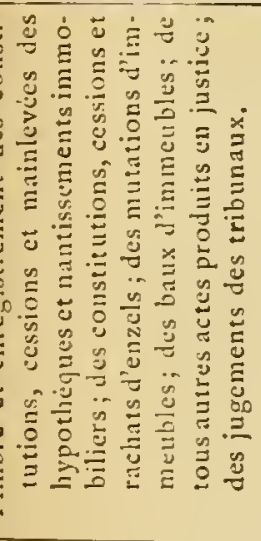 & 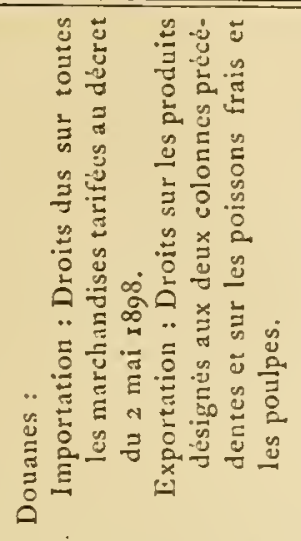 & 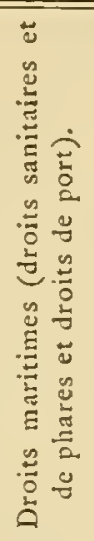 & 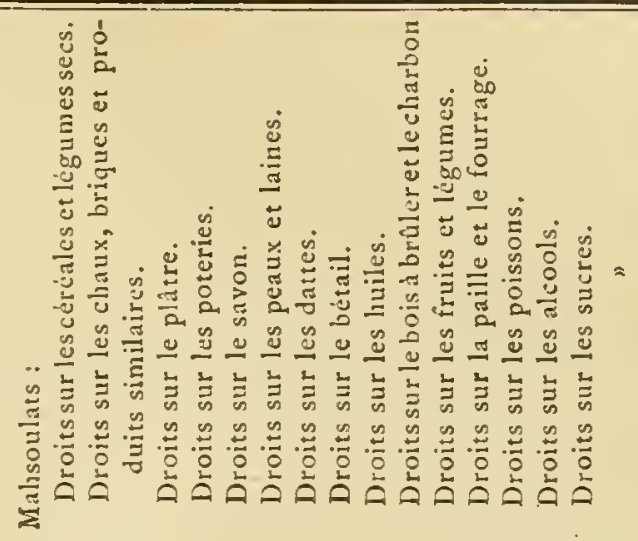 \\
\hline 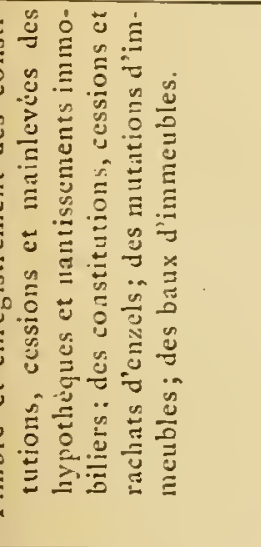 & 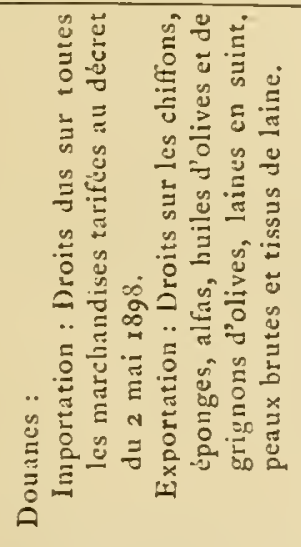 & 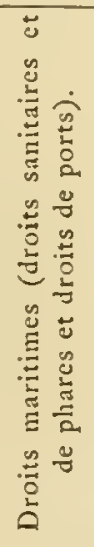 & 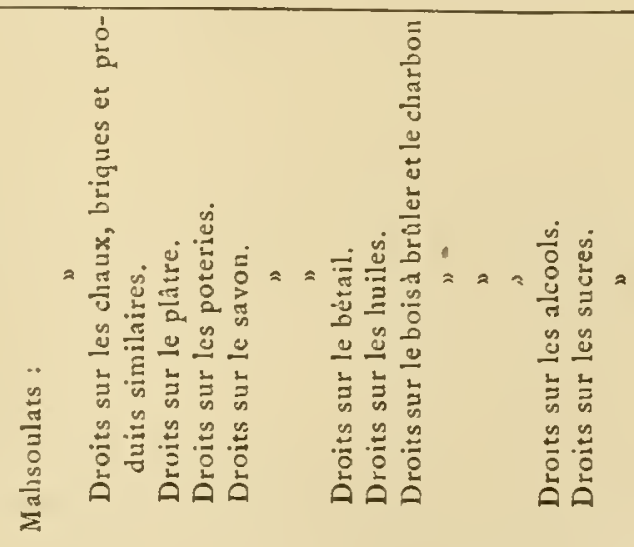 \\
\hline $\begin{array}{l}0 \\
0 \\
0\end{array}$ & 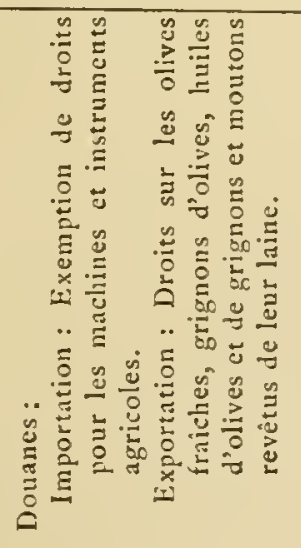 & $=$ & 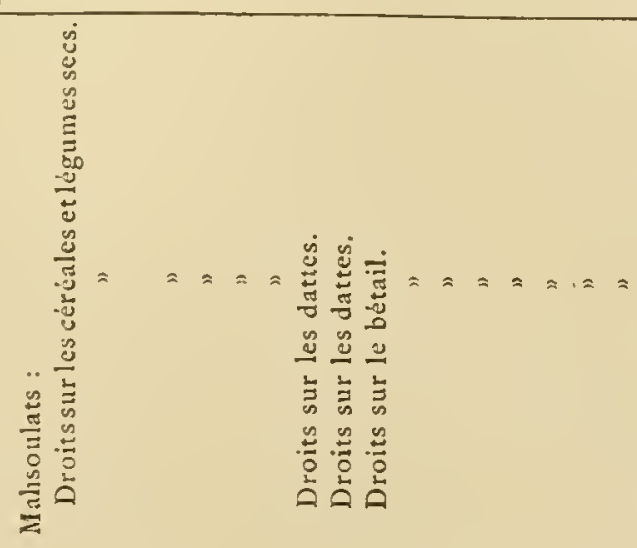 \\
\hline$\approx$ & $z^{\prime}$ & $=$ & 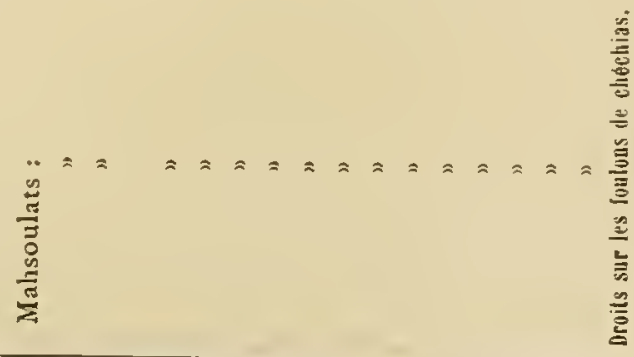 \\
\hline
\end{tabular}


vement clos. Ils avaient principalement pour objet la liquidation d'opérations de l'ancienne Dette tunisienne ou des conversions de ISS4, ISS9 et de I $S_{92}$. Toutes les sommes dont le 'Tresor tunisien pouvait être débiteur à ces divers titres sont aujourd'hui ou payées ou éteintes par suite de la déchéance sexennale opposable, en vertu de la législation tunisienne, aux créanciers de l'Étatt.

Répartition des impóts entre les diverses classes de la population tmisienne. (Voy. les tableaux, p. 206 et 207.)

Il a paru intéressant de rechercher de quelle manière les impôts se répartissent entre les divers groupes de la population établie en Tunisie. Il ne faut pas se dissimuler, toutefois, qu'un pareil traviil ne peut offrir un caractère d'exactitude absolue. Seuls, en effet, les impôts qui atteignent directement la personne du contribuable peuvent fournir un élément certain d'appréciation.

A l'égard des impóts directs qui frappent les biens, le problème de savoir dans quelle proportion ils portent sur telle ou telle catégorie de lis population est déjà bien difficile à résoudre, en l'absence de renscignements statistiques sur la manière dont la propriété immobilière est possédée en Tunisie par les diverses nationalités. Mais où le problème apparait comme presque insoluble, c'est sur le point de savoir comment les impôts indirects se répartissent entre les divers contribuables. D'une part, il est très difficile de déterminer par qui l'impôt est payé au premier degré; d'autre part, il est presque impossible de savoir sur qui il retombe cn définitive après un ou plusieurs cals d'incidence. Notamment, il n'est pas absolument exact de dire, comme on le fait généralement, que les droits de douane, les droits sur les alcools, ceux sur les sucres, frappent le commerce pro- 
prement dit, puisque le commerce augmente d'autant ses prix de vente au consommateur.

Quoi qu'il en soit, on a essayé d'établir un tableau des charges qui grèvent plus particulièrement l'agriculture et le commerce, abstraction faite de la nationalité des personnes qui s'y adonnent. C'est ce que fait ressortir le tableau d'autre part, qui indique en même temps les impôts exclusivement payés par les indigènes et ceux qui frappent les contribuables, européens ou indigènes, qui ne sont ni agriculteurs ni commerçants.

RÉSULTATS DE L'ADMINISTRATION DE LA DIRECTION GÉNÉRALE DES FINANCES DEPUIS LE I 3 OCTOBRE I $8 S_{+}^{+}$

La gestion de la direction des finances depuis le I 3 octobre $\mathrm{I} S 8_{4}$ a produit les résultats suivants :

I. - La Dette tunisienne, par trois conversions successives, a pu être transformée de perpétuelle en amortissable.

II. - Le système monétaire de la Régence a été réformé en $\mathrm{I} 892$.

III. - Tous les budgets depuis I 884 , sauf deux, se sont liquidés par des excédents de recettes qui constituent une réserve pour le cas de déficit et le principal aliment du budget extraordinaire des travaux publics.

Ces résultats vont être successivement examinés:

\section{CONVERSIONS DE LA DETTE}

Conversion de $I \$ \$ 4$. - Sur l'engagement pris par le bey, le $S$ juin $\mathrm{I}_{3} S_{3}$, de procéder aux réformes administratives, judiciaires et financières qui lui seraient indiquées, le gou- 
rernement de la République française s'est engagé (loi du I o avril ISS 4) à garantir un emprunt à émettre par le gourermement tunisien pour la conversion ou le remboursement de sa Dette perpétuelle s p. Ioo au capital nominal de. . . . . . . . . . $125,000,000 \mathrm{fr}$. et d'une Dette flottante évaluée à

$$
17,550,000
$$

Total.

I $42,550,000 \mathrm{fr}$.

Cet emprunt a été négocié sous la forme de 3 i, 376 obligations perpétuelles de $500 \mathrm{fr} .4 \mathrm{p}$. roo au porteur, exigeant un intérêt annuel de 6,307,520 fr. Ainsi qu'il a été dit plus haut, l'opération a laissé au Gouvernement un boni de $4,472,796 \mathrm{fr}$. I9 $\mathrm{c}$.

Conversion de I $S \mathcal{S 9}$. - Avec l'autorisation du gouvernement français (loi du 9 février ISS9), le gouvernement tunisien a substitué, le 7 mars suivant, à sa Dette perpétuelle 4 p. I00, 34S,S I 5 obligations de $500 \mathrm{fr}$. 3 I $/ 2$ p. I 00 au porteur, amortissables en quatre-ringt-dix-neuf ans par la voie de tirages au sort semestriels. Cet amortissement a régulièrement fonctionné et, en I $\$ 92$, au moment de la conversion dont il va être parlé ci-après, il ne restait plus en circulation que 347,54 I titres 3 I $/ 2$ p. Ioo.

La conversion de I8S9 a rapporté au gouvernement tunisien un bénéfice de six millions de francs, qui s'est trouvé porté à $6,132,247 \mathrm{fr} .72 \mathrm{c}$. par suite d'opérations diverses.

Conversion de IS92. - Toujours avec l'autorisation du gouvernement français (loi du 25 juin I 892 ), le gouvernement tunisien a décidé, en I $\$ 92$, de ramener l'intérêt de sa Dette de 3 I $/ 2$ p. Ioo it 3 p. I OO. L'opération a été réalisée 
le I 2 juillet I 892 , par la substitution aux 347,54 I titres 3 I/2 p. Ioo encore en circulation, de 396,386 obligations 3 p. 100 de $500 \mathrm{fr}$., amortissables en quatre-vingt-seize ans. L'opération a rapporté au trésor tunisien un boni de 9,805,766 fr. 25 c.

L'intérêt et l'amortissement de la Dette 3 p. Ioo sont assurés avec l'annuité de 6,307,250 fr. qui était déjà affectée en I 884 au seul intérêt de la dette perpétuelle 4 p. IoO. Ainsi, sans charge nouvelle pour le Trésor, et tout en lui procurant pour plus de vingt millions de boni, la gestion de la direction des finances a permis l'amortissement d'une dette autrefois perpétuclle.

Le gouvernement beylical s'est interdit la faculté de procéder à une nouvelle conversion avant l'année I 902.

RÉSULTATS DES RÉGLEMENTS DE BUDGETS DEPUIS I $88_{4}$

Sauf les budgets de i 887 -I 888 et de r 888 -1 889 , tous les budgets de la Régence se sont liquidés par des excédents de recettes dont le total dépasse 36 millions de francs.

Ce capital, joint aux disponibilités léguées par l'adninistration financière (près de 8 millions), boni des trois conversions de la Dette et aux intérêts de ces capitaux, a permis d'affecter aux truvaux publics et à diverses autres dépenses extriordinaires des crédits qui, à ce jour, atteignent un total d'environ 60 millions de francs.

Le surplus des excédents a servi à constituer un fonds de réserve au capital de $S$ millions et un autre fonds dit "des excédents disponibles", qui présente encore à ce jour un actif de près de deux millions. 
LA TUNisie.

Ces résultats sont d'autant plus significatifs qu'ils ont été atteints malgré des dégrèvements ou abandons de taxes qui représentent un chiffre annuel de plus de six millions de francs. 


\title{
CHAPITRE XXIV
}

\author{
PROGRESSION ET REPPARTITION DES DÉPENSES \\ DU PROTECTORAT
}

Les dépenses publiques ordinaires du gouvernement tunisien peuvent être divisées en quatre groupes:

$I^{\circ}$ Dette;

$2^{\circ}$ Liste civile. A la liste civile se rattachent les dépenses d'entretien de la garde beylicale;

$3^{\circ}$ Frais d'administration;

$4^{\circ}$ Travaux publics.

$$
\text { I. - DETTE }
$$

Les dépenses de la Dette sont classées dans le budget sous le chapitre Ier (Direction générale des finances). Elles sont présentées, sous trois articles relatifs, l'un aux échéances de l'année courante, l'autre aux arriérés des échéances antérieures ${ }^{1}$, le troisième, aux frais divers qu'entraîne le paiement de la Dette en France.

Les intérêts de la Dette se prescrivent par cinq ans. Ils sont généralement réclamés par les porteurs avant cette

I. Jusqu'en $189 \mathrm{~g}$ inclusivement, ces arriérés ont figuré au budget parmi les dépenses d'exercices clos. 11 y est fait face au moyen du report, d'exercice en exercice, des crédits affectés au service de la Dette et non employés. 
échéince et la valeur des coupons dont le Trésor bénéficie par suite de la prescription est insignifiante.

En r 898, le gouvernement tunisien a payé pour le service de la rente la somme de $6,307,520 \mathrm{fr}$.

\section{II. - LISTE CIVILE}

Un décret beylical du 26 avril i86I (I chaoual I277), relat if a l'organisation politique de la Régence, a réglementé ainsi qu'il suit (articles 29 et 30 ) la composition de la liste civile :

720,000 fr. par an étaient ailoués au chef de l'État.

Les princes et princesses de la famille régnante avaient droit :

$1^{\circ}$ A des dotations annuelles de chiffres variables ( $\mathrm{r}, 800 \mathrm{fr}$., 3,600 fr., 4,800 fr., 7,200 fr., I2,000 fr., 39,600 fr.), suivant qu'il s'agissait d'un prince ou d'une princesse et que le bénéficiaire était orphelin ou sous la puissance patternelle, majeur ou mineur, cellibataire, marié ou veuf;

$2^{\circ} \mathrm{A}$ des dotations une fois payées pour frais de noces (9,000 fr. aux princes et $30,000 \mathrm{fr}$. aux princesses).

On voit par là que le chiffre des dotations des princes et princesses n'était ni fixe ni limité et qu'il pouvait indéfiniment s'accroitre avec l'accroissement de la famille régnante.

A la suite de l'établissement du protectorat, la liste civile a été réglementée à nouvenu. Arrêtée d’abord à la somme fixe de $\mathrm{r}, 200,000 \mathrm{fr}$. par an par la convention du $S$ juin 1883 entre la France et la Tunisie (loi française du ro avril I884), elle a été élevée, en vertu d'une délibération du conseil des ministres et chefs de service du gourernement 
tunisien du 1 I novembre I 884 , approuvée par S. A. le Bey et par le gouvernement français, à la somme fixe annuelle de I, 680,00o fr. ainsi répartie :

Dotation de S. A. le Bey. . . . . . . 920,000 fr.

Dotations des princes et princesses. . . 660, 0 0

Personnel et service des palais ... I 120,000

Total. ... $\overline{\mathrm{I}, 680,000} \mathrm{fr}$.

Sur l'ordre dı gouvernement français, le chiffre des dotations des princes et princesses a été, en I 885 , augmenté de 60,000 fr. et porté à 720,000 fr. Mris, à la suite de conventions spéciales avec le prince dotataire de cette augmentation, il a été ramené à 660,000 fr. à partir du I ${ }^{\text {er }}$ janvier I 893 .

Le chiffre des dotations des princes et princesses est fixe, c'est-ì-dire qu'il ne varie pas avec le nombre et les changements d'état civil des membres de la famille régnante. Aucune dotation nouvelie ne peut être constituée, ni aucune dotation existante augmentée, que dans la limite des extinctions.

Aux dépenses de la liste civile se rattachent celles de la garde beylicale. Les corps de troupe qui la composent ${ }^{\mathrm{I}}$ sont en effet exclusivement affectés au service de $S$. A. le Bey, dont ils constituent la garde et l'escorte ${ }^{2}$.

Au même cliapitre du budget sont rattachées les dépenses

1. Quatre compagnies d'infanterie, un peloton de cavalerie, trois sections d'artillerie.

2. Dans le rapport qu'il a adressé à S. A. le Bey pour lui présenter !e projet du budget pour l'exercice I 300 ( $\left.188_{3}-1894\right)$, le Résident gènéral s'est exprimé ainsi qu'il suit à cet ègard :

"L'armée tunisienne a été complètenent réformée. Elle se composera d'un bataillon "d'infanterie, d'un peloton de cavalerie et d'une section d'artillerie. Ces troupes seront " armèes et entretenues comme l'armée française elle-même; elles formeront une garde

"digne de Votre Altesse." 
de la Résidence générale et des contrôles civils. Au budget de 1900 ces dépenses s'élevilient pour le personnel à la somme de I06,600 fr. et pour frais de service et matériel, conférence consultative, secours et rapatriements à la somme de 96, ioo fr. Le service des contrôles civils al été créé par un décret du Président de la République du 4 octobre $S S_{+}$pour exercer auprès de l'administration locale les droits de protectorat que le Résident lui-même exerce auprès du Bey et le secrétaire général du gouvernement atuprès de l'administration générale tunisienne. Les dépenses des contrôles civils ont d'abord été classées sous le chapitre III du budget, c'est-i-dire avec les dépenses d'administration générale. Elles ont fait en I 89 I l'objet d'un chapitre distinct, qui a été ouvert dans les comptes, il la suite de la création, par le décret du Président de la République du I 6 octobre I 890 , de la Direction des renseignements et des contrôles. A partir du $\mathrm{I}^{\text {er }}$ janvier $\mathrm{r} 895$, le service des contrôles a été rattiché ì la Résidence générale. En I goo, les dépenses de ce service se sont élevées pour le personnel

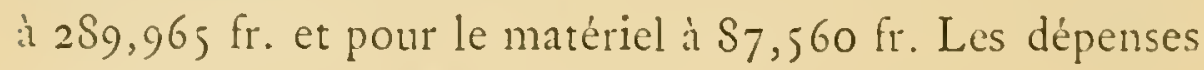
de ce service ont suivi la progression suivante:

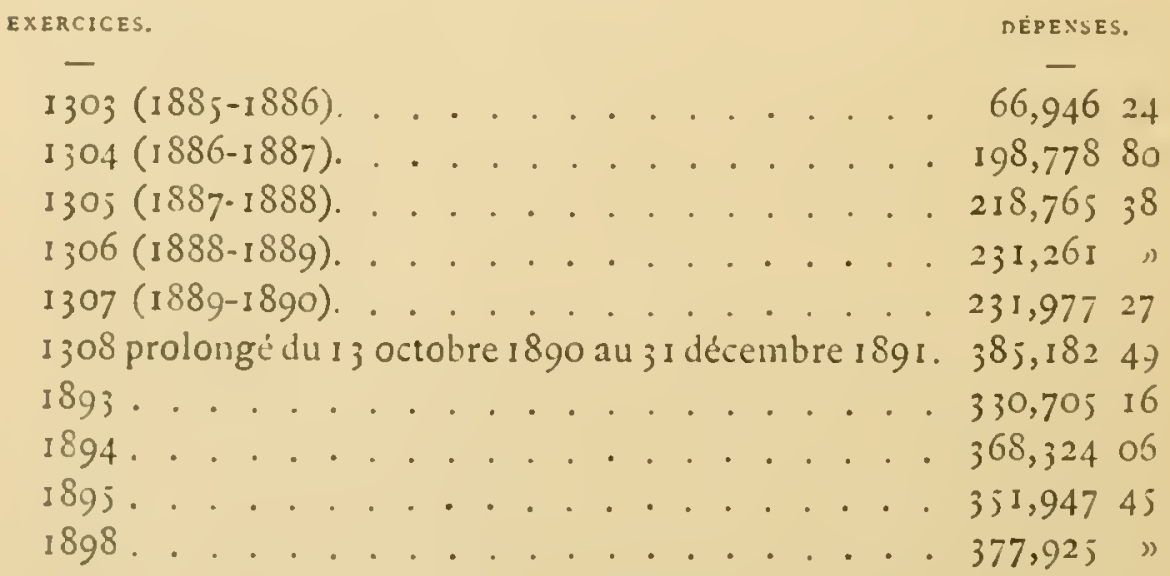


Les dépenses d'administration figurent actuellement au budget sous cinq chapitres :

Chap. Ier. - Finances.

Chap. II. - Postes et télégraphes.

Chap. III. - Administration générale.

Chap. IV. - Agriculture et commerce.

Chap. V. - Enseignement public.

Chap. VI. - Armée tunisienne; - Recrutement et Maghzens.

Chap. VII. - Travaux publics.

Chatitre ${ }^{\mathrm{er}}$. - Finances.

Les dépenses d'administration rattachées à ce chapitre sont :

Les frais des décorations tunisiennes;

Les pensions civiles et militaires;

Les frais du fonctionnement des régies financières et $\mathrm{du}$ service central;

Le traitement du personnel et les dépenses de matériel de la Cour des comptes;

Les frais de frappe de monnaies;

Le remboursement au Trésor français des frais du service médical des indigènes nécessiteux en territoire de commandement.

Frais des décorations tunisiennes. - Les décorations tunisiennes sont de trois sortes:

La décoration de l'Aal, dite du Sang, réservée aux prin- 
ces de la famille beylicale, mais qui est quelquefois conférée à des membres de familles régnantes étrangères;

L'insigne du Pacte (Nichan-el-Ahed), dont l'attribution et le port sont réglementés par un décret du i 6 janvier I 860 et qui place son titulaire en dehors de la classe des grandscroix et au-dessus de celle des grands-officiers du NichanIfiickar;

Les décorations du Nichan-Ifrickar sont divisées en quatre classes : chevalier, officier, commandeur, grand-officier, et une clisse majeure : grand cordon. Elles sont réglementées par un décret du 2 I août I $S S 7$ et conférées, suivant le cas, gratuitement ou contre le paiement de droits gradués de chancellerie de deux catégories différentes.

Le service de la chancellerie du Nichan figure au budget de l'Etat, saroir :

En recette, sous un article spécial intitulé : "Droits de chancellerie du Nichan-Ifticliar », et alimenté, comme l'indique ce titre, par le produit des droits établis par le décret précité du 2 I août I $S S_{7}$;

En dépense, sous l'article 4 du chapitre I ${ }^{\text {er }}$, où sont inscrits les frais de fabrication (achat de métal, rubans et maind'œuvre) des insignes et le traitement du secrétariat de la chancellerie.

En I 898 , les recettes se sont élevées à la somme de 2 I, $200 \mathrm{fr}$., les dépenses ì $32,700 \mathrm{fr}$.

Pensions civiles et militaires. - Il n'existe pas en Tunisic de légishation conférant aux fonctionnaires civils ou militaires un droit à une pension de retraite. L'Étalt n'a contracté aucun engrgement vis-i-vis d'eux et ne leur doit rien après lia cessation de li position d'activité.

Ce n'est qu'ì titre trìs exceptionnel qu'il a été concédé 
depuis I 884 des secours viagers, plutôt que des pensions de retraite proprement dites, à quelques agents qui s'étaient créé des droits tout particuliers à la bienveillance du Gouvernement. La majeure partie du crédit ( $128,000 \mathrm{fr}$.) inscrit au budget de la Direction générale des finances pour i 900 sous le titre: "Pensions civiles et militaires ", est attribuée à des officiers de terre ou de mer ou fonctionnaires assimilés licenciés à l'organisation du protectorat et auxquels il a été attribué des pensions équivalentes au quart de leur ancienue solde.

Le gouvernement subventionne également la société de prévoyance des fonctionnaires et employés tunisiens destinée à assurer une retraite aux fonctionnaires cépendant du gouvernement tunisien. Une somme de I $8,960 \mathrm{fr}$. a été établie à cet effet au budget de 1900.

Cour des comptes. - C'est le tribunal chargé de statuer souverainement sur les comptes des comptables publics de la Régence. Ses dépenses sont prévues au budget de i 898 pour I $4,680 \mathrm{fr}$.

Frais du fonctionmement du service central des finances et des diverses régies financières. - Les dépenses classées sous cette rubrique sont celles des services suivants :

Services financiers, personnel - matériel - achat, fabrication, manutention et transport des matières premières. et fournitures diverses nécessaires aux services du Timbre et des monopoles. Ces dépenses se sont élevées en I 900 à I,907,030 fr. pour le personnel, à 537,250 fr. pour le matériel et à $1,663,800$ fr. pour les autres services.

Frais de frappes de monnaies. - Le décret organique du 
I ${ }^{\text {er }}$ juillet I $S_{9}$ I sur la réforme monétaire tunisienne, rendu d'accord arec le gouvernement français, dispose que les nouvelles monnaies tunisiennes, du système décimal, seront désormais frappées à l'hôtel des Monnaies à Paris.

En vertu de cette indication, il a été frappé à Paris, en I S9 I et en I $S_{92}$, pour une valeur de 36, I 33,223 fr. $56 \mathrm{c}$. de nouvelles monnaies

Il a été fabriqué une quantité suffisante de monnaies d'argent et de billon, mais il est à prévoir que de nourelles frappes de momnaie d'or seront nécessaires. Les frais de ces frappes supplémentaires sont prévus au budget pour une somme annuelle de $20,000 \mathrm{fr}$.

Il n'a été frappé en I 893 et I $\$ 94$ de monnaies tunisiennes que pour une somme annuelle de $3,000 \mathrm{fr}$. Ces frappes, dites du nourel an, c'est-it-dire aux millésimes des années de l'hégire ( 13 I 2 et I j 3 ) qui ont commencé en I $S_{93}$ et en I $\$ 94$, n'ayarıt cồté que des sommes insignifiantes, les crédits disponibles ont servi à rapatrier en 'Tunisie pour 5 millions de monnaies tunisiennes d'or qui existaient en dépôt dans les caves de la Banque de France où le commerce les avait expédiés pour solder ses différences.

Chapitre II. - Office des postes et des télégraphes.

Le service des postes et des télégraphes, qui était rattaché auparavant au service français, a été constitué en office autonome le I er juillet $\mathrm{I} S S S$.

Antérieurement à cette date, le Trésor tunisien ne contribuait aux dépenses du service que jusqu'ì concurrence du montant des loyers des bureaux. Cette charge, qui figurait dans les comptes du gouvernement tunisien sous le 
chapitre Ier (finances), s'est élevée en moyenne à i 5,000 fr. par an.

Depuis le $1^{\text {er }}$ juillet I 888 , toutes les dépenses de l'office sont supportées par le budget de lar Régence qui, en compensation, perçoit les produits de l'exploitation.

En I 899 , les recettes de l'office des postes se décomposaient ainsi :

Produits des postes . . . . . . 646,400 fr.

Produits des télégraphes. . . . . 329,300

Produits des téléphones . . . . . 30,900

Subvention de la caisse d'épargne de France I7, 300

L'Office assure les dépenses de l'exploitation : $1^{\circ}$ des postes; $2^{\circ}$ des télégraphes; $3^{\circ}$ des téléphones. Il a pris en outre, depuis le I $^{\text {er }}$ janvier I892, la charge du trafic des colis postaux et a ouvert à ce trafic, jusque-là limité aux gares du chemin de fer Bône-Guelma et aux escales de la Compagnie transatlintique, toutes ses recettes et même les distributions reconnues aptes à y participer. Enfin, il est le correspondant, en Tunisie, de lis caisse d'épargne postale française.

Ses principales dépenses normales, qui font l'objet du chapitre II du budget des dépenses du gouvernement tunisien, sont les suivantes, d'après les chiffres du budget de l'exercice I 899 :

Personnel de l'office. . . . . 766,500 fr.

Frais divers d'exécution du service. . . 60,000

Transport des dépêches et des colis postaux. ......... 170,000

Dépenses de matíriel ..... I05,000

Subventions aux lignes maritimes postales ......... I50,000

Dépenses des exercices clos. . . . 500 Total. ... $\overline{\mathrm{I}, 252,000} \mathrm{fr}$. 


\section{Chapitre III. - Administration générale.}

Les divers services de l'administration générale ont ì leur tête le Premier Ministre et le ministre de la Plume. Le secrétaire général du Gouvernement exerce les fonctions du contrôle.

C'est le secrétaire général du Gouvernement qui est l'ordonnateur des dépenses de ces divers services. Elles font, dans le budget de l'exercice I900, l'objet du chapitre III, divisé en 24 articles, non compris ceux des dépenses des exercices clos et périmés.

Sous l'article I ${ }^{\text {er }}$, doté en 1900 de 220,585 fr. 60 c., sont classées les dépenses des traitements des deux ministres indigènes, du secrétaire général du Gouvernement, de ses deux adjoints, du premier interprète de S. A. le Bey, ainsi que les dépenses da matériel. Sous l'article 2 sont inscrites en I 900 pour la somme de 196,539 fr. les dépenses du personnel de l'administration centrale. Ce personnel est réparti entre onze groupes : cabinet, bureau du service pénitentiaire, de la publication de l'Officiel et de la propriété industrielle, comptabilité, traduction, archives, service d'ordre et d'expédition, section d'État, service de l'instruction judicinire, tribunal de l'Ouzara, section des affaires civiles, bureau des communes. Des huissiers, baouabs et ouarglis, clangés du service matériel des bureaux, sont en outre rétribués sur l'article 2. Les dépenses pour le matériel inscrites à l'article 3 se sont élevées en 1900 à $\$_{4}, 570$ fr., elles comprennent les frais de bureau de l'administration centrale, ceux des fêtes publiques du Mouled, du Ramadan et du i 4 juillet, les frais de la publication du Journal officiel tunisien, les frais de la justice criminelle indigène, etc., etc. 
Les articles 4,5 et 6 ont pour objet le service sanitaire, personnel, matériel et subvention à l'hôpital civil français. Le total de ces dépenses est pour I 900 de 214,378 fr.

Les services français ratlachés pour ordre à l'administration générale et rétribués sous l'article 7 sont : les services des antiquités et des arts. Ces dépenses s'élèvent à la somme de 173,904 fr., une somme de 60,000 fr. est accordée au Diocèse de Carthage.

Les dépenses du service de la sûreté publique, personnel et matériel, se sont élevées en I 900 à la somme de $485,850 \mathrm{fr}$. pour le personnel et à celle de 75, I30 fr. pour le matériel.

Les dépenses de la gendarmerie indigène (oudjak), classées sous l'article $\mathrm{I}_{4}$, ont été prévues en 1900 pour une somme des I65,688 fr. 80 c.

Les dépenses des prisons, qui font l'objet des articles I6, 17, comprennent :

$I^{\circ}$ Les frais d'inspection et du service médical et anthropométrique.

$2^{\circ}$ Le personnel des gardiens:

a) des prisons européennes (Tunis, Sousse, Sfax et Kairouan).

b) des prisons indigènes (nourelle prison de Tunis, Zendala du Bardo, Drida, prison des femmes, bagnes de PortoFarina, Nabeul, Medjez-el-Bab, le Kef et Teboursouk).

$3^{\circ}$ La nourriture des détenus :

a) Européens.

b) Indigènes.

$4^{\circ}$ Le matériel et les fournitures diverses (eau, éclairage, médicaments, habillement, loyers, etc.).

Ces frais forment un total de 315,779 fr. $60 \mathrm{c}$. 
Sous le titre : "Gourernements de Tunis, de la Goulette et de l'Arad », l'article 9 pourvoit aux dépenses suivantes:

Personnel et matériel de la Driba.

Administration de la ville de Tunis (traitement du cheikl Médiza et des cheikhs de Bab-Souika et Bab-Djezira, de l'amin des vivres et de sun adjoint).

Tribunal rabbinique.

Administration de la ville de la Goulette.

Gouvernement de l'Arad (réception des hôtes, traitement des khalifas, loyer des bureaux du commandant militaire de Gabès).

Au total : 83,468 fr.

Les membres du corps religieux perçoivent sur le budget de l'État, indépendamment des allocations que leur sert l'administration des habous, des rétributions diverses qui sont inscrites sous l'article so du chapitre de l'administration générale. Cet article a reçu, en 1895 , la rẹpartition suivante:

a) Tribunaux religieux (Tunis, Kairouan, Bejja, Gafsia).

b) Imans et Kodjas.

c) Indemnités à des professeurs.

d) Prieurs du Prophète.

e) Indemnités à des chérifs.

f) Imans prêcheurs.

g) Subventions ì des zaouias,

En tout : 69, $832 \mathrm{fr} .40 \mathrm{c}$.

Les dépenses de la magistrature française en Tunisic sont payées par le Trésor français, mais à charge de rem- 
boursement par le Trésor tunisien. La dépense de ce remboursement est inscrite au budget de l'administration générale sous l'article I9. Elle figure au budget de 1900 pour la somme de $357,200 \mathrm{fr}$.

Indépendamment des dépenses de la magistrature française, le gouvernement beylical supporte celles de la gendarmerie française, qui figurent dans le budget de r 900 pour une somme totale de $36 \mathrm{I}, 860 \mathrm{fr}$. $40 \mathrm{c}$. Il acquitte les unes directement : ce sont les loyers des loc.ux affectés aux brigades. Il rembourse les autres au Trésor français qui en fait d'abord l'avance, à saroir la solde et les frais d'entretien des officiers et des hommes du corps de la gendarmerie détachés en Tunisie.

Enfin, le budget de l'administration générale subventionne les budgets des communes de la Régence en attendant que les ressources propres de ces agglomérations leur permettent de se suffire à elles-mêmes. Ces subventions sont prévues au budget de I 899 pour $454,205 \mathrm{fr}$. et font l'objet de l'article 9 da chapitre de l’administration générale.

Chapitre IV. - Direction de l'agriculture et du commerce.

Le service de l'agriculture, d'abord annexé à la Direction des renseignements et contrôles, a ensuite formé une administration distincte à laquelle ont été successivement rattichés le service de la Ghaba, chargé de la surveillance des oliviers dans les caidats de Tunis, Tébourba, Zaghouan, Soliman et Bizerte, celui de la colonisation, enfin, à partir

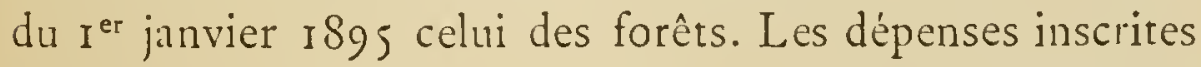
au budget de 1900 ont été de 23,500 fr. pour le personnel de l'administration centrale et de $16,400 \mathrm{fr}$. pour le matériel. Les articles 3 et 4 comprennent les subventions accor- 
dées aux chambres de commerce et d'agriculture et aux sociétís de courses, les subventions et encouragements attribués à l'agriculture et à l'élevinge. Ces subventions se sont élevées en I 900 ì la somme totale de I 13,600 fr. Sous les articles 5 et 6 sont classés les divers services de l'agriculture, de l'élevage, des laboratoires (laboratoire de chimie, laboratoire de vinification et de bactériologi:), de l'enseignement agricole, les dépenses de ces divers services ont été pour I 900 de 167,600 fr. Les services du commerce, de la propriété industrielle, des poids et mesures, compris sous les articles 7 et $S$, ont exigé en 1900 une dépense de 49, I $50 \mathrm{fr}$. Les dépenses de colonisation proprement dites figurent au budget de I 900 pour une somme de I7,000 fr. Les services des domaines sont classés sous les articles 9 et Io du budget de l'agriculture, ils sont prévus pour l'année I 900 ì la somme de $9 \delta, \delta 20 \mathrm{fr}$. Enfin, l'administration de la forêt des oliviers de Tunis, service de la Ghaba, fait l'objet des articles I2 et I 3 : sa dépense pour I 900 est de $4 \mathrm{I}, 200 \mathrm{fr}$.

Les articles I4, I5, I6, I7 et is concernent le service des forêts et se décomposent ainsi :

Personnel et matériel. . . . . . 224000 Sr.

Amélioration des forits domaniales . . 205,000

Entretien des forèts domaniales.... 60,000

Fixation des dunes ........ 16,000

Tot.1.

j05, $000 \mathrm{fr}$

D'autre part, les recettes se sont élerées, en 1900 , ì la somme de 6;0,200 fr.

Les recettes présentent don sur les dépenses un excédent qui ne peut que s'accentuer mintenant que le service vil procéder chaque ainnée à une récolte de liège de reproduction. 
Chapitre V. - Ensei-gnement public.

Les dépenses de l'enseignement public ont été jusqu'en I 887 rattachées au budget de l'administration générale. Elles ont commencé à former un chapitre distinct du budget général à partir de $\mathrm{I} S S S$.

Elles présentent, depuis l'établissement du protectorat, la progression suivante :

$$
\begin{aligned}
& \text { Exercice I302 (1884-1885) . . . . . II3,582f 65 } \\
& \text { - } \quad 1303(1885-1886) \ldots \ldots \ldots \text { I9I,761,84 } \\
& \text { - 1304(1885-1887) . . . . 276,486,55 } \\
& \text { - } \quad 1305(1887-1888) \ldots \ldots .305,787,70 \\
& \text { - } 1306(1888-1889) \ldots \ldots . .435,116,39 \\
& \text {-_ } \quad 1307(188,-1870) \ldots \ldots .530,135,52 \\
& \text { — I joS prolongé (I89J I891). . . 724,887,95 } \\
& \text { - } 1892 \ldots \ldots \ldots \ldots 664,805,08 \\
& \text { - } 1893 \ldots \ldots \ldots \ldots 705,997,36 \\
& \text { - } 1894 \ldots \ldots \ldots \ldots 762,008,78 \\
& \text { - } \quad 1899 \ldots \ldots \ldots . . . .995,000,00
\end{aligned}
$$

Elles sont prévues au budget de I 900 pour I, o I , 500 fr. qui se décomposent de la manière suivante :

Direction de l'enseignement ....... 122,056 fr. Enseignement secondaire : Lycée de Tunis (Lycée

Carnot). - École normale (Coll'ège Alaoui). -

École secondaire de jeunes filles. . . . . 301,250

Enseignement primaire, perso nnel et matériel. . . 5 56I,334

Bourses dans les lycées, collèges et écoles . . . 13,975

École próessionielle. . . . . . . . . . . 9, 975

$$
\text { Total. ... } \overline{\text { I,OII, } 500 \mathrm{fr} .}
$$

A ces dépenses, il y a lieu de rattacher celles du collège 
Sadiki, établissement indigène d'instruction secondaire, qui subrient it ses charges au moyen des revenus d'un patrimoine habous éralués pour i 895 ì la somme de i $82,000 \mathrm{fr}$.

\section{Chapitre VI. - Armée tunisienne.}

L'armée tunisienne relève du général commandant la division française d'occupation, ministre de la guerre du gouvernement tunisien.

Elle est, sous la haute autorité du général, dirigée par une mission militaire française composée :

$I^{\circ}$ D'un commandant, chef de la mission, directeur de l'administration centrale;

$2^{\circ}$ D'un capitaine, adjoint au directeur;

$3^{\circ}$ D'uni interprète militaire.

Des comptables et écrivains, français et indigènes, tiennent les écritures de l'administration centrale.

La solde et les indemnités de la mission militaire et les traitements des employés de l'administration centrale font l'objet de l'article $1^{\text {er }}$ du chapitre VI du budget des dépenses du gourernement tunisien. Leur total est préru au budget de I $\$ 99$ pour $37,572 \mathrm{fr}$. Les frais de matériel de cette administration s'élevant à 3,000 fr. font l'objet de l'article 4 du même chapitre VI.

Lil solde des officiers sans troupe et en disponibilité, l'entretien de leurs montures et les indemnités aux médecins militaires français chargés du service de santé de la garde beylicale it Tunis, la Goulette, la Marsa et le Bardo, sont payés sur l'article 2 du chapitre VI du budget des 
dépenses du gouvernement tunisien : leur total est prévu au budget de I $\$ 99$ pour $\$ 3,529$ fr. $60 \mathrm{c}$.

L'entretien des corps de troupe exige, d'après le même budget, une dépense de $348,730 \mathrm{fr}$.

Les invalides touchent des pensions au total de $7,953 \mathrm{fr}$. So c. et des secours pour I, Soo fr. (articles I 6 et $17 \mathrm{du}$ budget).

Le directeur de l'administration centrale de l'armée tunisienne est en outre chargé de l'exécution des lois beylicales sur le recrutement. C'est en effet par le mode de la conscription et du tirage au sort que se recrutent, en dehors des engagements volontaires, non seulement lit garde beylicale, mais encore les cavaliers de la Ghaba préposés à la surveillance de la forêt de Tunis, les marins du service des ports et de la navigation et les régiments français de spahis et de tirailleurs stationnés en 'Tunisie. La législation sur le recrutement est successivement étendue par décrets à tous les territoires de la Régence sans que cette mesure, dont les effets sont atténués par le remplacement militaire qui est autorisé, ait jusqu'ici donné lieu à des difficultés. La dépense du service de recrutement fait l'objet de l'article I 4 du chapitre VI du budget. Elle est prévue pour 1899 i $25,000 \mathrm{fr}$.

Indépendamment des dépenses de la garde beylicale et des dépenses de recrutement, l'administration centrale de l'armée tunisienne pourvoit à l'entretien dans le sud de la Régence, de Maghzens, sorte de gendarmerie spéciale aux régions (Médenine, Foum-Tatahouine, Zarzis et Nefzaoua) avoisinant la Tripolitaine et comprises dans le commandement militaire de Gabès. Le gouvernement tunisien a exposé en I S8S une dépense de 600,000 fr. une fois payée pour l'installation, dans cette région, de postes militaires 
servant de points de concentration aux Maghzens. Il supporte depuis cette époque le paiement de leur solde. Leur cffectif est présentement de I 60 hommes exigeant une dépense totale annuelle de $125,090 \mathrm{fr}$.

\section{Chapire VII. - Travaux publics.}

Sous ce titre générique le budget tunisien a groupé les dépenses des services qui relèvent de la Direction générale des travaux publics de la Régence, saroir:

Le service central;

Le service des ponts et chaussées;

Le service des mines;

Le service topographique;

Le service de la police des ports et des pêcheries.

La Direction générale des trivaux publics a compris en outre jusqu'en I $\$ 95$ le service des forèts; mais depuis le I janvier de ladite année il a été rattaché à la Direction de l'agriculture.

Chacun des cinq services précités fait l'objet, dans les comptes budgétaires, d'une section distincte du chapitre des travaux publics. Chaque section se subdivise clle-même en dépenses de personnel, dépenses de matériel et dépenses d'exécution de travaux.

Le tableau ci-après présente le relevé récapitulatif de chacun de ces groupes de dépenses pendant la dernière période de dix ans, la moyenne annuelle qui s'en dégage, et le chiffre correspondant de prévisions de dépenses pour l'exercice en cours i 900 .

10 Personnel de l'administration centrale..... 100,00 fr. $2^{\circ}$ Frais généraux, matériel, missions et dépenses diverses.............. . . 55,000 
Service des ponts et chaussées. 465.000 fr.

Matériel et dépenses direrses.

Routes et ponts

I. 780000

Chemins de fer.

82,000

Ports maritimes, canaux etc. . . . . . 316,600

Aménagement des eaux . . . . . . . . 480.coo

Butiments civils.

Travaux des villes non érigées en communes .

I 45,000

Les travaux dont il est question an tablcau qui précède ne sont que des travaux ordinaires à la charge de l'État. La Direction générale des traraux publics assure en outre, avec le personnel et le matériel chiffrés à ce mème tableau:

a) L'exécution des travaux des prestations;

b) L.'exécution des travaux des communes die la Régence (roirie, éclairage, bâtiments, adduction d'eau potable, etc.);

c) La surveillance et parfois l'exécution des dépenses extraordinaires à la charge de l'État (voir ci-après).

\section{DÉPENSES EXTRAORDINALRES}

Le gouvernement tunisien a fait face, depuis l'organisation du protectorat, à d'impoitantes dépenses extraordinaires qu'il a couvertes au moyen soit des ressources ordinaires de son budget, soit de prélèvements effectués sur ses divers excédents de recettes, et arec le produit des bénéfices que lui ont procurés les deux conversions de sa Dette en I 889 et 1892 .

Nous citerons en particulier les dépenses pour les travaux maritimes de Bizerte, pour les chemins de fer, les routes, les télégraphes, pour les aménagements de points d'eau, enfin pour la dotation à la société de prévoyance des fonctionnaires et employés tunisiens. 
A lil Elòture de l'exercice I $\$ 94$, le montant des dépenses extraordinares payé s'élerait i1 33,617,928 fr. $45 \mathrm{c}$, et les dépenses engagées it $9,755, \mathrm{r} 20 \mathrm{fr}$. So $c$., soit un total de $43,373,053$ fr. $25 \mathrm{C}$.

\section{DÉPENSES SPÉCIALES}

Ces dépenses consistent dans l'emploi des ressourees spéciales dont l'origine, la nature et l'objet ont été décrits au chapitre relatif aux diverses espèces de recettes du gouvernement tunisien.

Nous citerons parmi elles les dépenses nécessités par lia liquidation de l'adninistrtion des revenus concédés, de l'emprunt de I $\$ 8 \delta$ et des conversions de $18 \$ 9$ et de I $\$ 92$.

\section{NOTICE SUR LE SISTÉME DES MONNAIES EN TUNISIE}

Avant la réforme monétaire de IS9I-IS92, l'unité monétaire de la Régence était la fiastre; l'étalon de la monniae, la pièce de cent piastres en or.

Le poids de cette pièce, fixé à Ioo nonayas ( I $9 \mathrm{gr}$. $684,531,250$ ) par un décret du 23 octobre i 855 (I I Sfar I 272), était théoriquement supérieur au poids total de trois pieces d'or de $20 \mathrm{fr}$. de l'Union latine $(3 \times 6 \mathrm{gr} .45, \mathrm{I} 6 \mathrm{r}=$ $\left.19 \mathrm{gr} .35,4 S_{3}\right)$. Elle devait done avoir une plus grande valeur que ces trois pièces réunies et représenter exactement $6 \mathrm{I}$ fr. o2 c. Mais, en fait, comme les frappes de monnaies tunisiennes s'effectuaient, le plus généralement, non avec du métal neuf, mais simplement par la refonte de monnaies de l'Union latine, la pièce de Ioo piastres en 
or résultait, dans la pratique, de la transformation de trois pièces de $20 \mathrm{fr}$. et ne valait que $60 \mathrm{fr}$.

Les autres pièces d'or s'obtenaient en observant la même proportion, et c'est ainsi que la pièce d'or de 25 piastres qui, aux termes du décret précité du 23 octobre 1855 , devait peser 25 nonayas ou $4 \mathrm{gr}$. $92 \mathrm{I}$, n'a jamais eu qu'un poids moyen correspondant plus ou moins exactement, suivant la perfection de la fabrication, aux trois quarts du poids de la pièce de $20 \mathrm{fr} .\left(\frac{3 \times 6 \mathrm{gr} \cdot 45, \mathrm{r} 6 \mathrm{I}}{4}=4 \mathrm{gr}\right.$. 83,87 I)

De ce mode de fabrication et de ce rapport entre les monnaies tunisiennes et les monnaies de l'Union latine, est résultée la valeur de la piastre qui s'est trouvée ainsi fixée à soixante centièmes de franc (o fr. 60 c.), sauf, bien entendu, les variations du change.

Au moment où la réforme monétaire a été décrétée, les monnaies légalement en circulation dans la Régence étaient celles frappées sous l'empire des décrets du 23 octobre I 855 (I I Sfar I 272) pour l'or, du 2 I avril i 872 (I 2 Sfar I 289) pour l'argent, et du 22 mai i 872 ( 44 Rabia-el-aoual r 289 ) pour le bronze.

Le tableau détaillé en a été donné par le décret du 27 août I 89 I (23 Moharrem I309), qui a réglé la procédure de la réforme monétaire; il est reproduit à la page suivante. 


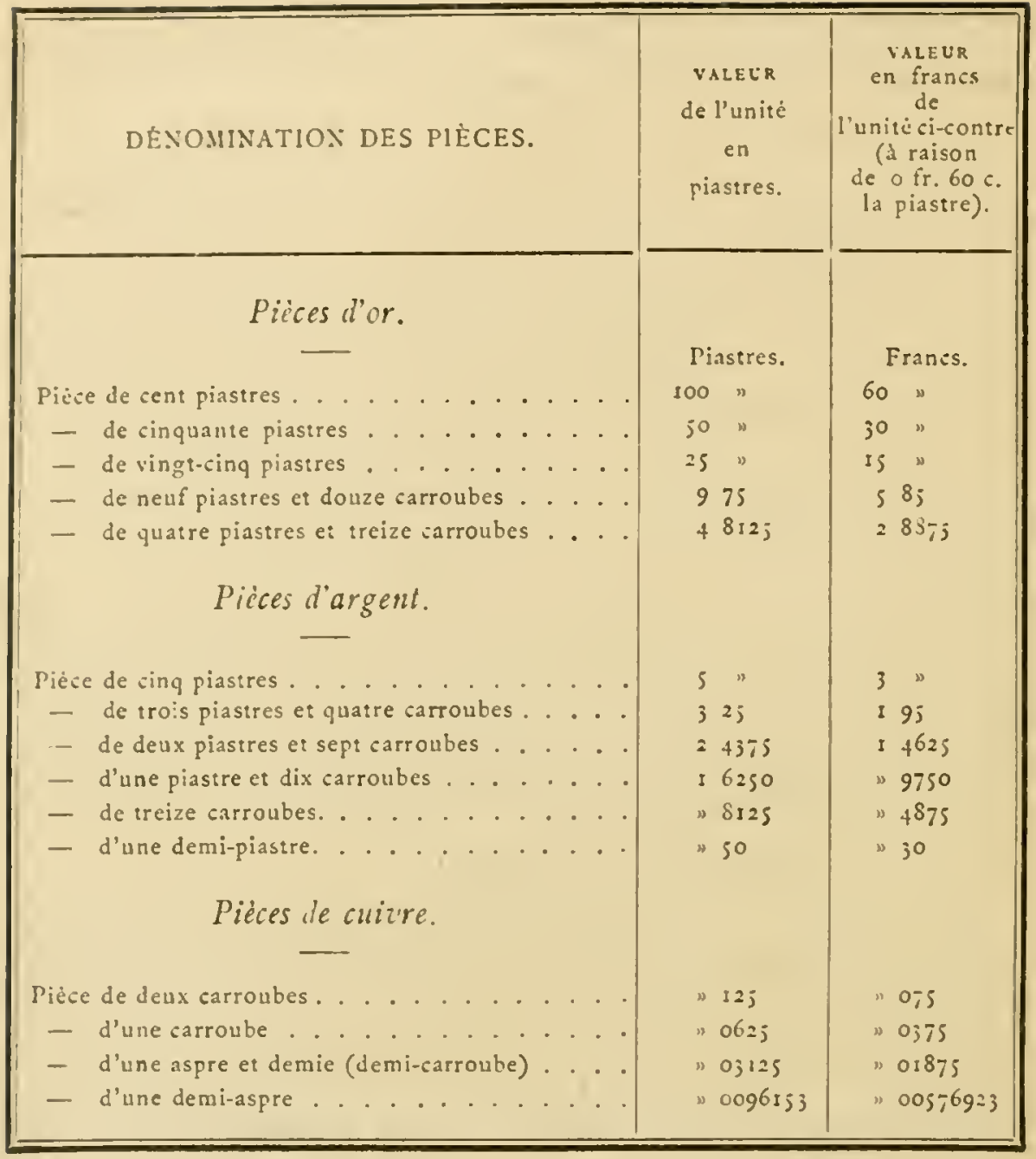

Ce tableau f.it ressortir cette particularité qu'aucune coupure ne représentait l'unité monétaire, c'est-ì-dire qu'il n'existait pas de pièces d'une piastre, et que les types de pièces d'argent n'étaient pas tous d'un nombre entier de piastres ( 3 p. 25, 2 p. 4375, I p. 625, o p. Si 25 ). Même parmi les piéces d'or, deux coupures, cellés de ro piastres et de 5 piastres, n'avilent qu'une valcur nominale inférieure ¿̀ leur dénomination officielle et n'étaient données et reçues respectivement en paicment que pour 9 p. 75 et 4 p. Si 25 . On comprend s.ms peine les complications et les difficultés 
qui résultaient dans les transactions journalières de ces dénominations fractionnaires.

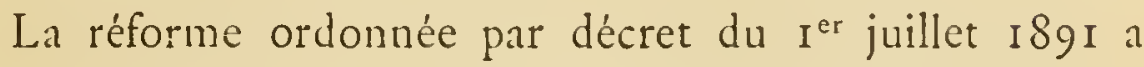
eu pour objet la substitution du franc à la piastre comme unité monétaire de la Régence (article $\mathrm{I}^{\text {er }}$ du décret $^{\mathrm{I}}$ ).

Mais elle n'a rien changé à la base essentielle du système, et, depuis comme avant la réforme, la Tunisie est un pays de monométallisme ì étalon d'or.

En conséquence (article 5 du décret), sa monnaie d'or a seule été investie d'un pouroir libératoire indéfini. Ses autres monnaies n'ont qu'un pouvoir libératoire limité, saroir: les monnaies d'argent, sorte de billon supérieur, à jo fr., et les monnaies de bronze, réduites au rôle d'appoint, it $5 \mathrm{fr}$. pour un seul paiement.

Sauf sur ce point, qui la différencie d'ailleurs profondément du régime en vigueur dans les États signataires de la convention du 6 novembre ISS5, dite de l'Union latine, l'organisation monétaire tunisienne a été calquée sur l'organisation françaice.

A l'exception de la pièce d'argent de $5 \mathrm{fr}$. au titre de 900 millièmes et à pouvoir libératoire indéfini, dont l'existence ne se comprend que dans le système du bimétallisme, le décret du I $^{\text {er }}$ juillet I 89 I a adopté purement et simplement, comme valeur nominale, diamètre, taille, titre, poids et tolérances en fort et en faible, les types de monnaies en circulation en France.

Toutefois, on a jugé inutile de frapper en Tunisie des pièces d'or de Ioo, de 50 et de $\mathrm{g}$ fr. (ces dernières sont

I Le franc étant l'unité monétaire de la Régence, l'emploi du franz a èté rendu obligatoire dans les actes notariés et jugements des tribunaux indigènes par un décret du 3I a 
d'ailleurs peu à peu retirées de la circulation en France) et des pieces d'argent de 20 centimes.

Les types de monnaies en vigueur en Tunisie sont done: Les pièces d'or de 20 et de $10 \mathrm{fr}$.;

Les pièces d'argent de 2 fr., I fr. et o fr. $50 \mathrm{c}$.;

Les pièces de bronze de 10, 5, 2 centimes et I centime.

L'article 2 du décret du I er juillet I 89 I détermine dans un tableau les conditions de fabrication de ces divers types de monnaies. Il spécific que les pièces auront cours tant que le poids n'en aura pas été réduit par le frai au-dessous des tolérances indiquées au tableau ou que les empreintes n'en auront pas disparu.

Les monnaies tunisiennes portent (article 4), d'un cóté, en caractères arabes, le monogramme de S. A. le Bey, lindication de la valeur en francs et le millésime de l'année arabe de la fabrication; sur l'autre face, en caractères français, le mot "Tunisie ", l'indication de la valeur en francs et le millésime de l'année grégorienne de la fabrication.

Pour domer aux monnaies tunisiennes toutes garanties

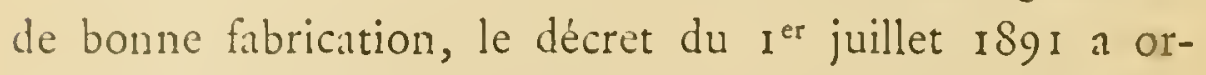
donné (article S) qu'elles seraient désormais frappées à l'Hôtel des monnaies de Paris et que des vérifications annuclles en seraient faites, comme pour les monnaies françaises, par les soins de la commission de contrôle de la circulation monétaire instituée par la loi française du 3 I juillet 1879 .

Les anciennes monnaies tunisiennes d'or, d'argent et de cuivre en circulation au moment de la promulgation de la réforme monétaire ont été retirées de la circulation du 15 septembre IS9I au It septembre I 892. Les échanges ont eu lieu au parir, c'est-i-dire sur la base de o fr. $60 \mathrm{c}$. par piasire. 
Les retraits ont été :

Four les monnaies d'or . . . 22,253,91684

\begin{tabular}{rrr}
- & d'argent. . & $3,387,729,94$ \\
- & de cuivre. . & $423,605,53$ \\
\hline & Total. . . & $26,065,25$ If 88 \\
\hline
\end{tabular}

Il a été frappé jusqu'à ce jour (août I 895 ) pour 36 millions I 39,223 fr. 56 c. de monnaies nouvelles, soit une valeur supérieure de $10,073,97 . \mathrm{fr}$. $68 \mathrm{c}$. à celle $(26,065,25$ I fr. SS c.) des anciennes monnaies retirées de la circulation.

Le tableau suivant indique la répartition de cette valeur en monnaies d'or, d'argent et de billon, et la comparaison de ces élćments avec ceux correspondants des anciennes monnaies.

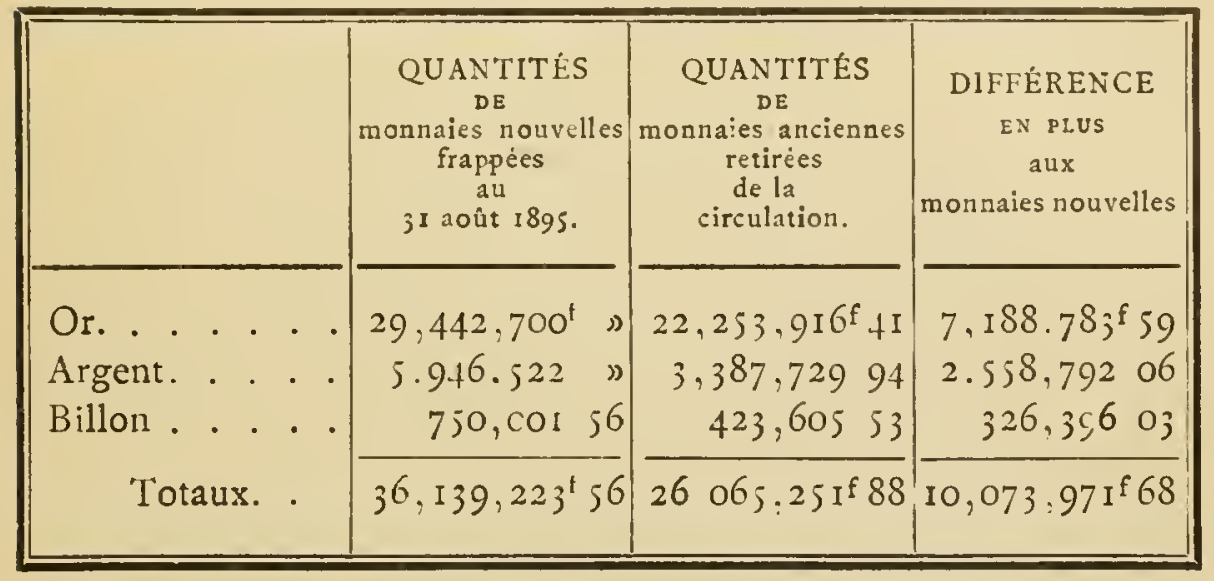

La différence en plus aux monnaies nouvelles est surtout appréciable pour les monnaies d'or. La frappe de ces monnaies n'est d'ailleurs pas limitée, et des crédits annuels sont inscrits au budget pour faire face aux frais des nouvelles fabrications reconnues nécessaires.

La quantité des monnaies nouvelles d'argent est supérieure de plus des deux tiers à celle des anciennes monnaies de même métal. Elle est plus que suffisante pour les besoins 
actuels et même, suivant toute vraisemblance, pour les besoins d'un arenir encore éloigné.

Il en est de mime des monniles nouvelles de billon dont il a été frappé une quantité supérieure des trois quarts à celle des anciennes monnaies.

A l'exemple de la convention monétaire du 6 novembre

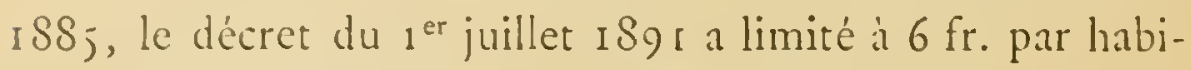
tant le pouvoir d'émission du gouvernement en ce quiconcerne les monnaies d'argent, et, supposant à la Tunisie une population actuelle de $2,000,000$ d'habitants, il a. fixé à I 2,000,000 de francs le miximum de la frappe de ces monmaies.

De même, le pouvoir d'émission du gouvernement a été limité à $2 \mathrm{fr}$. par habitant pour les monnaies de billon et le maximum de la frappe de ces monnaies fixé à t,000,000 de francs.

Il ne saurait être évidemment question d'épuiser la très large marge que ces chiffres de i 2,000,000 et de 4,000,000 de francs réservent au gouvernement. La prudence s'impose d'autant plus alu cas particulicr que le chiffre de population attribué a la Tunisie par le décret parait exagéré, et que l'émission des monnaies qui, aussi bien celles d'argent que celles de billon, n'ont qu'une valeur de convention hors de proportion avec leur valeur intrinsèque, doit être surtout limitée aux facultés d'absorption du pays.

La réforme monétaire a rapporté un bénéfice brut de I $, 285,178$ fr. $59 \mathrm{c}$. Comme elle a exigé un total de frais de 963,759 fr. 02 c., le bénéfice net s'est trouvé réduit à $321,4 \mathrm{Ig}$ fr. $57 \mathrm{c}$.

La monnatie ancienne en piastres constituait un réel obstalcle au déreloppenent des relations commerciales avec l'Europe. Le change qui s'établissait nécessairement entre 
elle et les monnaies de l'Union latine était, par ses fluctuations profondes et imprévues, une cause de difficultés incessantes qui paralysaient toutes les affrires à terme tant au dehors que dans l'intérieur de la Régence.

Aujourd'hui, cet agio a disparu et la Tunisie ne subit pas d'autre change que celui qui résulte de la loi des échanges internationnaux et auquel nul pays ne peut se soustraire.

On a reproché, il est vrai, à la réforme monétaire d’aroir, en supprimant la piastre comme unité monétaire de la Régence, élevé la mesure des échanges et occasionné par suite le renchérissement des produits.

Mais le fait n'est pas exact en ce qui concerne le commerce d'exportation qui a toujours eu pour base le franc; et quant aux échanges intérieurs, si le renchérissement produit n'est pas niable, il trouvera, s'il ne l'a déja trouvé, sa contre-partie et son correctif dans l'élévation correspondante aux salaires.

La réforme monétaire a eu cet autre avantage de permettre de confirmer les dispositions d'un décret du 26 juillet i 888 ( I 8 Kada I 305), d'après lequel les caisses publiques beylicales ont été autorisées à recevoir et à donner en paiement les monnaies d'or de l'Union latine, qui jusqu'alors n'avaient eu en Tunisie qu'une circulation de fait.

A titre de tolérance provisoire et d'accord avec le gouvernement français, les caisses publiques beylicales admettent également les pièces d'argent de 5 fr. de l'Union latine qui s'ajoutent aux monnaies d'or comme élément de remise sur l'Europe, et, dans les transactions intérieures, constituent un intermédiaire utile entre lia plus petite coupure d'or tunisienne ( $\mathrm{o}$ fr.) et les monnaies divisionnaires.

Les monnaies divisionnaires d'argent de l'Union latine ne sont pas admises à la circulation en Tunisie, mais les caisses 
publiques du Trésor français en 'Tunisie reçoivent les monnaies nationales.

Quant aux monnaies de billon de l'Union, elles tombent sous l'application du décret du is décembre i \$9 I ( 4 Djoumadi-el-aoual I 309), complément nécessaire du décret or-

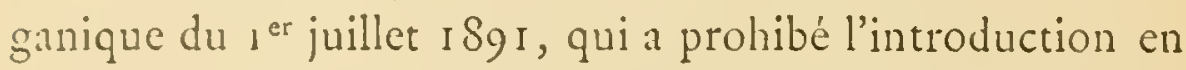
Tunisie et maintenu l'exclusion des caissse publiques beylicales des monnaies de cuivre et de billon de fabrication érrangère. 


\title{
TABLE DES MATIÈRES
}

\author{
TROISIËME PARTIE
}

\section{Commerce.}

ChapITre XVII. - L'outillage économique; voies de communication et ports. . . . . . I I

- XVIII. - Situation économique de la Tunisie avant et apris le protectorat . . . . . 6;

- XIX. - Mouvement du commerce de la Tunisie dep dis l'occupation. . . . . . . 95

- XX. - Exportation (mouvement général et part des différents pays). . . . . . . III

- XXI. - Importation (modvement général et part des différents puys) . . . . . . . II9

- XXII. - Mouvement du commerce et de la navigation dans les principaux ports . . . . .

\section{QUATRIEME PARTIE}

\section{Finances.}

Chapitre XXili. - Les finances tunisiennes . . . . . . I53

- XXIV. - Progression et répartition des dépenses du protectorat ......... 2I3 





PLEASE DO NOT REMOVE CARDS OR SLIPS FROM THIS POCKET

\section{UN.VERSITY OF TORONTO LIBRARY}

HD La Tunisie

2135

$\mathrm{T} 85 \mathrm{~T} 8$

1900

t. 2 
:

1

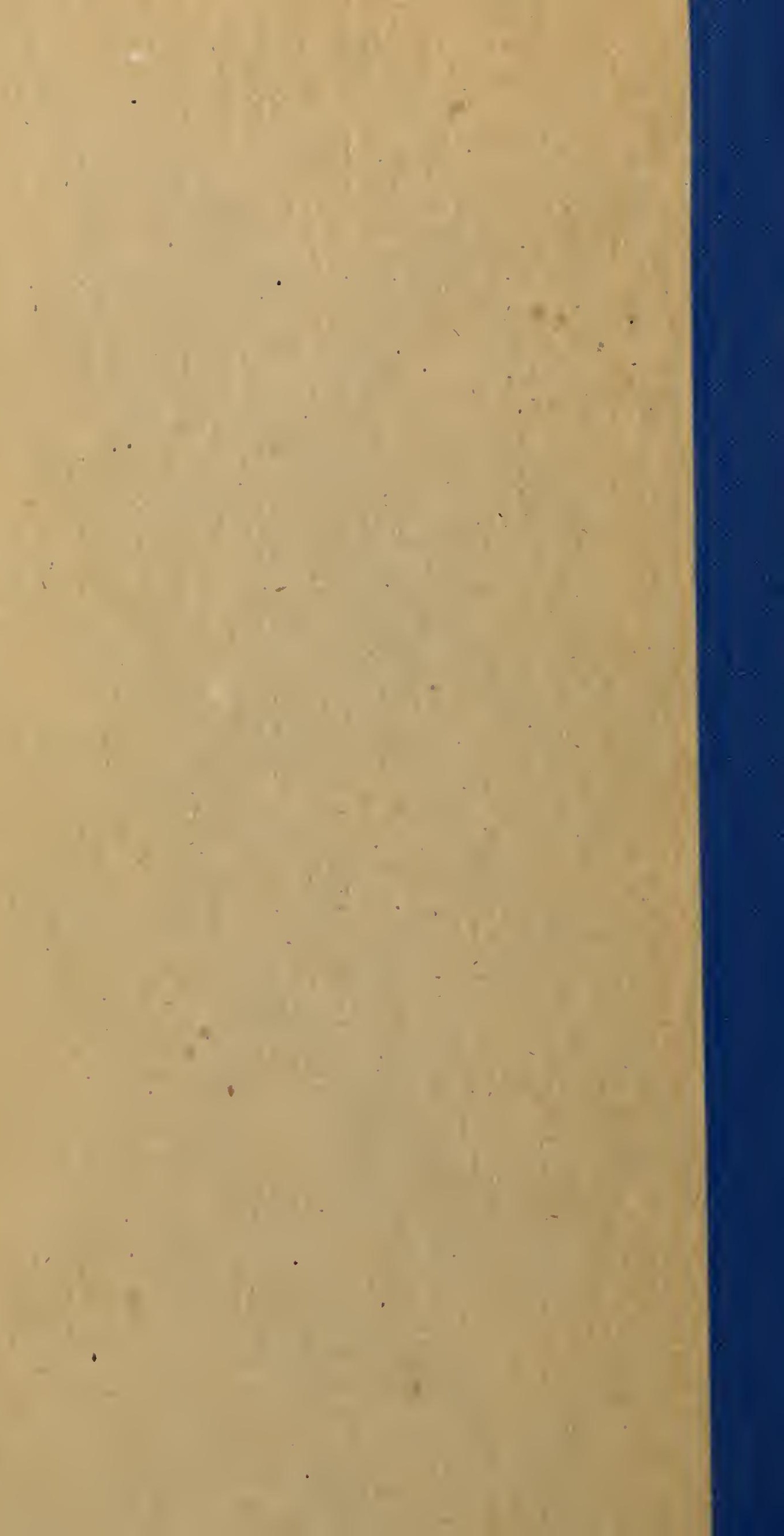

